\title{
WestVirginiaUniversity
}

THE RESEARCH REPOSITORY @ WVU

Graduate Theses, Dissertations, and Problem Reports

2012

\section{Effect of seat orientation on ingress/egress joint kinematics and reach envelope}

Christopher W. Moore

West Virginia University

Follow this and additional works at: https://researchrepository.wvu.edu/etd

\section{Recommended Citation}

Moore, Christopher W., "Effect of seat orientation on ingress/egress joint kinematics and reach envelope" (2012). Graduate Theses, Dissertations, and Problem Reports. 3335.

https://researchrepository.wvu.edu/etd/3335

This Thesis is protected by copyright and/or related rights. It has been brought to you by the The Research Repository @ WVU with permission from the rights-holder(s). You are free to use this Thesis in any way that is permitted by the copyright and related rights legislation that applies to your use. For other uses you must obtain permission from the rights-holder(s) directly, unless additional rights are indicated by a Creative Commons license in the record and/ or on the work itself. This Thesis has been accepted for inclusion in WVU Graduate Theses, Dissertations, and Problem Reports collection by an authorized administrator of The Research Repository @ WVU. For more information, please contact researchrepository@mail.wvu.edu. 


\title{
EFFECT OF SEAT ORIENTATION ON INGRESS/EGRESS JOINT KINEMATICS AND REACH ENVELOPE \\ by
}

\section{Christopher W. Moore}

\author{
Thesis submitted to the \\ Benjamin M. Statler College of Engineering and Mineral Resources at \\ West Virginia University \\ In partial fulfillment of the degree of \\ Master of Science \\ in \\ Industrial Hygiene \\ Dr. Ashish Nimbarte, Ph. D., Committee Chairperson \\ Dr. Steve Guffey, Ph. D \\ Dr. Xiaopeng Ning, Ph. D \\ Department of Industrial and Management Systems Engineering \\ Morgantown, West Virginia \\ 2012
}

Keywords: Ingress, Egress, Recumbent Seats, Kinematics, Reach Envelope 


\section{ABSTRACT \\ Effect of seat orientation on ingress/egress joint kinematics and reach envelope}

\section{Christopher W. Moore}

Crew modules use recumbent seats to sustain increased acceleration in the upright direction. Entry (ingress) and exit (egress) of such seats require different techniques. Most of the existing research on ingress and egress biomechanics was done using vertically mounted automobile seats. In this study, ingress and egress and planar reach motions performed using seats mounted in vertical and horizontal orientations were evaluated. An eight camera (MX-13 series) optical motion analysis system (Vicon, Nexus, UK) was used to record the 3D kinematic data. Ten healthy male participants performed ingress and egress motions using the following three seat orientations, while reach tasks were only performed in the first two: (1) vertically mounted with a $90^{\circ}$ seat angle, (2) horizontally mounted with a $90^{\circ}$ seat angle, and (3) horizontally mounted with a $120^{\circ}$ seat angle. A custom full-body marker set was used for the kinematic data collection. Visual3D software (C-Motion, Inc., Germantown, MD, USA) was used to formulate a dynamic model using this marker set to compute the joint angles for the ingress/egress tasks, while the distance from the clavicle to the finger markers during the reach tasks was used to determine reach in different anatomical planes. In general, peak joint angles and ranges of motion of the upper body were much higher in the horizontal seat than the horizontal seats. Differences in the lower body were less drastic, and change in kinematics between horizontal seats was negligible. These results suggest that ingress and egress of horizontal seats require more energy and can result in more strain on the user. Therefore, when horizontal seats must be used, ingress/egress space requirements, control placement, and appropriate user training are crucial considerations. 


\section{ACKNOWLEDGEMENT}

I would like to sincerely thank Dr. Ashish Nimbarte for his guidance and support throughout my research, as well as helping me stay on track and motivated. I'd also like to thank Dr. Steve

Guffey and Dr. Xiaopeng Ning for their assistance, as well as all of the staff and faculty of the WVU IMSE department.

Finally, I'd like to thank my family and friends for all of their support throughout my college career, and for their understanding when I wasn't able to spend as much time with them as I'd have liked. 


\section{TABLE OF CONTENTS}

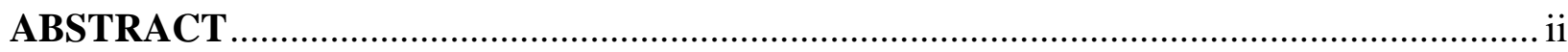

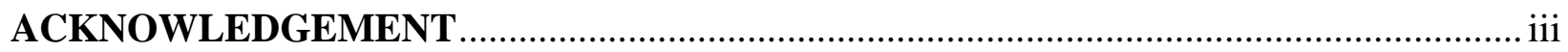

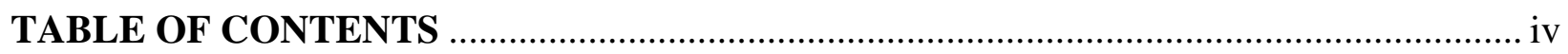

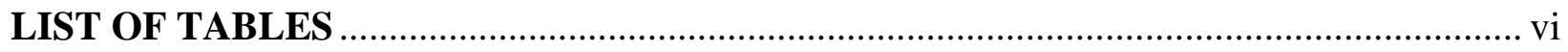

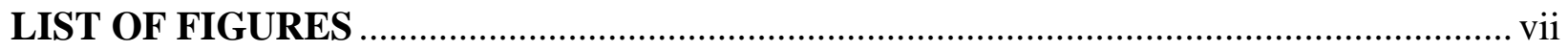

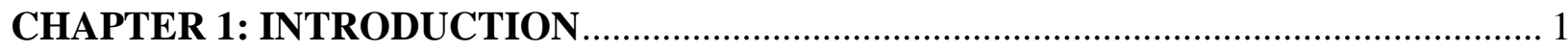

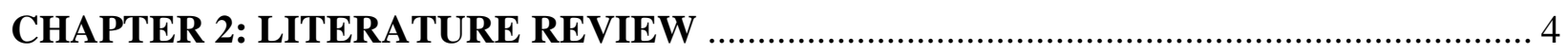

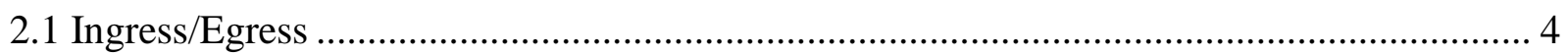

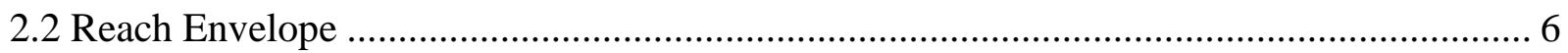

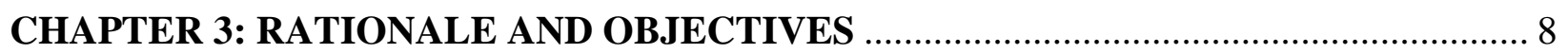

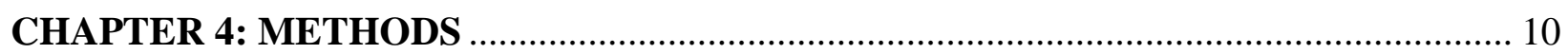

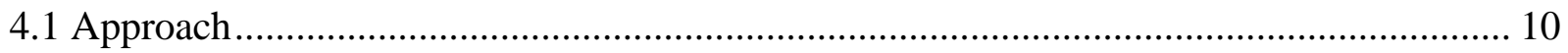

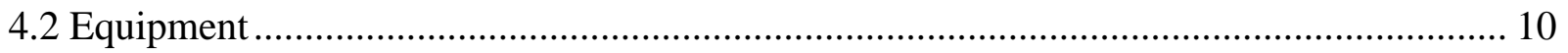

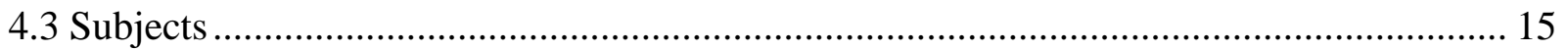

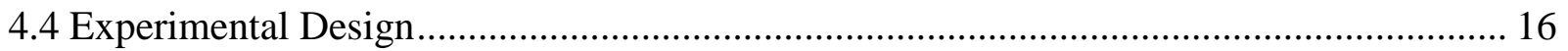

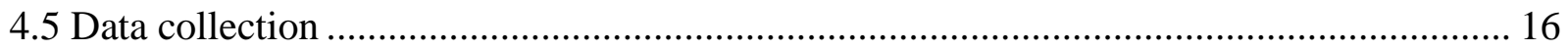

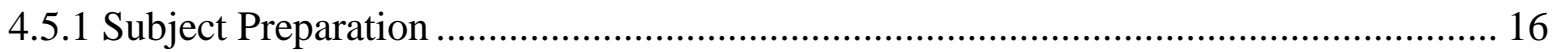

4.5.2 Anthropometric Measurements.............................................................................. 18

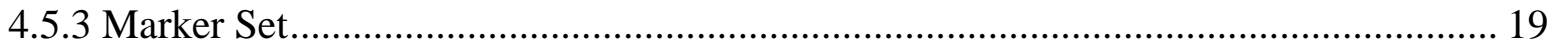

4.5.4 Experimental Tasks..................................................................................... 19

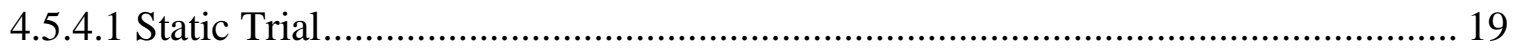

4.5.4.2 Ingress / Egress Tasks .............................................................................. 23

4.5.4.3 Planar Reach Tasks .................................................................................... 26

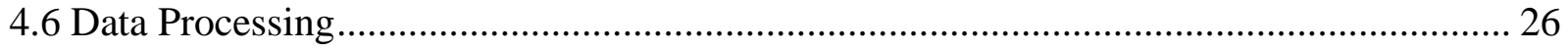

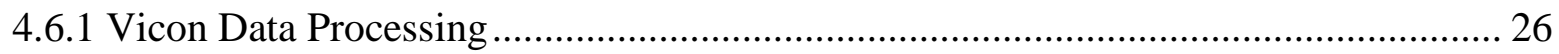

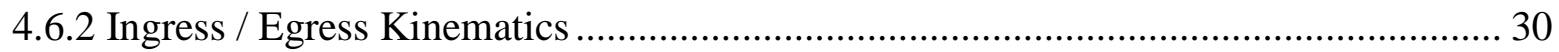

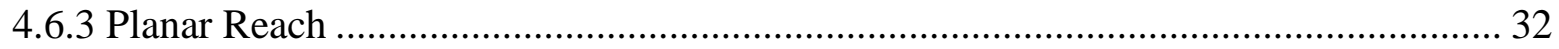

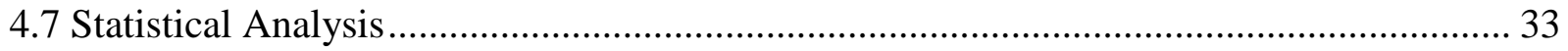

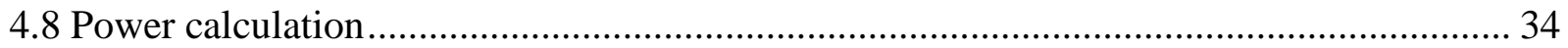

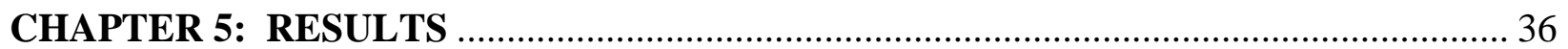

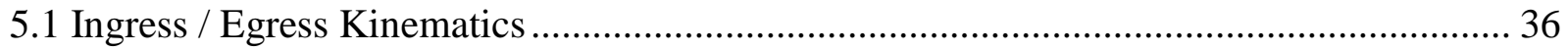

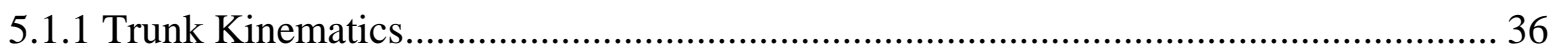




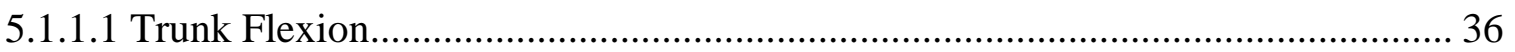

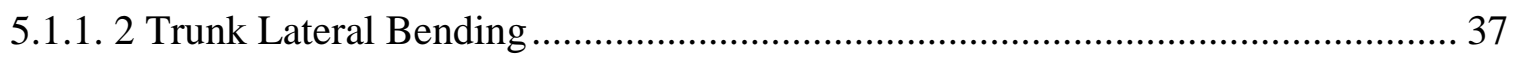

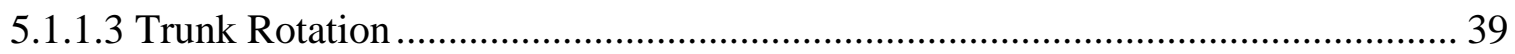

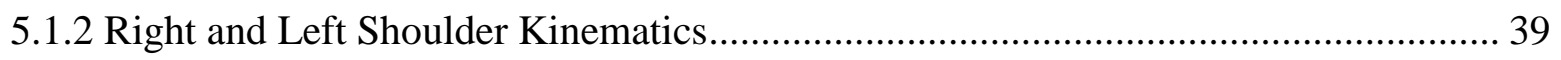

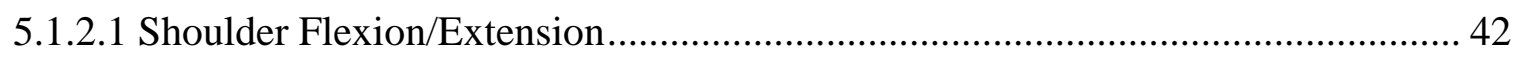

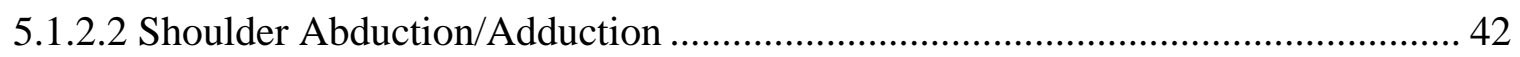

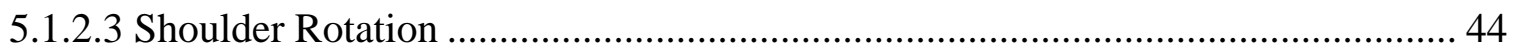

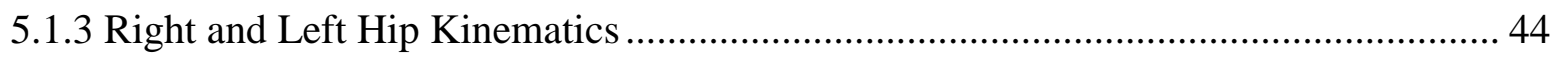

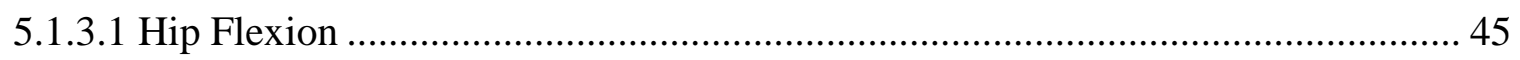

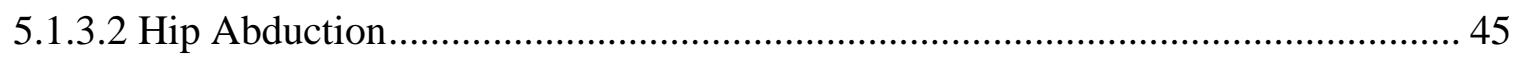

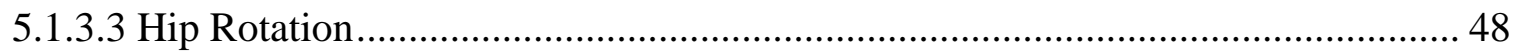

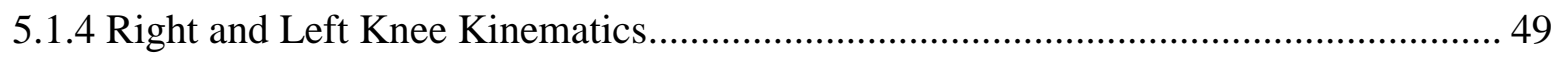

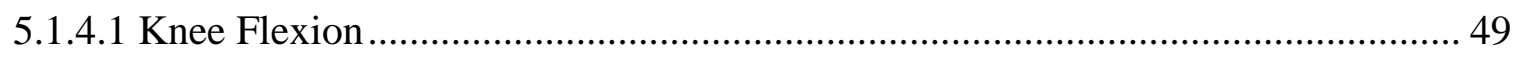

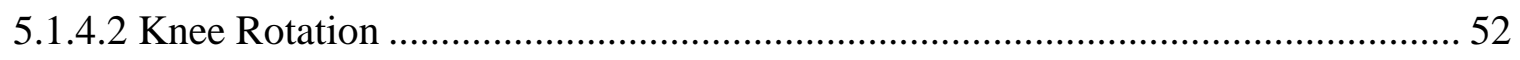

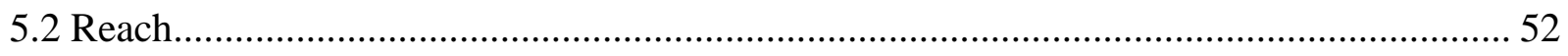

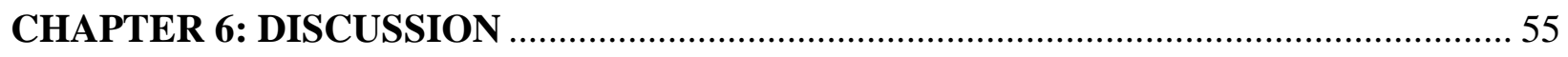

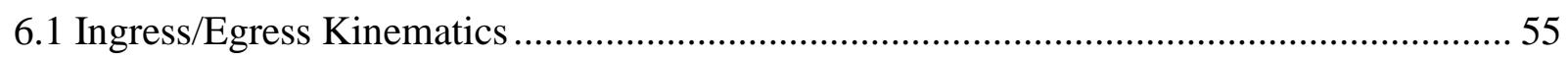

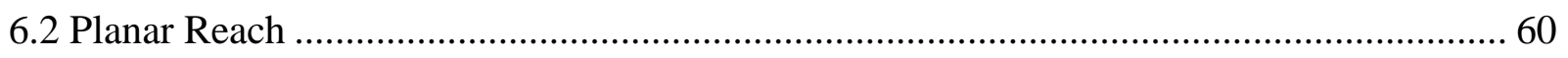

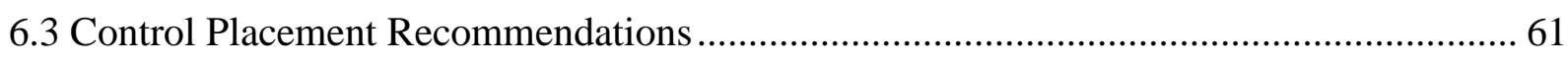

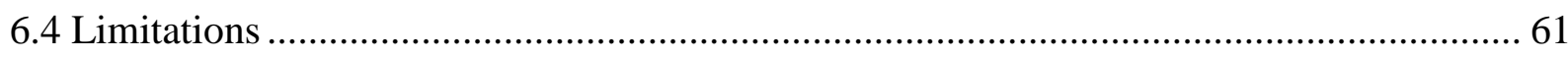

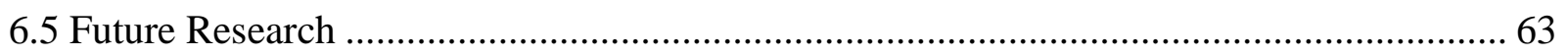

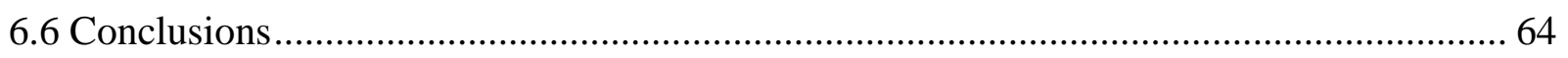

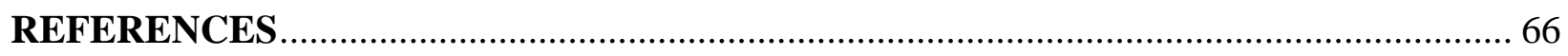

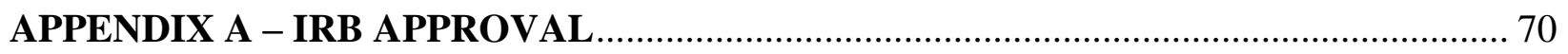

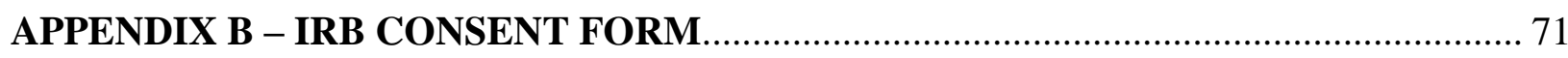

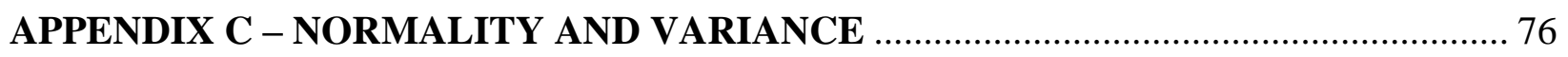

APPENDIX D - INGRESS/EGRESS ANOVA \& TUKEY HSD RESULTS ……….............. 77

APPENDIX E - REACH ANOVA \& TUKEY HSD RESULTS ……………....................... 96

APPENDIX F - SUMMARIZED JOINT ANGLE DATA - HIPS AND KNEES ….............. 99

APPENDIX G - SUMMARIZED JOINT ANGLE DATA - SHOULDERS ……………....... 104

APPENDIX H - SUMMARIZED JOINT ANGLE DATA - TRUNK ……........................... 109

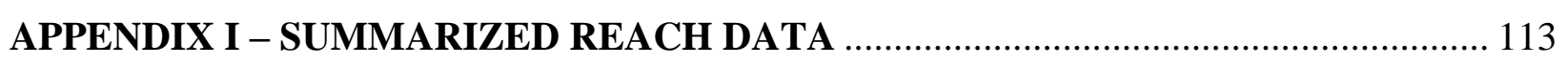




\section{LIST OF TABLES}

Table 1. Complete list of dependent variables for ingress/egress tasks ................................ 17

Table 2. Upper body markers of the marker set............................................................... 21

Table 3. Lower body markers of the custom marker set.................................................... 22

Table 4. List of body segments modeled by C-Motion Visual3D ......................................... 23

Table 5. Power determination of several kinematic variables ............................................. 35

Table 6. Mean (SD) peak angles and ranges of motion of the trunk ...................................... 38

Table 7. Mean (SD) peak angles and ranges of motion of the right shoulder ......................... 41

Table 8. Mean (SD) peak angles and ranges of motion of the left shoulder............................ 41

Table 9. Mean (SD) peak angles and ranges of motion of the right hip ................................ 46

Table 10. Mean (SD) peak angles and ranges of motion of the left hip ................................. 46

Table 11. Mean (SD) peak angles and ranges of motion of the right knee............................... 51

Table 12. Mean (SD) peak angles and ranges of motion of the left knee............................... 51

Table 13. Mean (SD) reach of the right and left arms ...................................................... 54 


\section{LIST OF FIGURES}

Figure 1. Design of a typical crew module for space exploration .......................................... 2

Figure 2. Vertical seats used by Ait El Menceur et al. (2008) ............................................... 5

Figure 3. Digitally modeled vertical seats used in research by Kennedy et al. (2004)................ 5

Figure 4. Vicon MX camera with infrared strobe lights .............................................. 11

Figure 5. 14mm (0.55in) Retro-reflective markers ................................................... 11

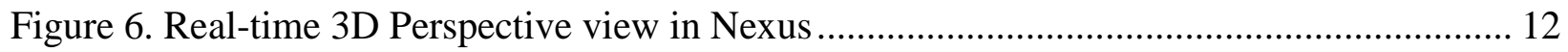

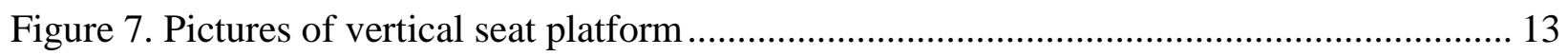

Figure 8 . Horizontal seat platform with the seat in the $120^{\circ}$ orientation................................ 14

Figure 9. Horizontal seat platform with the seat in a $90^{\circ}$ orientation................................... 14

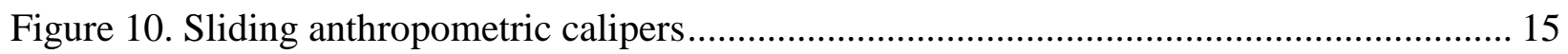

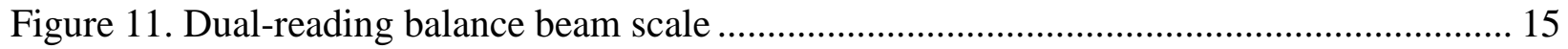

Figure 12. The custom marker set, including calibration-only markers, affixed to a human ....... 20

Figure 13. Progression used to ingress and egress horizontally oriented seat. .......................... 25

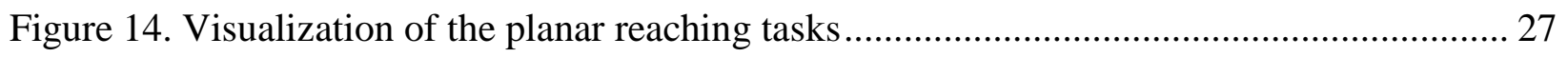

Figure 15. Frame of a static trial before and after processing in Vicon Nexus. ........................ 28

Figure 16. Plot of sagittal, frontal, and transverse reach tasks and the extreme points.............. 33

Figure 17. Kinematics of the trunk during ingress/egress tasks ........................................ 37

Figure 18. Kinematics of the shoulders during ingress/egress tasks ..................................... 40

Figure 19. Kinematics of the hips during ingress/egress tasks........................................ 47

Figure 20. Kinematics of the knees during ingress/egress tasks......................................... 50

Figure 21. Planar reach extreme points of the right and left arm ....................................... 53

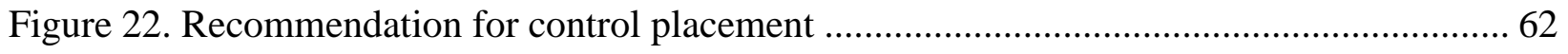




\section{CHAPTER 1: INTRODUCTION}

Ergonomics is the science of adapting tools, workstations, equipment and tasks that fit the user (OSHA Ergonomics). Research has shown that ergonomically designed workstations and tasks can improve worker comfort, reduce the risk of musculoskeletal disorders, and increase overall productivity. Several studies have evaluated the benefits of implementing an ergonomic intervention under different industrial settings including offices (Amick et al., 2003), automobile manufacturing plants (Moore, 1994; Halpern and Dawson, 1997), and engineering firms (Aaras et al, 1998). These studies have found benefits to workers' health, injury expenses, and productivity.

As noted, a number of areas benefitted from the application of ergonomics. However, one area that has been largely overlooked is space-travel, including design of space modules and extra-vehicular activities. Until research was conducted in 2000 to determine the important ergonomic factors in spacecraft cabin design, crew modules of spacecrafts were designed to minimize structure, weight, and volume (Sanchez, 2000). Even in current designs, size is still an important consideration in crew module design. For example, the crew module of the upcoming Orion spacecraft has a volume of approximately $15 \mathrm{~m}^{3}$ and will hold up to six people (NASA, 2000). While this space may be sufficient when positioned into a seat, movement could be challenging and uncomfortable. Designing the spacecraft cabin with a comfortable, ergonomically-correct seat and controls that are easy to reach without using abnormal body position is important to relieve some of the physical and mental stress experienced by the user. 
Unlike many seats that are used on a daily basis, spacecraft seats are positioned horizontally instead of vertically, as seen in Figure 1. This requires different techniques for ingress and

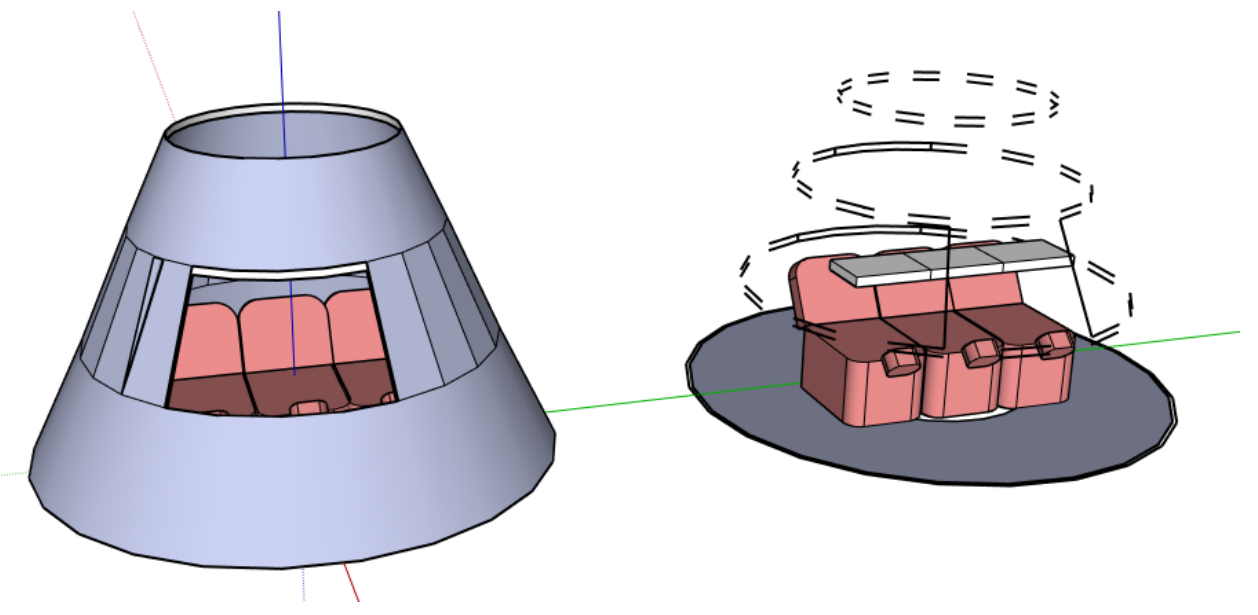

Figure 1. Design of a typical crew module for space exploration

egress which may require different biomechanical movements. For instance, in most upright seats, the user can move in front of the seat and lower their pelvis into it. In a recumbent seat, ingress is typically done from a supine position. Ingress from a supine position requires using the arms and legs to lift and move the torso into the seat. To exacerbate issues further, recumbent seats, such as those used in the spacecraft, are not adjustable like many upright seats. Along with the issues posed by the use of a recumbent seat, reach ability is also important and may be altered by the use of the recumbent seat. When ingressed into a recumbent seat, the back of the seat maintains contact with the user's back more than in an upright seat. This, along with the effect of gravity, is suspected to have a significant effect on the reach ability of the user. Additionally, placement of controls must be considered. Controls located within easy reach of the seated user could further hinder ingress and egress. However, if the controls are moved farther from the seat to allow easier ingress and egress, the controls may be difficult to reach. In order to facilitate ingress and egress and reaching requirements while using spacecraft seats, it is 
necessary to understand how different seat configurations affect ingress and egress joint kinematics and reach envelope. Therefore, the purpose of this study was to evaluate the effect of recumbent seat configuration on the ingress/egress joint kinematics and maximal planar reach by comparing it with an upright seat configuration. 


\section{CHAPTER 2: LITERATURE REVIEW}

\subsection{Ingress/Egress}

While extensive research has been done on the ingress and egress of vertically oriented seats and workstations, very little research has been done on the ingress and egress of horizontally mounted seats. Due to the widespread use of automobiles and the space constraints associated with them, the majority of horizontal ingress/egress research has been done using automobiles. For example, Giacomin et al. (1997) analyzed the comfort when entering and exiting the rear seat of a vehicle. In this study, a VHS recorder and a motion measurement system were used in combination with a questionnaire to determine which design factors influenced comfort the most. Results of the research found that, while roof rail height influenced ingress/egress the most, the stature of the participant is most responsible for the magnitude of the effect of each design parameter. Loczi et al. (1993) completed research assessing the ergonomics of exiting a vehicle. This research used 3-D digitizing software to examine the effects of changing the seat height, door height, and seat position. Results from the study found that seat and door heights had significant effects on egress kinematics, while seat position had no effect. More recently, Ait El Menceur et al. (2008) examined alternative techniques and movements used in entering and exiting four types of vehicles (small car, medium car, minivan, and small utility) by young ablebodied participants $(n=8$; age $=26 \pm 5)$, elderly able-bodied participants $(n=19 ;$ age $=71 \pm 5)$, and participants with prostheses $(n=14 ;$ age $=62 \pm 13)$. Five ingress techniques (three one-foot movements, 2 two-foot movements) and three egress techniques (two one-foot movements, one two-foot movement) were identified. The research found that, in general, participants that used two-foot ingress/egress techniques either had prostheses, or was of exceptional anthropometric 
dimensions (i.e. very tall), while able-bodied participants tended toward techniques involving one-foot movement. Vehicle type appeared to have no relationship with ingress/egress technique.

In addition to the research done on typical passenger automobiles, some studies have been done in more specific applications. For example, Kennedy et al. (2004) of the Army Research Laboratory evaluated the ability of aviator's to ingress/egress the RAH-66 Comanche Crew Station using a Vicon system similar to the one in the proposed research. Their research used Jack Modeling Software to model the data collected with the Vicon system to determine safety and speed of egress and find and eliminate any deficiencies in the Crew Station design. In addition to the 1993 study, Loczi et al. developed and evaluated RAMSIS, a 3-D CAD human model for ergonomic evaluation of vehicles, and used the model to evaluate cab design of heavy trucks $(1999,2000)$. However, in all of these studies, the research was focused on seats in a vertical orientation (Figure 2, 3).
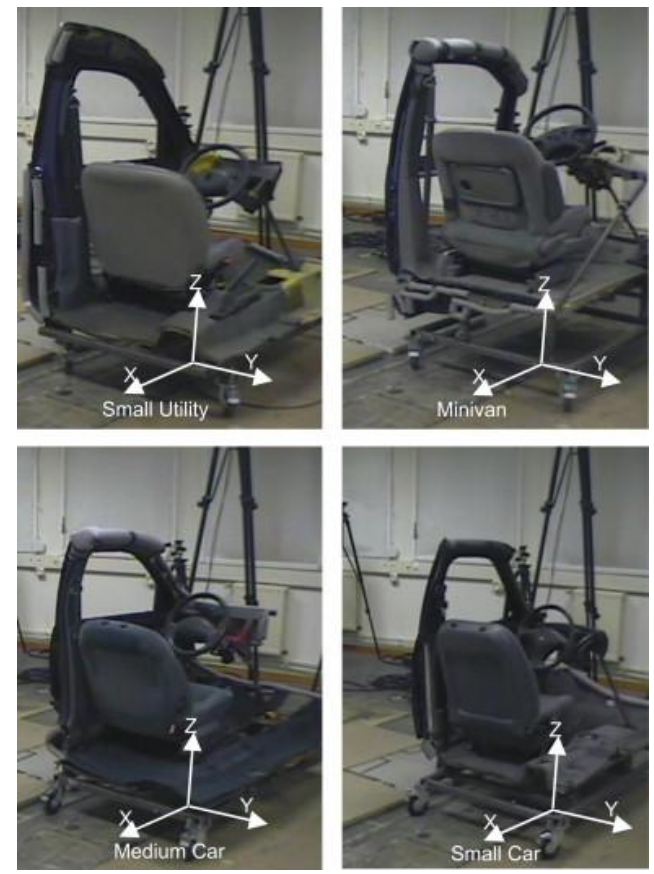

Figure 2. Vertical seats used by Ait El Menceur et al. (2008)

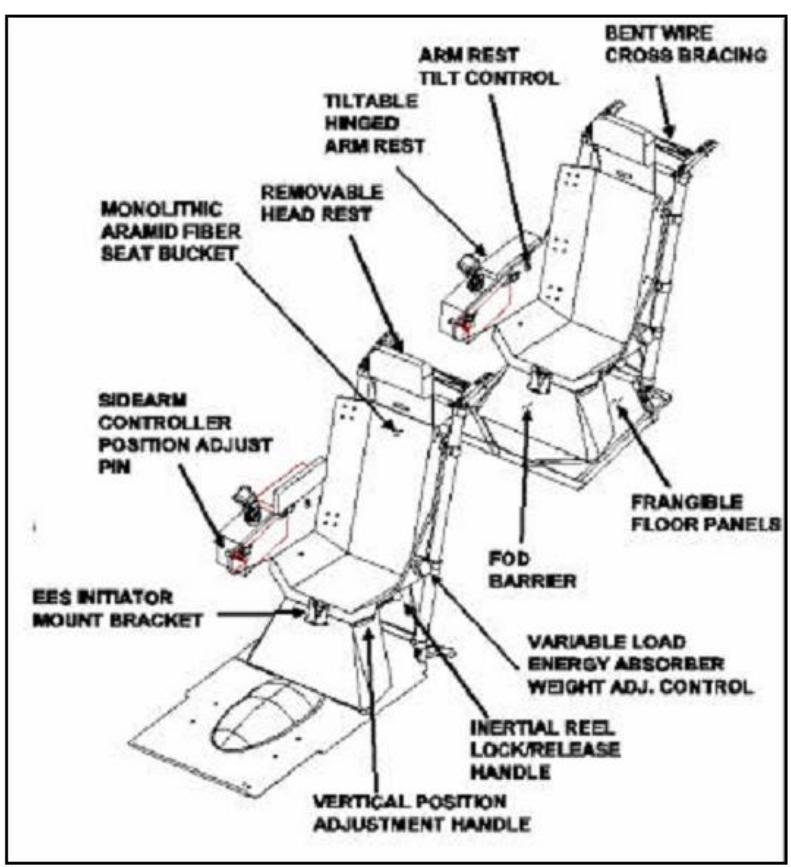

Figure 3. Digitally modeled vertical seats used in research by Kennedy et al. (2004) 


\subsection{Reach Envelope}

Although many studies have been done on the human reach envelope, the majority of these studies focus on new methods of determining, calculating, or defining the reach envelope. There are two general methods to determine the reach envelope: analytical and experimental. Yang et al. (2005) published an article in which an analytical method, mathematical modeling, was used to determine the reach envelope of the upper extremity. Based on knowledge of anatomy, kinesiology, and the anatomical barriers to arm and shoulder movement, the researchers were able to create a 9 degree-of-freedom model of the reach envelope. Software, such as ERGONAUT, has also been developed to model the reach envelope based on human body limitations and anthropometric dimensions. The ERGONAUT software has the ability to determine the interaction between modeled subjects and mocked-up virtual environments, allowing a designer to consider ergonomics early in development. ERGONAUT has been evaluated and deemed accurate enough for practical use (Deisinger, 2000).

Software and modeling can be used to fairly accurately determine the reach envelope based on body dimensions, but there are several factors that are not taken into account, such as flexibility. When a more accurate determination of the reach envelope is necessary, it should be determined experimentally. Several experimental methods have been successfully used to determine the reach envelope. Das et al. (1994) developed a method of three dimensional tracking using a stylus attached to four potentiometers through pulleys. The change in voltages in the potentiometers could be used to calculate the location of the stylus in three-dimensional space. Sengupta and Das (2000) used this method to determine the reach envelope for seated and standing male and female industrial workers by having participants hold the stylus while moving through the full range of motion. During the experimental tasks, the participants were instructed to keep the back of their neck in contact with a bar, limiting the reach to motion in the shoulder 
and arm. This research found that the maximum reach envelope while standing was significantly higher than when seated for both males and females. Furthermore, the average reach of females was $13.5 \%$ higher than for males (Sengupta et al., 2000). More recently, Reed et al. (2003) conducted research which incorporated comfort ratings into the reach envelope measurements. Participants performed reaching task for 216 different target locations. The participants rated the target from 1-10 based on ease of reach and comfort. Targets that were unreachable were rated 11. This allowed the researchers to create a maximal reach envelope as well as reach envelopes based on the level of comfort and ease. The research found that reach difficulty was a function of radius, with increased difficulty at higher radii. Additionally, it was determined that reach was most difficult in the $120^{\circ}$ radial plane (in relationship to the forward direction).

While many methods have been developed to determine the reach envelope, most of the research has led to two developments: 1) software models that are used to design ergonomically appropriate workstations and 2) charts that can be used to approximate the reach envelope based on experimental data. However, research on reach has only been completed for standing and upright sitting positions. No research has been done to determine the reach envelope in a recumbent seat or to compare reach envelope between recumbent and vertical seat configurations. 


\section{CHAPTER 3: RATIONALE AND OBJECTIVES}

Ergonomics in space travel has more considerations than most non-space applications. Due to the space constraints of a spacecraft, workstations utilizing recumbent seats and multiple controls in close proximity are typical. In addition to the ergonomic stresses of such a workstation, there are several other concerns, such as muscle mass and bone density loss, which have to be considered also. After long periods in space, the body goes through several physiological changes that make it more susceptible to injury in general, including acute and chronic musculoskeletal problems. As space travel becomes more common and space tourism flourishes, it is crucial to design future spacecraft cabins as ergonomically safe as possible.

When designing an ergonomically appropriate workstation utilizing controls and a recumbent seat, the locations of the seat and the controls are important considerations. To determine the best position of the seat, the joint kinematics during ingress/egress must be understood for the different seating options. This research used custom-made vertical and horizontal seat platforms and a motion-capture system to evaluate the differences in ingress and egress joint kinematics and reach envelope between vertically- and horizontally-positioned seats.

There were two primary objectives in this study:

Objective 1: Evaluate the effect of different seat orientations (vertical with $90^{\circ}$ seat angle, horizontal with $90^{\circ}$ seat angle, horizontal with $120^{\circ}$ seat angle) and direction of motion (ingress, egress) on the peak joint angles and range of motion of the major body joints, including hip, knee, and trunk joints.

Research Hypotheses: 
$\mathrm{H}_{01}$ - Seat orientation has no effect on the peak joint angles and range of motion of the major body joints

$\mathrm{H}_{02}$ - Direction of motion has no effect on the peak joint angles and range of motion of the major body joints

$\mathrm{H}_{03}$ - There is no interaction of seat orientation and direction of motion on the peak joint angles and range of motion of the major body joints.

Objective 2: Evaluate the effect of different seat orientations (vertical, horizontal with $90^{\circ}$ seat angle) and anatomical planes (sagittal, frontal, transverse) on the maximal reach .

Research Hypotheses:

$\mathrm{H}_{01}$ - Seat orientation has no effect on the maximal reach

$\mathrm{H}_{02}$ - Anatomical plane has no effect on the maximal reach

$\mathrm{H}_{03}$ - There is no interaction of seat orientation and anatomical plane on the maximal reach 


\section{CHAPTER 4: METHODS}

\subsection{Approach}

In this study, ingress/egress and reaching tasks in vertically and horizontally oriented seats were evaluated using a lab-based simulation. An optical motion capture system (Vicon Motion Systems, Oxford, UK) was used to record three-dimensional locations of retro-reflective markers placed on anatomical landmarks of the participant's body. Reach in three anatomical places was computed using the marker data. Vicon Nexus and C-Motion Visual3D software were used to process the marker data to quantify joint kinematics.

\subsection{Equipment}

Optical Motion Capture System: Eight-Camera Vicon System (MX-Series, Vicon Motion Systems, Oxford, UK) was used to record body motion during ingress/egress and reaching tasks. This system uses cameras with infrared strobes that emit pulses of infrared light at high frequencies (Figure 4) The infrared light reflects off of small, round retro-reflective markers (Figure 5) and is captured by the cameras in the Vicon system. When multiple cameras capture reflections from the markers, the location of the marker in three-dimensional space can be determined by the Vicon Nexus software. Ideally, each marker would be tracked perfectly throughout the capture, however, markers sometimes become hidden from the cameras and cannot be tracked. When this happens, the marker is not able to have its position determined which causes a gap in the data that must later be filled. 

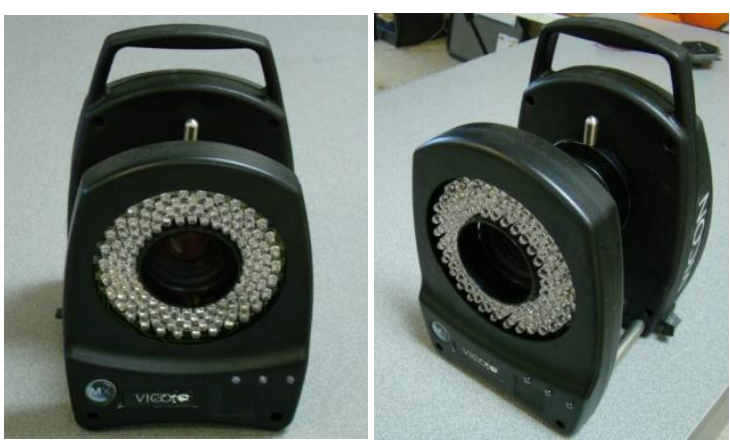

Figure 4. Vicon MX camera with infrared strobe lights

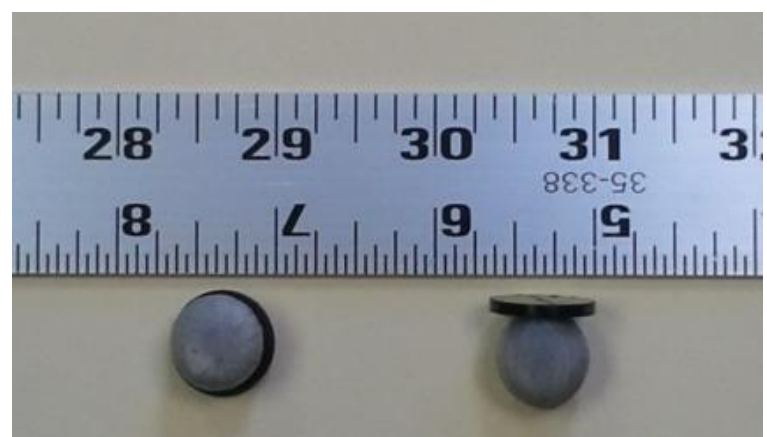

Figure $\quad 5 . \quad 14 \mathrm{~mm} \quad$ (0.55in) Retro-reflective markers

Motion Analysis Software: Vicon Nexus 1.5.1 (Vicon Motion Labs, Oxford, UK) software was used to capture and analyze marker data from the Vicon cameras. The software tracks the location of the markers by using raw data from the camera system. A three-dimensional representation of the markers is displayed on screen throughout the capture (Figure 6). Our data was captured at a rate of 100 frames per second $(100 \mathrm{~Hz})$.

After capturing the data, the software is used to label the markers. Each marker has a unique name to represent where it is located on the body. For example, in the marker set in this research, the marker located on the medial aspect of the pivot axis of the left elbow was named LMELB. After labeling the markers, the software has operations to assist in filling any gaps in the marker data. The frame-by-frame coordinates of the markers can then be exported for further analysis. 


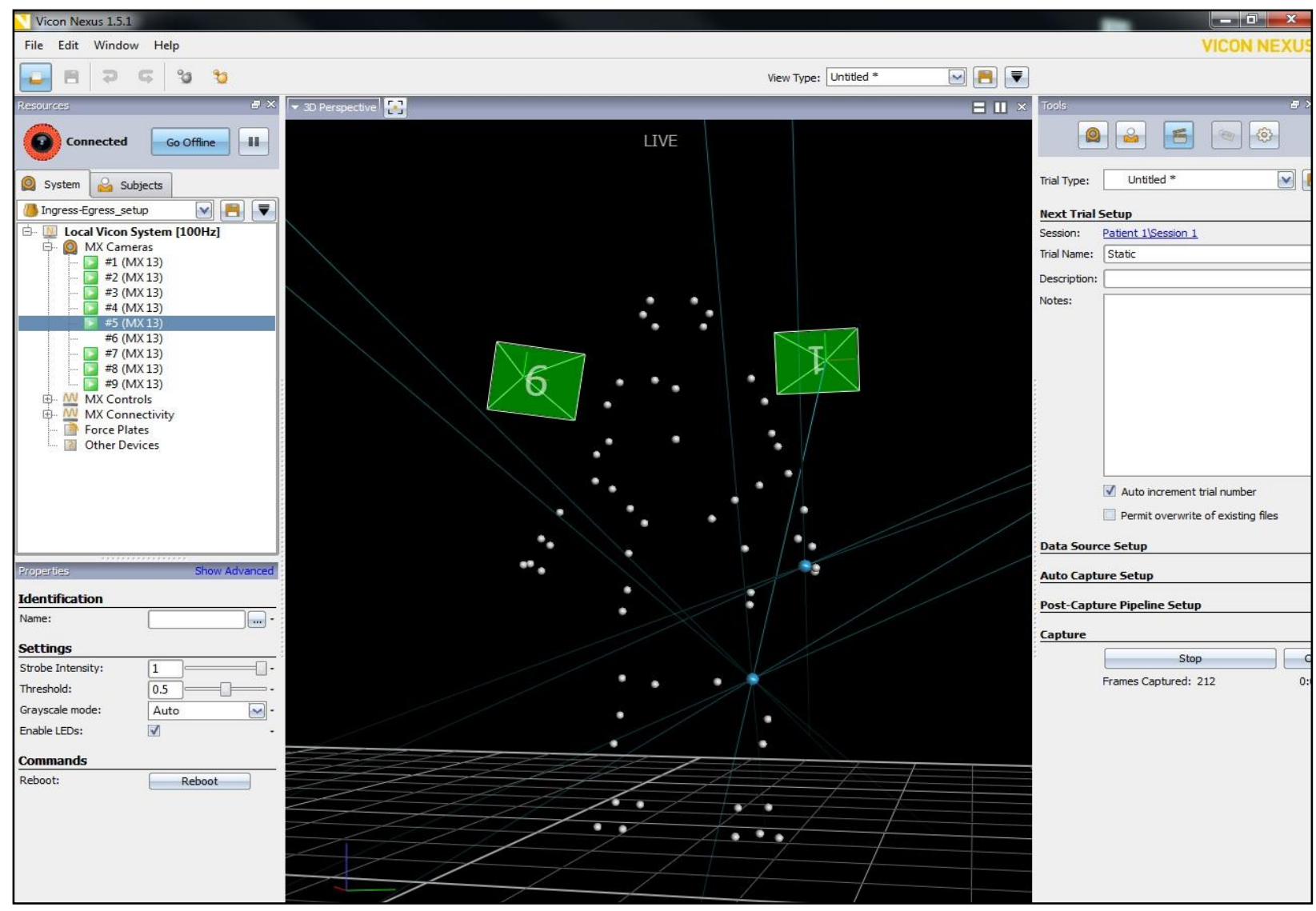

Figure 6. Real-time 3D Perspective view in Nexus. The real-time visual representation can be panned, zoomed, and rotated in any direction.

Kinematic Computation Software: Visual3D 4.89 (C-Motion Inc, Germantown, MD, USA) software was used for analysis and modeling of three-dimensional capture data. By capturing a static-posture trial, the software can create a human model and apply it to dynamic capture data from .c3d files based on the trajectories (locations) of calibration and cluster markers. For example, for tracking the location of the upper arm, the following four markers are used in this research: one marker on the Acromion process of the shoulder, one marker on the lateral side of 
the elbow, and two markers on the upper arm. The software can then determine frame-by-frame joint angles based on outputs from the model.

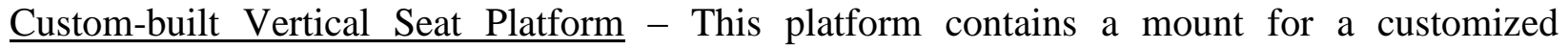
automobile seat with a rear support and adjustable strap to keep seat stationary and, for reaching tasks, to secure the participant's back against the seat (Figure 7).

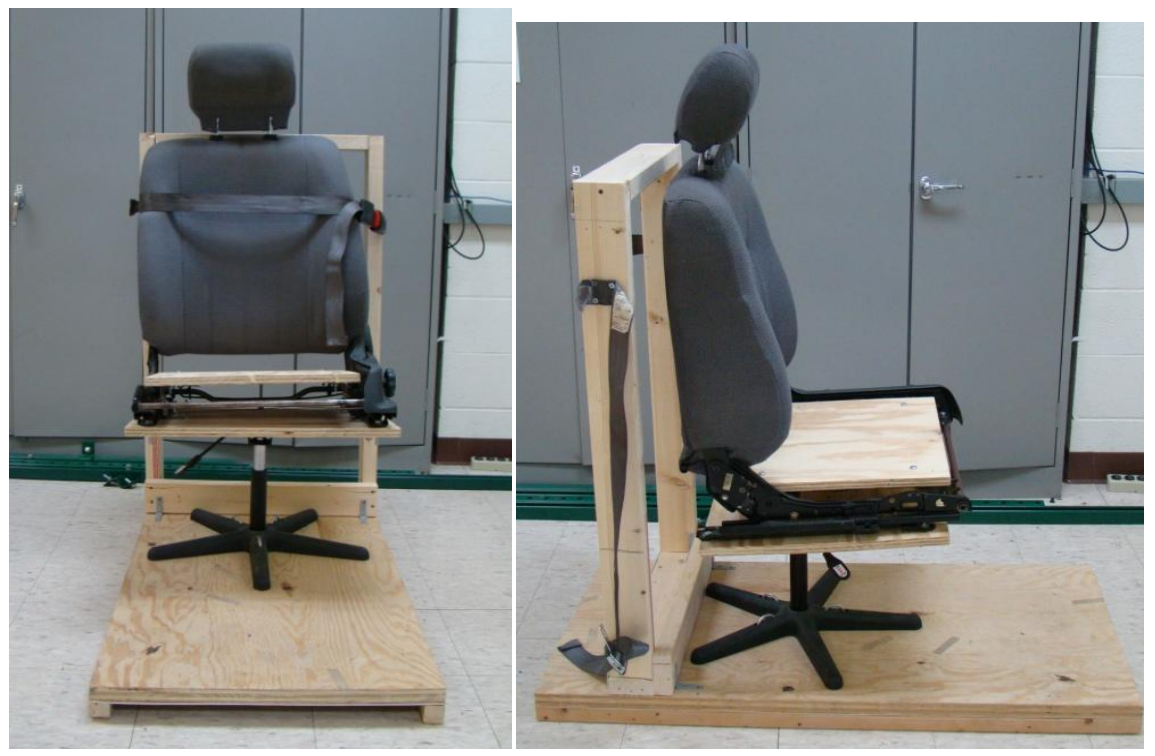

Figure 7. Pictures of vertical seat platform The strap was used to stabilize the participant's back against the seat.

Custom-built Horizontal Seat Platform - Platform secures a customized automobile seat with the seat-back mounted in a horizontal position. Platform surface is 6 feet by 8 feet, with the seat on the right-side to provide space for the subject to lay supine to the left of the seat. The seat orientation can be adjusted to $120^{\circ}$ (Figure 8 ) or $90^{\circ}$ (Figure 9). 


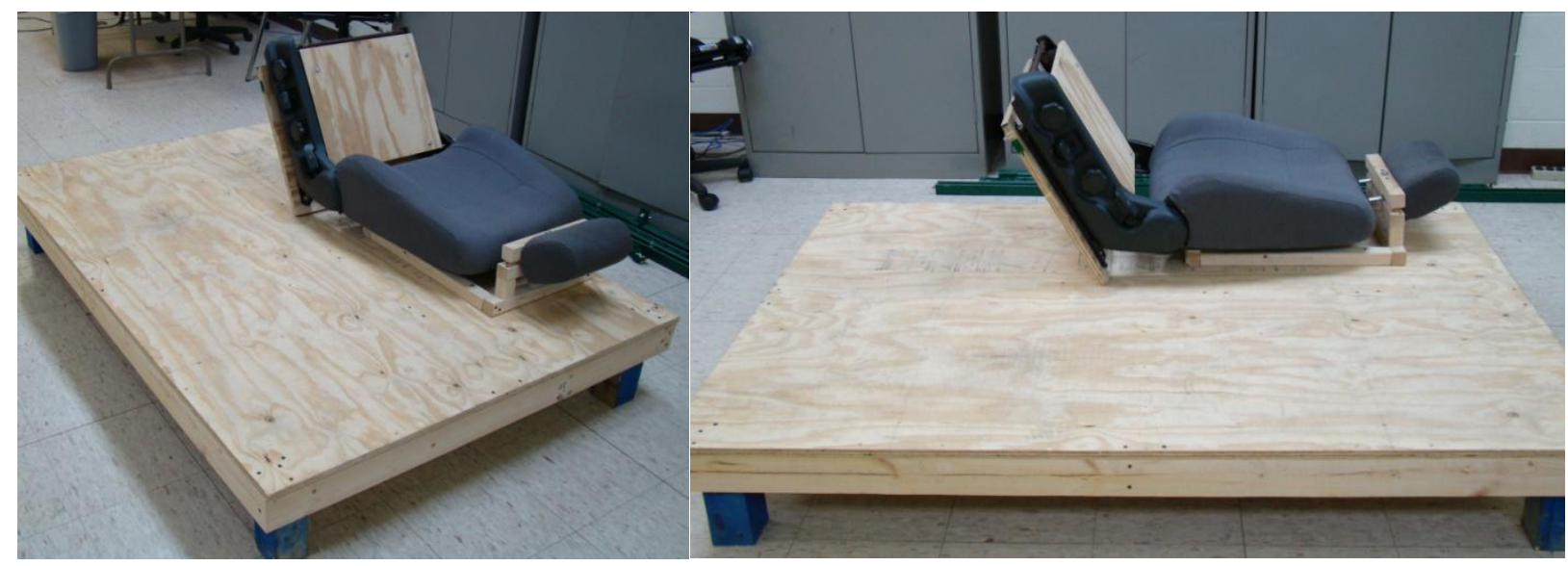

Figure 8 . Horizontal seat platform with the seat in the $120^{\circ}$ orientation.

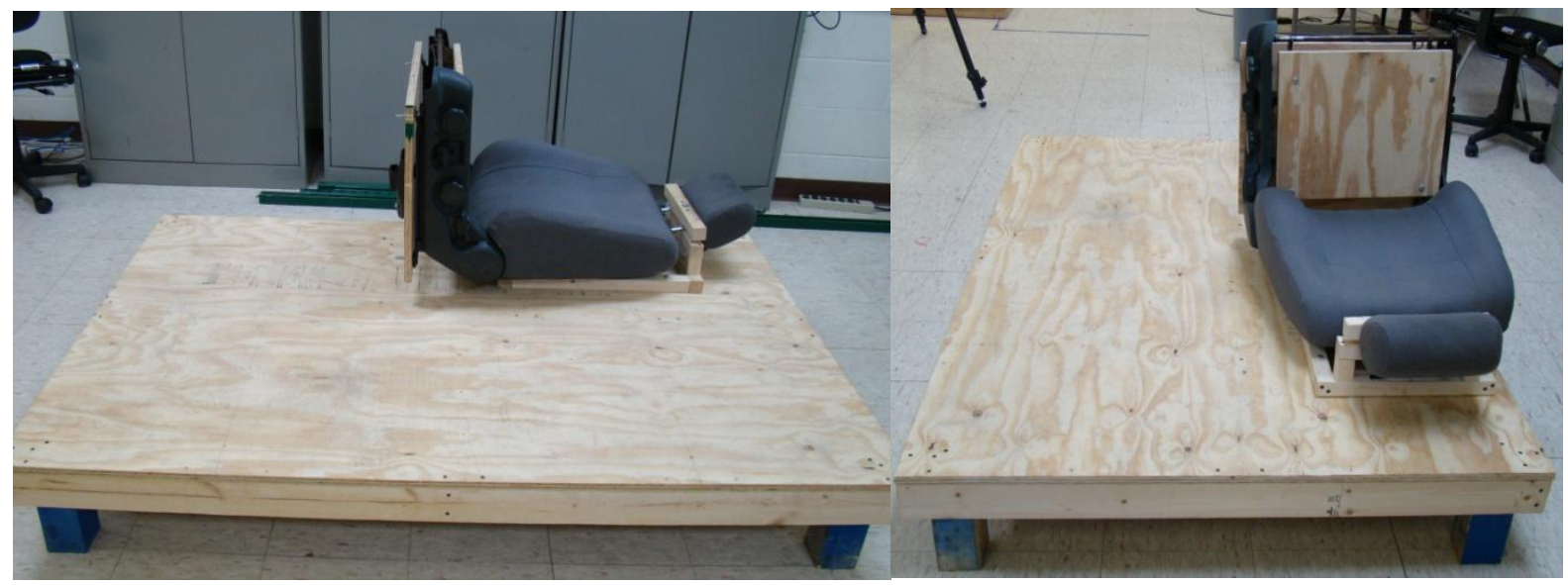

Figure 9. Horizontal seat platform with the seat in a $90^{\circ}$ orientation.

Anthropometry Kit (Model 113, DKSH Ltd, Zurich, Switzerland) - This kit consists of several styles of sliding calipers (Figure 10). A number of anthropometric measurements (listed in section 4.5.2) were obtained from participants in this study to evaluate joint kinematics. 
Dual-Reading Balance Beam Scale (Healthometer Professional Scales, Pelstar LLC, Alsip, IL,

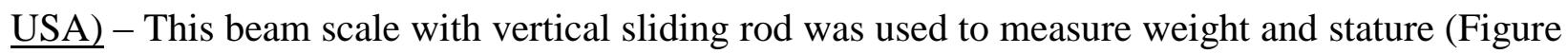

$11)$.

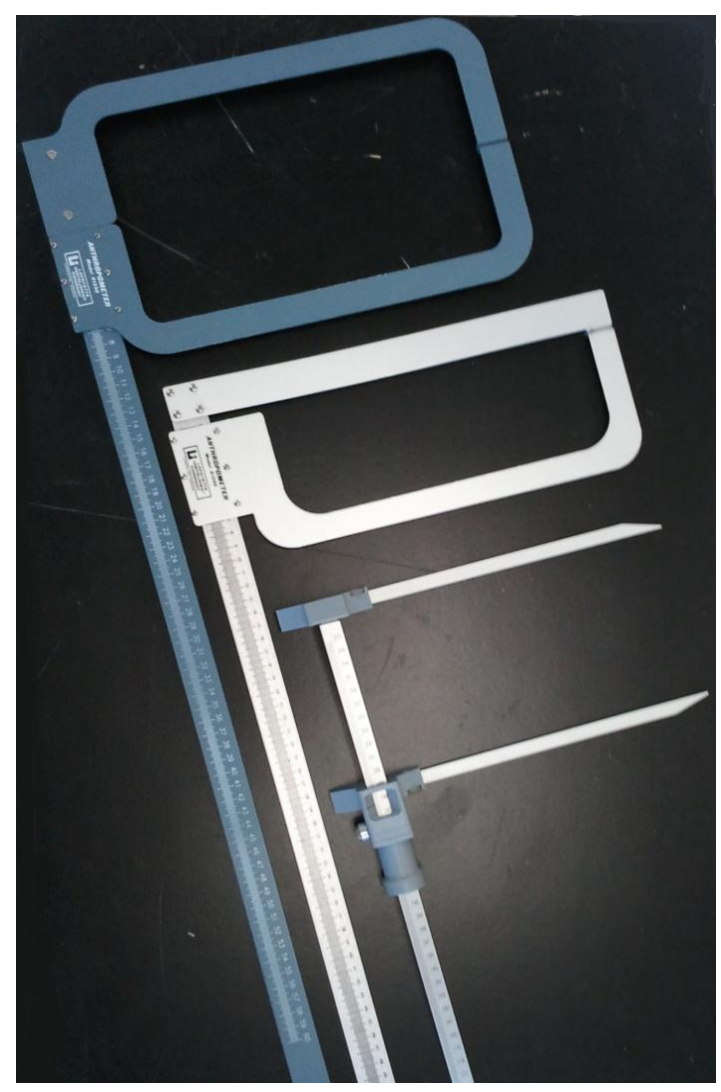

Figure 10. Sliding anthropometric calipers

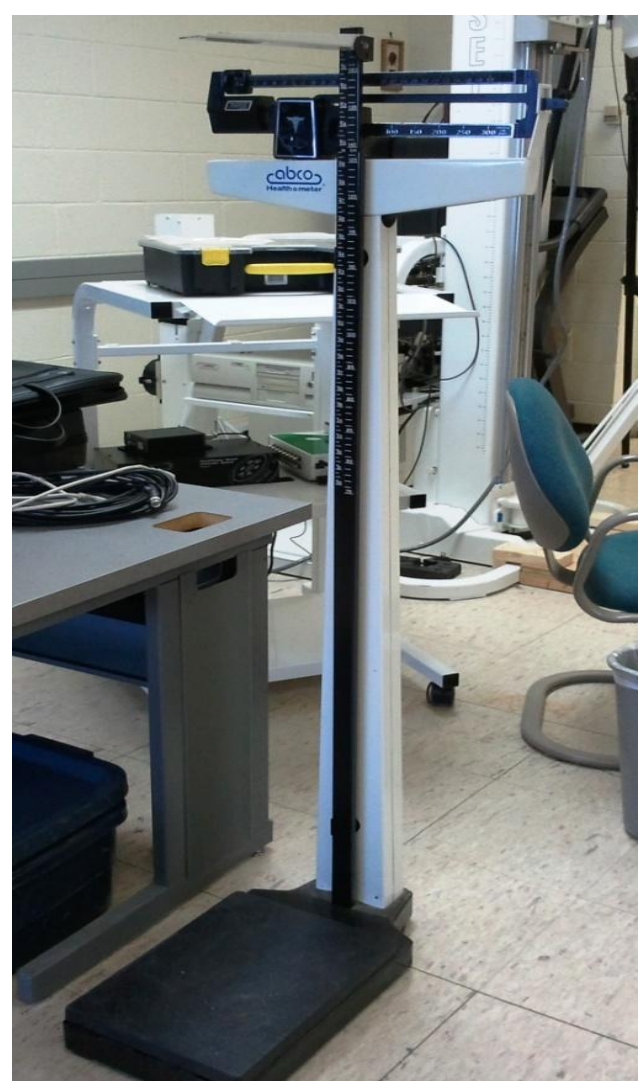

Figure 11. Dual-reading balance beam scale

\subsection{Subjects}

Ten healthy, male participants with mean $( \pm \mathrm{sd})$ age, height, weight of $24( \pm 2.3)$ years, $174( \pm 7.7) \mathrm{cm}$, and $73.3( \pm 7.0) \mathrm{kgs}$, respectively, were recruited for participation in this research. Potential participants were excluded if they a) were unable to perform the tasks, or b) had any deformity or physical issue that would not allow use of the full marker set. The investigator informed the participants of the study procedures and provided the participants with a consent 
form that was signed prior to beginning research. IRB Approval and a copy of the consent form provided by the West Virginia University Institutional Review Board can be found in Appendix A and B, respectively. Subjects were compensated at a rate of $\$ 10$ per hour for their participation.

\subsection{Experimental Design}

The effect of seat orientation on ingress/egress kinematics was studied using a $2 \times 3$ factorial experimental design. The independent variables were the task (ingress; egress) and the seat orientation (vertical $90^{\circ}$; horizontal $90^{\circ}$; horizontal $120^{\circ}$ ). Peak joint angles and ranges of motion of the shoulders, trunk, hips, and knees acted as the dependent variables. A complete list of dependent variables can be found in Table 1.

The reach tasks were analyzed using a $2 \times 3$ factorial experimental design. The independent variables were the seat orientation (vertical $90^{\circ}$; horizontal $90^{\circ}$ ) and anatomical planes (frontal, sagittal, and transverse). The dependent variables of interest were three extreme points, representing maximum reach, for the left and right arms.

\subsection{Data collection}

\subsubsection{Subject Preparation}

In order to accurately determine the joint angles, the markers on each body segment must be accurately tracked. The markers placed on the body must precisely follow the movement of the segment. Therefore, upon arrival, the participant was instructed to change into tight-fitting, spandex shorts and remove their shirt. The spandex shorts also helped ensure that the markers were not hidden during the capture. 
Table 1. Complete list of dependent variables for ingress/egress tasks

\begin{tabular}{|c|c|}
\hline Right Shoulder (Right Upper Arm vs. Thorax) & Left Shoulder (Left Upper Arm. Vs. Thorax) \\
\hline 1. Flexion & 1. Flexion \\
\hline 2. Extension & 2. Extension \\
\hline 3. Abduction & 3. Abduction \\
\hline 4. Adduction & 4. Adduction \\
\hline 5. External Rotation & 5. External Rotation \\
\hline 6. Internal Rotation & 6. Internal Rotation \\
\hline 7. Flexion/Extension (Range of Motion) & 7. Flexion/Extension (Range of Motion) \\
\hline 8. Abduction/Adduction (Range of Motion) & 8. Abduction/Adduction (Range of Motion) \\
\hline 9. Rotation (Range of Motion) & 9. Rotation (Range of Motion) \\
\hline Right Hip (Right Thigh vs. Pelvis) & Left Hip (Left Thigh vs. Pelvis) \\
\hline 1. Flexion & 1. Flexion \\
\hline 2. Abduction & 2. Abduction \\
\hline 3. External Rotation & 3. External Rotation \\
\hline 4. Internal Rotation & 4. Internal Rotation \\
\hline 5. Rotation (Range of Motion) & 5. Rotation (Range of Motion) \\
\hline $\begin{array}{l}\text { Right Knee (Right Shank vs. Right Thigh) } \\
\text { 1. Flexion } \\
\text { 2. External Rotation } \\
\text { 3. Internal Rotation } \\
\text { 4. Rotation (Range of Motion) }\end{array}$ & $\begin{array}{l}\text { Left Knee (Left Shank vs. Left Thigh) } \\
\text { 1. Flexion } \\
\text { 2. External Rotation } \\
\text { 3. Internal Rotation } \\
\text { 4. Rotation (Range of Motion) }\end{array}$ \\
\hline $\begin{array}{l}\text { Trunk (Thorax vs. Pel } \\
\text { 1. Flexion } \\
\text { 2. Right Lateral Bend } \\
\text { 3. Left Lateral Bendin } \\
\text { 4. Right Rotation } \\
\text { 5. Left Rotation } \\
\text { 6. Lateral Bending (R } \\
\text { 7. Rotation (Range of }\end{array}$ & $\begin{array}{l}\text { is) } \\
\mathrm{ng} \\
\mathrm{g} \\
\text { ange of Motion) } \\
\text { Motion) }\end{array}$ \\
\hline
\end{tabular}




\subsubsection{Anthropometric Measurements}

Visual3D software requires several anthropometric dimensions to accurately develop a model of the participant. Therefore, the following anthropometric dimensions were measured and recorded for each participant:

- Body mass

- Height

- Chin to top of head

- C1 vertebrae to top of head

- C7 vertebrae to top of head

- Trunk length - C1 to L5/S1

- Upper arm length - Acromion process to elbow joint axis

- Lower arm length - Elbow joint axis to wrist

- Hand length - Wrist center to tip of middle finger with fingers fully extended

- Hand breadth - Width across knuckles of hand with thumb abducted

- Pelvis width - Left greater trochanter to right greater trochanter

- Thigh length - Greater trochanter to lateral femoral condyle of the knee.

- Shank length - Lateral femoral condyle to lateral malleolus of the ankle

- Heel to toe

- Lateral malleolus to toe 


\subsubsection{Marker Set}

Next, the participant was outfitted with the retro-reflective markers (Figure 12). The markers were affixed to certain landmarks of the participant's body with hair/toupee tape, a highly adhesive, double-sided tape. A custom marker set using 62 markers was created for this research. The marker set was designed for use with C-Motion Visual 3D software. Ten of the markers were required only for the static, calibration trial and were removed before dynamic trials are performed. The extra calibration markers helped ensure model accuracy. To ensure model accuracy, the static calibration trial had markers on the most distal, most proximal, most lateral, and most medial points of each segment. However, in a lot of cases, these markers were not visible during the dynamic captures (i.e. LKNEM, LBHD, etc. ), therefore, once the model was created with data from the static calibration trial, the segments were tracked using the tracking markers, which were placed in more visible areas of the body segment. Tables 1 and 2 provide a list of the upper and lower body markers, respectively, and their location on the body. A list of the body segments in the Visual3D model and their corresponding calibration and tracking markers can be found in Table 3.

\subsubsection{Experimental Tasks}

\subsubsection{Static Trial}

After the participant's anthropometric measurements were taken and the participant was fitted with the marker set, the participant stood in the middle of the capture volume of the Vicon camera system, with the legs spread approximately shoulder-width and the arms abducted approximately $30^{\circ}$ from the body. Once it was verified that all the markers on the participant 


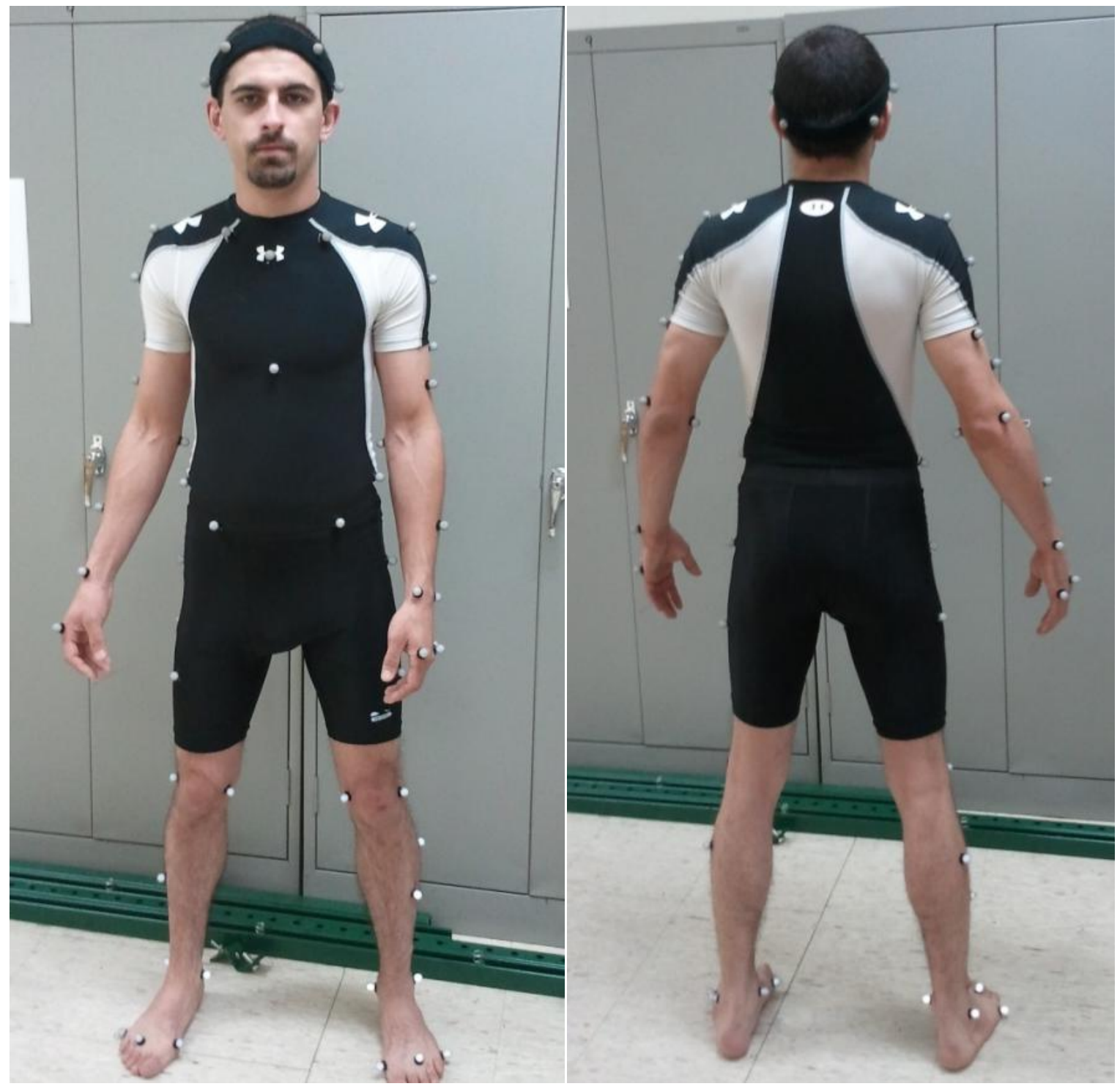

Figure 12. The custom marker set, including calibration-only markers, affixed to a human. The marker set was symmetrical right to left. 
Table 2. Upper body markers of the marker set. Markers denoted with a '*' are calibration-only markers and were removed before dynamic trials.

\begin{tabular}{|c|c|}
\hline \multicolumn{2}{|l|}{ Upper Body Markers } \\
\hline Markers: & Location: \\
\hline LFHD / RFHD & Left and right side of the forehead \\
\hline LMHD/ RMHD & Left and right sides of the head, above the ears \\
\hline LBHD* / RBHD* & Left and right side of the back of the head \\
\hline LMCLAV / RMCLAV & Midpoint of the left and right clavicles \\
\hline CLAV & Jugular notch at the proximal aspect of the sternum \\
\hline STRN & Xyphoid process at the distal aspect of the sternum \\
\hline LSHO / RSHO & Tip of the left and right acromion processes \\
\hline LSHD / RSHD & $\begin{array}{l}\text { Upper portion of the upper arm, lateral to the center of the shoulder } \\
\text { Joint }\end{array}$ \\
\hline LUPA / RUPA & $\begin{array}{l}\text { Approximately } 1 / 3 \text { of the distance from the shoulder to the elbow, } \\
\text { and slightly to the posterior }\end{array}$ \\
\hline LUPA2 / RUPA2 & $\begin{array}{l}\text { Approximately } 1 / 2 \text { of the distance from the shoulder to the elbow, } \\
\text { and slightly to the anterior }\end{array}$ \\
\hline LELB / RELB & Lateral epicondyle of the humerus \\
\hline LMELB* / RMELB* & Medial epicondyle of the humerus \\
\hline LFRM / RFRM & Midpoint of the front of the forearm, between the radius and ulna \\
\hline LWRA / RWRA & Medial aspect of the wrist (thumb side) \\
\hline LWRB / RWRB & Lateral aspect of the wrist (pinky side) \\
\hline LFIN / RFIN & Distal aspect of the third metacarpal on the back of the hand \\
\hline $\mathrm{LDMH}^{*} / \mathrm{RDMH}^{*}$ & Distal aspect of the second metacarpal on the back of the hand \\
\hline $\mathrm{LDLH}^{*} / \mathrm{RDLH}^{*}$ & Distal aspect of the fifth metacarpal on the back of the hand \\
\hline
\end{tabular}


Table 3. Lower body markers of the custom marker set. Markers denoted with a '*' are calibration-only markers and were removed before dynamic trials.

\begin{tabular}{|c|c|}
\hline \multicolumn{2}{|c|}{ Lower Body Markers } \\
\hline Markers: & Location: \\
\hline LASI / RASI & Anterior superior iliac spine \\
\hline LPSI / RPSI & Lateral aspect of pelvis, at the most superior point of the Ilium \\
\hline LTROC / RTROC & Greater trochanter of the femur \\
\hline LTHI / RTHI & $\begin{array}{l}\text { Approximately } 1 / 3 \text { of the distance from the greater trochanter to the } \\
\text { knee, and slightly to the posterior }\end{array}$ \\
\hline LTHI2 / RTHI2 & $\begin{array}{l}\text { Approximately } 1 / 2 \text { of the distance from the greater trochanter to the } \\
\text { knee, and slightly to the anterior }\end{array}$ \\
\hline LKNE / RKNE & Lateral condyle of the knee \\
\hline LKNEM* / RKNEM* & Medial condyle of the knee \\
\hline LTIB / RTIB & $\begin{array}{l}\text { Approximately } 1 / 3 \text { of the distance from the knee to the ankle, and } \\
\text { slightly to the posterior }\end{array}$ \\
\hline LTIB2 / RTIB2 & $\begin{array}{l}\text { Approximately } 1 / 2 \text { of the distance from the knee to the ankle, and } \\
\text { slightly to the anterior }\end{array}$ \\
\hline LANK / RANK & Lateral malleolus of the tibia \\
\hline LMANK / RMANK & Medial malleolus of the fibula \\
\hline LDMANK / RDMANK & Distal aspect of the first metatarsal on the top of the foot \\
\hline LDLANK / RDLANK & Distal aspect of the fifth metatarsal on the top of the foot \\
\hline LTOE / RTOE & Distal aspect of the third metatarsal on the top of the foot \\
\hline
\end{tabular}


Table 4. List of body segments modeled by C-Motion Visual3D and their corresponding markers. Markers denoted with a '*' are calibration-only markers and were removed before dynamic trials.

\begin{tabular}{|l|l|}
\hline \multicolumn{1}{|l|}{ Segment } & Markers \\
\hline Head & LFHD, LMHD, LBHD*, RFHD, RMHD, RBHD* \\
\hline Thorax/Abdomen & RMCLAV, LMCLAV, CLAV, STRN, RSHO, LSHO \\
\hline Right Upper Arm & RSHO, RSHD, RUPA, RUPA2, RELB, RMELB* \\
\hline Left Upper Arm & LSHO, LSHD, LUPA, LUPA2, LELB, LMELB* \\
\hline Right Forearm & RELB, RMELB*, RFRM, RWRA, RWRB \\
\hline Left Forearm & LELB, LMELB*, LFRM, LWRA, LWRB \\
Right Hand & RWRA, RWRB, RDMH*, RDLH*, RFIN \\
\hline Left Hand & LWRA, LWRB, LDMH*, LDLH*, LFIN \\
\hline Pelvis & LASI, RASI, LPSI, RPSI, LTROC, TROC \\
\hline Right Thigh & RTROC, RTHI, RTHI2, RKNE, RKNEM* \\
Left Thigh & LTROC, LTHI, LTHI2, LKNE, LKNEM* \\
\hline Right Shank & RKNE, RKNEM*, RTIB, RTIB2, RANK, RMANK \\
\hline Left Shank & LKNE, LKNEM*, LTIB, LTIB2, LANK, LMANK \\
\hline Right Foot & RANK, RMANK, RDLANK, RDMANK, RTOE \\
\hline Left Foot & LANK, LMANK, LDLANK, LDMANK, LTOE \\
\hline
\end{tabular}

were visible by the cameras, a five second capture was taken with the participant holding this posture.

\subsubsection{Ingress / Egress Tasks}

Participants performed ingress and egress maneuvers with the seat in three different orientations. One vertical and two horizontal seat orientations were used. For the horizontal seat orientation, seat angles of $90^{\circ}$ and $120^{\circ}$ were used. In the vertical orientation, only a $90^{\circ}$ seat angle was used. Three ingress and three egress trials were performed for each seat orientation. The order of the seat orientations was randomized between participants.

For the trials using the horizontal seat orientations, the participant was instructed to begin by lying supine on the horizontal seat platform on the left side of the seat with the legs extended 
and the hands, palm-down, on the abdominal region. A verbal command was given for the participant to ingress into the seat. The participant used the following progression (Figure 13) to enter the seat:

1. Begin laying flat on the back with legs straight and hands on abdomen.

2. Flex left leg and place foot flat on the platform.

3. Place right arm over the seat.

4. Place left hand palm on the platform and using both hands, lift upper body towards a seated position

5. Use left foot and arms to lift the pelvis off of the platform

6. Move pelvis into seat and lift left leg into seat

7. Place hands back on the abdomen

8. The ingress motion capture will then be stopped.

After ingress, the motion capture began again and the participant egressed from the seat by following the progression in reverse. Once the participant had returned to the supine position to the left of the seat with the hands on the abdomen, the capture was stopped. For the trials using the vertical seat orientation, the participant began by standing to the left of the vertical seat platform facing forward with hands on the abdomen and their back aligned with the back of the seat. Upon verbal command, the capture began and the participant ingressed into the seat by moving the right leg to the front of the seat, then bringing the left leg in front of the seat and sitting down. The capture ended when the participant was sitting in the seat with the hands on the abdomen. Next, a verbal command to egress was given, and the participant stood up and returned 

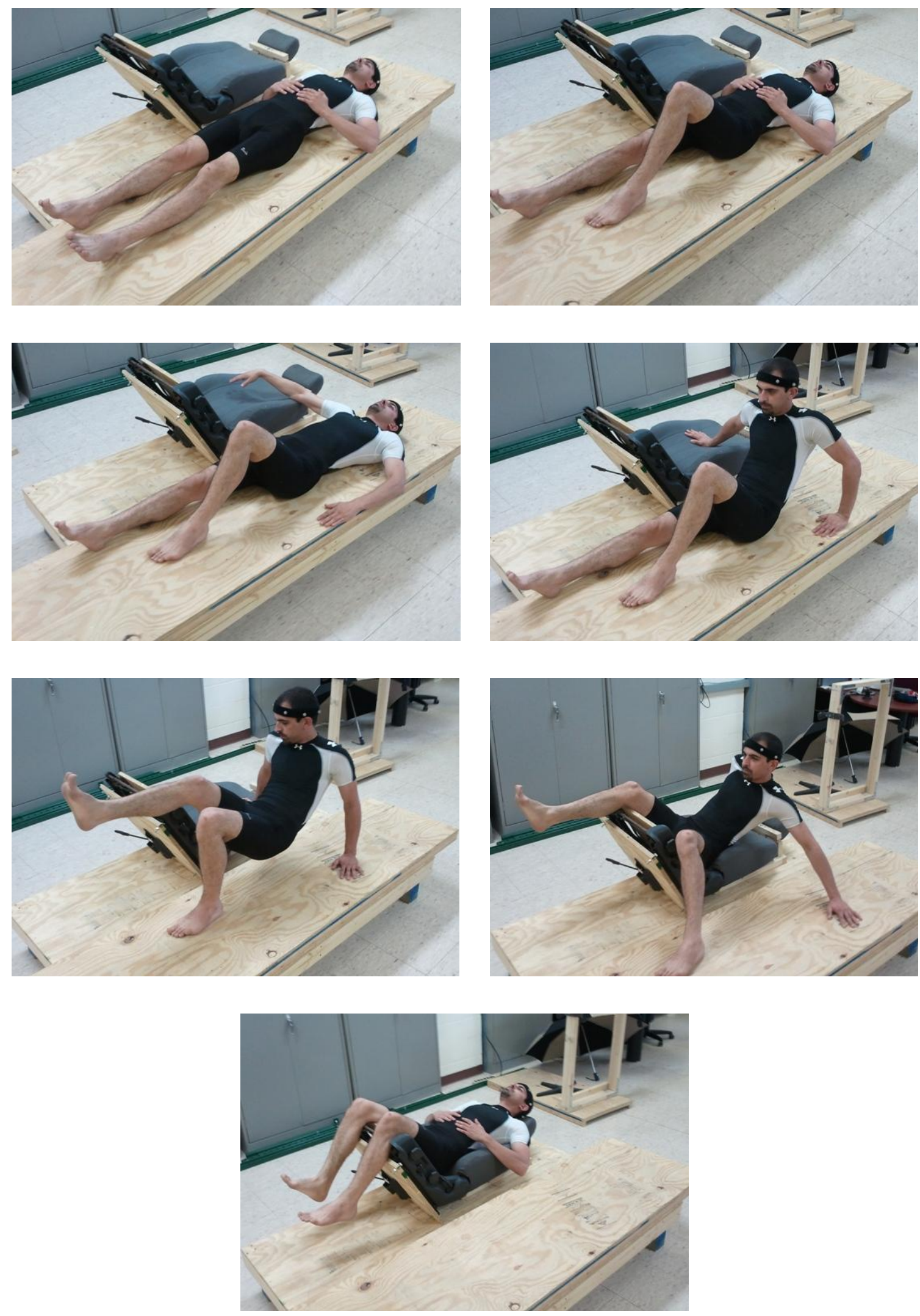

Figure 13. Progression used to ingress and egress horizontally oriented seat. 
to the standing posture to the left side of the seat. The capture was stopped as soon as the participant was standing in the proper location with the hands on the abdomen.Participants were given a rest period of about five minutes when the seat orientation was being changed. After capturing three ingress and three egress trials for each of the three seat orientations, the participant began the reaching tasks.

\subsubsection{Planar Reach Tasks}

In order to explore the effect of seat orientation on the maximal reach, several planar reaching tasks were completed with the seat in the vertical orientation with a seat angle of $90^{\circ}$ and in the horizontal orientation with a seat angle of $90^{\circ}$. Reaching tasks were not done with the seat in a horizontal orientation with a seat angle of $120^{\circ}$.

Each participant completed planar reaching tasks while ingressed into the vertical and horizontal seats. When ingressed into the seat, the subject moved their fully-extended arm though the full range-of-motion in the frontal plane, sagittal plane, and transverse plane (Figure 14).

\subsection{Data Processing}

\subsubsection{Vicon Data Processing}

Each static and dynamic trial was loaded into Vicon Nexus Software, where it was labeled, gap-filled, and exported (Figure 15) for further processing/analysis in other software. When processing a trial in Vicon Nexus, the markers must first be labeled in the trial. A list of markers in the current marker set is displayed on the side of the screen where each marker can be selected. An unlabeled marker can then be clicked within the trial view which will label it with 
a)
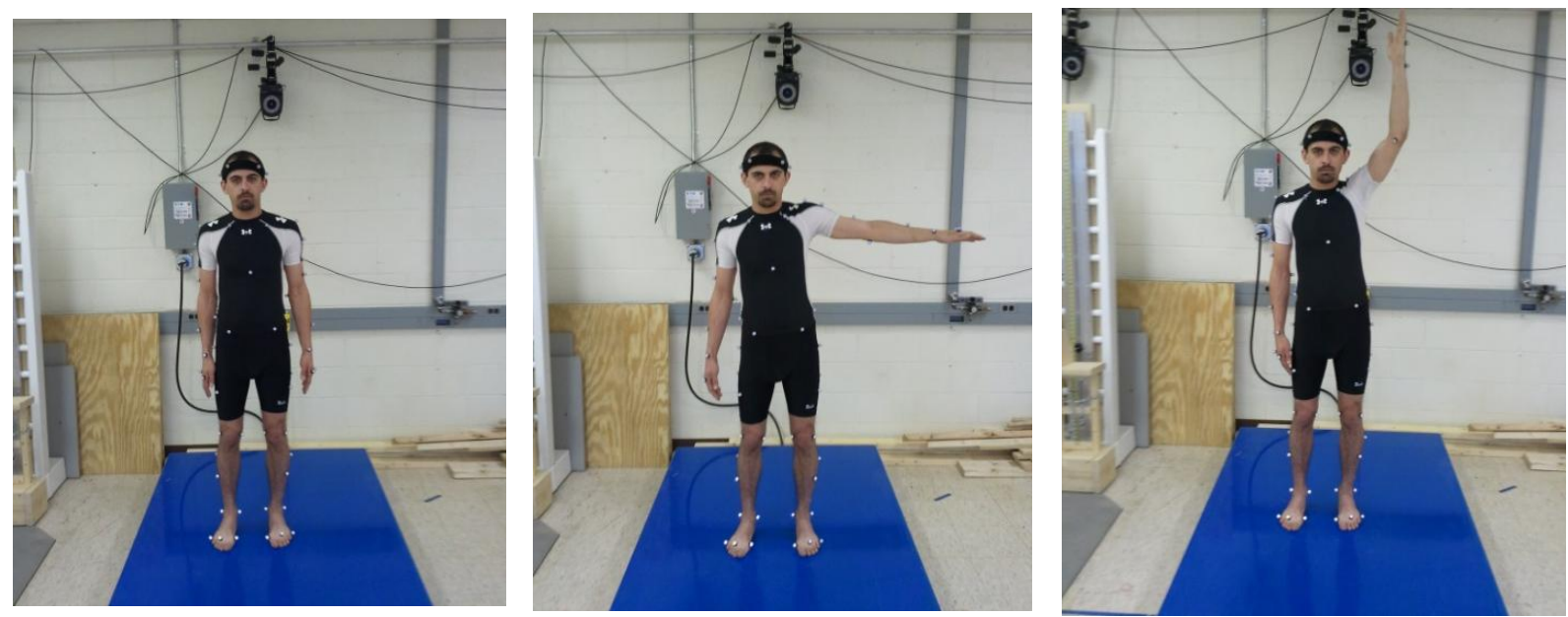

b)
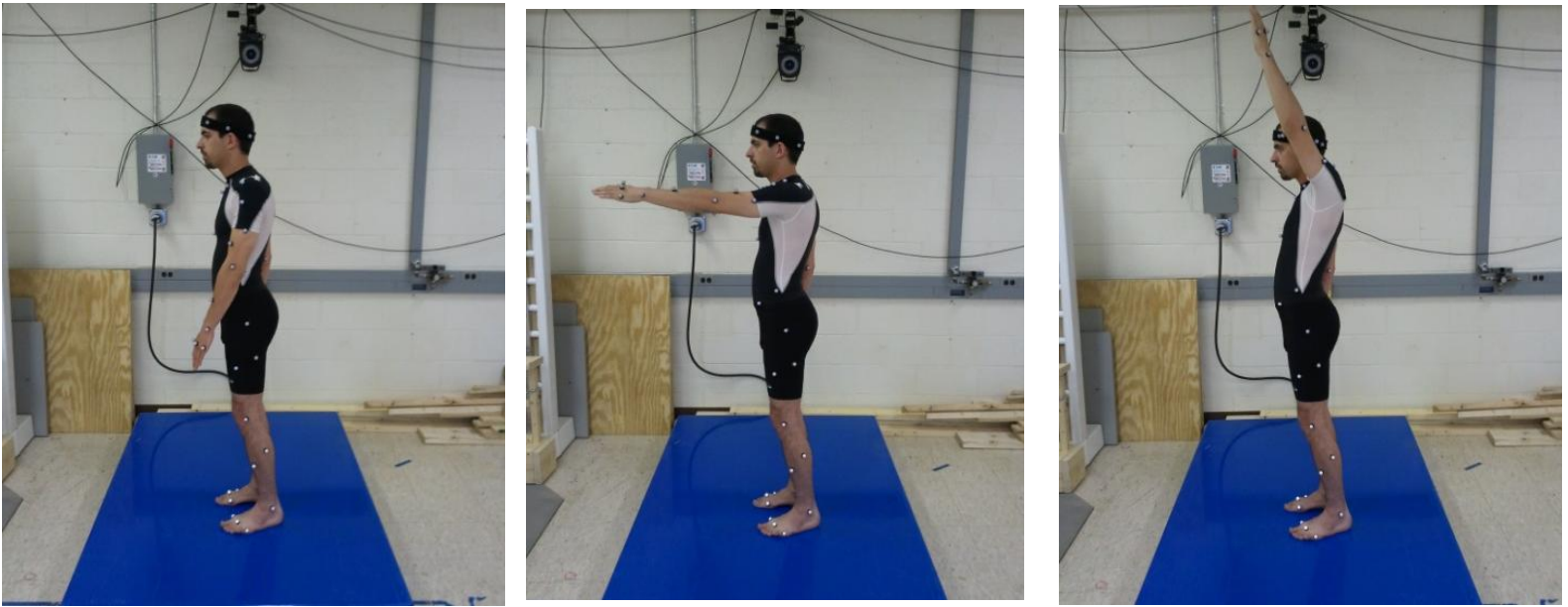

c)
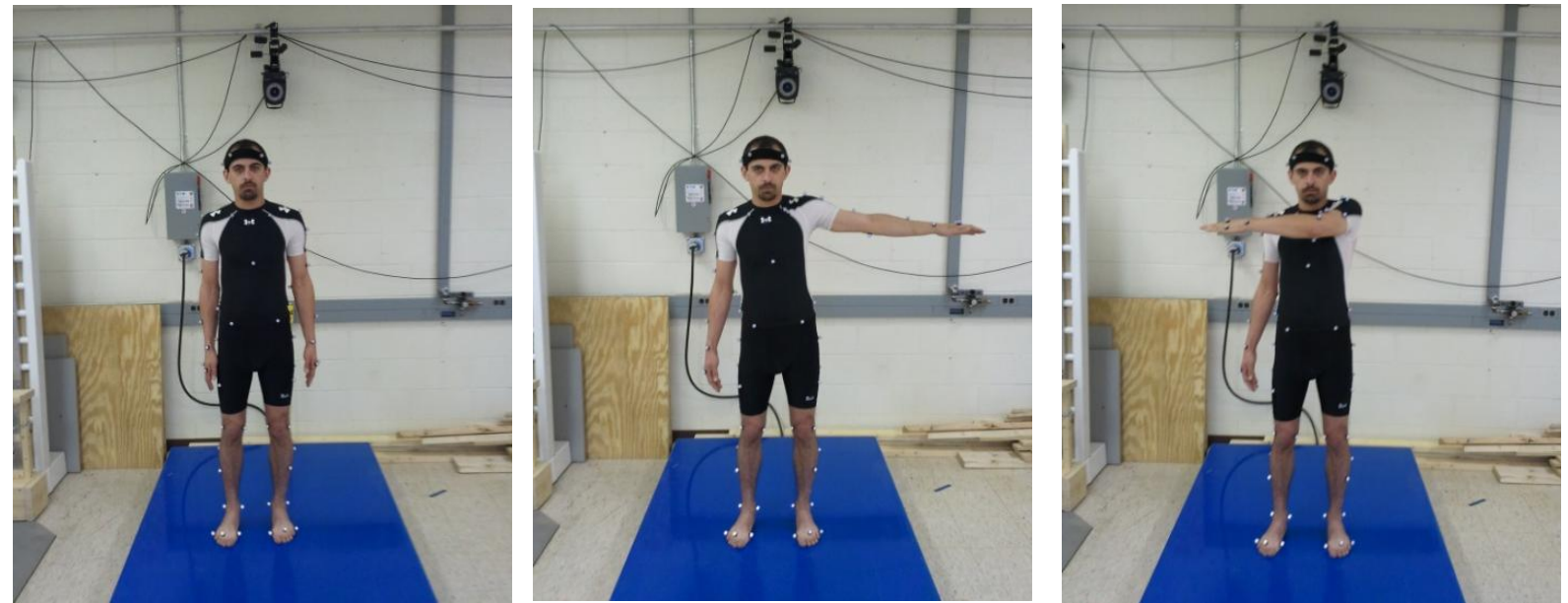

Figure 14. Visualization of the planar reaching tasks; a) frontal plane, b) sagittal plane, and c) transverse plane. 

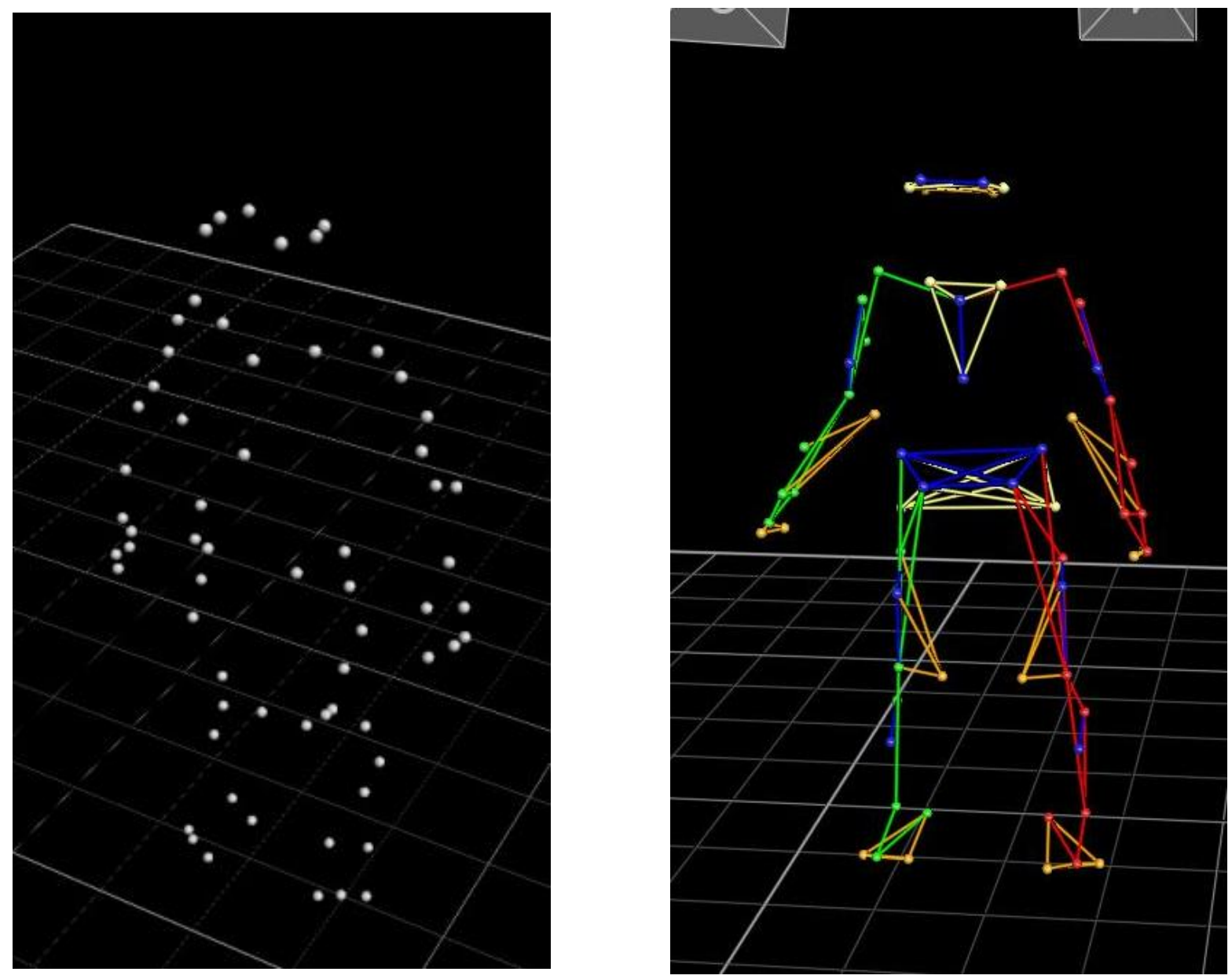

Figure 15. Frame of a static trial before and after processing in Vicon Nexus.

the name and color of the selected marker. When a marker is labeled in a frame, it is labeled in each subsequent and previous frame until a gap is encountered. When the marker reappears in the frames on the other end of the gap, it will not automatically be labeled. Therefore, it is often necessary to navigate the trial frame-by-frame, labeling each marker several times throughout the capture. Once there are no unlabeled marker trajectories, the trial data can be gapfilled.

Gap-filling is the process of filling in any gaps in the marker data in the trial after it is labeled. The Vicon Nexus software includes three operations to assist in the gap-filling: a 
Woltring gap-filling routine, a spline-fill operation, and a pattern-fill operation. The most basic of the three operations is the spline-fill routine.

The most complex of the gap filling operations is the Woltring gap fill routine. The Woltring routine uses a cubic spline algorithm to automatically fill gaps up to a user-specified length. This routine was used first with a ten-frame gap limit (approximately $1 / 5$ of a second). A small frame limit is necessary because the accuracy of the Woltring routine decreases as the length of the gap increases. The recommended frame limit in Nexus is five frames, however the participants will execute the tasks in this research slowly, and pilot data has suggested that the ten frame limit maintains accuracy compatible with the Visual3D software.

Once the short gaps in the marker data were filled using the Woltring gap-fill routine, the remainder of the gaps were filled with the more basic spline- and pattern-fill operations. These operations only fill one gap at a time, however the result of running each operation is shown on screen, allowing the user to easily decide which routine to use. The spline-fill operation analyzes the marker trajectory before and after the gap, and extrapolates the trajectory of the marker in the most logical way. In other words, it logically guesses where the marker should move during the gap based on where it was moving before and after the gap. This operation is best for shorter gaps with smooth movements. However, its ability to fill longer gaps is poor.

The pattern-fill operation analyzes the movement of a different, user-specified marker and attempts to mimic that movement pattern in the gap in the original marker's data. This operation is better suited for the longer gaps; however it requires another marker with a similar movement pattern to be labeled and visible in every frame of the gap. If a marker with a dissimilar movement pattern or gaps is used, the gap may be inaccurately filled, making it impossible to model in Visual3D. 
The gaps in the marker data were viewed one at a time, and a marker with the most similar movement pattern was selected. The result of each operation was visually inspected and a determination was made about which routine best fills the gap. After this was done for each gap in the data, the trial was visually inspected from beginning to end to ensure it is correctly labeled and gap-filled. After the data was labeled and gap-filled, the ingress and egress data was exported for further processing in C-Motion Visual3D. The reach task data was exported for further processing in Microsoft Excel. The remainder of the processing steps for the ingress and egress data will be explained next, followed by an explanation of the remaining steps used to process the reach data.

\subsubsection{Ingress / Egress Kinematics}

The ingress and egress data from Vicon Nexus was used in Visual3D to create dynamic, three-dimensional models of the participants. Static calibration trials were used to form the models. Each body segment (Table 4) was defined by an X,Y,Z coordinate frame formed using the markers on the proximal and distal ends of the segments and four tracking markers. Coordinate frames were assigned following the right-hand rule with the user in the standard anatomical position. For each segment, the $\mathrm{X}$-axis pointed laterally to the right, $\mathrm{Y}$-axis pointed anteriorly, and the Z-axis pointed superiorly along the long axis of each segment. The tracking markers for some segments included the calibration markers. Afterwards, the model template was saved by the software that contains information on each segment in the model, including dimensions and marker information. This template was then applied to each dynamic capture file. The software used the frame-by-frame marker information from the data file in conjunction with the information in the template file to track and model the movement of the body segments in the dynamic trials. 
Finally, computational outputs were defined in Visual3D which allowed the software to calculate frame-by-frame joint angles, based on the orientations of the assigned coordinate frames. In this research, the following computational outputs were defined:

1. Trunk angles - Flexion, lateral bending, and rotation of the trunk, with the thorax/abdomen segment as the primary segment, and the pelvis segment as the reference segment.

2. Right hip angles - Flexion, abduction/adduction, and rotation of the right hip, with the right thigh segment as the primary segment and the pelvis segment as the reference segment.

3. Left hip angles - Flexion, abduction/adduction, and rotation of the left hip, with the left thigh segment as the primary segment and the pelvis segment as the reference segment.

4. Right knee angles - Flexion and rotation of the right knee, with the right shank as the primary segment and the right thigh as the reference segment.

5. Left knee angles - Flexion and rotation of the left knee, with the left shank as the primary segment and the left thigh as the reference segment.

6. Right shoulder angles - Flexion/extension, abduction/adduction, and rotation of the right shoulder, with the right upper arm as the primary segment and the thorax/abdomen as the reference segment.

7. Left shoulder angles - Flexion/extension, abduction/adduction, and rotation of the left shoulder, with the left upper arm as the primary segment and the thorax/abdomen as the reference segment. 
An X-Y-Z rotation sequence was used for all joint angles. In general, rotations around the X, Y, and $\mathrm{Z}$ axes represent flexion/extension, abduction/adduction, and rotation, respectively. The exception in our research is the trunk, in which a rotation around the Y-axis represents lateral bending, as the trunk does not abduct/adduct, by definition. Thus, for each rotation around an $\mathrm{X}$ axis, positive joint angles represented either flexion or extension, while negative joint angles represented the opposing motion. In each case, a joint angle of $0^{\circ}$ represents the neutral location of the motion. For instance, when the knee is fully extended (neutral posture), the flexion/extension and rotation angles are both $0^{\circ}$. After defining the computational outputs, the Visual3D software was used to export the frame-by-frame joint angles. Peak joint angles and ranges of motion (Table 1) were determined and prepared for statistical analysis.

\subsubsection{Planar Reach}

Three-dimensional position of the marker located at the distal aspect of the third metacarpal (RFIN, LFIN) was used to quantify the planar reach. The origin of this marker was transformed from the global reference frame to the marker located at the clavicle. In each reach task, movements were limited to two axes, allowing us to ignore one component of the threedimensional coordinates. To better illustrate, Figure 16 displays a plot of a reaching task in each plane. The resulting plot was parabolic with the clavicle marker as the origin. The maximal and minimal values along the $\mathrm{X}$ axis, and maximum value along the $\mathrm{Y}$ axis were recorded as the maximum reach for the respective planar motion or anatomical planes. 

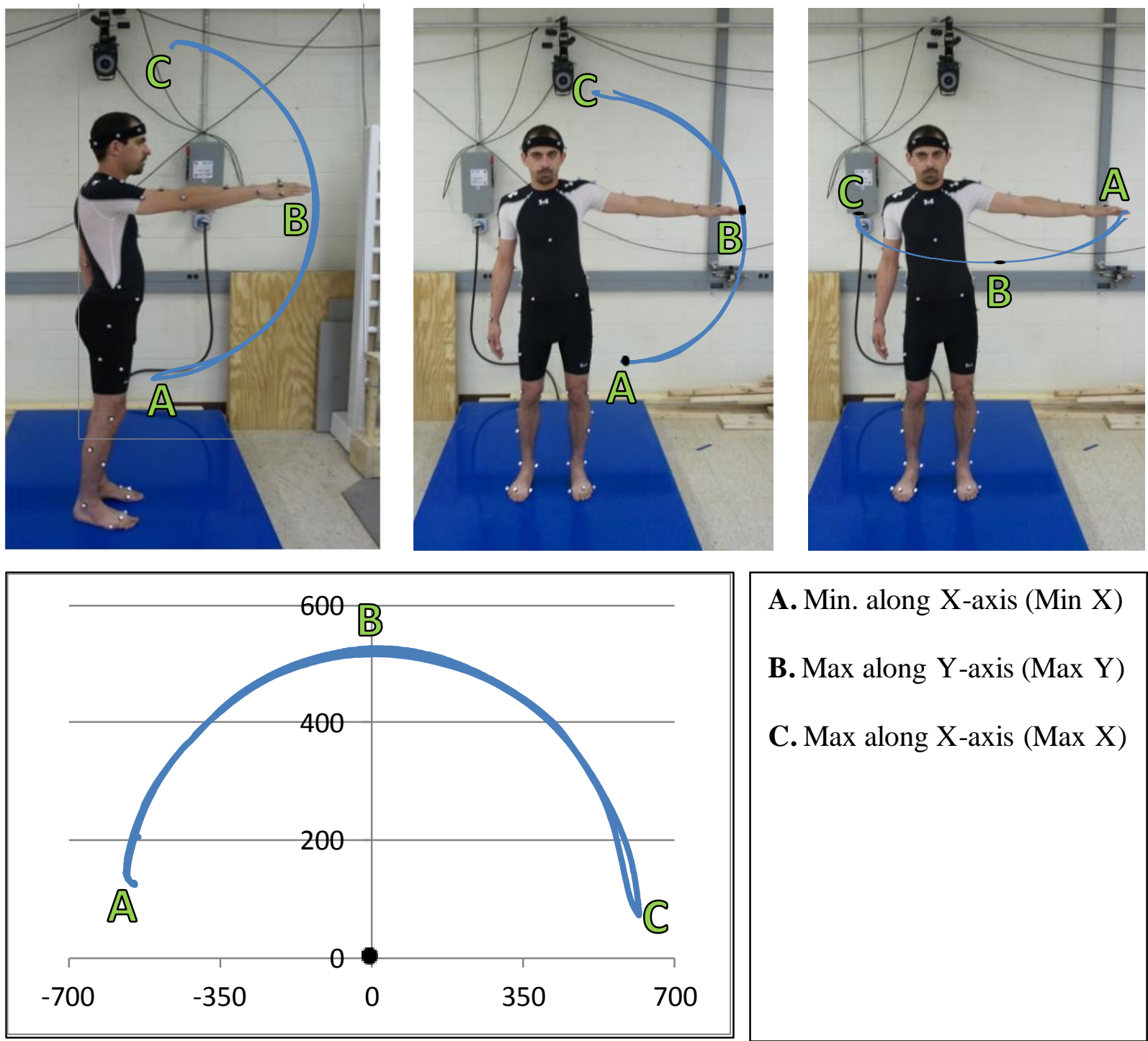

A. Min. along $\mathrm{X}$-axis $(\operatorname{Min} \mathrm{X})$

B. Max along $\mathrm{Y}$-axis (Max Y)

C. Max along $\mathrm{X}$-axis (Max $\mathrm{X})$

Figure 16. plot of sagittal, frontal, and transverse reach tasks (left to right), and the extreme points for each.

\subsection{Statistical Analysis}

A two-way ANOVA (analysis of variance) was performed to test the effect of seat orientation and direction of motion (ingress vs. egress) on the joint angles and ranges of motions. Seat orientation and direction of motion were treated as the fixed effects and participants as a random factor. Effect of seat orientation on reach was also assessed using two-way general linear 
ANOVA. Seat orientation and the anatomical plane of motion were treated as the fixed effects and participants as a random factor.

Normality of data was tested using Kolmogorov-Smirnov's normality test and equal variance assumption was tested using Lavene's test. For the majority of variables, the normality and equal variance assumption was found to be true (Appendix C). Significance level was set to 95\%. All analyses were performed using Minitab statistical software (Minitab Inc., State College, PA). Significant main and/or interaction effects were further evaluated by conducting comparison between means using Tukey's HSD all-pairwise comparison test.

\subsection{Power calculation}

Operating characteristics curves (OC curves), a graph of $\beta$ (type II error probability) versus the true difference in means were used for the sample size estimation. $\Phi$ was calculated for seat orientation using the following equation.

$$
\Phi=\sqrt{\frac{n^{\prime} \sum_{m=1}^{k \prime}\left(\mu_{m}-\mu\right)^{2}}{k^{\prime} S^{2}}}
$$

Where,

$k^{\prime}$ is levels of the factor;

$\mu$ is population mean;

$\mu_{\mathrm{m}}$ is mean for each factor

$s^{2}$ is within-cell MS;

$n$ ' is the number of subjects times levels of other factor.

Based on this equation, the powers for several dependent variables are given in Table 5 
Table 5. Power determination of several kinematic variables

\begin{tabular}{|c|c|c|}
\hline \multirow[b]{2}{*}{ Variable } & \multicolumn{2}{|c|}{$\begin{array}{c}\text { Seat Orientation } \\
\left(\mathrm{v}_{1}=2, \mathrm{v}_{2}=27\right)\end{array}$} \\
\hline & $\Phi$ & Power \\
\hline Trunk (Flexion) & 7.11 & $>99 \%$ \\
\hline Rigjht Shoulder (Flexion) & 6.54 & $>99 \%$ \\
\hline Left Shoulder (Flexion) & 2.79 & $99 \%$ \\
\hline Right Hip (Flexion) & 2.42 & $95 \%$ \\
\hline Left hip (Flexion) & 1.8 & $75 \%$ \\
\hline Right Knee (Flexion) & 1.66 & $65 \%$ \\
\hline Left Knee (Flexion) & 5.89 & $>99 \%$ \\
\hline
\end{tabular}




\section{CHAPTER 5: RESULTS}

\subsection{Ingress / Egress Kinematics}

Results from analysis of variance tests showed that main and interaction effects of the seat orientation and direction of motion (ingress vs. egress) were statistically significant for several joint angles and ranges of motion (Appendix D). Summarized kinematic data used in this analysis can be found in Appendices F, G, and H for the hips/knees, shoulders, and trunk, respectively. In general, the joint angles and ranges of motion were much higher during ingress and egress of the horizontal seat orientations compared to the vertical seat orientation. Due to the extensive number of dependent variables, the kinematics of each of the seven joints (trunk and left and right shoulders, hips, and knees) is discussed in depth in the following sections.

\subsubsection{Trunk Kinematics}

Flexion, lateral bending, and rotation of the trunk were selected for analysis (Figure 17). Trunk extension was not of interest, as extension of the trunk (past neutral) was not used in the tasks. Range of motion of lateral bending and rotation were also of interest, however, since peak extension is assumed to be $0^{\circ}$, flexion/extension range of motion would be equivalent to the flexion angle, and therefore redundant. In general, joint angles and ranges of motion of the trunk were significantly higher in the horizontal seats than the vertical orientation (Table 6).

\subsubsection{Trunk Flexion}

Trunk flexion angles were significantly different between seat orientations; however, direction of motion had no significant affect. The interaction effect of seat orientation and 
direction of motion on trunk flexion was statistically insignificant. Trunk flexion in the vertical seat was significantly lower than the two horizontal seat orientations.

\subsubsection{Trunk Lateral Bending}

Interaction effect and main effect of seat orientation and direction of motion were significant for left and right lateral bending. However, only seat orientation was significant for lateral bending range of motion. Left and right lateral bending and lateral bending range of motion of the trunk in the vertical seat were significantly lower than the two horizontal positions. The lateral bending ranges of motion in the horizontal seats were not significantly different from one another, but there was more lateral bending to the left in the horizontal- $120^{\circ}$ seat, while right lateral bending was higher in the $90^{\circ}$ seat angle. While range of motion was not significantly different between ingress and egress, the angles during egress were slightly higher for both left and right lateral bending. Interaction effect of seat orientation and direction of

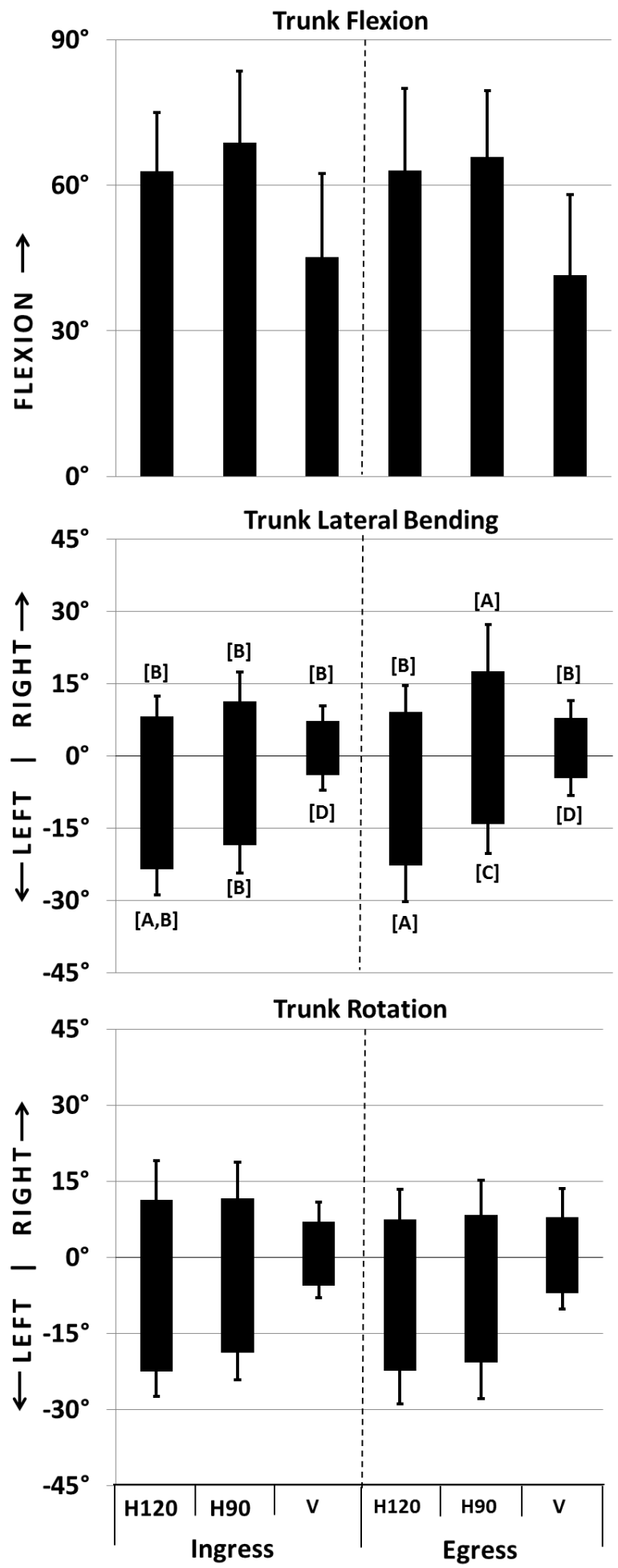

Figure 17. Kinematics of the trunk during ingress/egress tasks expressed in terms of means of peak angles (error bars represent one standard deviation). Neutral position is $0^{\circ}$. Upper-case letters above and below bars are significant interaction effect based on the Tukey HSD test. 
Table 6. Mean (SD) peak angles and ranges of motion of the trunk, stratified by seat orientation (left) and direction of motion (right). Significance denoted by '*'. Letters in superscript represent significant Tukey HSD results.

\begin{tabular}{|c|c|c|c|c|c|c|c|}
\hline & \multicolumn{3}{|c|}{ Mean (SD) Angles (Degrees) } & \multirow{2}{*}{$\begin{array}{c}\text { P-Value } \\
\text { (Seat Orien.) }\end{array}$} & \multicolumn{2}{|c|}{ Mean (SD) Angles (Degrees) } & \multirow{2}{*}{$\begin{array}{c}\text { P-Value } \\
\text { (Ing. vs Egr.) }\end{array}$} \\
\hline Peak Joint Angles & Horiz. - 120 ${ }^{\circ}$ & Horiz. - 90 ${ }^{\circ}$ & Vertical & & Egress & Ingress & \\
\hline Flexion & $62.96(14.54)^{\mathrm{a}}$ & $67.32(14.13)^{b}$ & $43.36(16.78)^{\mathrm{c}}$ & $0.000 *$ & $58.03(18.65)$ & $60.06(17.41)$ & 0.300 \\
\hline Right Lateral Bending & $8.68(4.81)$ & $14.40(8.57)$ & $7.58(3.37)$ & $0.000 *$ & $11.89(8.15)$ & $9.10(5.02)$ & $0.000 *$ \\
\hline Left Lateral Bending & $23.09(6.48)$ & $16.34(6.34)$ & $4.33(3.30)$ & $0.000 *$ & $14.52(9.37)$ & $16.10(9.39)$ & $0.016 *$ \\
\hline Right Rotation & $9.42(7.08)$ & $10.00(7.18)$ & $7.50(4.80)$ & 0.494 & $7.93(6.15)^{\mathrm{a}}$ & $10.23(6.87)^{\mathrm{b}}$ & $0.037 *$ \\
\hline Left Rotation & $22.41(5.72)^{\mathrm{a}}$ & $19.73(6.31)^{b}$ & $6.33(2.81)^{\mathrm{c}}$ & $0.000 *$ & $17.50(8.84)$ & $16.30(8.30)$ & 0.607 \\
\hline \multicolumn{8}{|l|}{ Ranges of Motion } \\
\hline Lateral Bending & $31.77(6.97)^{\mathrm{a}}$ & $30.74(7.69)^{\mathrm{a}}$ & $11.90(3.56)^{b}$ & $0.000 *$ & $26.41(11.38)$ & $25.20(10.38)$ & 0.245 \\
\hline Rotation & $31.83(9.38)^{\mathrm{a}}$ & $29.73(7.58)^{\mathrm{a}}$ & $13.83(4.51)^{b}$ & $0.000 *$ & $25.44(9.33)$ & $26.53(12.05)$ & 0.215 \\
\hline
\end{tabular}


motion resulted in significantly higher angles during egress of the horizontal- $90^{\circ}$ seat.

\subsubsection{Trunk Rotation}

Interaction of direction of motion and seat orientation had no significant effect on the results. Main effect of seat orientation resulted in significantly lower left rotation and rotational range of motion in the vertical seat orientations. Despite insignificance, right rotation in vertical seat was lower due to seat orientation, as well. In fact, rotational range of motion in the vertical seat rarely exceeded $15^{\circ}$, while it commonly surpassed $30^{\circ}$ for the horizontal seats. Effect due to direction of motion was only significant for rotation to the right.

\subsubsection{Right and Left Shoulder Kinematics}

Peak flexion/extension, abduction/adduction, and rotation angles and their corresponding ranges of motion at the right (Table 7) and left shoulders (Table 8) were evaluated in this research. Seat orientation significantly affected all shoulder kinematic variables. The effect of direction of motion was significant on all but two shoulder kinematic variables; flexion and internal rotation of the right shoulder. Interaction effect of seat orientation and direction of motion was also significant for a majority of the shoulder angles and ranges of motion. Similar to the trunk, shoulder angles and ranges of motion were significantly higher in the horizontal seat orientations. Differences in shoulder kinematics between the two horizontal seats were less pronounced (Figure 18). 

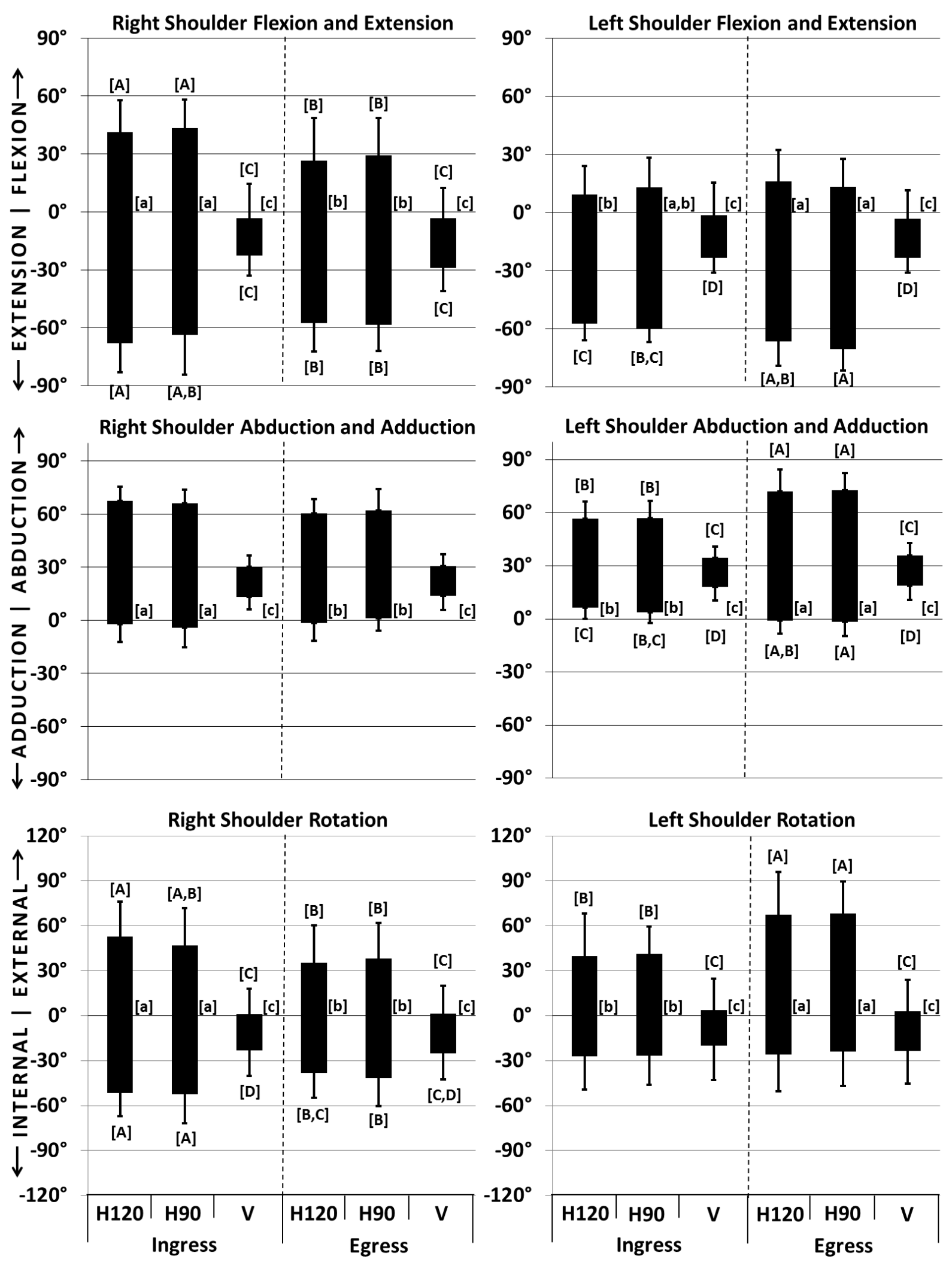

Figure 18. Kinematics of the shoulders during ingress/egress tasks. Neutral position is $0^{\circ}$. Upper-case letters above and below bars are significant interaction effect on peak angles estimated using Tukey HSD test. Lower-case letters represent a significant interaction effect on range of motion using Tukey HSD test. Error bars represent one standard deviation. 
Table 7. Mean (SD) peak angles and ranges of motion of the right shoulder, stratified by seat orientation (left) and direction of motion (right). Significance denoted by '*'. Letters in superscript represent significant Tukey HSD results.

\begin{tabular}{|c|c|c|c|c|c|c|c|}
\hline & \multicolumn{3}{|c|}{ Mean (SD) Angles (Degrees) } & \multirow{2}{*}{\begin{tabular}{c|} 
P-Value \\
(Seat Orien.) \\
\end{tabular}} & \multicolumn{2}{|c|}{ Mean (SD) Angles (Degrees) } & \multirow{2}{*}{$\begin{array}{c}\text { P-Value } \\
\text { (Ing. vs Egr.) }\end{array}$} \\
\hline Peak Joint Angles & Horiz - 120 ${ }^{\circ}$ & Horiz. - 90 ${ }^{\circ}$ & Vertical & & Egress & Ingress & \\
\hline Flexion & $33.96(20.68)$ & $36.30(18.42)$ & $-4.44(16.58)$ & $0.000 *$ & $18.54(24.49)$ & $29.28(26.23)$ & $0.000 *$ \\
\hline Extension & $62.78(15.81)$ & $61.29(17.54)$ & $24.28(11.15)$ & $0.000 *$ & $49.18(19.78)$ & $53.56(25.47)$ & $0.031 *$ \\
\hline Abduction & $63.81(9.11)^{\mathrm{a}}$ & $64.02(11.17)^{\mathrm{a}}$ & $30.50(6.33)^{b}$ & $0.000 *$ & $52.73(16.82)^{\mathrm{a}}$ & $56.27(18.41)^{b}$ & $0.002 *$ \\
\hline Adduction & $1.97(9.93)^{\mathrm{a}}$ & $1.53(9.83)^{\mathrm{a}}$ & $-13.50(7.41)^{b}$ & $0.000 *$ & $-3.75(10.69)^{\mathrm{a}}$ & $-1.36(12.15)^{b}$ & $0.023 *$ \\
\hline External Rotation & $44.01(25.62)$ & $42.58(24.64)$ & $1.02(17.59)$ & $0.000 *$ & $26.76(27.90)$ & $35.91(31.36)$ & $0.001 *$ \\
\hline Internal Rotation & $44.90(17.30)$ & $46.99(19.57)$ & $24.24(16.93)$ & $0.000 *$ & $35.85(18.68)$ & $43.72(21.51)$ & $0.000 *$ \\
\hline \multicolumn{8}{|l|}{ Ranges of Motion } \\
\hline Flexion/Extension & $96.74(27.24)$ & $95.16(23.99)$ & $19.84(17.12)$ & $0.000 *$ & $67.72(37.40)$ & $80.81(44.80)$ & $0.000 *$ \\
\hline Abduction/Adduction & $65.78(12.41)$ & $65.56(12.20)$ & $17.00(7.75)$ & $0.000 *$ & $48.97(22.91)$ & $54.91(25.98)$ & $0.000 *$ \\
\hline Rotation & $88.91(29.21)$ & $86.82(28.29)$ & $25.26(13.00)$ & $0.000 *$ & $62.61(32.93)$ & $77.45(41.16)$ & $0.000 *$ \\
\hline
\end{tabular}

Table 8. Mean (SD) peak angles and ranges of motion of the left shoulder, stratified by seat orientation (left) and direction of motion (right). Significance denoted by '*'. Letters in superscript represent significant Tukey HSD results.

\begin{tabular}{|c|c|c|c|c|c|c|c|}
\hline & \multicolumn{3}{|c|}{ Mean (SD) Angles (Degrees) } & \multirow{2}{*}{\begin{tabular}{c|} 
P-Value \\
(Seat Orien.)
\end{tabular}} & \multicolumn{2}{|c|}{ Mean (SD) Angles (Degrees) } & \multirow{2}{*}{$\begin{array}{c}\text { P-Value } \\
\text { (Ing. vs Egr.) }\end{array}$} \\
\hline Peak Joint Angles & Horiz. $-\mathbf{1 2 0}^{\circ}$ & Horiz. - 90 & Vertical & & Egress & Ingress & \\
\hline Flexion & $12.55(15.62)^{\mathrm{a}}$ & $13.10(14.84)^{\mathrm{a}}$ & $-2.37(15.72)^{b}$ & $0.000 *$ & $9.35(17.15)$ & $7.55(16.46)$ & 0.473 \\
\hline Extension & $61.71(11.41)$ & $64.97(10.53)$ & $23.32(7.68)$ & $0.000 *$ & $55.19(23.46)$ & $48.67(17.83)$ & $0.000 *$ \\
\hline Abduction & $64.43(13.41)$ & $64.65(12.67)$ & $35.24(6.61)$ & $0.000 *$ & $62.30(19.21)$ & $50.45(13.47)$ & $0.000 *$ \\
\hline Adduction & $-2.62(7.73)$ & $-0.97(7.43)$ & $-18.44(7.75)$ & $0.000 *$ & $-4.22(11.94)$ & $-8.65(8.85)$ & $0.000 *$ \\
\hline External Rotation & $53.21(31.63)$ & $54.59(23.84)$ & $3.48(20.45)$ & $0.000^{*}$ & $49.55(37.69)$ & $30.11(28.09)$ & $0.000 *$ \\
\hline Internal Rotation & $26.58(23.26)^{\mathrm{a}}$ & $25.36(21.05)^{\mathrm{a}}$ & $21.58(22.46)^{\mathrm{b}}$ & $0.004 *$ & $24.43(23.14)$ & $24.96(21.40)$ & 0.652 \\
\hline \multicolumn{8}{|l|}{ Ranges of Motion } \\
\hline Flexion/Extension & $74.42(17.53)$ & $79.16(19.23)$ & $20.95(15.76)$ & $0.000 *$ & $64.80(33.63)$ & $56.90(28.15)$ & $0.001 *$ \\
\hline Abduction/Adduction & $61.81(17.46)$ & $63.68(15.22)$ & $16.80(7.45)$ & $0.000^{*}$ & $58.08(28.57)$ & $41.80(18.32)$ & $0.000 *$ \\
\hline Rotation & $75.38(20.67)$ & $79.01(18.57)$ & $25.06(13.93)$ & $0.000 *$ & $69.85(33.92)$ & $55.07(23.72)$ & $0.000 * 41$ \\
\hline
\end{tabular}




\subsubsection{Shoulder Flexion/Extension}

Flexion, extension and range of motion of the right shoulder and extension and range of motion of the left shoulder were significantly affected by main and interaction effect of seat orientation and direction of motion. Flexion of the right shoulder was negligible during ingress of vertical seats. However, right shoulder flexion in the horizontal seats was significantly higher than in the vertical seat. Additionally, flexion angles were higher during ingress compared to egress in the horizontal seats. Extension was much more prominent than flexion, however extension still remained significantly lower in the vertical seat. Flexion/extension range of motion was significantly lower in the vertical seats. Also, range of motion during ingress of the horizontal seats was significantly higher than during ingress.

Regarding the left shoulder, interaction and main effect of direction of motion were significant for only extension and range of motion, while seat orientation had a significant effect on flexion, extension, and range of motion. Flexion, extension and range of motion of the left shoulder were significantly lower in the vertical seats due to main effect of seat orientation. However, peak extension also differed significantly between the two horizontal seats. Interaction of seat orientation and direction of motion resulted in similar angles between ingress and egress of the vertical seats, but significantly higher angles during egress of the horizontal seats than during ingress.

\subsubsection{Shoulder Abduction/Adduction}

As expected, abduction was dominant over adduction during all tasks. Adduction angles for both shoulders were less than $5^{\circ}$ for all tasks. Furthermore, participants did not cross neutral during the majority of trials, remaining abducted to some extent throughout the entire trial. 
Abduction, adduction, and range of motion of the right shoulder were effected significantly by the main effect of seat orientation and direction of motion. Range of motion of the right shoulder also differed significantly due to the interaction effect. Right shoulder abduction, adduction and range of motion in the vertical seats were significantly lower than the horizontal seats. In fact, subjected never moved the shoulder into adduction during ingress/egress of the vertical seats. Differences between the horizontal seats were insignificant. Interaction of seat orientation and direction of motion resulted in significantly lower angles during egress of the horizontal seats when compared to ingress.

Main effects and interaction effect of seat orientation and direction of motion affected abduction, adduction, and range of motion of the left shoulder. Abduction angles of the left shoulder were significantly lower in the vertical seats. While abduction angle was not significantly different between ingress and egress in the vertical seats, the interaction effect resulted in more abduction during egress of the horizontal seats compared to ingress. Adduction was significantly lower in the vertical seat than the horizontal seats. During ingress/egress of the vertical seats, adducted postures were not used. In the vertical seat, left shoulder adduction was lowest, but not significantly different between ingress and egress. However, adduction angles were during ingress/egress of the horizontal seats was significantly higher during egress, due to the interaction effect. Abduction/adduction range of motion was significantly lower in the vertical seat than the horizontal seats. While range of motion of the vertical seat during ingress and egress were not significantly different, the interaction effect resulted in significantly higher range of motion during egress of the horizontal seats when compared to ingress. 


\subsubsection{Shoulder Rotation}

Main effects and interaction effect of seat orientation and direction of motion had a significant effect on the internal rotation, external rotation and range of motion of the right shoulder but only external rotation and range of motion for the left shoulder. Internal rotation, external rotation, and range of motion of the right shoulder were significantly lower during ingress/egress of the vertical seat versus the horizontal seat. While rotation and range of motion were not significantly different between ingress and egress of the vertical seat, due to the interaction effect of seat orientation and direction of motion, significantly higher angles existed during ingress compared to egress of the horizontal seats.

Interaction effect and main effects of seat orientation and direction of motion were responsible for significantly reduced external rotation and range of motion of the left shoulder during ingress and egress of the vertical seat, as well as significantly higher external rotation and range of motion in the during egress of the horizontal seats than ingress of the horizontal seats.

Internal rotation of the left shoulder was affected significantly by only the seat orientation, resulting in a much less internal rotation in the vertical seat than the horizontal seats.

\subsubsection{Right and Left Hip Kinematics}

Peak flexion, abduction, and internal and external rotation angles were selected for analysis of the right (Table 9) and left (Table 10) hip. During all tasks, hip joints ranged from neutral to flexion and from neutral to abduction. In other words, the participants did not extend past neutral or adduct past neutral. Additionally, the participants began the ingress trials and ended the egress trials with the hips at neutral. Therefore, only the rotational range of motion will be analyzed for the hips, as ranges of motions of the others would be redundant. While the right 
hip was only significantly affected by the main effects of seat direction and/or direction of motion, left hip angles were significantly altered by the interaction (Figure 19).

\subsubsection{Hip Flexion}

Left hip flexion was influenced significantly by the main effect of seat orientation and interaction effect of seat orientation and direction of motion. Direction of motion, by itself, had no significant effect. However, flexion of the right hip was only significantly different due to effect of the seat orientation. Right hip flexion was significantly higher in the horizontal- $90^{\circ}$ seat, but no significant differences were found between the vertical and horizontal- $120^{\circ}$ seats.

Interaction effect of seat orientation and direction of motion was also responsible for significant differences in left hip flexion. Flexion of the left hip during ingress and egress of the horizontal $-90^{\circ}$ seat were not significantly different, however during ingress and egress of the horizontal- $120^{\circ}$ and vertical seats the interaction effect resulted in a more complex relationship. During egress, left hip flexion for the horizontal-120 seat was lower than the other two seat orientations, however no difference in flexion of the left hip was found during ingress.

\subsubsection{Hip Abduction}

Abduction of the left hip was much more prominent than the right hip. Abduction of the right hip was only significantly affected by direction of motion, resulting in significantly higher angles during egress tasks. Abduction of the left hip, on the other hand, was significantly affected by main effects and interaction effect of seat orientation and direction of motion. Left hip abduction during ingress of the vertical seat was not significantly different than abduction angle during 
Table 10. Mean (SD) peak angles and ranges of motion of the right hip, stratified by seat orientation (left) and direction of motion (right). Significance denoted by '*'. Letters in superscript represent significant Tukey HSD results.

\begin{tabular}{|c|c|c|c|c|c|c|c|}
\hline & \multicolumn{3}{|c|}{ Mean (SD) Angles (Degrees) } & \multirow{2}{*}{$\frac{\text { P-Value }}{\text { (Seat Orien.) }}$} & \multicolumn{2}{|c|}{ Mean (SD) Angles (Degrees) } & \multirow{2}{*}{$\begin{array}{c}\text { P-Value } \\
\text { (Ing. vs Egr.) }\end{array}$} \\
\hline Peak Joint Angles & Horiz. $-120^{\circ}$ & Horiz. $-90^{\circ}$ & Vertical & & Egress & Ingress & \\
\hline Flexion & $65.63(12.51)^{\mathrm{a}}$ & $74.91(16.75)^{b}$ & $64.07(16.32)^{\mathrm{a}}$ & $0.000 *$ & $69.68(14.83)$ & $67.58(16.96)$ & 0.415 \\
\hline Abduction & $17.09(10.26)$ & $18.63(11.71)$ & $20.83(4.56)$ & 0.162 & $21.40(10.99)^{\mathrm{a}}$ & $16.08(7.47)^{\mathrm{b}}$ & $0.000 *$ \\
\hline External Rotation & $22.27(10.75)$ & $23.14(11.50)$ & $22.31(9.16)$ & 0.273 & $23.82(10.32)^{\mathrm{a}}$ & $21.44(10.75)^{b}$ & $0.004 *$ \\
\hline Internal Rotation & $2.96(8.99)^{\mathrm{a}}$ & $4.04(9.51)^{\mathrm{a}}$ & $-0.87(8.57)^{b}$ & $0.006 *$ & $1.66(8.54)$ & $2.97(9.89)$ & 0.169 \\
\hline \multicolumn{8}{|l|}{ Ranges of Motion } \\
\hline Rotation & $25.24(8.05)^{\mathrm{a}}$ & $27.18(8.74)^{\mathrm{a}}$ & $22.70(8.70)^{b}$ & $0.001 *$ & $25.48(6.21)$ & $25.04(10.47)$ & 0.270 \\
\hline
\end{tabular}

Table 9. Mean (SD) peak angles and ranges of motion of the left hip, stratified by seat orientation (left) and direction of motion (right). Significance denoted by '*'. Letters in superscript represent significant Tukey HSD results.

\begin{tabular}{|c|c|c|c|c|c|c|c|}
\hline & \multicolumn{3}{|c|}{ Mean (SD) Angles (Degrees) } & \multirow{2}{*}{\begin{tabular}{|c|} 
P-Value \\
(Seat Orien.)
\end{tabular}} & \multicolumn{2}{|c|}{ Mean (SD) Angles (Degrees) } & \multirow{2}{*}{$\begin{array}{c}\text { P-Value } \\
\text { (Ing. vs Egr.) }\end{array}$} \\
\hline Peak Joint Angles & Horiz $-120^{\circ}$ & Horiz $-90^{\circ}$ & Vertical & & Egress & Ingress & \\
\hline Flexion & $61.06(12.12)$ & $68.29(15.29)$ & $66.19(15.78)$ & $0.000 *$ & $65.60(15.25)$ & $64.75(14.15)$ & 0.914 \\
\hline Abduction & $40.86(6.59)$ & $39.91(6.73)$ & $24.89(5.41)$ & $0.000 *$ & $37.50(10.07)$ & $34.58(8.54)$ & $0.007 *$ \\
\hline External Rotation & $21.70(15.56)$ & $21.75(15.73)$ & $21.94(16.94)$ & 0.388 & $22.26(16.13)$ & $21.33(15.79)$ & 0.406 \\
\hline Internal Rotation & $10.58(13.8)^{\mathrm{a}}$ & $11.44(15.15)^{\mathrm{a}}$ & $0.75(15.17)^{b}$ & $0.000 *$ & $7.42(15.53)$ & $8.82(15.18)$ & 0.474 \\
\hline \multicolumn{8}{|l|}{ Ranges of Motion } \\
\hline Rotation & $32.28(9.67)$ & $33.19(9.84)$ & $22.69(7.81)$ & $0.000 *$ & $29.68(9.75)$ & 30.15 (10.79) & 0.927 \\
\hline
\end{tabular}



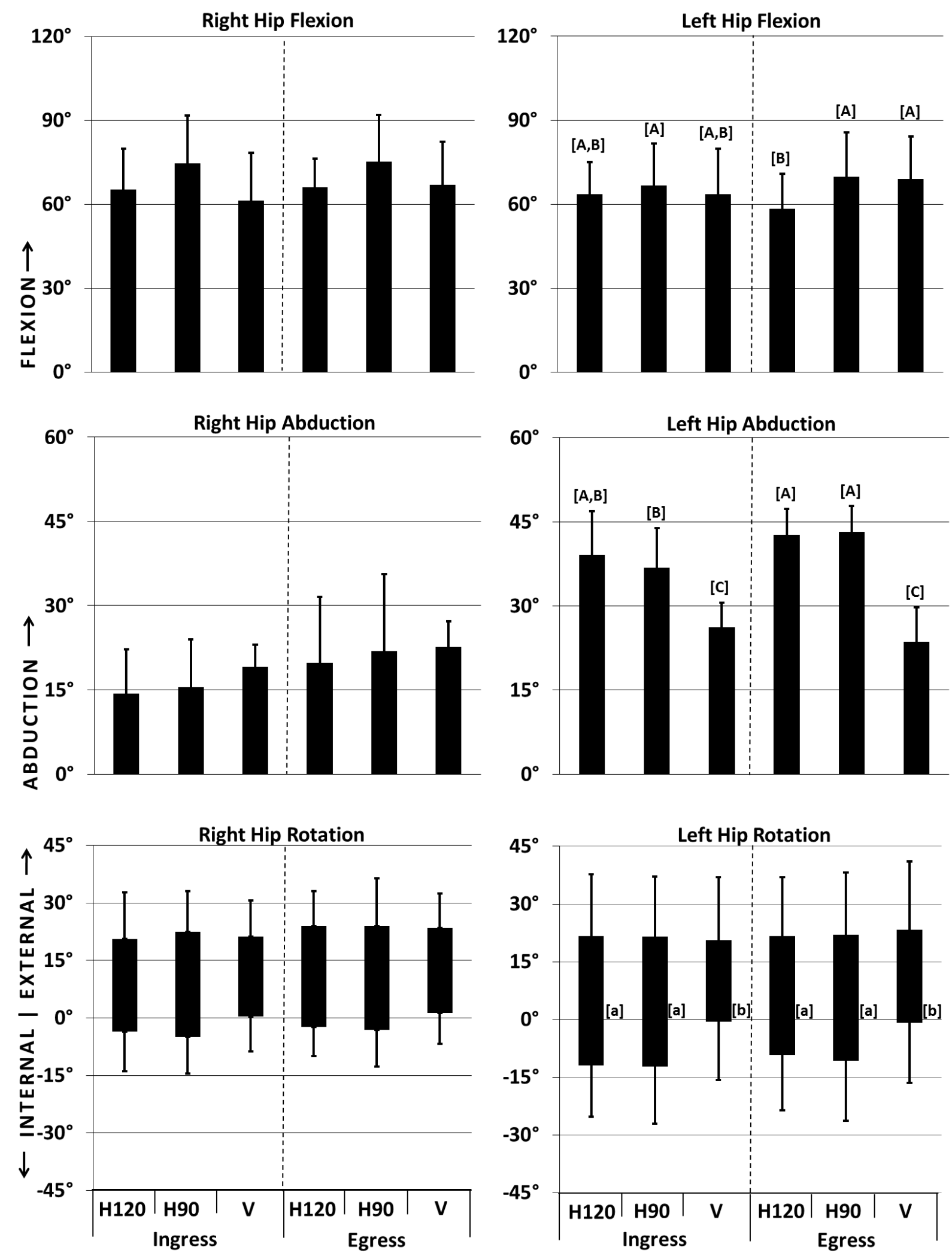

Figure 19. Kinematics of the hips during ingress/egress tasks. Neutral position is $0^{\circ}$. Upper-case letters above and below bars are significant interaction effect Tukey HSD results for peak angles. Lower-case letters are Tukey HSD results for range of motion. 
ingress. However, due to the interaction effect, left hip abduction during egress of the horizontal$90^{\circ}$ seat was significantly greater than during ingress, while no significant difference was found among the horizontal- $120^{\circ}$ ingress and egress angles and the horizontal- $90^{\circ}$ ingress angle.

\subsubsection{Hip Rotation}

External rotation was dominant over internal rotation of the hips for most tasks. Peak external rotation was fairly consistent, ranging from $20-25^{\circ}$ for all seats and both tasks. Internal rotation was more varied, ranging from $0^{\circ}$ to nearly $15^{\circ}$, with the participants often not passing their right shoulder through neutral into internal rotation during ingress and egress of the vertical seats. For the right hip, internal rotation and range of motion were significantly affected due to main effect of seat orientation, resulting in significantly lower values during ingress/egress of the vertical seats. External rotation of the right hip was only affected significantly by the direction of motion, with higher angles found during egress than during ingress.

No significant differences were found in left hip external rotation due to seat orientation or direction of motion. Internal rotation angle was significantly lower in the vertical seat than the horizontal seats due to the main effect of seat orientation. Range of motion of the left hip was significantly lower in the vertical seat compared to the horizontal seats. Range of motion was influenced significantly by interaction effect of seat orientation and direction of motion, resulting in higher range of motion during ingress versus egress of the horizontal seats. However, ranges of motion of the left hip during ingress and egress of the vertical seat were not significantly different. 


\subsubsection{Right and Left Knee Kinematics}

Since the knee is a hinge joint with only two degrees of freedom, only flexion and internal/external rotation of the right (Table 11) and left (Table 12) were analyzed, along with the rotational range of motion. Since the knee does not extend past neutral, and the knees are at neutral during the starting posture (ingress) or ending posture (egress), the peak extension angle for all participants was $0^{\circ}$. Therefore, analysis of flexion/extension range of motion would be redundant. Main effect of seat orientation significantly affected the flexion, external rotation, internal rotation, and range of motion of the right and left knees. Flexion, external rotation, and rotational range of motion of the left knee were significantly affected by the direction of motion. Significance of the interaction effect was limited to flexion of the left knee. Main effect of direction of motion and interaction effect had no significant effect on the kinematics of the right knee (Figure 20).

\subsubsection{Knee Flexion}

Right knee flexion was significantly higher in the horizontal- $90^{\circ}$ seat than the vertical and horizontal- $120^{\circ}$ seats due to the main effect of seat orientation, however the difference was small $\left(<10^{\circ}\right)$. The main effect of direction of motion and interaction effect did not significantly affect right knee flexion. Flexion of the left knee, however, was affected significantly by the main effects of seat orientation and direction of motion as well as the interaction effect of the two. Left knee flexion angles were lowest in the vertical seat, with no significant difference between ingress and egress were found. Due to the significant interaction effect of seat orientation and direction of motion, flexion of the left knee was higher during ingress of the horizontal seats than during egress. 

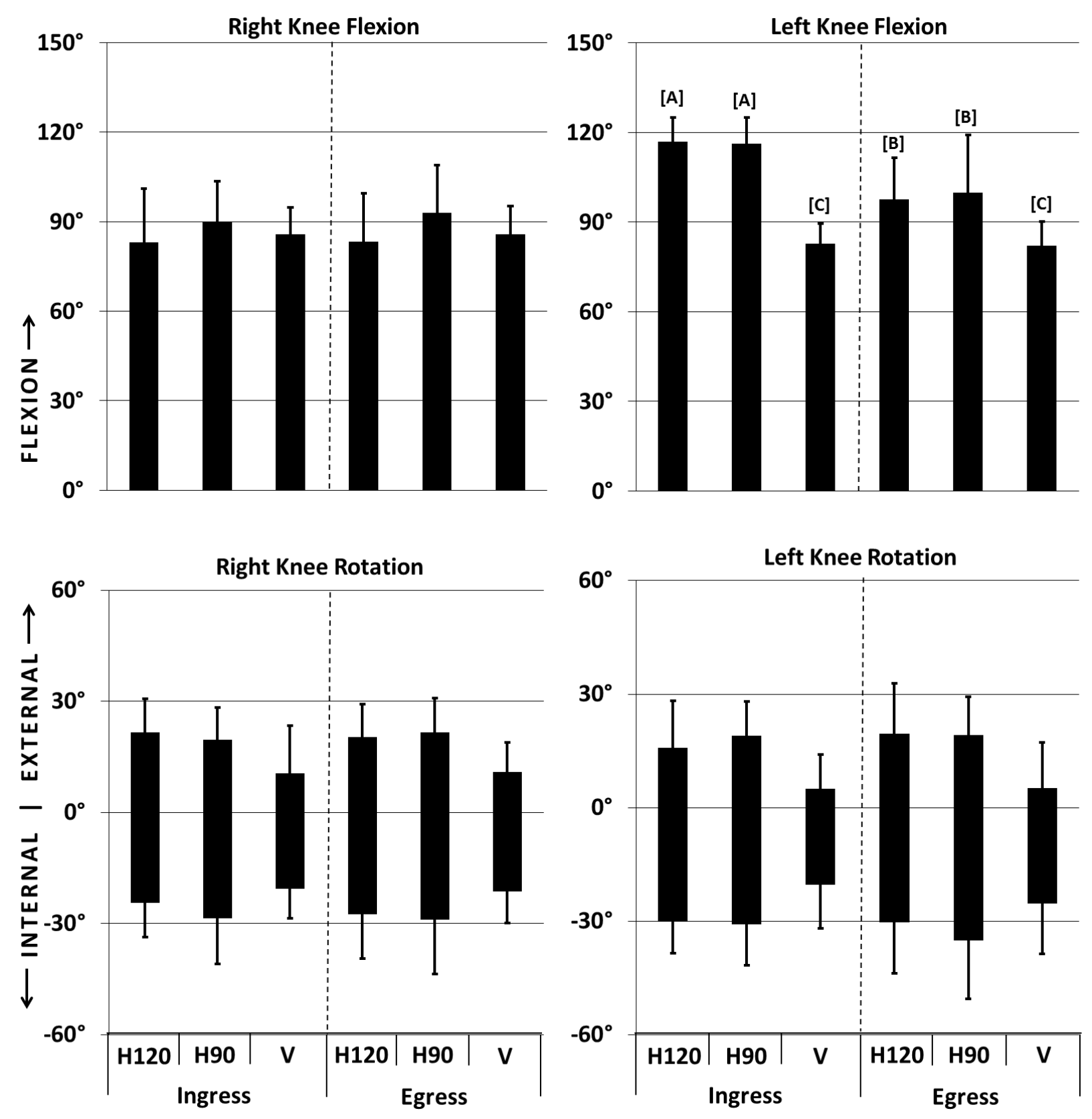

Figure 20. Kinematics of the knees during ingress/egress tasks. Neutral position is $0^{\circ}$. Upper-case letters above and below bars are significant interaction effect Tukey HSD results for peak angles 
Table 11. Mean (SD) peak angles and ranges of motion of the right knee, stratified by seat orientation (left) and direction of motion (right). Significance denoted by '*'. Letters in superscript represent significant Tukey HSD results.

\begin{tabular}{|c|c|c|c|c|c|c|c|}
\hline & \multicolumn{3}{|c|}{ Mean (SD) Angles (Degrees) } & \multirow{2}{*}{\begin{tabular}{c|} 
P-Value \\
(Seat Orien.) \\
\end{tabular}} & \multicolumn{2}{|c|}{ Mean (SD) Angles (Degrees) } & \multirow{2}{*}{$\begin{array}{c}\text { P-Value } \\
\text { (Ing. vs Egr.) }\end{array}$} \\
\hline Peak Joint Angles & Horiz. $-120^{\circ}$ & Horiz. - 90 ${ }^{\circ}$ & Vertical & & Egress & Ingress & \\
\hline Flexion & $83.17(16.95)^{\mathrm{a}}$ & $91.43(14.81)^{b}$ & $85.71(9.12)^{\mathrm{a}}$ & $0.000^{*}$ & $87.53(15.06)$ & $86.36(14.42)$ & 0.386 \\
\hline External Rotation & $21.00(8.88)^{\mathrm{a}}$ & $20.61(8.90)^{\mathrm{a}}$ & $10.69(10.75)^{b}$ & $0.000 *$ & $18.29(9.79)$ & $17.68(11.07)$ & 0.368 \\
\hline Internal Rotation & $25.96(10.67)^{\mathrm{a}}$ & $28.72(13.38)^{\mathrm{a}}$ & $20.91(8.14)^{b}$ & $0.000 *$ & $26.32(12.52)$ & $24.88(10.54)$ & 0.189 \\
\hline \multicolumn{8}{|l|}{ Ranges of Motion } \\
\hline Rotation & $46.90(12.14)^{\mathrm{a}}$ & $49.33(13.30)^{\mathrm{a}}$ & $31.60(12.31)^{b}$ & $0.000 *$ & $44.61(14.78)$ & $42.51(14.50)$ & 0.099 \\
\hline
\end{tabular}

Table 12. Mean (SD) peak angles and ranges of motion of the left knee, stratified by seat orientation (left) and direction of motion (right). Significance denoted by '*'. Letters in superscript represent significant Tukey HSD results.

\begin{tabular}{|c|c|c|c|c|c|c|c|}
\hline & \multicolumn{3}{|c|}{ Mean (SD) Angles (Degrees) } & \multirow{2}{*}{$\begin{array}{c}\text { P-Value } \\
\text { (Seat Orien.) }\end{array}$} & \multicolumn{2}{|c|}{ Mean (SD) Angles (Degrees) } & \multirow{2}{*}{$\frac{\text { P-Value }}{\text { (Ing. vs Egr.) }}$} \\
\hline Right Arm & Horiz. - 120 ${ }^{\circ}$ & Horiz. - $90^{\circ}$ & Vertical & & Egress & Ingress & \\
\hline Flexion & $107.30(14.85)$ & $108.12(16.98)$ & $82.45(7.37)$ & $\mathbf{0 . 0 0 0 *}$ & $94.10(16.63)$ & $106.96(17.22)$ & 0.000* \\
\hline External Rotation & $17.73(12.89)^{\mathrm{a}}$ & $19.12(9.41)^{\mathrm{a}}$ & $5.09(10.50)^{b}$ & $0.000 *$ & $15.45(13.34)^{\mathrm{a}}$ & $13.94(11.72)^{b}$ & $0.039^{*}$ \\
\hline Internal Rotation & $30.13(11.14)^{\mathrm{a}}$ & $32.90(13.36)^{\mathrm{a}}$ & $22.76(12.57)^{b}$ & $0.000 *$ & $30.64(14.56)$ & $27.56(11.15)$ & 0.071 \\
\hline \multicolumn{8}{|l|}{ Ranges of Motion } \\
\hline Rotation & $47.86(14.31)^{\mathrm{a}}$ & $52.02(17.05)^{\mathrm{a}}$ & $27.85(7.94)^{b}$ & $0.000 *$ & $46.09(17.86)^{\mathrm{a}}$ & $41.50(16.40)^{\mathrm{b}}$ & 0.003* \\
\hline
\end{tabular}




\subsubsection{Knee Rotation}

Internal rotation, external rotation, and rotational range of motion of the right and left knee were significantly higher in the horizontal seat orientations compared to the vertical seat, due to main effect of seat orientation. Effect of direction of motion was significant for external rotation and range of motion of the left knee, resulting in slightly higher values during ingress compared to egress. The interaction effect was insignificant for internal and external rotation and range of motion of both knees.

\subsection{Reach}

Effect of seat orientation (horizontal, vertical) and anatomical plane (frontal, sagittal, transverse) on the three extreme points (Min X, Max X, Max Y) for the right and left arm were analyzed (Table 13, Figure 21). Summarized reach data can be found in Appendix I. The effect of seat orientation on Max $\mathrm{Y}$ of the right arm resulted in a small, yet significant increase in the horizontal seat compared to the vertical seat. Seat orientation had no significant effect on the remaining extreme points of the right arm or the three extreme points of the left arm (Appendix E).

The interaction of seat orientation and anatomical plane had a significant effect on Max X and Max $\mathrm{Y}$ of the right arm. Due to the interaction effect, Max $\mathrm{X}$ of the right side was significantly lower in the transverse plane than the frontal and sagittal planes. Additionally, Max $\mathrm{X}$ was significantly higher in the horizontal seat than the vertical seat in the transverse plane. Max Y of the right arm was significantly higher in the frontal plane than the transverse or sagittal planes. Due to the interaction effect, Max Y was lower in the vertical seats than the horizontal seats in the transverse and sagittal planes, but only significantly in the sagittal plane. 
As expected, main effect of anatomical plane had a significant effect on all three extreme points for the left and right arm. For both the left and the right arms, Min X and Max X were significantly lower in the transverse plane than the frontal and sagittal planes. Max Y for both arms is significantly higher in the frontal plane than the transverse and sagittal.
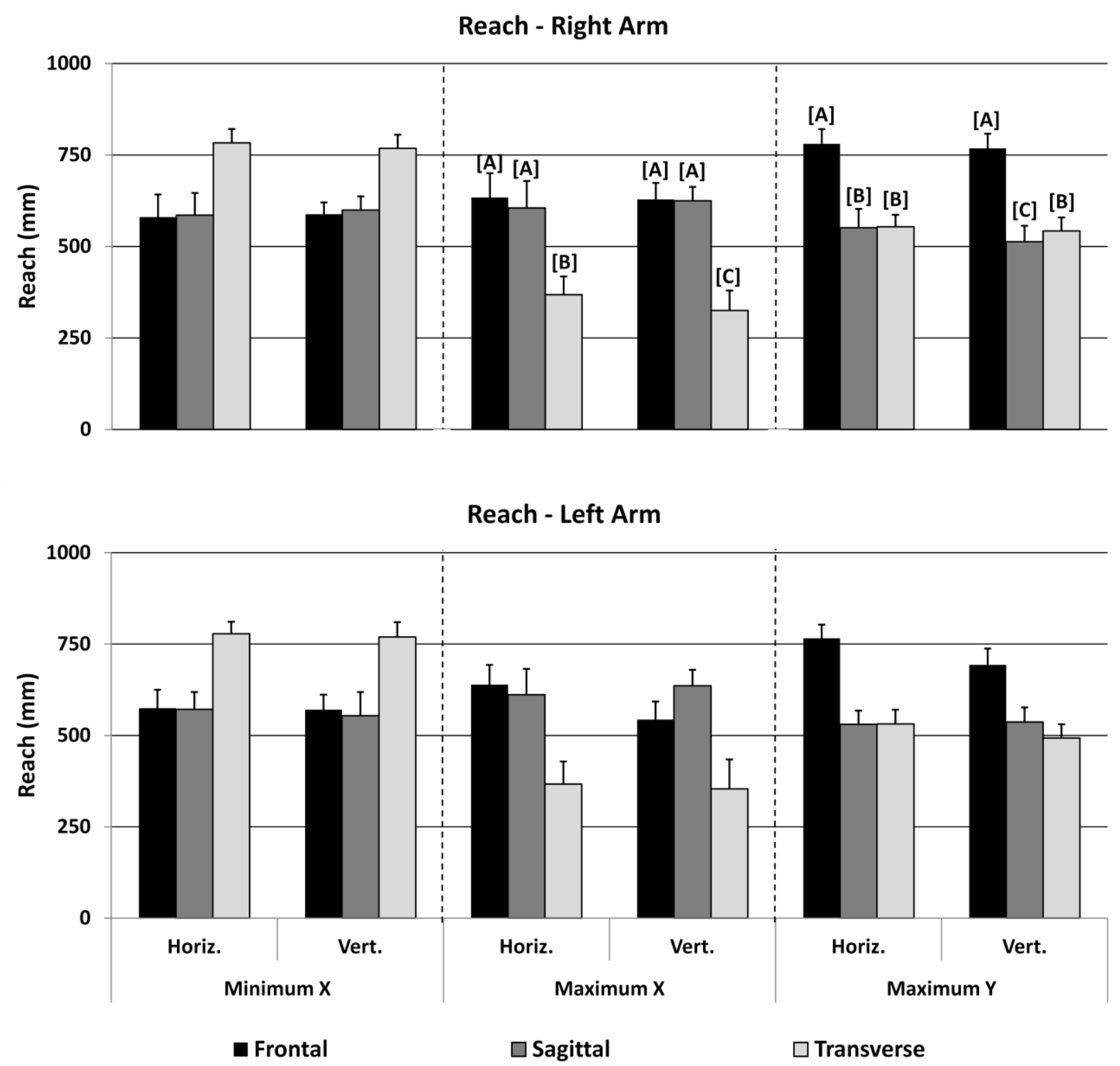

Figure 21. Planar reach extreme points of the right and left arm. Upper-case letters represent Tukey HSD results. 
Table 13. Mean (SD) reach of the right and left arms, stratified by seat orientation (left) and anatomical plane (right). Significance denoted by '*'. Letters in superscript represent significant Tukey HSD results.

\begin{tabular}{|c|c|c|c|c|c|c|c|}
\hline \multirow[b]{2}{*}{ Right Arm } & \multicolumn{2}{|c|}{ Mean (SD) Reach (mm) } & \multirow{2}{*}{$\begin{array}{c}\text { P-Value } \\
\text { (Seat Orien.) }\end{array}$} & \multicolumn{3}{|c|}{ Mean $(\mathrm{SD}) \operatorname{Reach}(\mathrm{mm})$} & \multirow{2}{*}{$\frac{\text { P-Value }}{\text { (Anat. Plane) }}$} \\
\hline & Horizontal & Vertical & & Frontal & Sagittal & Transverse & \\
\hline Minimum X & $647.4(108.7)$ & $653.6(91.0)$ & 0.482 & $584.24(48.53)$ & $591.98(51.00)$ & $775.52(37.84)$ & $0.000 *$ \\
\hline Maximum $X$ & $538.5(134.7)$ & $524.6(150.9)$ & 0.160 & $631.00(56.37)$ & $614.76(59.18)$ & $346.33(55.77)$ & $0.000 *$ \\
\hline Maximum $\mathrm{Y}$ & $629.7(116.4)$ & $609.4(121.9)$ & $0.000 *$ & $774.27(39.95)$ & $531.92(51.06)$ & $548.15(34.88)$ & $0.000 *$ \\
\hline \multicolumn{8}{|l|}{ Left Arm } \\
\hline Minimum $X$ & $639.2(106.2)$ & $628.9(109.9)$ & 0.074 & $572.47(45.51)$ & $562.61(57.04)$ & $774.03(36.41)$ & $0.000 *$ \\
\hline Maximum $X$ & $544.1(135.5)$ & $546.0(146.1)$ & 0.350 & $637.67(51.33)$ & $623.73(59.51)$ & $359.90(71.70)$ & $0.000^{*}$ \\
\hline Maximum Y & $610.7(118.5)$ & $620.2(112.9)$ & 0.054 & $766.16(40.76)$ & $533.59(38.32)$ & $543.00(39.59)$ & $0.000 *$ \\
\hline
\end{tabular}




\section{CHAPTER 6: DISCUSSION}

The purpose of this study was twofold. First, the differences in joint kinematics during ingress and egress of vertical (normal upright) and horizontal (recumbent) seats were analyzed. Second, the effect of these seat orientations on the maximum reach in different anatomical planes was analyzed. Seat orientation had a drastic effect on the ingress/egress kinematics, but was found to have little effect on planar reach.

\subsection{Ingress/Egress Kinematics}

The interaction of seat orientation and direction of motion influenced shoulder kinematics the most, with a significant effect on 14 of the 18 shoulder kinematic variables. The effect on the left hip was also noteworthy, with the interaction effect being significant for 3 of the 5 kinematic variables. Seat orientation had a significant effect on 39 of the 43 analyzed angles and ranges of motion. Kinematics of the upper body (trunk and shoulders) were affected more by seat orientation than the lower body, with most following the same trend. That is, the peak angles and ranges of motion during ingress/egress of the horizontal seats were significantly higher than the vertical seats, often by a factor of 3 or 4 , while only small insignificant differences existed between the two horizontal seats.

The lower body was much more active than the upper body during ingress/egress of the vertical seats, as little motion was required from the arms/shoulders and trunk. However, the upper body was much more active during ingress/egress of the horizontal seats. The need to lift the trunk and pelvis from the ground during ingress/egress of the horizontal seats requires a greater force exertion by the shoulders and lower back than during ingress/egress of a vertical seat. Furthermore, awkward postures of the trunk (rotation, lateral bending) and shoulders 
(extension) were assumed during horizontal ingress/egress while balancing the body weight making ingress/egress of the horizontal seats much more stressful than vertical seats. Also of note is the drastic differences between the kinematics of the left and right side of the bodies for several joints, most notably in the trunk (lateral bending, rotation), hips (abduction, rotation), and knees (flexion, rotation), which could be due to entry only from the left side of the seat.

While force exertion by the lower back and shoulder musculature and the resulting musculoskeletal loading during ingress/egress of recumbent spacecraft seats may not be an issue in weightless conditions, it is important to remember that astronauts undergo intensive training in preparation for space travel (Strauss et al., 2005). During the training, they perform multiple ingress/egress trials and all other related tasks that must be performed during spaceflight while suited in gravity conditions. Repeated loading of the shoulder and lower back during ingress/egress activities could increase risk of injury. While this precise posture has not been analyzed, a prospective cohort study done by Hoogendoorn et al. (2000) followed 861 participants from 34 different companies for 3 years, and found significantly increased relative risks of lower back pain due to trunk flexion of over $60^{\circ}$ for $5 \%$ of the shift $(\mathrm{RR}=1.5)$, trunk rotation over $30^{\circ}$ for more than $10 \%$ of working time $(\mathrm{RR}=1.3)$, and lifting more than $25 \mathrm{~kg}$ more than 15 times per shift $(\mathrm{RR}=1.6)$. While trunk rotation did not exceed $30^{\circ}$ in our study, trunk flexion angles exceeding $60^{\circ}$ were consistently observed during the awkward pelvis/trunk lifting during horizontal ingress/egress. However, this was measured in a standing posture, where $60^{\circ}$ of trunk flexion would create a significant moment on the lower back. In our research, a horizontal posture was used and some of the weight of the upper body was supported by the arms, thus, the risk could be lower than reported by Hoogedoorm et al. (2002). While a direct comparison cannot be made regarding the weight lifted, due to extremely different postures in 
our research compared to Hoogendoorn's research, it's safe to assume that the weight of the pelvis and upper body combined would be at least $25 \mathrm{~kg}$, considering the head, neck, and trunk account for over half of the body's mass (Clauser et al., 1969).

Furthermore, due to the fact that ingress and egress is done with no external load, forces on the body are rarely considered. As mentioned earlier, the awkward postures and increased forces on the lower back and shoulders greatly increase the strain on the body during horizontal ingress/egress. Therefore, fatigue should be considered when repeated ingress/egress trials are performed in succession, such as during training, and participants should be allowed sufficient rest periods to recover between tasks. Additionally, it is safe to assume that stresses on the body would increase while suited, compared to the unsuited conditions tested in this research. In another study by the author of this research, suited kinematics were evaluated using mock spacesuits and a motion capture system (Moore et al, 2012). The results showed that the space-suit segments often moved differently than the corresponding body segments. For instance, when performing a trunk flexion task, the participants were found to have moved approximately $15^{\circ}$ more than the trunk segment of the suit. This mismatch between body and suit kinematics may further augment the stresses on the shoulder and lower back, increasing the risk of chronic and acute injuries if proper rest periods are not provided.

In this study, participants performed ingress tasks beginning to the left of the seat, and returned to the left side of the seat during egress. Kinematics of the lower body and trunk showed interesting trends due to ingress from the left. The most notable difference was found in abduction of the hip, where left hip angles were nearly double the right hip angles during ingress/egress of the horizontal seats. Left rotation and left lateral bending of the trunk were also much more prominent than right rotation and lateral bending during ingress/egress of the 
horizontal seats. Knee flexion was also more prominent on the left side than right side, however the effect on knee flexion was not as great as the effect on the trunk and hips. Performing ingress from the same side of the seat each time could contribute to injuries due to excessive unilateral loading. Therefore, when ingress/egress of a horizontal seat is required, care should be taken to alleviate as much stress as possible. For instance, alternating between entry from the left and entry from the right is a possible solution to reduce the unilateral loading. However, this would increase the space requirement necessary around the seat.

Only minor differences existed between the horizontal- $90^{\circ}$ and horizontal- $120^{\circ}$ seats. Based on the results of our research, it is not possible to recommend a certain horizontal seat angle. While some peak angles and ranges of motion were higher in the horizontal- $90^{\circ}$ seat, others were higher in the horizontal- $120^{\circ}$ seat. Participants in this study were not questioned about comfort or ease of entry, however most participants seemed to struggle less with ingress/egress of the horizontal- $120^{\circ}$ seat.

Providing handles above the seat to assist the user during ingress/egress could eliminate the awkward shoulder posture observed in this research. Handles above the seat would also improve the coupling, as the subject would be able to get a better grip on the handle than with the hand palm-down on the floor. Additionally, while suited, the awkward posture required to lift the trunk and pelvis may be more difficult due to the decreased range of motion, while spacesuits are designed to allow easy forward reach.

Finally, energy requirements for the horizontal ingress/egress would be higher. While this research suggests increased ranges of motion and peak angles for most joints, an observation of the horizontal ingress/egress procedures makes it obvious that there is much more activity in the joints compared to ingress/egress of the vertical seats, especially in the trunk and shoulders. 
Furthermore, the energy requirements of horizontal ingress/egress would also be higher due to the need to progress from a standing posture to a supine posture prior to ingress of a horizontal seat, and vice-versa during egress.

In addition to all these considerations during horizontal ingress/egress, incorporating space travel creates additional issues. While astronauts are required to be in good physical shape and participate in vigorous training before going into space, the body undergoes many physiological changes that increase the stress on the body during spaceflight, including, but not limited to, reduced muscle volume (LeBlanc et al., 1995), increased calf muscle transverse relaxation time (suggesting possible muscle damage), changes in body composition (LeBlanc et al., 2000), altered nutritional status (Smith et al., 2005), bone demineralization (Williams et al., 2009) and disturbances in visuo-motor tracking and dual-task performance (Manzey and Lorenz, 1998)

Most people have no experience with ingress/egress of a horizontal seat and therefore, when implementing a horizontal workstation, appropriate training is essential to learn proper ingress/egress technique. During the initial phase of this study, it was realized that, unlike vertical ingress and egress, participants faced a lot of difficulties during ingress and egress of the horizontal seats when self-selected techniques were used. Standardization of technique and adequate training prior to the actual testing improved the user performance. In the crew modules, in addition to the horizontal seats various other factors such as suited condition, numerous controls, and displays further complicate the ingress and egress motions. Under such conditions, very precise training on ingress and egress motions is essential to minimize stress on the body and potential risk of injuries. 


\subsection{Planar Reach}

Surprisingly, there was no significant effect of seat orientation on the maximal planar reach. We expected to see a decrease in the horizontal seat due to the effect of gravity and weight of the arm. However, by securing the trunk to the vertical seat during the reach tasks, the effect of gravity may have been negated.

As expected, however, the anatomical plane of the reach task had a significant effect on the three extreme points for each arm. The majority of the motion during the reach tasks was handled by the shoulder, while the elbow remained straight. However, in the transverse plane, the shoulder quickly reaches a barrier and the elbow must be bent, decreasing reach across the body. Therefore, the value for this extreme point $(\operatorname{Max} X)$ was drastically lower than for the other anatomical planes. This is in agreement with the findings of Sengupta et al. (2000). In the research by Sengupta, reach was determined based on radial vectors from a table reference point at $15 \mathrm{~cm}$ intervals above table level, which showed that reach across the body (Max $\mathrm{X}$ in our research) was significantly lower than forward and lateral reach.

Min X and Max X for both arms are similar for the frontal and sagittal planes, which was expected since the arm is in approximately the same position at the Min X and Max X points. Max $\mathrm{Y}$ is much lower in the sagittal plane than the frontal plane. A possible explanation is the shoulder's ability to translate anterioposteriorly (forward and backward) and vertically at the glenohumeral joint. When performing a reach task in the frontal plane, the translation of the shoulder has no effect on the reach, as the shoulder does not have the ability to translate mediolaterally. However, when reaching in the sagittal plane, the ability of the shoulder to translate can have a drastic effect. For example, if the shoulder is translated posteriorly during a sagittal reach task, Max Y would be less than if the shoulder were translated anteriorly. During this research, participants were instructed to move their fully-extended arm through the range of 
motion. The participants were not instructed to translate their shoulder in any certain manner; therefore it is possible that the subjects maintained a more posterior translation of the shoulder during the sagittal reaching task, and not reflecting true maximal reach.

\subsection{Control Placement Recommendations}

Unlike ingress/egress of a vertical seat in which the seat can typically be moved inward and outward from the workstation to allow easy ingress/egress, horizontal seats are often used in workstations that do not allow that type of flexibility. Instead, it is important to consider the space used for ingress/egress when determining optimal control placement. To determine the general space requirement for ingress/egress of a horizontal seat, the X-component (offset from head-to-toe) of the marker data was stratified into $1 \mathrm{~cm}$ intervals. For each interval, the maximum Z-component (distance above platform) was collected to form an ingress/egress envelope. A parabola was formed from the three extreme points and superimposed above this graph as a guideline for control placement (Figure 22). This analysis suggests that control placement is a very important consideration since the area to place the controls is limited. If the controls are placed within the ingress/egress envelope, it will hinder ingress/egress and possibly result in injury. However, if the controls are not placed within the reach envelope, it will be difficult, if not impossible, for the user to reach the controls.

\subsection{Limitations}

While this research provides a lot of novel, valuable information on ingress and egress joint kinematics of a horizontal seat, it doesn't tell the whole story. For instance, analysis of the "additive" range of motion of the joints would also be beneficial. Additive range of motion tracks the entire motion of the body segment, instead of only the difference between minimum 
and maximum angles. For instance, if the knee begins at $45^{\circ}$ flexion, is flexed to $90^{\circ}$ degrees, and is extended back to $45^{\circ}$ flexion, the additive range of motion would be $90^{\circ}$ instead of $45^{\circ}$.

Determining the range of motion in this manner gives a better representation of the activity of the joint. Additionally, this research tells very little about the additional forces experienced during horizontal ingress/egress. However, based on observation, it appears that forces on the body would be much higher during ingress/egress of horizontal seats then vertical seats.

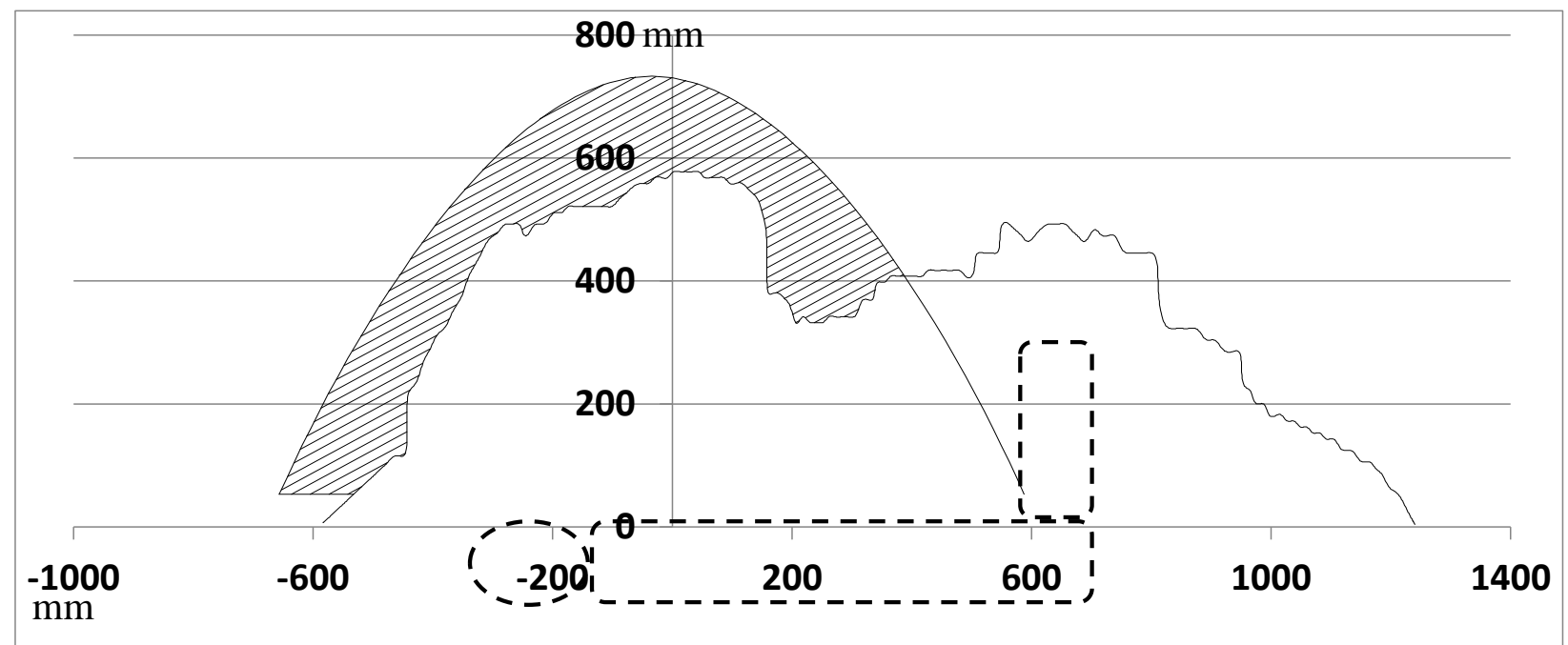

Figure 22. Recommendation for control placement based on reach and ingress/egress motion envelope. Dotted outline in the picture is the seat. Units are in millimeters.

Having the participants perform ingress/egress from the left side of the seat was also a drawback of this research. While logic suggests that the relationships between the left and right side of the body would be reversed during ingress/egress from the right side, other factors, such as handedness could have an effect on the outcome. However, due to time and financial limitations, it was not feasible for this research to consider both. 
In this research, the tasks were performed in an automobile seat that was held in position by custom-built platforms. Automobile seats are designed to provide support for the neck and back, especially the lumbar spine. On the other hand, horizontal seats are commonly flat "back boards" with a layer of padding, and no extra support. For the sake of consistency, we opted to use the same seat for both horizontal and vertical ingress/egress and reach, however using a more typical horizontal seat, as seen in Figure 1, could result in significantly different joint kinematics.

Additionally, this research recruited only males. Females typically have lower upper body strength and weight than males, which could cause significant differences in ingress/egress kinematics, reach, and ability to perform horizontal ingress/egress. A previous study has shown that female reach is approximately $13.5 \%$ lower than their male counterparts. Therefore, the results of this study should only be considered accurate for males.

With the focus of this research being the application to spaceflight, the fact that the participants were not wearing a spacesuit is a limitation as well. We would expect similar relationships and trends to exist during suited ingress/egress, however the effect of a spacesuit on ingress/egress kinematics is currently unknown. The added space constraint due to bulk of the suit would likely influence the magnitude of the peak angles and ranges of motion.

\subsection{Future Research}

Future studies of this type should focus on a more in-depth analysis of the joint kinematics, including additive range of motion. Determining additive range of motion will provide better information on the overall activity of the joint. Utilizing force sensors to determine the stress on the shoulder would also be beneficial research. Observation alone suggests that the forces on the shoulder and lower back are increased during horizontal compared to vertical ingress/egress. However, quantifying the forces exerted on the shoulder and lower 
back would improve the understanding to a greater extent. Additionally, performing ingress and egress from a variety of starting positions will determine whether the observations attributed to left-side entry are due entirely to left-side entry, or if other factors are influencing the kinematics.

Due to the negligible differences between the kinematics during ingress/egress of the horizontal seats, a method should be devised to determine optimal seat angle. A short questionnaire regarding ease of entry and comfort, as well as analysis of forces in the lower back, shoulders, and neck could suggest the optimal seat angle.

Additionally, alternate seating surfaces should be tested. Spacecraft seats are generally made of padding covered in a layer of vinyl (or similar) material. However, the automobile seats used in this research had a wooden seat platform and a cloth back. The friction characteristics of these surfaces, as well as the cradling effect of the automobile seat, could alter the metrics analyzed in this research, as well as ease of entry and comfort.

Finally, control panels could be implemented into this research. Adjusting the position of a control panel would help determine the best location for controls, as well as determine how the controls affect ingress and egress. When controls are in place, participants may attempt to avoid them which could alter the joint kinematics.

\subsection{Conclusions}

While only a few significant differences were observed for the effect of seat orientation on maximal reach, ingress/egress kinematics of the joints tested in this study were significantly affected by seat orientation. Ingress and egress of horizontal seats, in general, required higher joint angles and ranges of motion than vertical seats. In addition, horizontal ingress and egress required the trunk and shoulder joints to balance the upper body weight in various awkward 
postures. As a whole, this research suggests that vertical seats should remain in use when appropriate.

Differences between the two horizontal seats were minimal, therefore determination of the seat angle should be based on comfort and ease of use. Additionally, it is important to make the ingress/egress of horizontal seats as easy and safe as possible. Providing handles to aid ingress/egress, placing controls in non-obstructive positions, and ample training are all interventions that should be implemented. If repeated ingress/egress of horizontal seats is necessary, it is important to vary the side of entry and provide sufficient rest between the exertions to avoid excessive unilateral loading. 


\section{REFERENCES}

Aaras, A., G. Horgen, H.H. Bjorset, O. Ro, and M Thoresen. (1998) Musculoskeletal, visual, and psychosocial stress in VDU operators before and after multidisciplinary ergonomic interventions. Applied Ergonomics 29:335

Ait El Menceur, M.O., P. Pudlo, P. Gorce, A. Thevenon, and F. Lepoutre. (2008) Alternative movement identification in the automobile ingress and egress for young and elderly population with or without prostheses. International Journal of Industrial Ergonomics 36:1078-1087

Amick III, B.C., M.M. Robertson, K. DeRango, L. Bazzani, A. Moore, T. Rooney, and R. Harrist. (2003) Effect of office ergonomics interventionon reducing musculoskeletal symptoms. Spine 28(24):2706-2711

Boone, D.C. and S.P. Azen. (1979) Normal range of motion of joints in male subjects. Journal of Bone and Joint Surgery 61:756-759

Clauser, C.E., J.T. McConville, and J.W. Young. (1969) Weight, volume, and center of mass of segments of the human body. Aerospace Medical Research Laboratory. Accessed at http://ntrs.nasa.gov/archive/nasa/casi.ntrs.nasa.gov/19700027497_1970027497.pdf on July 5th, 2012.

Das, B., J.W. Kozey, and J.N. Tyson (1994) A computerized potentiometric system for structural and functional anthropometric measurements. Ergonomics 37(6):1031-1045

Deisinger J., R. Breining, and A. Roßler (2000) ERGONAUT: A tool for ergonomic analysis in virtual environments. 6th Eurographics Workshop on Virtual Environments, Amsterdam, Netherlands.

Giacomin, J. and S. Quattrocolo (1997) An analysis of human comfort when entering and exiting the rear seat of an automobile. Applied Ergonomics 28:397-406 
Halpern, C.A., and K.D. Dawson. (1997) Design and implementation of a participatory ergonomics program for machine sewing tasks. International Journal of Industrial Ergonomics 20:429-440

Hoogedoorn, W.E., P.M. bongers, H.C.W. de Vet, M. Douwes, B.W. Koes, M.C. Miedema, G.A.M. Ariens, and L.M. Bouter. (2000) Flexion and rotation of the trunk and lifting at work are risk factors for low back pain. Spine 25(23):3087-3092

Kennedy, J.S., D.B. Durbin, J.A. Faughn, R.W. Kozycki, and K.J. Nebel. (2004) Evaluation of an army aviator's ability to conduct ingress and egress of the RAH-66 comanche crew station while wearing the air warrior ensemble. Army Research Laboratory - Defense Technical Information Center. Accessed at www.dtic.mil/ on June 27, 2011

LeBlanc A, R. Rowe, V. Schneider, H. Evans, and T. Hedrick. (1995) Regional muscle loss after short duration space flight. Aviation, Space, and Environmental Medicine 66:1151-1154

LeBlanc A., C. Lin, L. Shackelford, V. Sinitsyn, H. Evans, O. Belichenko, B. Schenkman, I. Kozlovskaya, V. Oganov, A. Bakulin, T. Hedrick, and D. Feeback. (2000) Muscle volume, MRI relaxation times (T2), and body composition after spaceflight. Journal of Applied Physiology $89: 2158-2164$

Loczi, J. (1993) Ergonomic assessment of exiting automobiles. Human Factors and Ergonomics Society Annual Meeting Proceedings, Consumer Products 5:401-405

Loczi, J., N. Dietz, and G Nielson. (1999) Validation and Application of the 3-D CAD Manikin RAMSIS in automotive design. SAE Transactions 108(6):2307-2314

Loczi, J. (2000) Application of the 3-D CAD manikin RAMSIS to heavy truck design. Human Factors and Ergonomics Society Annual Meeting Proceedings, 4:832-835

Manzey D., and B. Lorenz. (1998) Mental performance during short-term and long-term spaceflight. Brain Research Reviews 28(1-2):215-221 
Moore, C., A. Nimbarte, S. Rajulu, and F. Aghazadeh. (2012) A study of the kinematics of ingress and egress of upright and recumbent seats. Work, 41:1316-1322

Moore, C., A. Nimbarte (2012) Study of suited kinematics using an optical analysis system. Proceeds of the $27^{\text {th }}$ Annual International Society of Occupational Ergonomics \& Safety, Ft. Lauderdale, FL, USA. June $6^{\text {th }}-$ June $8^{\text {th }}, 2012$.

Moore, J.S. (1994) Flywheel truing - a case-study of an ergonomic intervention. American Industrial Hygiene Association Journal, 55:236

National Aeronautics and Space Administration. (2006) NASA names new crew exploration vehicle Orion. NASA Press Release: August 22, 2006. Accessed at http://www.nasa.gov/home/hqnews/2006/aug/HQ_06299_Orion_announced.html on June 27, 2011

Occupational Safety and Health Administration. (2007) Ergonomics:Introduction Accessed at http://www.osha.gov/SLTC/ergonomics/ on June 27, 2011

Reed M.P., M. Parkinson, and D.B. Chaffin. (2003) A new approach to modeling driver reach, SAE Technical Paper 2003-01-0587, Warrendale, PA: SAE International World Congress

Sanchez, M. J. (2000) A human factors evaluation of a methodology for pressurized crew module acceptability for zero-gravity ingress of spacecraft. NASA Technical Memorandum. Accessed at http://hdl.handle.net/2060/20000032160 on June 27, 2010

Sengupta, A.K., and B. Das (2000) Maximum reach envelope for the seated and standing male and female for industrial workstation design. Ergonomics 43(9):1390-1404

Smith, S.M., S.R. Zwart, G. Block, B.L. Rice, and J.E. Davis-Street. (2005) The nutritional status of astraonauts is altered after long-term space flight aboard the International Space Station. Journal of Nutrition 135(3):437-443 
Strauss, S., R.L. Krog, and A.H. Feiveson (2005) Extravehicular mobility unit training and astronaut injuries. Aviation, Space, and Environmental Medicine 76(5):469-474

Williams, D., A. Kuipers, C. Mukai, and R. Thirsk (2009) Acclimation during space flight: effects on human physiology. Canadian Medical Association Journal 180(13):1317-1323

Yang, J., K. Abdel-Malek, and K. Nebel (2005) Reach envelope of a 9-degree-of-freedom model of the upper extremity. International Journal of Robotics and Automation 80(4):240-25 


\section{APPENDIX A - IRB APPROVAL}

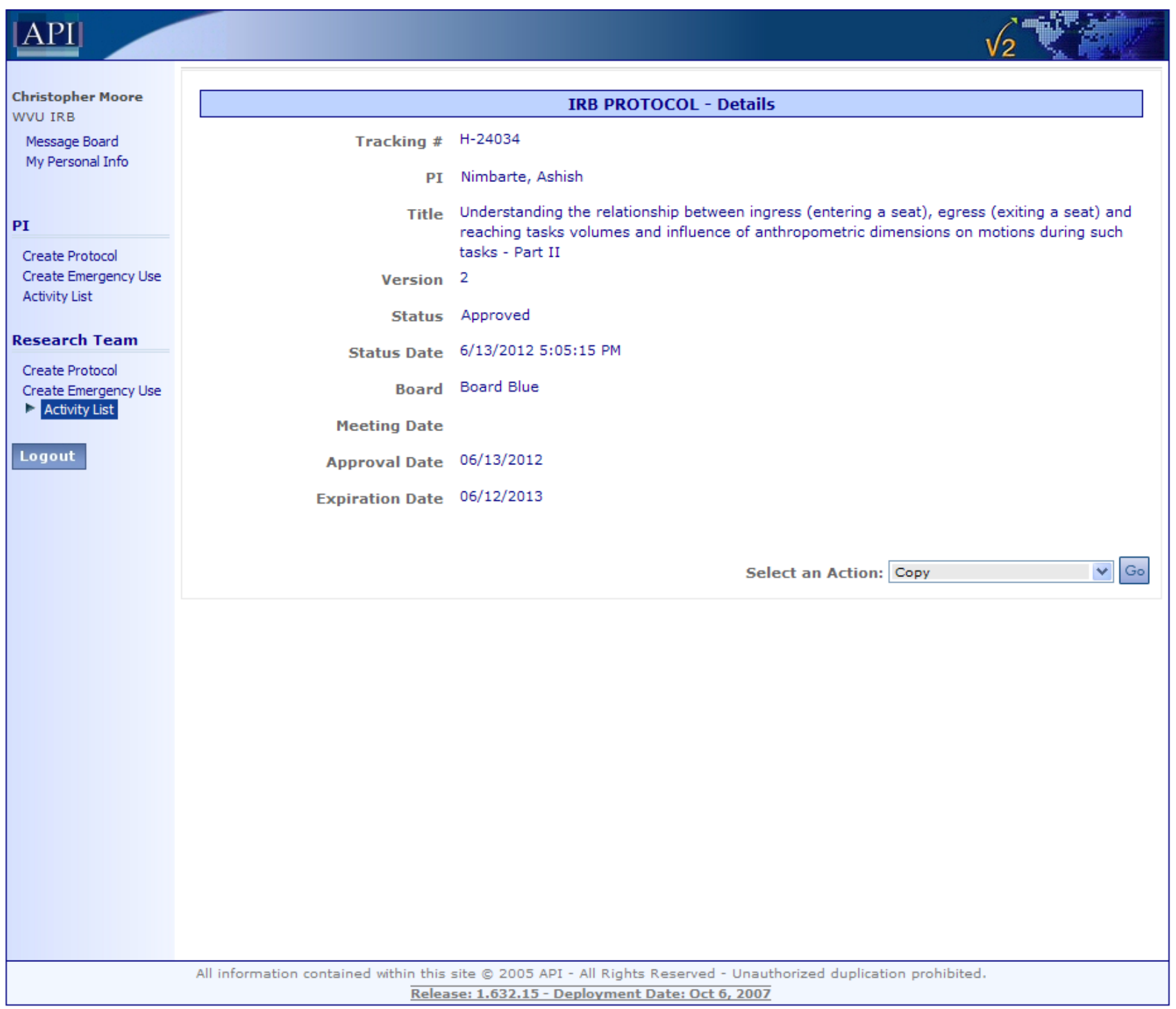




\title{
APPENDIX B - IRB CONSENT FORM
}

\section{WestVirginiaUniversity. \\ Office of Research Compliance \\ CONSENT AND INFORMATION FORM}

\author{
Ingress/Egress Study
}

Principal Investigator: Nimbarte, Ashish

Department: $\quad$ ENGINEERING - Ind./Mgt. Sys. Engineering

Tracking Number: $\quad \mathrm{H}-24034$

\section{Study Title:}

Understanding the relationship between ingress (entering a seat), egress (exiting a seat) and reaching tasks volumes and influence of anthropometric dimensions on motions during such tasks - Part II

\section{Co-Investigator(s):}

Moore, Christopher

Sponsor

NASA West Virginia Space Grant Consortium

\section{Contact Persons}

In the event you experience any side effects or injury related to this research, you should contact Dr. Ashish Nimbarte at 304/293-9473. (After hours contact Dr. Ashish Nimbarte at 225/226-8813.)

If you have any questions, concerns, or complaints about this research, you can contact Dr. Nimbarte at 304/293-9473 or Chris Moore at 304/2939669

For information regarding your rights as a research subject, you may contact the Office of Research Compliance at 304/293-7073.

Introduction

In addition if you would like to discuss problems, concerns, have suggestions related to research, or would like to offer input about the

\begin{tabular}{lll}
\hline Tracking \#: & $\mathrm{H}-24034$ & Page 1 of 5 \\
Approved On: & $06 / 13 / 2012$ & \\
Valid Through: & $06 / 12 / 2013$ & \\
Last Amended: & $\mathrm{N} / \mathrm{A}$ &
\end{tabular}

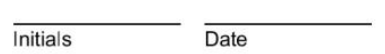

Last Amended: N/A 
Tracking \#: $\quad \mathrm{H}-24034$

research, contact the Office of Research Integrity and Compliance at 304293-7073.

You, have been asked to participate in this research study, which has been explained to you by Dr. Ashish Nimbarte, Ph.D. and Chris Moore, B.S. This study is being conducted by Dr. Ashish Nimbarte and Chris Moore in the Department of Industrial and Management Systems Engineering (IMSE) at West Virginia University with funding provided by NASA West Virginia Space Grant Consortium. This research is being conducted to fulfill the requirements for a master thesis of Mr. Chris Moore in the area of anthropometry and ergonomics in the Department of Indistrial and Management Systems Engineering at West Virginia University, under the supervision of Dr. Ashish Nimbarte, Ph.D.

\section{Purposes of the Study}

The purpose of this study is to understand how technique and joint angles differ when entering a horizontally vs. vertically mounted seat. In addition, effect of seat location on the 'reach envelope' i.e. the furthest distance that can be reached in all directions will also be evaluated. We expect to enroll approximately 10 subjects for this research.

\section{Description of Procedures}

Upon arrival, you will be asked to change to a tight short and t-shirt and several of your body dimensions (height, weight, limb length, etc.) will be measured and recorded. A set of reflective markers (approximately 30 ) will be placed on your body using a double-sided tape. You will then perform following experimental tasks:1) enter a seat 2) perform a reaching task by randomly moving your hand in different directions with the arm straight and the back against the seat. 3 ) exit the seat.Three seat arrangements will be used:1) seat mounted vertically with the seat-pad and seat-back forming a right angle2) seat mounted horizontally with the seat-pad and seat-back forming an "L"3) seat mounted horizontally with the seat-pad and seat-back making an " $\llcorner$ "Each of the above seat arrangements will be tested in the presence and absence of a simulated control panel placed directly in front of the you.

\section{Risks and Discomforts}

\begin{tabular}{lllll}
\hline Tracking \#: & $\mathrm{H}-24034$ & Page 2 of 5 & \\
Approved On: & $06 / 13 / 2012$ & & & \\
Valid Through: & $06 / 12 / 2013$ & & \\
Last Amended: & $\mathrm{N} / \mathrm{A}$ & &
\end{tabular}


Tracking \#: $\quad \mathrm{H}-24034$

There are no known or expected risks from participating in this study. Minor injuries are possible (scrape, bruise, etc.), but not expected.

\section{Alternatives}

You do not have to participate in this study.

You do not have to participate in this study.

\section{Benefits}

You may not receive any direct benefit from this study. The knowledge gained from this study may eventually benefit others.

\section{Financial Considerations}

Subjects will recieve $\$ 15 /$ hour for participation in the study and will not incur any costs related to the study. Participation is expected to take 1.5 hours and the payment for participating will be given at the completion of the study. It is very important for you to understand that neither the investigator norWVU or it associated affiliates has the funds set aside to pay for the cost oflost work wages or any care or treatment that might be necessary becauseyou get hurt or sick taking part in this study. Any injuries that may resultfrom this study would not be eligible for Workers 'Compensation as this isnot a job-related injury. Understand that any treatments necessary will bebilled to the participant or to your personal health insurance, and you maywish to consult your insurance provider before participating in this study

\section{Confidentiality}

Any information about you that is obtained as a result of your participationin this research will be kept as confidential as legally possible. Yourresearch records and test results, just like hospital records, may besubpoenaed by court order or may be inspected by federal regulatoryauthorities without your additional consent.In any publications that result from this research, neither your name norany information from which you might be identified will be publishedwithout your consent.

\section{Voluntary Participation}

\begin{tabular}{lllll}
\hline Tracking \#: & $\mathrm{H}-24034$ & Page 3 of 5 & \\
Approved On: & $06 / 13 / 2012$ & & & Date \\
Valid Through: & $06 / 12 / 2013$ & & \\
Last Amended: & N/A & &
\end{tabular}


Tracking \#: $\quad \mathrm{H}-24034$

Participation in this study is voluntary. You are free to withdraw your consent to participate in this study at any time. Refusal to participate or withdrawal will not affect your employee status at West Virginia University or, for students, your class standing or grades and will involve no penalty to you. In the event new information becomes available that may affect your willingness to participate in this study, this information will be given to you so that you can make an informed decision about whether or not to continue your participation. You have been given the opportunity to ask questions about the research, and you have received answers concerning areas you did not understand.

\begin{tabular}{lllll}
\hline Tracking \#: & H-24034 & Page 4 of 5 & \\
Approved On: & $06 / 13 / 2012$ & & Initials & \\
Valid Through: & $06 / 12 / 2013$ & & \\
Last Amended: & N/A & & &
\end{tabular}


Upon signing this form, you will receive a copy.

I willingly consent to participate in this research.

Signature of Subject or

Printed Name

$\overline{\text { Date }} \overline{\text { Time }}$

Subjects Legal Representative

The participant has had the opportunity to have questions addressed. The participant willingly agrees to be in the study.

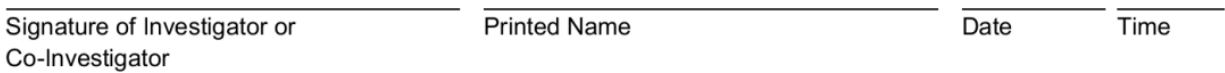

\begin{tabular}{lll}
\hline Tracking \#: & $\mathrm{H}-24034$ & Page 5 of 5 \\
Approved On: & $06 / 13 / 2012$ & \\
Valid Through: & $06 / 12 / 2013$ & \\
Last Amended: & $\mathrm{N} / \mathrm{A}$ &
\end{tabular}




\section{APPENDIX C - NORMALITY AND VARIANCE}

\begin{tabular}{|c|c|c|c|c|c|c|c|c|}
\hline Code & Motion & Variance & N: H120E & $\mathrm{N}: \mathrm{H} 120 \mathrm{I}$ & N: H9OE & N: H9OI & $\underline{\mathbf{N}: \text { VE }}$ & N: VI \\
\hline LHX+ & L. Hip Flexion & 0.849 & 0.150 & 0.052 & 0.010 & 0.150 & 0.046 & 0.113 \\
\hline LHY+ & L. Hip Abduction & 0.064 & 0.150 & 0.150 & 0.095 & 0.010 & 0.150 & 0.150 \\
\hline LHZ+ & L. Hip Ext. Rot. & 0.999 & 0.025 & 0.150 & 0.010 & 0.100 & 0.150 & 0.105 \\
\hline LHZ- & L. Hip Int. Rot. & 0.992 & 0.075 & 0.042 & 0.010 & 0.010 & 0.150 & 0.010 \\
\hline LHZR & L. Hip Rot. (ROM) & 0.045 & 0.150 & 0.150 & 0.150 & 0.150 & 0.150 & 0.142 \\
\hline LKX+ & L. Knee Flexion & 0.001 & 0.030 & 0.150 & 0.040 & 0.150 & 0.150 & 0.150 \\
\hline LKZ+ & L. Knee Ext. Rot. & 0.118 & 0.150 & 0.150 & 0.150 & 0.150 & 0.150 & 0.150 \\
\hline LKZ- & L. Knee Int. Rot. & 0.029 & 0.150 & 0.150 & 0.150 & 0.067 & 0.150 & 0.150 \\
\hline LKZR & L. Knee Rot. (ROM) & 0.000 & 0.150 & 0.150 & 0.150 & 0.150 & 0.150 & 0.071 \\
\hline LSX+ & L. Shldr Flexion & 0.915 & 0.150 & 0.150 & 0.150 & 0.032 & 0.150 & 0.010 \\
\hline LSX- & L. Shldr Extension & 0.047 & 0.150 & 0.150 & 0.150 & 0.150 & 0.042 & 0.010 \\
\hline LSXR & L. Shldr Flx/Ext (ROM) & 0.343 & 0.150 & 0.031 & 0.150 & 0.150 & 0.010 & 0.010 \\
\hline LSY+ & L. Shldr Abd. & 0.015 & 0.150 & 0.150 & 0.150 & 0.150 & 0.150 & 0.099 \\
\hline LSY- & L. Shldr Add. & 0.424 & 0.150 & 0.150 & 0.150 & 0.150 & 0.042 & 0.150 \\
\hline LSYR & L. Shldr Abd/Add (ROM) & 0.000 & 0.057 & 0.095 & 0.150 & 0.150 & 0.150 & 0.150 \\
\hline LSZ+ & L. Shldr Ext. Rot. & 0.099 & 0.150 & 0.150 & 0.150 & 0.150 & 0.150 & 0.150 \\
\hline LSZ- & L. Shldr Int. Rot. & 0.930 & 0.150 & 0.029 & 0.150 & 0.053 & 0.072 & 0.150 \\
\hline LSZR & L. Shldr Rot. (ROM) & 0.016 & 0.150 & 0.150 & 0.150 & 0.150 & 0.150 & 0.010 \\
\hline RHX+ & R. Hip Flexion & 0.315 & 0.044 & 0.150 & 0.150 & 0.150 & 0.150 & 0.150 \\
\hline RHY- & R. Hip Abd. & 0.000 & 0.150 & 0.034 & 0.010 & 0.010 & 0.150 & 0.150 \\
\hline $\mathrm{RHZ}+$ & R. Hip Int. Rot. & 0.799 & 0.150 & 0.150 & 0.059 & 0.035 & 0.150 & 0.048 \\
\hline RHZ- & R. Hip Ext. Rot. & 0.413 & 0.150 & 0.150 & 0.150 & 0.150 & 0.150 & 0.150 \\
\hline RHZR & R. Hip Rot. (ROM) & 0.333 & 0.150 & 0.150 & 0.150 & 0.010 & 0.093 & 0.010 \\
\hline RKX+ & R. Knee Flexion & 0.182 & 0.150 & 0.150 & 0.102 & 0.150 & 0.150 & 0.090 \\
\hline RKZ+ & R. Knee Int. Rot. & 0.090 & 0.150 & 0.010 & 0.150 & 0.150 & 0.150 & 0.150 \\
\hline RKZ- & R. Knee Ext. Rot. & 0.789 & 0.069 & 0.150 & 0.150 & 0.150 & 0.150 & 0.033 \\
\hline RKZR & R. Knee Rot. (ROM) & 0.241 & 0.150 & 0.086 & 0.150 & 0.150 & 0.098 & 0.010 \\
\hline RSX+ & R. Shldr Flexion & 0.299 & 0.150 & 0.150 & 0.097 & 0.150 & 0.150 & 0.150 \\
\hline RSX- & R. Shldr Extension & 0.202 & 0.046 & 0.150 & 0.150 & 0.150 & 0.150 & 0.010 \\
\hline RSXR & R. Shldr Flx/Ext (ROM) & 0.138 & 0.039 & 0.150 & 0.083 & 0.150 & 0.010 & 0.010 \\
\hline RSY+ & R. Shldr Add. & 0.100 & 0.150 & 0.150 & 0.150 & 0.150 & 0.010 & 0.150 \\
\hline RSY- & R. Shldr Abd. & 0.138 & 0.044 & 0.045 & 0.150 & 0.150 & 0.010 & 0.010 \\
\hline RSYR & R. Shldr Abd/Add (ROM) & 0.121 & 0.150 & 0.150 & 0.150 & 0.150 & 0.010 & 0.150 \\
\hline RSZ+ & R. Shldr Int. Rot. & 0.569 & 0.150 & 0.150 & 0.150 & 0.150 & 0.150 & 0.078 \\
\hline RSZ- & R. Shldr Ext. Rot. & 0.631 & 0.043 & 0.145 & 0.073 & 0.089 & 0.150 & 0.150 \\
\hline RSZR & R. Shldr Rot. (ROM) & 0.015 & 0.010 & 0.150 & 0.039 & 0.092 & 0.010 & 0.054 \\
\hline $\mathrm{TX}+$ & Trunk Flexion & 0.451 & 0.010 & 0.107 & 0.010 & 0.010 & 0.119 & 0.150 \\
\hline TY+ & R. Trunk Lat. Bending & 0.000 & 0.150 & 0.150 & 0.013 & 0.150 & 0.150 & 0.150 \\
\hline TY- & L. Trunk Lat. Bendng & 0.005 & 0.090 & 0.114 & 0.150 & 0.111 & 0.150 & 0.150 \\
\hline TYR & Trunk Lat. Bending (ROM) & 0.000 & 0.150 & 0.150 & 0.150 & 0.128 & 0.150 & 0.081 \\
\hline TZ+ & L. Trunk Rot. & 0.002 & 0.150 & 0.150 & 0.150 & 0.150 & 0.150 & 0.150 \\
\hline TZ- & R. Trunk Rot. & 0.548 & 0.028 & 0.010 & 0.046 & 0.010 & 0.076 & 0.150 \\
\hline TZR & Trunk Rot. (ROM) & 0.005 & 0.150 & 0.150 & 0.088 & 0.150 & 0.150 & 0.131 \\
\hline
\end{tabular}




\title{
APPENDIX D - INGRESS/EGRESS ANOVA \& TUKEY HSD RESULTS
}

\author{
General Linear Model: LHX+, LHY+, ... versus Subj, Seat, ... \\ Factor Type Levels Values \\ Subj random $101,2,3,4,5,6,7,8,9,10$ \\ Seat fixed $3 \mathrm{H} 120, \mathrm{H} 90, \mathrm{~V}$ \\ Task fixed $2 \mathrm{E}, \mathrm{I}$ \\ Analysis of Variance for LHX+, using Adjusted SS for Tests

$\begin{array}{lrrrrrr}\text { Source } & \text { DF } & \text { Seq SS } & \text { Adj SS } & \text { Adj MS } & \text { F } & \text { P } \\ \text { Subj } & 9 & 22557.7 & 22208.3 & 2467.6 & 43.11 & 0.000 \\ \text { Seat } & 2 & 1418.2 & 1474.9 & 737.5 & 12.88 & 0.000 \\ \text { Task } & 1 & 0.0 & 0.7 & 0.7 & 0.01 & 0.914 \\ \text { Seat*Task } & 2 & 409.2 & 409.2 & 204.6 & 3.57 & 0.031 \\ \text { Error } & 132 & 7555.5 & 7555.5 & 57.2 & & \\ \text { Total } & 146 & 31940.7 & & & & \end{array}$ \\ $S=7.56561 \quad R-S q=76.35 \% \quad R-S q(\operatorname{adj})=73.84 \%$ \\ Analysis of Variance for LHY+, using Adjusted SS for Tests

$\begin{array}{lrrrrrr}\text { Source } & \text { DF } & \text { Seq SS } & \text { Adj SS } & \text { Adj MS } & \text { F } & \text { P } \\ \text { Subj } & 9 & 1917.93 & 1637.04 & 181.89 & 6.82 & 0.000 \\ \text { Seat } & 2 & 6668.10 & 6837.40 & 3418.70 & 128.14 & 0.000 \\ \text { Task } & 1 & 271.96 & 202.73 & 202.73 & 7.60 & 0.007 \\ \text { Seat*Task } & 2 & 527.07 & 527.07 & 263.54 & 9.88 & 0.000 \\ \text { Error } & 132 & 3521.68 & 3521.68 & 26.68 & & \\ \text { Total } & 146 & 12906.74 & & & & \end{array}$ \\ $S=5.16521 \quad R-S q=72.71 \% \quad R-S q(\operatorname{adj})=69.82 \%$ \\ Analysis of Variance for $\mathrm{LHZ}+$, using Adjusted SS for Tests

$\begin{array}{lrrrrrr}\text { Source } & \text { DF } & \text { Seq SS } & \text { Adj SS } & \text { Adj MS } & \text { F } & \text { P } \\ \text { Subj } & 9 & 34680.6 & 34590.9 & 3843.4 & 148.90 & 0.000 \\ \text { Seat } & 2 & 51.5 & 49.3 & 24.6 & 0.95 & 0.388 \\ \text { Task } & 1 & 14.9 & 17.9 & 17.9 & 0.69 & 0.406 \\ \text { Seat*Task } & 2 & 47.0 & 47.0 & 23.5 & 0.91 & 0.405 \\ \text { Error } & 132 & 3407.3 & 3407.3 & 25.8 & & \\ \text { Total } & 146 & 38201.3 & & & & \end{array}$ \\ $S=5.08064 \quad R-S q=91.08 \% \quad R-S q(\operatorname{adj})=90.13 \%$ \\ Analysis of Variance for LHZ-, using Adjusted SS for Tests

$\begin{array}{lrrrrrr}\text { Source } & \text { DF } & \text { Seq SS } & \text { Adj SS } & \text { Adj MS } & \text { F } & \text { P } \\ \text { Subj } & 9 & 29874.5 & 28705.6 & 3189.5 & 120.14 & 0.000 \\ \text { Seat } & 2 & 2900.0 & 2861.2 & 1430.6 & 53.89 & 0.000 \\ \text { Task } & 1 & 19.2 & 13.7 & 13.7 & 0.51 & 0.474 \\ \text { Seat*Task } & 2 & 67.3 & 67.3 & 33.6 & 1.27 & 0.285 \\ \text { Error } & 132 & 3504.4 & 3504.4 & 26.5 & & \\ \text { Total } & 146 & 36365.4 & & & & \end{array}$ \\ $S=5.15254 \quad R-S q=90.36 \% \quad R-S q(\operatorname{adj})=89.34 \%$
}


Analysis of Variance for LHZR, using Adjusted SS for Tests

$\begin{array}{lrrrrrr}\text { Source } & \text { DF } & \text { Seq SS } & \text { Adj SS } & \text { Adj MS } & F & P \\ \text { Subj } & 9 & 7120.89 & 7746.89 & 860.77 & 25.36 & 0.000 \\ \text { Seat } & 2 & 3699.86 & 3639.61 & 1819.80 & 53.62 & 0.000 \\ \text { Task } & 1 & 0.27 & 0.29 & 0.29 & 0.01 & 0.927 \\ \text { Seat*Task } & 2 & 219.68 & 219.68 & 109.84 & 3.24 & 0.042 \\ \text { Error } & 132 & 4480.31 & 4480.31 & 33.94 & & \\ \text { Total } & 146 & 15521.01 & & & & \end{array}$

$S=5.82595 \quad R-S q=71.13 \% \quad R-S q(\operatorname{adj})=68.07 \%$

Analysis of Variance for LKX+, using Adjusted SS for Tests

$\begin{array}{lrrrrrr}\text { Source } & \text { DF } & \text { Seq SS } & \text { Adj SS } & \text { Adj MS } & \text { F } & \text { P } \\ \text { Subj } & 9 & 10638.9 & 10174.2 & 1130.5 & 13.81 & 0.000 \\ \text { Seat } & 2 & 20179.1 & 19368.5 & 9684.3 & 118.33 & 0.000 \\ \text { Task } & 1 & 5705.7 & 5148.9 & 5148.9 & 62.91 & 0.000 \\ \text { Seat*Task } & 2 & 2039.8 & 2039.8 & 1019.9 & 12.46 & 0.000 \\ \text { Error } & 132 & 10803.1 & 10803.1 & 81.8 & & \\ \text { Total } & 146 & 49366.8 & & & & \end{array}$

$S=9.04666 \quad R-S q=78.12 \% \quad R-S q(\operatorname{adj})=75.80 \%$

Analysis of Variance for LKZ+, using Adjusted SS for Tests

$\begin{array}{lrrrrrr}\text { Source } & \text { DF } & \text { Seq SS } & \text { Adj SS } & \text { Adj MS } & F & \text { P } \\ \text { Subj } & 9 & 12619.0 & 13006.0 & 1445.1 & 38.91 & 0.000 \\ \text { Seat } & 2 & 6434.4 & 6461.9 & 3231.0 & 87.00 & 0.000 \\ \text { Task } & 1 & 157.7 & 161.2 & 161.2 & 4.34 & 0.039 \\ \text { Seat*Task } & 2 & 56.5 & 56.5 & 28.2 & 0.76 & 0.469 \\ \text { Error } & 132 & 4902.2 & 4902.2 & 37.1 & & \\ \text { Total } & 146 & 24169.8 & & & & \end{array}$

$S=6.09409 \quad R-S q=79.72 \% \quad R-S q(\operatorname{adj})=77.57 \%$

Analysis of Variance for LKZ-, using Adjusted SS for Tests

$\begin{array}{lrrrrrr}\text { Source } & \text { DF } & \text { Seq SS } & \text { Adj SS } & \text { Adj MS } & F & \text { P } \\ \text { Subj } & 9 & 12713.2 & 12633.1 & 1403.7 & 21.16 & 0.000 \\ \text { Seat } & 2 & 2683.1 & 2693.1 & 1346.5 & 20.30 & 0.000 \\ \text { Task } & 1 & 220.2 & 220.5 & 220.5 & 3.32 & 0.071 \\ \text { Seat*Task } & 2 & 60.7 & 60.7 & 30.4 & 0.46 & 0.634 \\ \text { Error } & 132 & 8755.7 & 8755.7 & 66.3 & & \\ \text { Total } & 146 & 24432.9 & & & & \end{array}$

$S=8.14438 \quad R-S q=64.16 \% \quad R-S q(\operatorname{adj})=60.36 \%$

Analysis of Variance for LKZR, using Adjusted SS for Tests

$\begin{array}{lrrrrrr}\text { Source } & \text { DF } & \text { Seq SS } & \text { Adj SS } & \text { Adj MS } & F & \text { P } \\ \text { Subj } & 9 & 15945.8 & 16571.4 & 1841.3 & 21.89 & 0.000 \\ \text { Seat } & 2 & 17066.7 & 17119.6 & 8559.8 & 101.77 & 0.000 \\ \text { Task } & 1 & 750.5 & 758.7 & 758.7 & 9.02 & 0.003 \\ \text { Seat*Task } & 2 & 8.5 & 8.5 & 4.3 & 0.05 & 0.951 \\ \text { Error } & 132 & 11103.0 & 11103.0 & 84.1 & & \\ \text { Total } & 146 & 44874.5 & & & & \end{array}$

$S=9.17133 \quad R-S q=75.26 \% \quad R-S q(\operatorname{adj})=72.63 \%$ 
Analysis of Variance for LSX+, using Adjusted SS for Tests

$\begin{array}{lrrrrrr}\text { Source } & \text { DF } & \text { Seq SS } & \text { Adj SS } & \text { Adj MS } & \text { F } & \text { P } \\ \text { Subj } & 9 & 14375.2 & 16299.2 & 1811.0 & 13.73 & 0.000 \\ \text { Seat } & 2 & 8772.3 & 8831.5 & 4415.8 & 33.48 & 0.000 \\ \text { Task } & 1 & 74.5 & 68.2 & 68.2 & 0.52 & 0.473 \\ \text { Seat*Task } & 2 & 269.9 & 269.9 & 135.0 & 1.02 & 0.362 \\ \text { Error } & 132 & 17409.0 & 17409.0 & 131.9 & & \\ \text { Total } & 146 & 40900.8 & & & & \end{array}$

$S=11.4842 \quad R-S q=57.44 \% \quad R-S q(\operatorname{adj})=52.92 \%$

Analysis of Variance for LSX-, using Adjusted SS for Tests

$\begin{array}{lrrrrrr}\text { Source } & \text { DF } & \text { Seq SS } & \text { Adj SS } & \text { Adj MS } & F & \text { P } \\ \text { Subj } & 9 & 11169.4 & 4325.8 & 480.6 & 8.86 & 0.000 \\ \text { Seat } & 2 & 43381.9 & 43932.7 & 21966.4 & 405.13 & 0.000 \\ \text { Task } & 1 & 1426.8 & 1240.7 & 1240.7 & 22.88 & 0.000 \\ \text { Seat*Task } & 2 & 707.4 & 707.4 & 353.7 & 6.52 & 0.002 \\ \text { Error } & 132 & 7157.2 & 7157.2 & 54.2 & & \\ \text { Total } & 146 & 63842.6 & & & & \end{array}$

$S=7.36350 \quad R-S q=88.79 \% \quad R-S q(\operatorname{adj})=87.60 \%$

Analysis of Variance for LSXR, using Adjusted SS for Tests

$\begin{array}{lrrrrrr}\text { Source } & \text { DF } & \text { Seq SS } & \text { Adj SS } & \text { Adj MS } & \text { F } & \text { P } \\ \text { Subj } & 9 & 17539.2 & 15055.7 & 1672.9 & 10.04 & 0.000 \\ \text { Seat } & 2 & 91167.7 & 92155.4 & 46077.7 & 276.53 & 0.000 \\ \text { Task } & 1 & 2153.1 & 1890.9 & 1890.9 & 11.35 & 0.001 \\ \text { Seat*Task } & 2 & 1459.8 & 1459.8 & 729.9 & 4.38 & 0.014 \\ \text { Error } & 132 & 21995.0 & 21995.0 & 166.6 & & \\ \text { Total } & 146 & 134314.8 & & & & \end{array}$

$S=12.9085 \quad R-S q=83.62 \% \quad R-S q(\operatorname{adj})=81.89 \%$

Analysis of Variance for LSY+, using Adjusted SS for Tests

\begin{tabular}{|c|c|c|c|c|c|c|}
\hline Source & DF & Seq SS & Adj SS & Adj MS & $\mathrm{F}$ & $\mathrm{P}$ \\
\hline Subj & 9 & 5823.5 & 3087.3 & 343.0 & 5.03 & 0.000 \\
\hline Seat & 2 & 21968.7 & 22612.7 & 11306.4 & 165.65 & 0.000 \\
\hline Task & 1 & 3821.5 & 3395.3 & 3395.3 & 49.74 & 0.000 \\
\hline Seat*Task & 2 & 1332.5 & 1332.5 & 666.3 & 9.76 & 0.000 \\
\hline Error & 132 & 9009.6 & 9009.6 & 68.3 & & \\
\hline Total & 146 & 41955.9 & & & & \\
\hline$S=8.2616$ & & $-S q=78.5$ & $\mathrm{R}-\mathrm{Sq}$ & $\eta(\operatorname{adj})=7$ & $76.25 \%$ & \\
\hline nalysis o & $f$ Var & ince for & LSY-, us: & ng Adjust & ted SS fo & or Tests \\
\hline Source & DF & Seq SS & Adj SS & Adj MS & $F$ & $\mathrm{P}$ \\
\hline Subj & 9 & 2176.93 & 3262.78 & 362.53 & 13.33 & 0.000 \\
\hline Seat & 2 & 9693.36 & 9849.64 & 4924.82 & 181.03 & 0.000 \\
\hline Task & 1 & 661.62 & 594.23 & 594.23 & 21.84 & 0.000 \\
\hline Seat*Task & 2 & 217.38 & 217.38 & 108.69 & 4.00 & 0.021 \\
\hline Error & 132 & 3591.00 & 3591.00 & 27.20 & & \\
\hline Total & 146 & 16340.29 & & & & \\
\hline
\end{tabular}


Analysis of Variance for LSYR, using Adjusted SS for Tests

$\begin{array}{lrrrrrr}\text { Source } & \text { DF } & \text { Seq SS } & \text { Adj SS } & \text { Adj MS } & \text { F } & \text { P } \\ \text { Subj } & 9 & 4239.7 & 2853.8 & 317.1 & 3.50 & 0.001 \\ \text { Seat } & 2 & 60799.6 & 62254.6 & 31127.3 & 343.12 & 0.000 \\ \text { Task } & 1 & 7663.3 & 6830.4 & 6830.4 & 75.29 & 0.000 \\ \text { Seat*Task } & 2 & 2614.2 & 2614.2 & 1307.1 & 14.41 & 0.000 \\ \text { Error } & 132 & 11974.8 & 11974.8 & 90.7 & & \\ \text { Total } & 146 & 87291.6 & & & & \end{array}$

$S=9.52462 \quad R-S q=86.28 \% \quad R-S q(\operatorname{adj})=84.83 \%$

Analysis of Variance for LSZ+, using Adjusted SS for Tests

$\begin{array}{lrrrrrr}\text { Source } & \text { DF } & \text { Seq SS } & \text { Adj SS } & \text { Adj MS } & \text { F } & \text { P } \\ \text { Subj } & 9 & 74898 & 53989 & 5999 & 46.11 & 0.000 \\ \text { Seat } & 2 & 58423 & 59965 & 29982 & 230.45 & 0.000 \\ \text { Task } & 1 & 7863 & 6857 & 6857 & 52.71 & 0.000 \\ \text { Seat*Task } & 2 & 3729 & 3729 & 1865 & 14.33 & 0.000 \\ \text { Error } & 132 & 17174 & 17174 & 130 & & \\ \text { Total } & 146 & 162086 & & & & \end{array}$

$S=11.4063 \quad R-S q=89.40 \% \quad R-S q(\operatorname{adj})=88.28 \%$

Analysis of Variance for LSZ-, using Adjusted SS for Tests

$\begin{array}{lrrrrrr}\text { Source } & \text { DF } & \text { Seq SS } & \text { Adj SS } & \text { Adj MS } & \text { F } & \text { P } \\ \text { Subj } & 9 & 62715.4 & 63085.6 & 7009.5 & 128.31 & 0.000 \\ \text { Seat } & 2 & 673.7 & 638.7 & 319.3 & 5.85 & 0.004 \\ \text { Task } & 1 & 24.7 & 11.2 & 11.2 & 0.20 & 0.652 \\ \text { Seat*Task } & 2 & 282.9 & 282.9 & 141.4 & 2.59 & 0.079 \\ \text { Error } & 132 & 7211.0 & 7211.0 & 54.6 & & \\ \text { Total } & 146 & 70907.7 & & & & \end{array}$

$S=7.39114 \quad R-S q=89.83 \% \quad R-S q(\operatorname{adj})=88.75 \%$

Analysis of Variance for LSZR, using Adjusted SS for Tests

$\begin{array}{lrrrrrr}\text { Source } & \text { DF } & \text { Seq SS } & \text { Adj SS } & \text { Adj MS } & F & \text { P } \\ \text { Subj } & 9 & 22396.6 & 10682.2 & 1186.9 & 6.41 & 0.000 \\ \text { Seat } & 2 & 70908.5 & 72306.7 & 36153.3 & 195.38 & 0.000 \\ \text { Task } & 1 & 7005.9 & 6315.3 & 6315.3 & 34.13 & 0.000 \\ \text { Seat*Task } & 2 & 2038.9 & 2038.9 & 1019.4 & 5.51 & 0.005 \\ \text { Error } & 132 & 24424.9 & 24424.9 & 185.0 & & \\ \text { Total } & 146 & 126774.7 & & & & \end{array}$

$S=13.6028 \quad R-S q=80.73 \% \quad R-S q(\operatorname{adj})=78.69 \%$

Analysis of Variance for RHX+, using Adjusted SS for Tests

$\begin{array}{lrrrrrr}\text { Source } & \text { DF } & \text { Seq SS } & \text { Adj SS } & \text { Adj MS } & \text { F } & \text { P } \\ \text { Subj } & 9 & 23395.8 & 23973.1 & 2663.7 & 34.17 & 0.000 \\ \text { Seat } & 2 & 4946.4 & 4892.6 & 2446.3 & 31.38 & 0.000 \\ \text { Task } & 1 & 35.6 & 52.2 & 52.2 & 0.67 & 0.415 \\ \text { Seat*Task } & 2 & 181.5 & 181.5 & 90.8 & 1.16 & 0.315 \\ \text { Error } & 132 & 10289.2 & 10289.2 & 77.9 & & \\ \text { Total } & 146 & 38848.6 & & & & \end{array}$

$S=8.82883 \quad R-S q=73.51 \% \quad R-S q(\operatorname{adj})=70.71 \%$ 
Analysis of Variance for RHY-, using Adjusted SS for Tests

$\begin{array}{lrrrrrr}\text { Source } & \text { DF } & \text { Seq SS } & \text { Adj SS } & \text { Adj MS } & \text { F } & \text { P } \\ \text { Subj } & 9 & 8008.73 & 7698.42 & 855.38 & 22.45 & 0.000 \\ \text { Seat } & 2 & 167.79 & 140.55 & 70.27 & 1.84 & 0.162 \\ \text { Task } & 1 & 938.66 & 890.32 & 890.32 & 23.37 & 0.000 \\ \text { Seat*Task } & 2 & 47.25 & 47.25 & 23.62 & 0.62 & 0.539 \\ \text { Error } & 132 & 5029.10 & 5029.10 & 38.10 & & \\ \text { Total } & 146 & 14191.54 & & & & \end{array}$

$S=6.17246 \quad R-S q=64.56 \% \quad R-S q(\operatorname{adj})=60.80 \%$

Analysis of Variance for RHZ+, using Adjusted SS for Tests

$\begin{array}{lrrrrrr}\text { Source } & \text { DF } & \text { Seq SS } & \text { Adj SS } & \text { Adj MS } & F & \text { P } \\ \text { Subj } & 9 & 8694.93 & 8295.00 & 921.67 & 34.51 & 0.000 \\ \text { Seat } & 2 & 294.08 & 287.31 & 143.66 & 5.38 & 0.006 \\ \text { Task } & 1 & 55.36 & 51.05 & 51.05 & 1.91 & 0.169 \\ \text { Seat*Task } & 2 & 8.58 & 8.58 & 4.29 & 0.16 & 0.852 \\ \text { Error } & 132 & 3525.79 & 3525.79 & 26.71 & & \\ \text { Total } & 146 & 12578.74 & & & & \end{array}$

$S=5.16823 \quad R-S q=71.97 \% \quad R-S q(\operatorname{adj})=69.00 \%$

Analysis of Variance for RHZ-, using Adjusted SS for Tests

$\begin{array}{lrrrrrr}\text { Source } & \text { DF } & \text { Seq SS } & \text { Adj SS } & \text { Adj MS } & F & P \\ \text { Subj } & 9 & 12820.27 & 12871.97 & 1430.22 & 60.19 & 0.000 \\ \text { Seat } & 2 & 62.35 & 62.37 & 31.19 & 1.31 & 0.273 \\ \text { Task } & 1 & 212.07 & 206.28 & 206.28 & 8.68 & 0.004 \\ \text { Seat*Task } & 2 & 5.13 & 5.13 & 2.57 & 0.11 & 0.898 \\ \text { Error } & 132 & 3136.46 & 3136.46 & 23.76 & & \\ \text { Total } & 146 & 16236.28 & & & & \\ \text { S }=4.87453 & \text { R-Sq }=80.68 \% & R-S q(\text { adj })=78.63 \% & \end{array}$

Analysis of Variance for RHZR, using Adjusted SS for Tests

$\begin{array}{lrrrrrr}\text { Source } & \text { DF } & \text { Seq SS } & \text { Adj SS } & \text { Adj MS } & \text { F } & \text { P } \\ \text { Subj } & 9 & 1998.57 & 1980.28 & 220.03 & 5.19 & 0.000 \\ \text { Seat } & 2 & 591.08 & 591.46 & 295.73 & 6.97 & 0.001 \\ \text { Task } & 1 & 50.73 & 52.09 & 52.09 & 1.23 & 0.270 \\ \text { Seat*Task } & 2 & 10.05 & 10.05 & 5.02 & 0.12 & 0.888 \\ \text { Error } & 132 & 5597.20 & 5597.20 & 42.40 & & \\ \text { Total } & 146 & 8247.62 & & & & \end{array}$

$S=6.51176 \quad R-S q=32.14 \% \quad R-S q(\operatorname{adj})=24.94 \%$

Analysis of Variance for RKX+, using Adjusted SS for Tests

$\begin{array}{lrrrrrr}\text { Source } & \text { DF } & \text { Seq SS } & \text { Adj SS } & \text { Adj MS } & \text { F } & \text { P } \\ \text { Subj } & 9 & 18231.0 & 18080.8 & 2009.0 & 23.22 & 0.000 \\ \text { Seat } & 2 & 2330.8 & 2319.3 & 1159.7 & 13.40 & 0.000 \\ \text { Task } & 1 & 75.1 & 65.5 & 65.5 & 0.76 & 0.386 \\ \text { Seat*Task } & 2 & 32.5 & 32.5 & 16.2 & 0.19 & 0.829 \\ \text { Error } & 132 & 11419.9 & 11419.9 & 86.5 & & \\ \text { Total } & 146 & 32089.4 & & & & \end{array}$

$S=9.30132 \quad R-S q=64.41 \% \quad R-S q(\operatorname{adj})=60.64 \%$ 
Analysis of Variance for RKZ+, using Adjusted SS for Tests

$\begin{array}{lrrrrrr}\text { Source } & \text { DF } & \text { Seq SS } & \text { Adj SS } & \text { Adj MS } & F & P \\ \text { Subj } & 9 & 11385.02 & 11117.59 & 1235.29 & 24.56 & 0.000 \\ \text { Seat } & 2 & 1370.45 & 1361.62 & 680.81 & 13.54 & 0.000 \\ \text { Task } & 1 & 84.91 & 87.65 & 87.65 & 1.74 & 0.189 \\ \text { Seat*Task } & 2 & 61.57 & 61.57 & 30.79 & 0.61 & 0.544 \\ \text { Error } & 132 & 6638.24 & 6638.24 & 50.29 & & \\ \text { Total } & 146 & 19540.20 & & & & \\ \text { S 7.09153 } & \text { R-Sq }=66.03 \% & \text { R-Sq(adj) }=62.42 \% & \\ \text { Analysis of } & \text { Variance for } & \text { RKZ-, using Adjusted SS for Tests } \\ \text { Source } & \text { DF } & \text { Seq SS } & \text { Adj SS } & \text { Adj MS } & \text { F } & \text { P } \\ \text { Subj } & 9 & 5393.53 & 5367.18 & 596.35 & 15.38 & 0.000 \\ \text { Seat } & 2 & 3795.24 & 3777.01 & 1888.51 & 48.70 & 0.000 \\ \text { Task } & 1 & 28.88 & 31.67 & 31.67 & 0.82 & 0.368 \\ \text { Seat*Task } & 2 & 59.55 & 59.55 & 29.77 & 0.77 & 0.466 \\ \text { Error } & 132 & 5118.93 & 5118.93 & 38.78 & & \\ \text { Total } & 146 & 14396.12 & & & & \end{array}$

$S=6.22734 \quad R-S q=64.44 \% \quad R-S q(\operatorname{adj})=60.67 \%$

Analysis of Variance for RKZR, using Adjusted SS for Tests

$\begin{array}{lrrrrrr}\text { Source } & \text { DF } & \text { Seq SS } & \text { Adj SS } & \text { Adj MS } & \text { F } & \text { P } \\ \text { Subj } & 9 & 9373.6 & 8410.7 & 934.5 & 11.51 & 0.000 \\ \text { Seat } & 2 & 9046.4 & 9043.7 & 4521.9 & 55.69 & 0.000 \\ \text { Task } & 1 & 212.8 & 224.7 & 224.7 & 2.77 & 0.099 \\ \text { Seat*Task } & 2 & 24.1 & 24.1 & 12.0 & 0.15 & 0.862 \\ \text { Error } & 132 & 10718.5 & 10718.5 & 81.2 & & \\ \text { Total } & 146 & 29375.4 & & & & \end{array}$

$S=9.01116 \quad R-S q=63.51 \% \quad R-S q(\operatorname{adj})=59.64 \%$

Analysis of Variance for RSX+, using Adjusted SS for Tests

$\begin{array}{lrrrrrr}\text { Source } & \text { DF } & \text { Seq SS } & \text { Adj SS } & \text { Adj MS } & \text { F } & \text { P } \\ \text { Subj } & 9 & 33633.0 & 23196.2 & 2577.4 & 15.82 & 0.000 \\ \text { Seat } & 2 & 36036.1 & 35095.6 & 17547.8 & 107.72 & 0.000 \\ \text { Task } & 1 & 4223.1 & 3775.8 & 3775.8 & 23.18 & 0.000 \\ \text { Seat*Task } & 2 & 1406.7 & 1406.7 & 703.4 & 4.32 & 0.015 \\ \text { Error } & 132 & 21503.3 & 21503.3 & 162.9 & & \\ \text { Total } & 146 & 96802.2 & & & & \\ & & & & & \\ \text { S = 12.7634 } & \text { R-Sq }=77.79 \% & \text { R-Sq(adj) }=75.43 \% & \\ \text { Analysis of } & \text { Variance for } & \text { RSX-, using Adjusted SS for Tests } \\ \text { Source } & \text { DF } & \text { Seq SS } & \text { Adj SS } & \text { Adj MS } & \text { F } & \text { P } \\ \text { Subj } & 9 & 20381.8 & 13349.7 & 1483.3 & 11.91 & 0.000 \\ \text { Seat } & 2 & 36108.1 & 35513.5 & 17756.7 & 142.63 & 0.000 \\ \text { Task } & 1 & 670.9 & 588.5 & 588.5 & 4.73 & 0.031 \\ \text { Seat*Task } & 2 & 1022.3 & 1022.3 & 511.1 & 4.11 & 0.019 \\ \text { Error } & 132 & 16433.9 & 16433.9 & 124.5 & & \\ \text { Total } & 146 & 74617.0 & & & & \end{array}$


Analysis of Variance for RSXR, using Adjusted SS for Tests

$\begin{array}{lrrrrrr}\text { Source } & \text { DF } & \text { Seq SS } & \text { Adj SS } & \text { Adj MS } & \text { F } & \text { P } \\ \text { Subj } & 9 & 68096 & 33489 & 3721 & 13.01 & 0.000 \\ \text { Seat } & 2 & 143954 & 140869 & 70435 & 246.30 & 0.000 \\ \text { Task } & 1 & 8261 & 7346 & 7346 & 25.69 & 0.000 \\ \text { Seat*Task } & 2 & 4408 & 4408 & 2204 & 7.71 & 0.001 \\ \text { Error } & 132 & 37748 & 37748 & 286 & & \\ \text { Total } & 146 & 262467 & & & & \\ & & & & & \\ \text { S }=16.9106 & \text { R-Sq }=85.62 \% & \text { R-Sq(adj) }=84.09 \%\end{array}$

Analysis of Variance for RSY+, using Adjusted SS for Tests

$\begin{array}{lrrrrrr}\text { Source } & \text { DF } & \text { Seq SS } & \text { Adj SS } & \text { Adj MS } & \text { F } & \text { P } \\ \text { Subj } & 9 & 3374.55 & 4762.43 & 529.16 & 11.86 & 0.000 \\ \text { Seat } & 2 & 8405.42 & 8262.07 & 4131.04 & 92.59 & 0.000 \\ \text { Task } & 1 & 281.40 & 236.74 & 236.74 & 5.31 & 0.023 \\ \text { Seat*Task } & 2 & 189.61 & 189.61 & 94.81 & 2.12 & 0.124 \\ \text { Error } & 132 & 5889.38 & 5889.38 & 44.62 & & \\ \text { Total } & 146 & 18140.36 & & & & \end{array}$

$S=6.67956 \quad R-S q=67.53 \% \quad R-S q(\operatorname{adj})=64.09 \%$

Analysis of Variance for RSY-, using Adjusted SS for Tests

$\begin{array}{lrrrrrr}\text { Source } & \text { DF } & \text { Seq SS } & \text { Adj SS } & \text { Adj MS } & \text { F } & \text { P } \\ \text { Subj } & 9 & 13113.9 & 5428.3 & 603.1 & 13.18 & 0.000 \\ \text { Seat } & 2 & 26941.2 & 26611.8 & 13305.9 & 290.67 & 0.000 \\ \text { Task } & 1 & 487.9 & 441.4 & 441.4 & 9.64 & 0.002 \\ \text { Seat*Task } & 2 & 278.7 & 278.7 & 139.3 & 3.04 & 0.051 \\ \text { Error } & 132 & 6042.5 & 6042.5 & 45.8 & & \\ \text { Total } & 146 & 46864.1 & & & & \end{array}$

$S=6.76581 \quad R-S q=87.11 \% \quad R-S q(\operatorname{adj})=85.74 \%$

Analysis of Variance for RSYR, using Adjusted SS for Tests

$\begin{array}{lrrrrrr}\text { Source } & \text { DF } & \text { Seq SS } & \text { Adj SS } & \text { Adj MS } & F & P \\ \text { Subj } & 9 & 10942.6 & 4207.3 & 467.5 & 5.40 & 0.000 \\ \text { Seat } & 2 & 65440.7 & 64528.4 & 32264.2 & 372.40 & 0.000 \\ \text { Task } & 1 & 1510.3 & 1324.7 & 1324.7 & 15.29 & 0.000 \\ \text { Seat*Task } & 2 & 702.4 & 702.4 & 351.2 & 4.05 & 0.020 \\ \text { Error } & 132 & 11436.4 & 11436.4 & 86.6 & & \\ \text { Total } & 146 & 90032.2 & & & & \end{array}$

$S=9.30801 \quad R-S q=87.30 \% \quad R-S q(\operatorname{adj})=85.95 \%$

Analysis of Variance for RSZ+, using Adjusted SS for Tests

$\begin{array}{lrrrrrr}\text { Source } & \text { DF } & \text { Seq SS } & \text { Adj SS } & \text { Adj MS } & \text { F } & \text { P } \\ \text { Subj } & 9 & 30610.1 & 27440.3 & 3048.9 & 24.24 & 0.000 \\ \text { Seat } & 2 & 10001.6 & 9599.6 & 4799.8 & 38.16 & 0.000 \\ \text { Task } & 1 & 2374.1 & 2041.9 & 2041.9 & 16.23 & 0.000 \\ \text { Seat*Task } & 2 & 1565.2 & 1565.2 & 782.6 & 6.22 & 0.003 \\ \text { Error } & 132 & 16602.6 & 16602.6 & 125.8 & & \\ \text { Total } & 146 & 61153.6 & & & & \end{array}$

$S=11.2151 \quad R-S q=72.85 \% \quad R-S q(\operatorname{adj})=69.97 \%$ 
Analysis of Variance for RSZ-, using Adjusted SS for Tests

$\begin{array}{lrrrrrr}\text { Source } & \text { DF } & \text { Seq SS } & \text { Adj SS } & \text { Adj MS } & \text { F } & \text { P } \\ \text { Subj } & 9 & 57761.3 & 40415.5 & 4490.6 & 21.78 & 0.000 \\ \text { Seat } & 2 & 40648.6 & 39739.1 & 19869.5 & 96.38 & 0.000 \\ \text { Task } & 1 & 2345.8 & 2201.1 & 2201.1 & 10.68 & 0.001 \\ \text { Seat*Task } & 2 & 2078.5 & 2078.5 & 1039.2 & 5.04 & 0.008 \\ \text { Error } & 132 & 27212.3 & 27212.3 & 206.2 & & \\ \text { Total } & 146 & 130046.4 & & & & \\ \text { S }=14.3581 & \text { R-Sq }=79.07 \% & \text { R-Sq(adj) }=76.86 \% & \end{array}$

Analysis of Variance for RSZR, using Adjusted SS for Tests

$\begin{array}{lrrrrrr}\text { Source } & \text { DF } & \text { Seq SS } & \text { Adj SS } & \text { Adj MS } & \text { F } & \text { P } \\ \text { Subj } & 9 & 72805 & 37808 & 4201 & 13.42 & 0.000 \\ \text { Seat } & 2 & 90100 & 87493 & 43746 & 139.75 & 0.000 \\ \text { Task } & 1 & 9440 & 8483 & 8483 & 27.10 & 0.000 \\ \text { Seat*Task } & 2 & 6258 & 6258 & 3129 & 9.99 & 0.000 \\ \text { Error } & 132 & 41322 & 41322 & 313 & & \\ \text { Total } & 146 & 219924 & & & & \end{array}$

$S=17.6930 \quad R-S q=81.21 \% \quad R-S q(\operatorname{adj})=79.22 \%$

Analysis of Variance for TX+, using Adjusted SS for Tests

$\begin{array}{lrrrrrr}\text { Source } & \text { DF } & \text { Seq SS } & \text { Adj SS } & \text { Adj MS } & \text { F } & \text { P } \\ \text { Subj } & 9 & 27210.1 & 27408.1 & 3045.3 & 70.81 & 0.000 \\ \text { Seat } & 2 & 14862.4 & 14838.5 & 7419.2 & 172.52 & 0.000 \\ \text { Task } & 1 & 44.7 & 46.5 & 46.5 & 1.08 & 0.300 \\ \text { Seat*Task } & 2 & 11.3 & 11.3 & 5.6 & 0.13 & 0.877 \\ \text { Error } & 132 & 5676.7 & 5676.7 & 43.0 & & \\ \text { Total } & 146 & 47805.1 & & & & \end{array}$

$S=6.55782 \quad R-S q=88.13 \% \quad R-S q(\operatorname{adj})=86.87 \%$

Analysis of Variance for TY+, using Adjusted SS for Tests

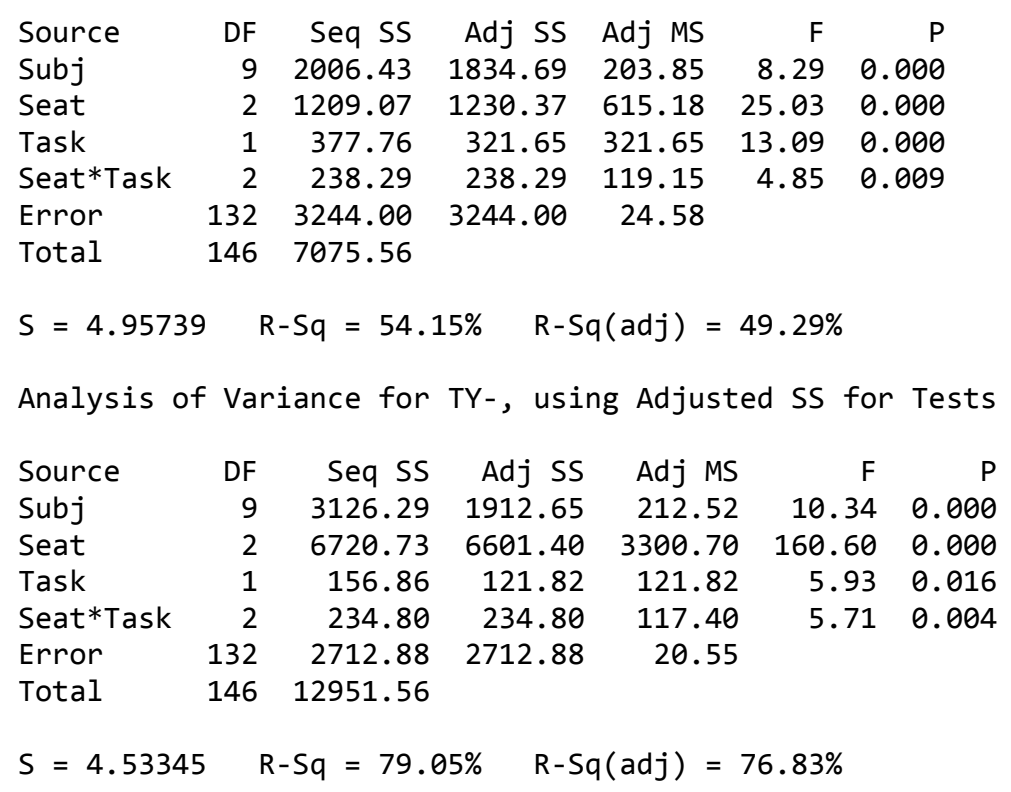




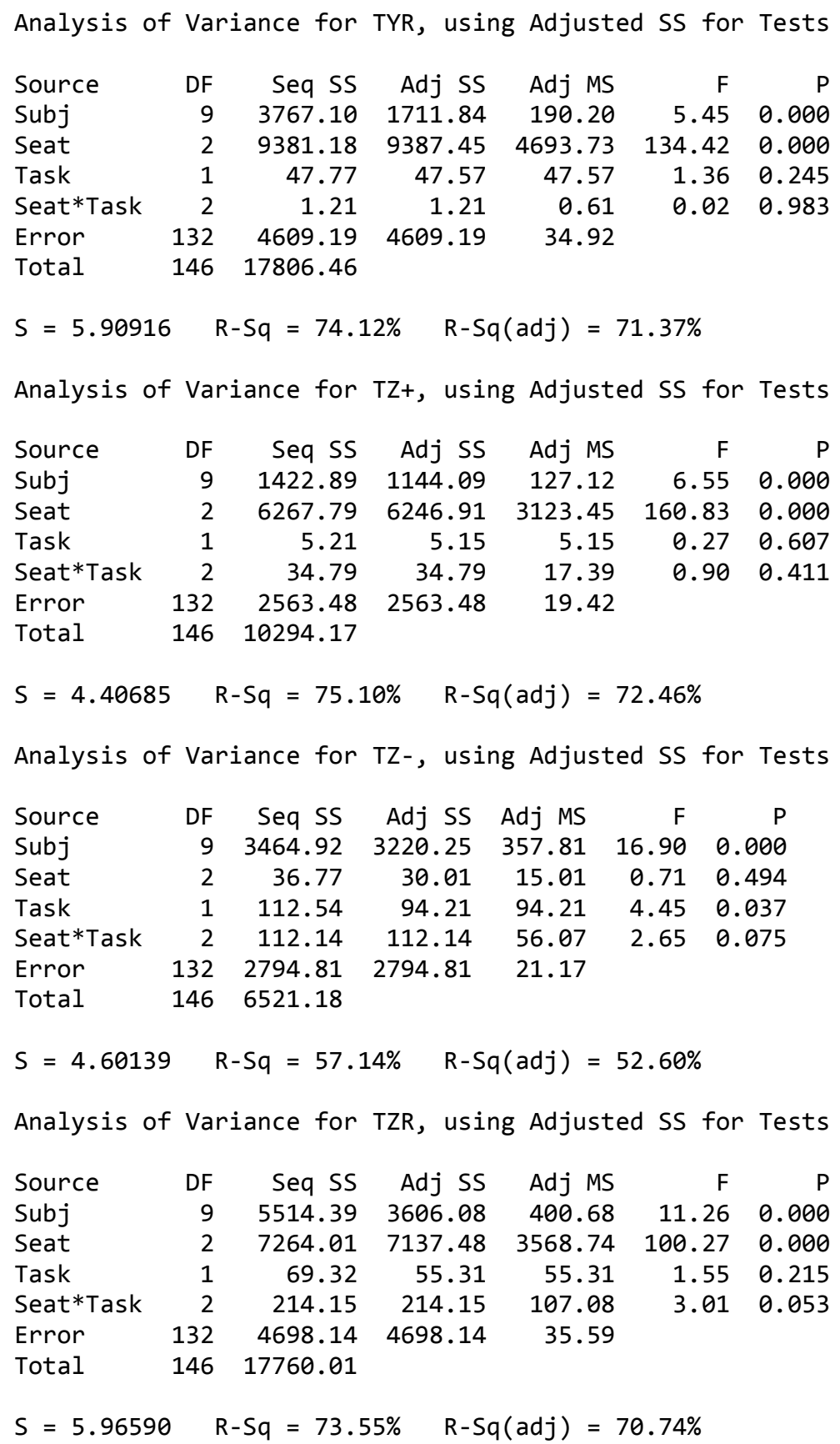


Grouping Information Using Tukey Method and 95.0\% Confidence for LHX+

$\begin{array}{lrrc}\text { Seat } & \text { N } & \text { Mean } & \text { Grouping } \\ \text { H90 } & 55 & 67.66 & \text { A } \\ \text { V } & 43 & 63.71 & \text { B } \\ \text { H120 } & 49 & 60.06 & \text { B }\end{array}$

Grouping Information Using Tukey Method and 95.0\% Confidence for LHX+

$\begin{array}{lrrl}\text { Task } & \mathrm{N} & \text { Mean } & \text { Grouping } \\ \mathrm{E} & 71 & 63.88 & \mathrm{~A} \\ \mathrm{I} & 76 & 63.74 & \mathrm{~A}\end{array}$

Grouping Information Using Tukey Method and 95.0\% Confidence for LHX+

$\begin{array}{llrrl}\text { Seat } & \text { Task } & \text { N } & \text { Mean } & \text { Grouping } \\ \text { H90 } & \text { E } & 27 & 68.13 & \text { A } \\ \text { H90 } & \text { I } & 28 & 67.19 & \text { A } \\ \text { V } & \text { E } & 21 & 65.66 & \text { A } \\ \text { H120 } & \text { I } & 26 & 62.27 & \text { A B } \\ \text { V } & \text { I } & 22 & 61.77 & \text { A B } \\ \text { H120 } & \text { E } & 23 & 57.85 & \text { B }\end{array}$

Grouping Information Using Tukey Method and 95.0\% Confidence for LHY+

\begin{tabular}{lrrrr} 
Seat & N & Mean & Grouping \\
H120 & 49 & 40.63 & A & \\
H90 & 55 & 39.65 & A & \\
V & 43 & 24.51 & \multicolumn{2}{c}{ B }
\end{tabular}

Grouping Information Using Tukey Method and 95.0\% Confidence for LHY+

$\begin{array}{lrrr}\text { Task } & \text { N } & \text { Mean } & \text { Grouping } \\ \text { E } & 71 & 36.12 & \text { A } \\ \text { I } & 76 & 33.75 & \text { B }\end{array}$

Grouping Information Using Tukey Method and 95.0\% Confidence for LHY+

\begin{tabular}{llrrrr} 
Seat & Task & N & Mean & Grouping \\
H90 & E & 27 & 42.90 & A & \\
H120 & E & 23 & 42.33 & A & \\
H120 & I & 26 & 38.93 & A B & \\
H90 & I & 28 & 36.40 & \multicolumn{2}{c}{ B } \\
V & I & 22 & 25.91 & & C \\
V & E & 21 & 23.12 & & C
\end{tabular}

Grouping Information Using Tukey Method and 95.0\% Confidence for LHZ+

$\begin{array}{lrrl}\text { Seat } & \text { N } & \text { Mean } & \text { Grouping } \\ \text { H120 } & 49 & 21.50 & \text { A } \\ \text { H90 } & 55 & 21.32 & \text { A } \\ \text { V } & 43 & 20.09 & \text { A }\end{array}$

Grouping Information Using Tukey Method and 95.0\% Confidence for $\mathrm{LHZ+}$

$\begin{array}{lrrl}\text { Task } & \text { N } & \text { Mean } & \text { Grouping } \\ \text { E } & 71 & 21.32 & \text { A } \\ \text { I } & 76 & 20.62 & \text { A }\end{array}$

Grouping Information Using Tukey Method and $95.0 \%$ Confidence for $\mathrm{LHZ}+$

$\begin{array}{llrrl}\text { Seat } & \text { Task } & \text { N } & \text { Mean } & \text { Grouping } \\ \text { H120 } & \text { I } & 26 & 21.81 & \text { A } \\ \text { H90 } & \text { E } & 27 & 21.57 & \text { A } \\ \text { V } & \text { E } & 21 & 21.21 & \text { A } \\ \text { H120 } & \text { E } & 23 & 21.19 & \text { A } \\ \text { H90 } & \text { I } & 28 & 21.07 & \text { A } \\ \text { V } & \text { I } & 22 & 18.97 & \text { A }\end{array}$

Grouping Information Using Tukey Method and 95.0\% Confidence for LHZ-

$\begin{array}{lrrc}\text { Seat } & \text { N } & \text { Mean } & \text { Grouping } \\ \text { V } & 43 & -1.02 & \text { A } \\ \text { H120 } & 49 & -10.41 & \text { B } \\ \text { H90 } & 55 & -11.59 & \text { B }\end{array}$

Grouping Information Using Tukey Method and 95.0\% Confidence for LHZ-

$$
\begin{array}{lrrl}
\text { Task } & \mathrm{N} & \text { Mean } & \text { Grouping } \\
\mathrm{E} & 71 & -7.37 & \mathrm{~A} \\
\mathrm{I} & 76 & -7.98 & \mathrm{~A}
\end{array}
$$

Grouping Information Using Tukey Method and 95.0\% Confidence for LHZ-

$\begin{array}{llrrr}\text { Seat } & \text { Task } & \text { N } & \text { Mean } & \text { Grouping } \\ \text { V } & \text { I } & 22 & -0.33 & \text { A } \\ \text { V } & \text { E } & 21 & -1.70 & \text { A } \\ \text { H120 } & \text { E } & 23 & -9.55 & \text { B } \\ \text { H90 } & \text { E } & 27 & -10.84 & \text { B } \\ \text { H120 } & \text { I } & 26 & -11.28 & \text { B } \\ \text { H90 } & \text { I } & 28 & -12.34 & \text { B }\end{array}$

Grouping Information Using Tukey Method and 95.0\% Confidence for LHZR

\begin{tabular}{lrrrr} 
Seat & N & Mean & Grouping \\
H90 & 55 & 32.91 & A & \\
H120 & 49 & 31.91 & A & \\
V & 43 & 21.10 & \multicolumn{2}{c}{ B }
\end{tabular}

Grouping Information Using Tukey Method and 95.0\% Confidence for LHZR

$\begin{array}{lrrl}\text { Task } & \text { N } & \text { Mean } & \text { Grouping } \\ \text { E } & 71 & 28.69 & \text { A } \\ \text { I } & 76 & 28.60 & \text { A }\end{array}$


Grouping Information Using Tukey Method and 95.0\% Confidence for LHZR

$\begin{array}{llrrr}\text { Seat } & \text { Task } & \text { N } & \text { Mean } & \text { Grouping } \\ \text { H90 } & \text { I } & 28 & 33.40 & \text { A } \\ \text { H120 } & \text { I } & 26 & 33.09 & \text { A } \\ \text { H90 } & \text { E } & 27 & 32.41 & \text { A } \\ \text { H120 } & \text { E } & 23 & 30.74 & \text { A } \\ \text { V } & \text { E } & 21 & 22.91 & \text { B } \\ \text { V } & \text { I } & 22 & 19.30 & \text { B }\end{array}$

Grouping Information Using Tukey Method and 95.0\% Confidence for LKX+

$\begin{array}{lrrrr}\text { Seat } & \text { N } & \text { Mean } & \text { Grouping } \\ \text { H90 } & 55 & 107.69 & \text { A } & \\ \text { H120 } & 49 & 106.76 & \text { A } & \\ \text { V } & 43 & 81.01 & \text { B }\end{array}$

Grouping Information Using Tukey Method and 95.0\% Confidence for LKX+

$\begin{array}{lrrr}\text { Task } & \text { N } & \text { Mean } & \text { Grouping } \\ \text { I } & 76 & 104.45 & \text { A } \\ \text { E } & 71 & 92.51 & \text { B }\end{array}$

Grouping Information Using Tukey Method and 95.0\% Confidence for LKX+

\begin{tabular}{llrrrr} 
Seat & Task & N & Mean & Grouping \\
H120 & I & 26 & 116.14 & A & \\
H90 & I & 28 & 115.68 & A & \\
H90 & E & 27 & 99.69 & B & \\
H120 & E & 23 & 97.37 & B & \\
V & I & 22 & 81.54 & \multicolumn{2}{c}{ C } \\
V & E & 21 & 80.47 & & C
\end{tabular}

Grouping Information Using Tukey Method and 95.0\% Confidence for LKZ+

$\begin{array}{lrrrrr}\text { Seat } & \text { N } & \text { Mean } & \text { Grouping } \\ \text { H90 } & 55 & 18.99 & \text { A } & \\ \text { H120 } & 49 & 18.64 & \text { A } & \\ \text { V } & 43 & 3.66 & \text { B }\end{array}$

Grouping Information Using Tukey Method and 95.0\% Confidence for LKZ+

\begin{tabular}{lrrr} 
Task & N & Mean & Grouping \\
E & 71 & 14.82 & A \\
I & 76 & 12.71 & \multicolumn{2}{c}{ B }
\end{tabular}

Grouping Information Using Tukey Method and 95.0\% Confidence for LKZ+

$\begin{array}{llrrl}\text { Seat } & \text { Task } & \text { N } & \text { Mean } & \text { Grouping } \\ \text { H120 } & \text { E } & 23 & 20.54 & \text { A } \\ \text { H90 } & \text { E } & 27 & 19.44 & \text { A } \\ \text { H90 } & \text { I } & 28 & 18.54 & \text { A } \\ \text { H120 } & \text { I } & 26 & 16.75 & \text { A } \\ \text { V } & \text { E } & 21 & 4.48 & \text { B }\end{array}$

$\begin{array}{lllll}V & I & 22 & 2.84 & B\end{array}$

Grouping Information Using Tukey Method and 95.0\% Confidence for LKZ-

$\begin{array}{lrrc}\text { Seat } & \text { N } & \text { Mean } & \text { Grouping } \\ \text { V } & 43 & -22.08 & \text { A } \\ \text { H120 } & 49 & -29.59 & \text { B } \\ \text { H90 } & 55 & -32.87 & \text { B }\end{array}$

Grouping Information Using Tukey Method and 95.0\% Confidence for LKZ-

$\begin{array}{lrrl}\text { Task } & \text { N } & \text { Mean } & \text { Grouping } \\ \text { I } & 76 & -26.94 & A \\ \text { E } & 71 & -29.42 & A\end{array}$

Grouping Information Using Tukey Method and 95.0\% Confidence for LKZ-

$\begin{array}{llrrr}\text { Seat } & \text { Task } & \text { N } & \text { Mean } & \text { Grouping } \\ \text { V } & \text { I } & 22 & -20.28 & \text { A } \\ \text { V } & \text { E } & 21 & -23.89 & \text { A B } \\ \text { H120 } & \text { I } & 26 & -29.27 & \text { B C } \\ \text { H120 } & \text { E } & 23 & -29.91 & \text { B C } \\ \text { H90 } & \text { I } & 28 & -31.28 & \text { C } \\ \text { H90 } & \text { E } & 27 & -34.45 & \text { C }\end{array}$

Grouping Information Using Tukey Method and $95.0 \%$ Confidence for LKZR

\begin{tabular}{lrrrr} 
Seat & N & Mean & Grouping \\
H90 & 55 & 51.85 & A & \\
H120 & 49 & 48.23 & A & \\
V & 43 & 25.74 & \multicolumn{2}{c}{ B }
\end{tabular}

Grouping Information Using Tukey Method and $95.0 \%$ Confidence for LKZR

$$
\begin{array}{lrrc}
\text { Task } & \mathrm{N} & \text { Mean } & \text { Grouping } \\
\mathrm{E} & 71 & 44.24 & \mathrm{~A} \\
\mathrm{I} & 76 & 39.65 & \mathrm{~B}
\end{array}
$$

\begin{tabular}{|c|c|c|c|c|}
\hline Seat & Task & $\mathrm{N}$ & Mean & Grouping \\
\hline H9O & $\mathrm{E}$ & 27 & 53.89 & A \\
\hline $\mathrm{H} 120$ & $E$ & 23 & 50.45 & $A B$ \\
\hline H9O & I & 28 & 49.82 & $A B$ \\
\hline $\mathrm{H} 120$ & I & 26 & 46.02 & B \\
\hline V & $E$ & 21 & 28.37 & C \\
\hline V & I & 22 & 23.12 & C \\
\hline
\end{tabular}

Grouping Information Using Tukey Method and 95.0\% Confidence for LKZR 
Grouping Information Using Tukey Method and 95.0\% Confidence for LSX+

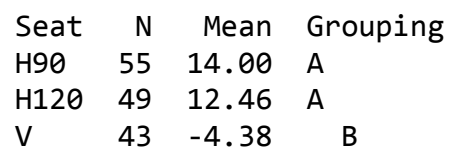

Grouping Information Using Tukey Method and $95.0 \%$ Confidence for LSX+

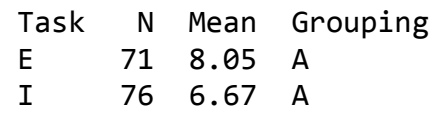

Grouping Information Using Tukey Method and 95.0\% Confidence for LSX+

$\begin{array}{llrrl}\text { Seat } & \text { Task } & \text { N } & \text { Mean } & \text { Grouping } \\ \text { H120 } & \text { E } & 23 & 15.06 & \text { A } \\ \text { H90 } & \text { E } & 27 & 14.13 & \text { A } \\ \text { H90 } & \text { I } & 28 & 13.87 & \text { A } \\ \text { H120 } & \text { I } & 26 & 9.87 & \text { A } \\ \text { V } & \text { I } & 22 & -3.72 & \text { B } \\ \text { V } & \text { E } & 21 & -5.04 & \text { B }\end{array}$

Grouping Information Using Tukey Method and $95.0 \%$ Confidence for LSX-

$\begin{array}{lrrrrr}\text { Seat } & \text { N } & \text { Mean } & \text { Grouping } \\ \text { V } & 43 & -24.11 & \text { A } & & \\ \text { H120 } & 49 & -61.31 & \text { B } & \\ \text { H90 } & 55 & -65.33 & & \text { C }\end{array}$

Grouping Information Using Tukey Method and 95.0\% Confidence for LSX-

$\begin{array}{lrrc}\text { Task } & \text { N } & \text { Mean } & \text { Grouping } \\ \text { I } & 76 & -47.32 & \text { A } \\ \text { E } & 71 & -53.18 & \text { B }\end{array}$

Grouping Information Using Tukey Method and 95.0\% Confidence for LSX-

\begin{tabular}{llrrrrrr} 
Seat & Task & N & Mean & Grouping \\
V & E & 21 & -23.86 & A & & \\
V & I & 22 & -24.37 & A & & \\
H120 & I & 26 & -57.12 & \multicolumn{2}{c}{ B } & & \\
H90 & I & 28 & -60.48 & & B C & \\
H120 & E & 23 & -65.50 & & C D \\
H90 & E & 27 & -70.18 & & & D
\end{tabular}

Grouping Information Using Tukey Method and $95.0 \%$ Confidence for LSXR

\begin{tabular}{lrrrr} 
Seat & N & Mean & Grouping \\
H90 & 55 & 79.33 & A & \\
H120 & 49 & 73.77 & A & \\
V & 43 & 19.73 & \multicolumn{2}{c}{ B }
\end{tabular}

Grouping Information Using Tukey Method and 95.0\% Confidence for LSXR

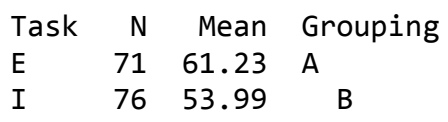

Grouping Information Using Tukey Method and 95.0\% Confidence for LSXR

\begin{tabular}{llrrll} 
Seat & Task & N & Mean & Grouping \\
H90 & E & 27 & 84.32 & A & \\
H120 & E & 23 & 80.56 & A & \\
H90 & I & 28 & 74.35 & A B & \\
H120 & I & 26 & 66.98 & \multicolumn{2}{c}{ B } \\
V & I & 22 & 20.65 & & \multicolumn{2}{c}{ C } \\
V & E & 21 & 18.82 & & C
\end{tabular}

Grouping Information Using Tukey Method and 95.0\% Confidence for LSY+

\begin{tabular}{lrrrr} 
Seat & N & Mean & Grouping \\
H90 & 55 & 64.34 & A & \\
H120 & 49 & 63.04 & A & \\
V & 43 & 35.39 & \multicolumn{2}{c}{ B }
\end{tabular}

Grouping Information Using Tukey Method and 95.0\% Confidence for LSY+

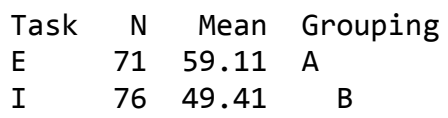

Grouping Information Using Tukey Method and 95.0\% Confidence for LSY+

$\begin{array}{llrrrr}\text { Seat } & \text { Task } & \text { N } & \text { Mean } & \text { Grouping } \\ \text { H90 } & \text { E } & 27 & 71.84 & \text { A } & \\ \text { H120 } & \text { E } & 23 & 69.61 & \text { A } & \\ \text { H90 } & \text { I } & 28 & 56.84 & \text { B } & \\ \text { H120 } & \text { I } & 26 & 56.47 & \text { B } \\ \text { V } & \text { E } & 21 & 35.87 & & \text { C } \\ \text { V } & \text { I } & 22 & 34.91 & & \text { C }\end{array}$

Grouping Information Using Tukey Method and 95.0\% Confidence for LSY-

$\begin{array}{lrrc}\text { Seat } & \text { N } & \text { Mean } & \text { Grouping } \\ \text { V } & 43 & 20.33 & \text { A } \\ \text { H120 } & 49 & 2.82 & \text { B } \\ \text { H90 } & 55 & 0.76 & \text { B }\end{array}$

Grouping Information Using Tukey Method and 95.0\% Confidence for LSY-

$\begin{array}{lrrr}\text { Task } & \text { N } & \text { Mean } & \text { Grouping } \\ \text { I } & 76 & 10.00 & \text { A } \\ \text { E } & 71 & 5.94 & \text { B }\end{array}$


Grouping Information Using Tukey Method and 95.0\% Confidence for LSY-

\begin{tabular}{llrrrrr} 
Seat & Task & N & Mean & Grouping \\
V & I & 22 & 20.57 & A & & \\
V & E & 21 & 20.09 & A & & \\
H120 & I & 26 & 5.77 & \multicolumn{2}{c}{ B } & \\
H90 & I & 28 & 3.65 & & B & C \\
H120 & E & 23 & -0.13 & & & C D \\
H90 & E & 27 & -2.13 & & & D
\end{tabular}

Grouping Information Using Tukey Method and 95.0\% Confidence for LSYR

\begin{tabular}{lrrrr} 
Seat & N & Mean & Grouping \\
H90 & 55 & 63.58 & A & \\
H120 & 49 & 60.22 & A & \\
V & 43 & 15.06 & \multicolumn{2}{c}{ B }
\end{tabular}

Grouping Information Using Tukey Method and 95.0\% Confidence for LSYR

$\begin{array}{lrrc}\text { Task } & \mathrm{N} & \text { Mean } & \text { Grouping } \\ \mathrm{E} & 71 & 53.16 & \mathrm{~A} \\ \mathrm{I} & 76 & 39.41 & \mathrm{~B}\end{array}$

Grouping Information Using Tukey Method and 95.0\% Confidence for LSYR

$\begin{array}{llrrrr}\text { Seat } & \text { Task } & \text { N } & \text { Mean } & \text { Grouping } \\ \text { H90 } & \text { E } & 27 & 73.97 & \text { A } & \\ \text { H120 } & \text { E } & 23 & 69.74 & \text { A } & \\ \text { H90 } & \text { I } & 28 & 53.19 & \text { B } & \\ \text { H120 } & \text { I } & 26 & 50.70 & \text { B } & \\ \text { V } & \text { E } & 21 & 15.78 & & \text { C } \\ \text { V } & \text { I } & 22 & 14.33 & & \text { C }\end{array}$

Grouping Information Using Tukey Method and 95.0\% Confidence for LSZ+

$\begin{array}{lrrrr}\text { Seat } & \text { N } & \text { Mean } & \text { Grouping } \\ \text { H90 } & 55 & 54.39 & \text { A } & \\ \text { H120 } & 49 & 49.11 & \text { A } & \\ \text { V } & 43 & 6.03 & \text { B }\end{array}$

Grouping Information Using Tukey Method and $95.0 \%$ Confidence for LSZ+

$\begin{array}{lrrc}\text { Task } & \text { N } & \text { Mean } & \text { Grouping } \\ \text { E } & 71 & 43.40 & \text { A } \\ \text { I } & 76 & 29.62 & \text { B }\end{array}$

Grouping Information Using Tukey Method and 95.0\% Confidence for LSZ+

\begin{tabular}{|c|c|c|c|c|}
\hline Seat & Task & $\mathrm{N}$ & Mean & Grouping \\
\hline H9O & $\mathrm{E}$ & 27 & 65.70 & A \\
\hline $\mathrm{H} 120$ & $E$ & 23 & 58.90 & A \\
\hline H9O & I & 28 & 43.08 & B \\
\hline $\mathrm{H} 120$ & I & 26 & 39.33 & B \\
\hline V & I & 22 & 6.45 & C \\
\hline
\end{tabular}

$\begin{array}{lllll}V & E & 21 & 5.61 & C\end{array}$

Grouping Information Using Tukey Method and 95.0\% Confidence for LSZ-

$\begin{array}{lrrc}\text { Seat } & \text { N } & \text { Mean } & \text { Grouping } \\ \text { V } & 43 & -20.80 & \text { A } \\ \text { H90 } & 55 & -24.95 & \text { B } \\ \text { H120 } & 49 & -26.05 & \text { B }\end{array}$

Grouping Information Using Tukey Method and $95.0 \%$ Confidence for LSZ-

$\begin{array}{lrrl}\text { Task } & \mathrm{N} & \text { Mean } & \text { Grouping } \\ \mathrm{E} & 71 & -23.65 & \mathrm{~A} \\ \mathrm{I} & 76 & -24.21 & \mathrm{~A}\end{array}$

Grouping Information Using Tukey Method and $95.0 \%$ Confidence for LSZ-

$\begin{array}{llrrl}\text { Seat } & \text { Task } & \text { N } & \text { Mean } & \text { Grouping } \\ \text { V } & \text { I } & 22 & -19.23 & \text { A } \\ \text { V } & \text { E } & 21 & -22.36 & \text { A B } \\ \text { H90 } & \text { E } & 27 & -23.09 & \text { A B } \\ \text { H120 } & \text { E } & 23 & -25.51 & \text { A B } \\ \text { H120 } & \text { I } & 26 & -26.59 & \text { B } \\ \text { H90 } & \text { I } & 28 & -26.81 & \text { B }\end{array}$

Grouping Information Using Tukey Method and 95.0\% Confidence for LSZR

\begin{tabular}{lrrrr} 
Seat & N & Mean & Grouping \\
H90 & 55 & 79.33 & A & \\
H120 & 49 & 75.16 & A & \\
V & 43 & 26.82 & \multicolumn{2}{c}{ B }
\end{tabular}

Grouping Information Using Tukey Method and $95.0 \%$ Confidence for LSZR

$$
\begin{array}{lrrr}
\text { Task } & \text { N } & \text { Mean } & \text { Grouping } \\
\text { E } & 71 & 67.05 & \text { A } \\
\text { I } & 76 & 53.83 & \text { B }
\end{array}
$$

Grouping Information Using Tukey Method and $95.0 \%$ Confidence for LSZR

\begin{tabular}{llrrrr} 
Seat & Task & N & Mean & Grouping \\
H90 & E & 27 & 88.78 & A & \\
H120 & E & 23 & 84.41 & A & \\
H90 & I & 28 & 69.88 & B & \\
H120 & I & 26 & 65.92 & B \\
V & E & 21 & 27.97 & \multicolumn{2}{c}{ C } \\
V & I & 22 & 25.68 & & C
\end{tabular}

Grouping Information Using Tukey Method and 95.0\% Confidence for RHX+

$\begin{array}{lrrc}\text { Seat } & \text { N } & \text { Mean } & \text { Grouping } \\ \text { H90 } & 55 & 74.56 & \text { A } \\ \text { H120 } & 49 & 64.56 & \text { B } \\ \text { V } & 43 & 60.85 & \text { B }\end{array}$


Grouping Information Using Tukey Method and 95.0\% Confidence for RHX+

$\begin{array}{lrrl}\text { Task } & \mathrm{N} & \text { Mean } & \text { Grouping } \\ \mathrm{E} & 71 & 67.26 & \mathrm{~A} \\ \mathrm{I} & 76 & 66.05 & \mathrm{~A}\end{array}$

Grouping Information Using Tukey Method and 95.0\% Confidence for RHX+

$\begin{array}{llrrc}\text { Seat } & \text { Task } & \text { N } & \text { Mean } & \text { Grouping } \\ \text { H90 } & \text { I } & 28 & 75.18 & \text { A } \\ \text { H90 } & \text { E } & 27 & 73.93 & \text { A } \\ \text { H120 } & \text { E } & 23 & 64.87 & \text { B } \\ \text { H120 } & \text { I } & 26 & 64.24 & \text { B } \\ \text { V } & \text { E } & 21 & 62.96 & \text { B } \\ \text { V } & \text { I } & 22 & 58.74 & \text { B }\end{array}$

Grouping Information Using Tukey Method and $95.0 \%$ Confidence for RHY-

$\begin{array}{lrrl}\text { Seat } & \text { N } & \text { Mean } & \text { Grouping } \\ \text { H120 } & 49 & -16.65 & \text { A } \\ \text { H90 } & 55 & -18.24 & \text { A } \\ \text { V } & 43 & -19.16 & \text { A }\end{array}$

Grouping Information Using Tukey Method and $95.0 \%$ Confidence for RHY-

$\begin{array}{lrrc}\text { Task } & \text { N } & \text { Mean } & \text { Grouping } \\ \text { I } & 76 & -15.54 & \text { A } \\ \text { E } & 71 & -20.50 & \text { B }\end{array}$

Grouping Information Using Tukey Method and $95.0 \%$ Confidence for RHY-

$\begin{array}{llrrl}\text { Seat } & \text { Task } & \text { N } & \text { Mean } & \text { Grouping } \\ \text { H120 } & \text { I } & 26 & -14.09 & \text { A } \\ \text { H90 } & \text { I } & 28 & -15.10 & \text { A } \\ \text { V } & \text { I } & 22 & -17.42 & \text { A B } \\ \text { H120 } & \text { E } & 23 & -19.22 & \text { A B } \\ \text { V } & \text { E } & 21 & -20.91 & \text { B } \\ \text { H90 } & \text { E } & 27 & -21.38 & \text { B }\end{array}$

Grouping Information Using Tukey Method and $95.0 \%$ Confidence for $\mathrm{RHZ}+$

\begin{tabular}{lrrrr} 
Seat & N & Mean & Grouping \\
H90 & 55 & 3.78 & A & \\
H120 & 49 & 3.28 & A & \\
V & 43 & 0.39 & \multicolumn{2}{c}{ B }
\end{tabular}

Grouping Information Using Tukey Method and 95.0\% Confidence for $\mathrm{RHZ}+$

$\begin{array}{lrrl}\text { Task } & \text { N } & \text { Mean } & \text { Grouping } \\ \text { I } & 76 & 3.08 & \text { A } \\ \text { E } & 71 & 1.89 & \text { A }\end{array}$

Grouping Information Using Tukey Method and 95.0\% Confidence for $\mathrm{RHZ}+$

\begin{tabular}{|c|c|c|c|c|}
\hline Seat & Task & $\mathrm{N}$ & Mean & Grouping \\
\hline H90 & I & 28 & 4.70 & A \\
\hline H120 & I & 26 & 3.76 & $A B$ \\
\hline $\mathrm{H} 90$ & $E$ & 27 & 2.85 & $A B$ \\
\hline H120 & $E$ & 23 & 2.80 & $A B$ \\
\hline V & I & 22 & 0.76 & $A B$ \\
\hline V & $E$ & 21 & 0.01 & B \\
\hline
\end{tabular}

Grouping Information Using Tukey Method and 95.0\% Confidence for RHZ-

$\begin{array}{lrrl}\text { Seat } & \text { N } & \text { Mean } & \text { Grouping } \\ \text { V } & 43 & -21.30 & \text { A } \\ \text { H120 } & 49 & -22.06 & \text { A } \\ \text { H90 } & 55 & -22.94 & \text { A }\end{array}$

Grouping Information Using Tukey Method and 95.0\% Confidence for RHZ-

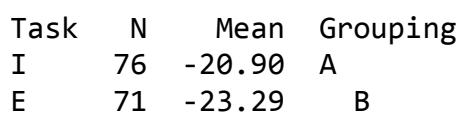

Grouping Information Using Tukey Method and 95.0\% Confidence for RHZ-

$\begin{array}{llrrl}\text { Seat } & \text { Task } & \text { N } & \text { Mean } & \text { Grouping } \\ \text { V } & \text { I } & 22 & -20.36 & \text { A } \\ \text { H120 } & \text { I } & 26 & -20.65 & \text { A } \\ \text { H90 } & \text { I } & 28 & -21.70 & \text { A } \\ \text { V } & \text { E } & 21 & -22.24 & \text { A } \\ \text { H120 } & \text { E } & 23 & -23.47 & \text { A } \\ \text { H90 } & \text { E } & 27 & -24.17 & \text { A }\end{array}$

Grouping Information Using Tukey Method and $95.0 \%$ Confidence for RHZR

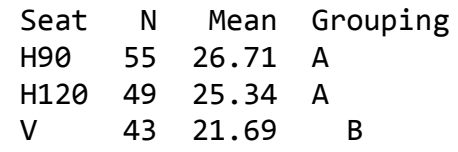

Grouping Information Using Tukey Method and 95.0\% Confidence for RHZR

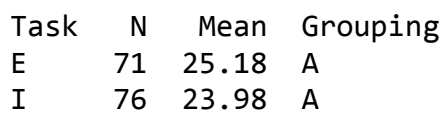

Grouping Information Using Tukey Method and 95.0\% Confidence for RHZR

$\begin{array}{llrrl}\text { Seat } & \text { Task } & \text { N } & \text { Mean } & \text { Grouping } \\ \text { H90 } & \text { E } & 27 & 27.02 & \text { A } \\ \text { H90 } & \text { I } & 28 & 26.41 & \text { A B } \\ \text { H120 } & \text { E } & 23 & 26.27 & \text { A B } \\ \text { H120 } & \text { I } & 26 & 24.41 & \text { A B } \\ \text { V } & \text { E } & 21 & 22.25 & \text { A B } \\ \text { V } & \text { I } & 22 & 21.12 & \text { B }\end{array}$


Grouping Information Using Tukey Method and 95.0\% Confidence for RKX+

$\begin{array}{lrrc}\text { Seat } & \text { N } & \text { Mean } & \text { Grouping } \\ \text { H90 } & 55 & 91.23 & \text { A } \\ \text { V } & 43 & 83.54 & \text { B } \\ \text { H120 } & 49 & 82.52 & \text { B }\end{array}$

Grouping Information Using Tukey Method and 95.0\% Confidence for RKX+

$\begin{array}{lrrl}\text { Task } & \mathrm{N} & \text { Mean } & \text { Grouping } \\ \mathrm{E} & 71 & 86.43 & \mathrm{~A} \\ \mathrm{I} & 76 & 85.09 & \mathrm{~A}\end{array}$

Grouping Information Using Tukey Method and 95.0\% Confidence for RKX+

\begin{tabular}{|c|c|c|c|c|}
\hline Seat & Task & $\mathrm{N}$ & Mean & Grouping \\
\hline $\mathrm{H} 90$ & $\mathrm{E}$ & 27 & 92.40 & A \\
\hline H9O & I & 28 & 90.05 & $A B$ \\
\hline V & $E$ & 21 & 83.56 & B C \\
\hline V & I & 22 & 83.51 & B C \\
\hline $\mathrm{H} 120$ & $E$ & 23 & 83.33 & B C \\
\hline $\mathrm{H} 120$ & I & 26 & 81.70 & C \\
\hline
\end{tabular}

Grouping Information Using Tukey Method and 95.0\% Confidence for RKZ+

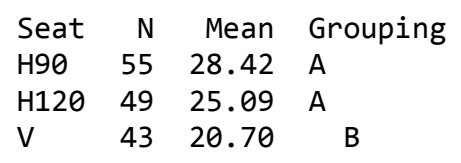

Grouping Information Using Tukey Method and 95.0\% Confidence for RKZ+

$\begin{array}{lrrl}\text { Task } & \mathrm{N} & \text { Mean } & \text { Grouping } \\ \mathrm{E} & 71 & 25.52 & \mathrm{~A} \\ \mathrm{I} & 76 & 23.96 & \mathrm{~A}\end{array}$

Grouping Information Using Tukey Method and 95.0\% Confidence for RKZ+

$\begin{array}{llrrll}\text { Seat } & \text { Task } & \text { N } & \text { Mean } & \text { Grouping } \\ \text { H90 } & \text { E } & 27 & 28.58 & \text { A } & \\ \text { H90 } & \text { I } & 28 & 28.26 & \text { A } & \\ \text { H120 } & \text { E } & 23 & 26.76 & \text { A B } & \\ \text { H120 } & \text { I } & 26 & 23.43 & \text { A B C } \\ \text { V } & \text { E } & 21 & 21.22 & \text { B C } \\ \text { V } & \text { I } & 22 & 20.18 & & \text { C }\end{array}$

Grouping Information Using Tukey Method and 95.0\% Confidence for RKZ-

$\begin{array}{lrrc}\text { Seat } & \text { N } & \text { Mean } & \text { Grouping } \\ \text { V } & 43 & -9.37 & \text { A } \\ \text { H90 } & 55 & -20.61 & \text { B } \\ \text { H120 } & 49 & -21.35 & \text { B }\end{array}$

Grouping Information Using Tukey Method and 95.0\% Confidence for RKZ-

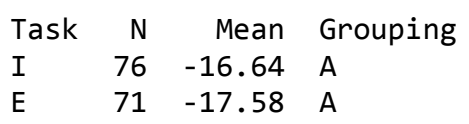

Grouping Information Using Tukey Method and 95.0\% Confidence for RKZ-

$\begin{array}{llrrc}\text { Seat } & \text { Task } & \text { N } & \text { Mean } & \text { Grouping } \\ \text { V } & \text { I } & 22 & -8.16 & \text { A } \\ \text { V } & \text { E } & 21 & -10.58 & \text { A } \\ \text { H90 } & \text { I } & 28 & -20.03 & \text { B } \\ \text { H120 } & \text { E } & 23 & -20.97 & \text { B } \\ \text { H90 } & \text { E } & 27 & -21.19 & \text { B } \\ \text { H120 } & \text { I } & 26 & -21.74 & \text { B }\end{array}$

Grouping Information Using Tukey Method and 95.0\% Confidence for RKZR

\begin{tabular}{lrrrr} 
Seat & N & Mean & Grouping \\
H90 & 55 & 49.03 & A & \\
H120 & 49 & 46.45 & A & \\
V & 43 & 30.07 & \multicolumn{2}{c}{ B }
\end{tabular}

Grouping Information Using Tukey Method and 95.0\% Confidence for RKZR

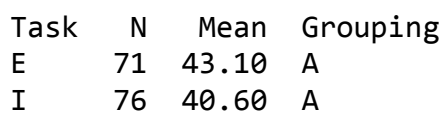

Grouping Information Using Tukey Method and 95.0\% Confidence for RKZR

$\begin{array}{llrrl}\text { Seat } & \text { Task } & \text { N } & \text { Mean } & \text { Grouping } \\ \text { H90 } & \text { E } & 27 & 49.77 & \text { A } \\ \text { H90 } & \text { I } & 28 & 48.29 & \text { A } \\ \text { H120 } & \text { E } & 23 & 47.72 & \text { A } \\ \text { H120 } & \text { I } & 26 & 45.17 & \text { A } \\ \text { V } & \text { E } & 21 & 31.80 & \text { B } \\ \text { V } & \text { I } & 22 & 28.34 & \text { B }\end{array}$

Grouping Information Using Tukey Method and 95.0\% Confidence for RSX+

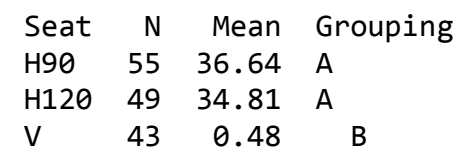

Grouping Information Using Tukey Method and 95.0\% Confidence for RSX+

$\begin{array}{lrrcc}\text { Task } & \text { N } & \text { Mean } & \text { Grouping } \\ \text { I } & 76 & 29.09 & \text { A } & \\ \text { E } & 71 & 18.86 & \text { B }\end{array}$


Grouping Information Using Tukey Method and 95.0\% Confidence for RSX+

$\begin{array}{llrrrr}\text { Seat } & \text { Task } & \text { N } & \text { Mean } & \text { Grouping } \\ \text { H90 } & \text { I } & 28 & 44.20 & \text { A } & \\ \text { H120 } & \text { I } & 26 & 42.01 & \text { A } & \\ \text { H90 } & \text { E } & 27 & 29.08 & \text { B } & \\ \text { H120 } & \text { E } & 23 & 27.61 & \text { B } & \\ \text { V } & \text { I } & 22 & 1.06 & & \text { C } \\ \text { V } & \text { E } & 21 & -0.10 & & \text { C }\end{array}$

Grouping Information Using Tukey Method and 95.0\% Confidence for RSX-

$\begin{array}{lrrc}\text { Seat } & \text { N } & \text { Mean } & \text { Grouping } \\ \text { V } & 43 & -25.19 & \text { A } \\ \text { H90 } & 55 & -59.87 & \text { B } \\ \text { H120 } & 49 & -61.73 & \text { B }\end{array}$

Grouping Information Using Tukey Method and 95.0\% Confidence for RSX-

\begin{tabular}{lrrc} 
Task & $N$ & Mean & Grouping \\
E & 71 & -46.91 & A \\
I & 76 & -50.95 & \multicolumn{2}{c}{ B }
\end{tabular}

Grouping Information Using Tukey Method and 95.0\% Confidence for RSX-

\begin{tabular}{|c|c|c|c|c|}
\hline Seat & Task & $\mathrm{N}$ & Mean & Grouping \\
\hline V & I & 22 & -23.83 & A \\
\hline V & $E$ & 21 & -26.54 & A \\
\hline $\mathrm{H} 120$ & $E$ & 23 & -56.37 & B \\
\hline H9O & $E$ & 27 & -57.82 & B \\
\hline H90 & I & 28 & -61.92 & B C \\
\hline $\mathrm{H} 120$ & I & 26 & -67.09 & C \\
\hline
\end{tabular}

Grouping Information Using Tukey Method and 95.0\% Confidence for RSXR

$\begin{array}{lrrrr}\text { Seat } & \text { N } & \text { Mean } & \text { Grouping } \\ \text { H120 } & 49 & 96.54 & \text { A } & \\ \text { H90 } & 55 & 96.51 & \text { A } & \\ \text { V } & 43 & 25.67 & \text { B }\end{array}$

Grouping Information Using Tukey Method and $95.0 \%$ Confidence for RSXR

\begin{tabular}{lrrc} 
Task & N & Mean & Grouping \\
I & 76 & 80.04 & A \\
E & 71 & 65.77 & \multicolumn{2}{c}{ B }
\end{tabular}

Grouping Information Using Tukey Method and 95.0\% Confidence for RSXR

\begin{tabular}{|c|c|c|c|c|}
\hline Seat & Task & $\mathrm{N}$ & Mean & Grouping \\
\hline $\mathrm{H} 120$ & I & 26 & 109.10 & A \\
\hline H90 & I & 28 & 106.12 & A \\
\hline $\mathrm{H} 90$ & $E$ & 27 & 86.89 & B \\
\hline $\mathrm{H} 120$ & $E$ & 23 & 83.99 & B \\
\hline V & $E$ & 21 & 26.44 & C \\
\hline
\end{tabular}

$\begin{array}{lllll}V & I & 22 & 24.90 \quad C\end{array}$

Grouping Information Using Tukey Method and 95.0\% Confidence for RSY+

$\begin{array}{lrrrr}\text { Seat } & \text { N } & \text { Mean } & \text { Grouping } \\ \text { H90 } & 55 & 1.64 & \text { A } & \\ \text { H120 } & 49 & 1.33 & \text { A } & \\ \text { V } & 43 & -15.66 & \text { B }\end{array}$

Grouping Information Using Tukey Method and 95.0\% Confidence for RSY+

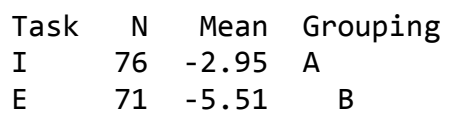

Grouping Information Using Tukey Method and 95.0\% Confidence for RSY+

\begin{tabular}{|c|c|c|c|c|}
\hline Seat & Task & $\mathrm{N}$ & Mean & Grouping \\
\hline H90 & I & 28 & 4.37 & A \\
\hline $\mathrm{H} 120$ & I & 26 & 2.48 & $A B$ \\
\hline H120 & $E$ & 23 & 0.18 & $A B$ \\
\hline H9O & $E$ & 27 & -1.10 & B \\
\hline V & $E$ & 21 & -15.62 & C \\
\hline V & I & 22 & -15.70 & C \\
\hline
\end{tabular}

Grouping Information Using Tukey Method and 95.0\% Confidence for RSY-

$\begin{array}{lrrc}\text { Seat } & \text { N } & \text { Mean } & \text { Grouping } \\ \text { V } & 43 & -32.96 & \text { A } \\ \text { H120 } & 49 & -63.63 & \text { B } \\ \text { H90 } & 55 & -63.86 & \text { B }\end{array}$

Grouping Information Using Tukey Method and 95.0\% Confidence for RSY-

$$
\begin{array}{lrrc}
\text { Task } & \mathrm{N} & \text { Mean } & \text { Grouping } \\
\text { E } & 71 & -51.73 & \text { A } \\
\text { I } & 76 & -55.23 & \text { B }
\end{array}
$$

\begin{tabular}{|c|c|c|c|c|}
\hline Seat & Task & $\mathrm{N}$ & Mean & Grouping \\
\hline V & I & 22 & -32.83 & A \\
\hline V & $E$ & 21 & -33.09 & A \\
\hline H120 & $E$ & 23 & -60.27 & B \\
\hline H90 & $E$ & 27 & -61.84 & B C \\
\hline H9O & I & 28 & -65.88 & C \\
\hline H120 & I & 26 & -66.98 & C \\
\hline
\end{tabular}

Grouping Information Using Tukey Method and 95.0\% Confidence for RSY-

Grouping Information Using Tukey Method and 95.0\% Confidence for RSYR

\begin{tabular}{lrrrr} 
Seat & N & Mean & Grouping \\
H90 & 55 & 65.50 & A & \\
H120 & 49 & 64.96 & A & \\
V & 43 & 17.30 & \multicolumn{2}{c}{ B }
\end{tabular}


Grouping Information Using Tukey Method and 95.0\% Confidence for RSYR

\begin{tabular}{lrrc} 
Task & $\mathrm{N}$ & Mean & Grouping \\
$\mathrm{I}$ & 76 & 52.28 & $\mathrm{~A}$ \\
$\mathrm{E}$ & 71 & 46.22 & \multicolumn{2}{c}{$\mathrm{B}$}
\end{tabular}

Grouping Information Using Tukey Method and 95.0\% Confidence for RSYR

\begin{tabular}{|c|c|c|c|c|}
\hline Seat & Task & $\mathrm{N}$ & Mean & Grouping \\
\hline H9O & I & 28 & 70.26 & $A$ \\
\hline $\mathrm{H} 120$ & I & 26 & 69.46 & A \\
\hline H9O & E & 27 & 60.74 & B \\
\hline $\mathrm{H} 120$ & E & 23 & 60.45 & B \\
\hline V & E & 21 & 17.47 & C \\
\hline V & I & 22 & 17.13 & C \\
\hline
\end{tabular}

Grouping Information Using Tukey Method and $95.0 \%$ Confidence for RSZ+

\begin{tabular}{lrrrr} 
Seat & N & Mean & Grouping \\
H90 & 55 & 47.18 & A & \\
H120 & 49 & 44.50 & A & \\
V & 43 & 27.64 & \multicolumn{2}{c}{ B }
\end{tabular}

Grouping Information Using Tukey Method and $95.0 \%$ Confidence for RSZ+

$\begin{array}{lrrr}\text { Task } & \mathrm{N} & \text { Mean } & \text { Grouping } \\ \text { I } & 76 & 43.53 & \text { A } \\ \text { E } & 71 & 36.01 & \text { B }\end{array}$

Grouping Information Using Tukey Method and $95.0 \%$ Confidence for RSZ+

$\begin{array}{llrrrrr}\text { Seat } & \text { Task } & \text { N } & \text { Mean } & \text { Grouping } \\ \text { H90 } & \text { I } & 28 & 53.30 & \text { A } & & \\ \text { H120 } & \text { I } & 26 & 50.70 & \text { A } & & \\ \text { H90 } & \text { E } & 27 & 41.05 & \text { B } & \\ \text { H120 } & \text { E } & 23 & 38.31 & & \text { B C C } \\ \text { V } & \text { E } & 21 & 28.67 & & \text { C D } \\ \text { V } & \text { I } & 22 & 26.60 & & & \text { D }\end{array}$

Grouping Information Using Tukey Method and $95.0 \%$ Confidence for RSZ-

$\begin{array}{lrrc}\text { Seat } & \text { N } & \text { Mean } & \text { Grouping } \\ \text { V } & 43 & -5.07 & \text { A } \\ \text { H90 } & 55 & -41.19 & \text { B } \\ \text { H120 } & 49 & -44.27 & \text { B }\end{array}$

Grouping Information Using Tukey Method and 95.0\% Confidence for RSZ-

$$
\begin{array}{lrrc}
\text { Task } & \text { N } & \text { Mean } & \text { Grouping } \\
\text { E } & 71 & -26.27 & \text { A } \\
\text { I } & 76 & -34.08 & \text { B }
\end{array}
$$

\begin{tabular}{|c|c|c|c|c|}
\hline Seat & Task & $\mathrm{N}$ & Mean & Grouping \\
\hline V & I & 22 & -4.88 & A \\
\hline V & $E$ & 21 & -5.27 & A \\
\hline $\mathrm{H} 120$ & $E$ & 23 & -35.17 & B \\
\hline H9O & $E$ & 27 & -38.37 & B \\
\hline H9O & I & 28 & -44.00 & B C \\
\hline $\mathrm{H} 120$ & I & 26 & -53.36 & C \\
\hline
\end{tabular}

Grouping Information Using Tukey Method and $95.0 \%$ Confidence for RSZ-
Grouping Information Using Tukey Method and 95.0\% Confidence for RSZR

$\begin{array}{lrrrr}\text { Seat } & \text { N } & \text { Mean } & \text { Grouping } \\ \text { H120 } & 49 & 88.77 & \text { A } & \\ \text { H90 } & 55 & 88.36 & \text { A } & \\ \text { V } & 43 & 32.71 & & \text { B }\end{array}$

Grouping Information Using Tukey Method and 95.0\% Confidence for RSZR

$$
\begin{array}{lrrc}
\text { Task } & \text { N } & \text { Mean } & \text { Grouping } \\
\text { I } & 76 & 77.61 & \text { A } \\
\text { E } & 71 & 62.28 & \text { B }
\end{array}
$$

Grouping Information Using Tukey Method and 95.0\% Confidence for RSZR

\begin{tabular}{llrrrr} 
Seat & Task & N & Mean & Grouping \\
H120 & I & 26 & 104.06 & A & \\
H90 & I & 28 & 97.30 & A & \\
H90 & E & 27 & 79.43 & \multicolumn{2}{c}{ B } \\
H120 & E & 23 & 73.48 & \multicolumn{2}{c}{ B } \\
V & E & 21 & 33.94 & & C \\
V & I & 22 & 31.48 & & C
\end{tabular}

Grouping Information Using Tukey Method and 95.0\% Confidence for TX+

\begin{tabular}{lrrrrr} 
Seat & N & Mean & \multicolumn{2}{c}{ Grouping } \\
H90 & 55 & 67.71 & A & & \\
H120 & 49 & 63.96 & & B & \\
V & 43 & 43.28 & & \multicolumn{2}{c}{ C }
\end{tabular}

Grouping Information Using Tukey Method and $95.0 \%$ Confidence for TX+

$$
\begin{array}{lrrl}
\text { Task } & \text { N } & \text { Mean } & \text { Grouping } \\
\text { I } & 76 & 58.88 & \text { A } \\
\text { E } & 71 & 57.75 & \text { A }
\end{array}
$$

Grouping Information Using Tukey Method and $95.0 \%$ Confidence for $\mathrm{TX}+$

$\begin{array}{llrrl}\text { Seat } & \text { Task } & \text { N } & \text { Mean } & \text { Grouping } \\ \text { H90 } & \text { I } & 28 & 68.26 & \text { A } \\ \text { H90 } & \text { E } & 27 & 67.15 & \text { A } \\ \text { H120 } & \text { I } & 26 & 64.18 & \text { A } \\ \text { H120 } & \text { E } & 23 & 63.74 & \text { A } \\ \text { V } & \text { I } & 22 & 44.21 & \text { B } \\ \text { V } & \text { E } & 21 & 42.35 & \text { B }\end{array}$


Grouping Information Using Tukey Method and 95.0\% Confidence for TY+

$\begin{array}{lrrc}\text { Seat } & \text { N } & \text { Mean } & \text { Grouping } \\ \text { H90 } & 55 & 14.56 & \text { A } \\ \text { H120 } & 49 & 9.23 & \text { B } \\ \text { V } & 43 & 7.87 & \text { B }\end{array}$

Grouping Information Using Tukey Method and 95.0\% Confidence for TY+

$\begin{array}{lrrr}\text { Task } & \mathrm{N} & \text { Mean } & \text { Grouping } \\ \mathrm{E} & 71 & 12.05 & \mathrm{~A} \\ \mathrm{I} & 76 & 9.06 & \mathrm{~B}\end{array}$

Grouping Information Using Tukey Method and 95.0\% Confidence for TY+

$\begin{array}{llrrr}\text { Seat } & \text { Task } & \text { N } & \text { Mean } & \text { Grouping } \\ \text { H90 } & \text { E } & 27 & 17.78 & \text { A } \\ \text { H90 } & \text { I } & 28 & 11.34 & \text { B } \\ \text { H120 } & \text { E } & 23 & 10.24 & \text { B } \\ \text { H120 } & \text { I } & 26 & 8.22 & \text { B } \\ \text { V } & \text { E } & 21 & 8.12 & \text { B } \\ \text { V } & \text { I } & 22 & 7.63 & \text { B }\end{array}$

Grouping Information Using Tukey Method and $95.0 \%$ Confidence for TY-

Seat $N$ Mean Grouping

$\begin{array}{llll}\mathrm{V} & 43 & -5.23 \quad \mathrm{~A}\end{array}$

$\begin{array}{llll}H 90 & 55 & -16.23 \quad B\end{array}$

$\begin{array}{llll}\mathrm{H} 120 & 49 & -22.81 & \mathrm{C}\end{array}$

Grouping Information Using Tukey Method and 95.0\% Confidence for TY-

$$
\begin{array}{lrrc}
\text { Task } & \mathrm{N} & \text { Mean } & \text { Grouping } \\
\mathrm{E} & 71 & -13.84 & \mathrm{~A} \\
\mathrm{I} & 76 & -15.67 & \mathrm{~B}
\end{array}
$$

Grouping Information Using Tukey Method and 95.0\% Confidence for TY-

\begin{tabular}{llrrrrrr} 
Seat & Task & N & Mean & Grouping \\
V & I & 22 & -4.81 & A & & \\
V & E & 21 & -5.65 & A & & \\
H90 & E & 27 & -13.62 & \multicolumn{2}{c}{ B } & & \\
H90 & I & 28 & -18.83 & & \multicolumn{2}{c}{ C } & \\
H120 & E & 23 & -22.24 & & \multicolumn{2}{c}{ C D } \\
H120 & I & 26 & -23.38 & & & D
\end{tabular}

Grouping Information Using Tukey Method and 95.0\% Confidence for TYR

\begin{tabular}{lrrrr} 
Seat & N & Mean & Grouping \\
H120 & 49 & 32.04 & A & \\
H90 & 55 & 30.78 & A & \\
V & 43 & 13.10 & \multicolumn{2}{c}{ B }
\end{tabular}

Grouping Information Using Tukey Method and 95.0\% Confidence for TYR

$$
\begin{array}{lrrl}
\text { Task } & \mathrm{N} & \text { Mean } & \text { Grouping } \\
\mathrm{E} & 71 & 25.88 & \mathrm{~A} \\
\mathrm{I} & 76 & 24.73 & \mathrm{~A}
\end{array}
$$

Grouping Information Using Tukey Method and 95.0\% Confidence for TYR

$\begin{array}{llrrr}\text { Seat } & \text { Task } & \text { N } & \text { Mean } & \text { Grouping } \\ \text { H120 } & \text { E } & 23 & 32.48 & \text { A } \\ \text { H120 } & \text { I } & 26 & 31.59 & \text { A } \\ \text { H90 } & \text { E } & 27 & 31.40 & \text { A } \\ \text { H90 } & \text { I } & 28 & 30.17 & \text { A } \\ \text { V } & \text { E } & 21 & 13.76 & \text { B } \\ \text { V } & \text { I } & 22 & 12.44 & \text { B }\end{array}$

Grouping Information Using Tukey Method and 95.0\% Confidence for TZ+

$\begin{array}{lrrrrr}\text { Seat } & \text { N } & \text { Mean } & \text { Grouping } \\ \text { H120 } & 49 & 21.75 & \text { A } & & \\ \text { H90 } & 55 & 19.53 & \text { B } & \\ \text { V } & 43 & 5.77 & & \text { C }\end{array}$

Grouping Information Using Tukey Method and 95.0\% Confidence for TZ+

$$
\begin{array}{lrrl}
\text { Task } & \mathrm{N} & \text { Mean } & \text { Grouping } \\
\mathrm{E} & 71 & 15.87 & \mathrm{~A} \\
\mathrm{I} & 76 & 15.49 & \mathrm{~A}
\end{array}
$$

Grouping Information Using Tukey Method and 95.0\% Confidence for TZ+

$\begin{array}{llrrl}\text { Seat } & \text { Task } & \text { N } & \text { Mean } & \text { Grouping } \\ \text { H120 } & \text { I } & 26 & 22.25 & \text { A } \\ \text { H120 } & \text { E } & 23 & 21.24 & \text { A } \\ \text { H90 } & \text { E } & 27 & 20.05 & \text { A } \\ \text { H90 } & \text { I } & 28 & 19.01 & \text { A } \\ \text { V } & \text { E } & 21 & 6.32 & \text { B } \\ \text { V } & \text { I } & 22 & 5.22 & \text { B }\end{array}$

Grouping Information Using Tukey Method and 95.0\% Confidence for TZ-

$\begin{array}{lrrl}\text { Seat } & \text { N } & \text { Mean } & \text { Grouping } \\ \text { V } & 43 & -9.04 & \text { A } \\ \text { H90 } & 55 & -10.06 & \text { A } \\ \text { H120 } & 49 & -10.09 & \text { A }\end{array}$

Grouping Information Using Tukey Method and 95.0\% Confidence for TZ-

$\begin{array}{lrrr}\text { Task } & \text { N } & \text { Mean } & \text { Grouping } \\ \text { E } & 71 & -8.92 & \text { A } \\ \text { I } & 76 & -10.54 & \text { B }\end{array}$


Grouping Information Using Tukey Method and 95.0\% Confidence for TZ-

$\begin{array}{llrrl}\text { Seat } & \text { Task } & \text { N } & \text { Mean } & \text { Grouping } \\ \text { V } & \text { I } & 22 & -8.56 & \text { A } \\ \text { H120 } & \text { E } & 23 & -8.57 & \text { A } \\ \text { H90 } & \text { E } & 27 & -8.69 & \text { A } \\ \text { V } & \text { E } & 21 & -9.52 & \text { A } \\ \text { H90 } & \text { I } & 28 & -11.43 & \text { A } \\ \text { H120 } & \text { I } & 26 & -11.62 & \text { A }\end{array}$

Grouping Information Using Tukey Method and 95.0\% Confidence for TZR

\begin{tabular}{lrrrr} 
Seat & N & Mean & Grouping \\
H120 & 49 & 31.84 & A & \\
H90 & 55 & 29.59 & A & \\
V & 43 & 14.81 & \multicolumn{2}{c}{ B }
\end{tabular}

Grouping Information Using Tukey Method and $95.0 \%$ Confidence for TZR

$\begin{array}{lrrl}\text { Task } & \mathrm{N} & \text { Mean } & \text { Grouping } \\ \mathrm{I} & 76 & 26.03 & \mathrm{~A} \\ \mathrm{E} & 71 & 24.79 & \mathrm{~A}\end{array}$

Grouping Information Using Tukey Method and 95.0\% Confidence for TZR

\begin{tabular}{llrrrr} 
Seat & Task & N & Mean & Grouping \\
H120 & I & 26 & 33.87 & A & \\
H90 & I & 28 & 30.44 & A B & \\
H120 & E & 23 & 29.81 & A B & \\
H90 & E & 27 & 28.73 & \multicolumn{2}{c}{ B } \\
V & E & 21 & 15.84 & \multicolumn{2}{c}{ C } \\
V & I & 22 & 13.78 & & C
\end{tabular}




\title{
APPENDIX E - REACH ANOVA \& TUKEY HSD RESULTS
}

\author{
General Linear Model: Left Min X, Left Max $x, \ldots$ versus Subject, Seat, ... \\ Factor Type Levels Values \\ Subject random $101,2,3,4,5,6,7,8,9,10$ \\ Seat fixed $2 \mathrm{H}, \mathrm{V}$ \\ Plane fixed $3 \mathrm{~F}, \mathrm{~S}, \mathrm{~T}$ \\ Analysis of Variance for Left Min X, using Adjusted SS for Tests

$\begin{array}{lrrrrrr}\text { Source } & \text { DF } & \text { Seq SS } & \text { Adj SS } & \text { Adj MS } & \text { F } & \text { P } \\ \text { Subject } & 9 & 125036 & 130764 & 14529 & 23.15 & 0.000 \\ \text { Seat } & 1 & 522 & 2044 & 2044 & 3.26 & 0.074 \\ \text { Plane } & 2 & 958931 & 956075 & 478038 & 761.76 & 0.000 \\ \text { Seat*Plane } & 2 & 521 & 521 & 261 & 0.42 & 0.661 \\ \text { Error } & 96 & 60244 & 60244 & 628 & & \\ \text { Total } & 110 & 1145254 & & & & \end{array}$ \\ $S=25.0508 \quad R-S q=94.74 \% \quad R-S q(\operatorname{adj})=93.97 \%$ \\ Analysis of Variance for Left Max X, using Adjusted SS for Tests

$\begin{array}{lrrrrrr}\text { Source } & \text { DF } & \text { Seq SS } & \text { Adj SS } & \text { Adj MS } & \text { F } & \text { P } \\ \text { Subject } & 9 & 201505 & 186763 & 20751 & 9.09 & 0.000 \\ \text { Seat } & 1 & 1860 & 2017 & 2017 & 0.88 & 0.350 \\ \text { Plane } & 2 & 1773487 & 1754148 & 877074 & 384.19 & 0.000 \\ \text { Seat*Plane } & 2 & 4361 & 4361 & 2181 & 0.96 & 0.388 \\ \text { Error } & 96 & 219159 & 219159 & 2283 & & \\ \text { Total } & 110 & 2200372 & & & & \end{array}$ \\ $S=47.7797 \quad R-S q=90.04 \% \quad R-S q(\operatorname{adj})=88.59 \%$ \\ Analysis of Variance for Left Max Y, using Adjusted SS for Tests

$\begin{array}{lrrrrrr}\text { Source } & \text { DF } & \text { Seq SS } & \text { Adj SS } & \text { Adj MS } & \text { F } & \text { P } \\ \text { Subject } & 9 & 103532 & 110137 & 12237 & 18.99 & 0.000 \\ \text { Seat } & 1 & 701 & 2459 & 2459 & 3.81 & 0.054 \\ \text { Plane } & 2 & 1334863 & 1337065 & 668532 & 1037.28 & 0.000 \\ \text { Seat*Plane } & 2 & 2817 & 2817 & 1408 & 2.19 & 0.118 \\ \text { Error } & 96 & 61873 & 61873 & 645 & & \\ \text { Total } & 110 & 1503784 & & & & \end{array}$ \\ $S=25.3871 \quad R-S q=95.89 \% \quad R-S q(\operatorname{adj})=95.29 \%$
}

Analysis of Variance for Right Min X, using Adjusted SS for Tests

$\begin{array}{lrrrrrr}\text { Source } & \text { DF } & \text { Seq SS } & \text { Adj SS } & \text { Adj MS } & \text { F } & \text { P } \\ \text { Subject } & 9 & 119334 & 128977 & 14331 & 15.74 & 0.000 \\ \text { Seat } & 1 & 2048 & 453 & 453 & 0.50 & 0.482 \\ \text { Plane } & 2 & 840239 & 845350 & 422675 & 464.32 & 0.000 \\ \text { Seat*Plane } & 2 & 5133 & 5133 & 2566 & 2.82 & 0.065 \\ \text { Error } & 96 & 87391 & 87391 & 910 & & \\ \text { Total } & 110 & 1054145 & & & & \\ \text { S }=30.1715 & \text { R-Sq }=91.71 \% & \text { R-Sq(adj) }=90.50 \% & \end{array}$


Analysis of Variance for Right Max X, using Adjusted SS for Tests

$\begin{array}{lrrrrrr}\text { Source } & \text { DF } & \text { Seq SS } & \text { Adj SS } & \text { Adj MS } & \text { F } & \text { P } \\ \text { Subject } & 9 & 170461 & 157256 & 17473 & 9.68 & 0.000 \\ \text { Seat } & 1 & 20004 & 3624 & 3624 & 2.01 & 0.160 \\ \text { Plane } & 2 & 1764002 & 1723160 & 861580 & 477.48 & 0.000 \\ \text { Seat*Plane } & 2 & 23844 & 23844 & 11922 & 6.61 & 0.002 \\ \text { Error } & 96 & 173224 & 173224 & 1804 & & \\ \text { Total } & 110 & 2151535 & & & & \\ \text { S }=42.4784 & \text { R-Sq }=91.95 \% & R-S q(\text { adj })=90.77 \% & \end{array}$

Analysis of Variance for Right Max Y, using Adjusted SS for Tests

$\begin{array}{lrrrrrr}\text { Source } & \text { DF } & \text { Seq SS } & \text { Adj SS } & \text { Adj MS } & F & P \\ \text { Subject } & 9 & 92026 & 109021 & 12113 & 15.44 & 0.000 \\ \text { Seat } & 1 & 16884 & 12518 & 12518 & 15.95 & 0.000 \\ \text { Plane } & 2 & 1422286 & 1424731 & 712366 & 907.83 & 0.000 \\ \text { Seat*Plane } & 2 & 5056 & 5056 & 2528 & 3.22 & 0.044 \\ \text { Error } & 96 & 75331 & 75331 & 785 & & \\ \text { Total } & 110 & 1611583 & & & & \end{array}$

$\mathrm{S}=28.0124 \quad \mathrm{R}-\mathrm{Sq}=95.33 \% \quad \mathrm{R}-\mathrm{Sq}(\operatorname{adj})=94.64 \%$

Grouping Information Using Tukey Method and $95.0 \%$ Confidence for Left Min $X$

$$
\begin{array}{lrrl}
\text { Seat } & \text { N } & \text { Mean } & \text { Grouping } \\
\text { V } & 57 & -635.0 & A \\
\text { H } & 54 & -643.6 & A
\end{array}
$$

Grouping Information Using Tukey Method and $95.0 \%$ Confidence for Left Min $X$

\begin{tabular}{lrrlr} 
Plane & N & Mean & Grouping \\
S & 37 & -570.6 & A & \\
F & 40 & -572.5 & A & \\
T & 34 & -774.8 & \multicolumn{2}{c}{ B }
\end{tabular}

Grouping Information Using Tukey Method and 95.0\% Confidence for Left Min X

$\begin{array}{llrrl}\text { Seat } & \text { Plane } & \text { N } & \text { Mean } & \text { Grouping } \\ \text { V } & \text { S } & 18 & -567.0 & \text { A } \\ \text { V } & \text { F } & 20 & -570.5 & \text { A } \\ \text { H } & \text { S } & 19 & -574.3 & \text { A } \\ \text { H } & \text { F } & 20 & -574.5 & \text { A } \\ \text { V } & \text { T } & 19 & -767.5 & \text { B } \\ \text { H } & \text { T } & 15 & -782.1 & \text { B }\end{array}$

Grouping Information Using Tukey Method and 95.0\% Confidence for Left Max $X$

$\begin{array}{lrrl}\text { Seat } & \text { N } & \text { Mean } & \text { Grouping } \\ \text { V } & 57 & 543.8 & \text { A } \\ \text { H } & 54 & 535.2 & \text { A }\end{array}$

Grouping Information Using Tukey Method and 95.0\% Confidence for Left Max X

\begin{tabular}{lrrlr} 
Plane & N & Mean & Grouping \\
F & 40 & 637.7 & A & \\
S & 37 & 624.4 & A & \\
T & 34 & 356.3 & \multicolumn{2}{c}{ B }
\end{tabular}

Grouping Information Using Tukey Method and 95.0\% Confidence for Left Max $X$

$\begin{array}{llrrl}\text { Seat } & \text { Plane } & \text { N } & \text { Mean } & \text { Grouping } \\ \text { V } & \text { F } & 20 & 639.0 & \text { A } \\ \text { V } & \text { S } & 18 & 637.5 & \text { A } \\ \text { H } & \text { F } & 20 & 636.3 & \text { A } \\ \text { H } & \text { S } & 19 & 611.2 & \text { A } \\ \text { H } & \text { T } & 15 & 357.9 & \text { B } \\ \text { V } & \text { T } & 19 & 354.7 & \text { B }\end{array}$

Grouping Information Using Tukey Method and 95.0\% Confidence for Left Max $Y$

$\begin{array}{lrrl}\text { Seat } & \text { N } & \text { Mean } & \text { Grouping } \\ \text { V } & 57 & 618.4 & \text { A } \\ \text { H } & 54 & 608.9 & \text { A }\end{array}$


Grouping Information Using Tukey Method and 95.0\% Confidence for Left Max $Y$

$\begin{array}{lrrc}\text { Plane } & N & \text { Mean } & \text { Grouping } \\ \text { F } & 40 & 766.2 & \text { A } \\ \text { T } & 34 & 541.8 & \text { B } \\ \text { S } & 37 & 532.8 & \text { B }\end{array}$

Grouping Information Using Tukey Method and 95.0\% Confidence for Left Max $Y$

$\begin{array}{llrrr}\text { Seat } & \text { Plane } & \text { N } & \text { Mean } & \text { Grouping } \\ \text { H } & \text { F } & 20 & 766.4 & \text { A } \\ \text { V } & \text { F } & 20 & 765.9 & \text { A } \\ \text { V } & \text { T } & 19 & 553.7 & \text { B } \\ \text { V } & \text { S } & 18 & 535.5 & \text { B } \\ \text { H } & \text { S } & 19 & 530.2 & \text { B } \\ \text { H } & \text { T } & 15 & 530.0 & \text { B }\end{array}$

Grouping Information Using Tukey Method and 95.0\% Confidence for Right Min X

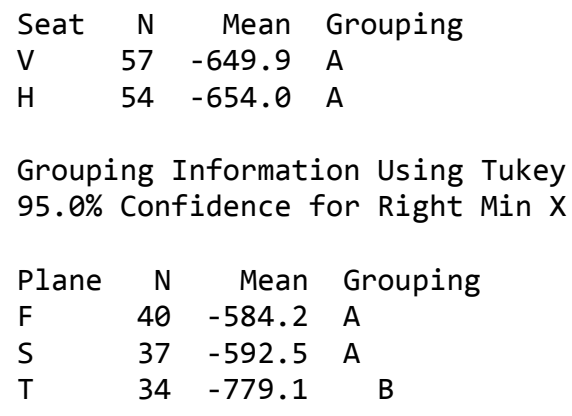

$\begin{array}{llrrl}\text { Seat } & \text { Plane } & \text { N } & \text { Mean } & \text { Grouping } \\ \text { H } & \text { F } & 20 & -580.5 & \text { A } \\ \text { V } & \text { F } & 20 & -588.0 & \text { A } \\ \text { H } & \text { S } & 19 & -590.5 & \text { A } \\ \text { V } & \text { S } & 18 & -594.5 & \text { A } \\ \text { V } & \text { T } & 19 & -767.2 & \text { B } \\ \text { H } & \text { T } & 15 & -791.0 & \text { B }\end{array}$

Grouping Information Using Tukey Method and 95.0\% Confidence for Right Max $X$

$\begin{array}{lrrl}\text { Seat } & \text { N } & \text { Mean } & \text { Grouping } \\ \text { H } & 54 & 537.0 & \text { A } \\ \text { V } & 57 & 525.4 & \text { A }\end{array}$

Grouping Information Using Tukey Method and 95.0\% Confidence for Right Max X

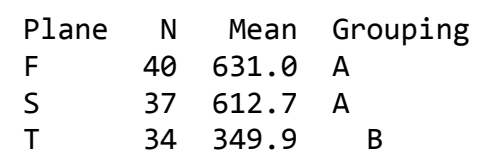

Grouping Information Using Tukey Method and 95.0\% Confidence for Right Max X

\begin{tabular}{llrrll} 
Seat & Plane & N & Mean & Grouping \\
H & F & 20 & 633.5 & A & \\
V & F & 20 & 628.5 & A & \\
V & S & 18 & 623.7 & A & \\
H & S & 19 & 601.7 & A & \\
H & T & 15 & 375.7 & \multicolumn{2}{c}{ B } \\
V & T & 19 & 324.1 & \multicolumn{2}{c}{ C }
\end{tabular}

Grouping Information Using Tukey Method and 95.0\% Confidence for Right Max $Y$

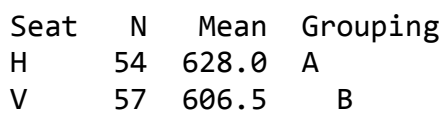
95.0\% Confidence for Right Max $Y$

\begin{tabular}{lrrrrr} 
Plane & N & Mean & Grouping \\
F & 40 & 774.3 & A & \\
T & 34 & 548.4 & \multicolumn{2}{c}{ B } & \\
S & 37 & 529.1 & \multicolumn{2}{c}{ C }
\end{tabular}

Grouping Information Using Tukey Method and 95.0\% Confidence for Right Max $Y$

\begin{tabular}{llrrrr} 
Seat & Plane & N & Mean & Grouping \\
H & F & 20 & 780.4 & A & \\
V & F & 20 & 768.1 & A & \\
H & T & 15 & 554.0 & B & \\
H & S & 19 & 549.4 & \multicolumn{2}{c}{ B } \\
V & T & 19 & 542.7 & \multicolumn{2}{c}{ B } \\
V & S & 18 & 508.7 & \multicolumn{2}{c}{ C }
\end{tabular}




\section{APPENDIX F - SUMMARIZED JOINT ANGLE DATA - HIPS AND KNEES}

\begin{tabular}{|c|c|c|c|c|c|c|c|c|c|c|c|c|c|c|c|c|c|c|c|c|c|}
\hline Subject & Seat & Task & Rep & LHX+ & LHY+ & LHZ+ & LHZ- & LHZR & RHX+ & RHY- & $\mathrm{RHZ}+$ & RHZ- & RHZR & LKX+ & LKZ+ & LKZ- & LKZR & RKX+ & RKZ+ & RKZ- & RKZR \\
\hline 1 & $\mathrm{H} 120$ & $\mathrm{E}$ & 1 & 54.8 & 45.4 & 16.9 & -7.9 & 24.8 & 62.9 & -13.1 & 5.7 & -14.1 & 19.9 & -66 & 70 & 74.6 & -4.2 & 79.5 & 26.4 & -15.7 & 42.1 \\
\hline 1 & $\mathrm{H} 120$ & $\mathrm{E}$ & 2 & 58.4 & 45.6 & 11.5 & -8 & 19.5 & 74.5 & -20.6 & 2 & -19.2 & 21.2 & -59.9 & 60 & 73.2 & -7.1 & 90.1 & 37.2 & -12.8 & 49.9 \\
\hline 1 & $\mathrm{H} 120$ & $E$ & 3 & 63.9 & 45.5 & 13 & -7 & 20 & 70.9 & -15.2 & 1.3 & -16.6 & 17.9 & -52.7 & 55.1 & 60.6 & 5.2 & 82.8 & 45.4 & -12.3 & 57.7 \\
\hline 1 & $\mathrm{H} 120$ & 1 & 1 & 75.8 & 32.9 & 11.5 & -6.7 & 18.1 & 58.5 & -9.3 & 4.6 & -5.5 & 10.1 & -49.3 & 46.9 & 43.2 & 4.3 & 74.7 & 34.7 & -17.3 & 52.1 \\
\hline 1 & $\mathrm{H} 120$ & 1 & 2 & 78.7 & 39.8 & 14.6 & -6.1 & 20.7 & 60.8 & -7.3 & 6.5 & -5.5 & 12 & -54.3 & 46.8 & 58.1 & 4.5 & 88.1 & 32.8 & -14.6 & 47.4 \\
\hline 1 & $\mathrm{H} 120$ & I & 3 & 78.2 & 37.7 & 9.6 & -6.4 & 16 & 53.2 & -11.3 & 2 & -9.4 & 11.3 & -57.3 & 75.4 & 72.9 & 5.1 & 82.8 & 32 & -12.2 & 44.2 \\
\hline 1 & H9O & $\mathrm{E}$ & 1 & 72.3 & 40.5 & 14.7 & -5.6 & 20.3 & 111.9 & -16 & 10.1 & -14.2 & 24.3 & -60.9 & 62.7 & 59.2 & 2.7 & 81.8 & 50.5 & -14.2 & 64.7 \\
\hline 1 & $\mathrm{H} 90$ & $\mathrm{E}$ & 2 & 72.3 & 45.9 & 13.1 & -5.4 & 18.5 & 101.7 & -13.6 & 9.7 & -17.6 & 27.3 & -67.3 & 75.2 & 63 & -7.9 & 99.8 & 39.5 & -8.1 & 47.6 \\
\hline 1 & $\mathrm{H} 90$ & $E$ & 3 & 75.1 & 45 & 13.3 & -4.5 & 17.8 & 102.8 & -14.4 & 5.2 & -18.1 & 23.3 & -75.3 & 82.1 & 60.3 & -8.4 & 92.7 & 48.4 & -9.2 & 57.6 \\
\hline 1 & $\mathrm{H} 90$ & 1 & 1 & 64.8 & 30.5 & 9.7 & -5.6 & 15.3 & 81.5 & -10.3 & 7.6 & -12.1 & 19.7 & -72 & 71.3 & 49.8 & 1.2 & 82 & 37.9 & -9.9 & 47.8 \\
\hline 1 & $\mathrm{H} 90$ & 1 & 2 & 77.6 & 26.6 & 11.3 & -7.6 & 18.8 & 83.2 & -11.3 & 7.9 & -21.9 & 29.8 & -65.9 & 76.5 & 67.6 & 5.7 & 99.9 & 34.9 & -18.3 & 53.2 \\
\hline 1 & $\mathrm{H} 90$ & 1 & 3 & 73.4 & 40.1 & 15.6 & -7.8 & 23.4 & 78.1 & -11.7 & 9.2 & -19.7 & 28.9 & -70.9 & 103.1 & 70.6 & 3.9 & 93.1 & 59 & -13.5 & 72.5 \\
\hline 1 & v & $\mathrm{E}$ & 1 & 85.2 & 24.1 & 19.9 & -0.3 & 20.1 & 88.4 & -26.5 & 6.5 & -14.1 & 20.6 & -26.3 & 18.7 & 40.3 & 21.5 & 99.3 & 31.2 & -1.7 & 32.9 \\
\hline 1 & v & $\mathrm{E}$ & 2 & 87.9 & 21.5 & 18.2 & 1.5 & 16.7 & 87.6 & -16.2 & $*$ & $*$ & $*$ & -29 & 18.3 & 41.4 & 28.8 & $*$ & $*$ & $*$ & $*$ \\
\hline 1 & V & $E$ & 3 & 84.5 & 25.7 & 24.8 & -2.2 & 27 & 87.5 & -24.3 & 16.5 & -18.3 & 34.8 & -24.4 & 13.5 & 40.2 & 30.8 & 101 & 33.2 & -27 & 60.3 \\
\hline 1 & v & 1 & 1 & 75.1 & 27.6 & 19.2 & 0.9 & 18.4 & 80.1 & -22.5 & -0.2 & -12.9 & 12.7 & -27.2 & 14.6 & 37.7 & 26.9 & 99.1 & 29.9 & -3.8 & 33.7 \\
\hline 1 & v & I & 2 & 78.8 & 25 & 18.4 & -18.8 & 37.2 & 82.6 & -20.4 & $*$ & -13.3 & 67.7 & -30.1 & 23 & 39.8 & 2.5 & 97.6 & 31.2 & -55.9 & 87.1 \\
\hline 1 & V & 1 & 3 & 82.5 & 29.5 & 21.8 & 1.4 & 20.4 & 86.6 & -22.5 & 22.1 & -13.3 & 35.4 & -28.2 & 12.2 & 38 & 27.2 & 99.7 & 31.7 & -26.5 & 58.2 \\
\hline 2 & $\mathrm{H} 120$ & $\mathrm{E}$ & 1 & 71.2 & 36.5 & 35.5 & 2.6 & 32.9 & 75.2 & -17.1 & 4.8 & -25.1 & 30 & -53 & 87.2 & 69.2 & 5.4 & 81.7 & 34.3 & -35.1 & 69.4 \\
\hline 2 & $\mathrm{H} 120$ & $\mathrm{E}$ & 2 & 65.4 & 33.5 & 41.5 & 3.4 & 38.1 & 77.1 & -18.4 & 5.9 & -24.2 & 30.1 & -57.5 & 90.7 & 51.7 & 2 & 90.7 & 29.9 & -34.4 & 64.3 \\
\hline 2 & $\mathrm{H} 120$ & $\mathrm{E}$ & 3 & 69.2 & 35 & 35.3 & 6.1 & 29.2 & 69.5 & -15.7 & 1.9 & -25 & 26.9 & -57.6 & 82.6 & 44.8 & 0.8 & 84.9 & 27.6 & -27.7 & 55.3 \\
\hline 2 & $\mathrm{H} 120$ & I & 1 & 70.8 & 25.7 & 32.9 & 0.1 & 32.7 & 77.3 & -23.7 & 1.9 & -20.7 & 22.6 & -56.9 & 77.7 & 51.9 & -2.3 & 87 & 30.4 & -38.9 & 69.3 \\
\hline 2 & $\mathrm{H} 120$ & I & 2 & 69.6 & 33.1 & 32 & -4 & 36 & 70.7 & -25.4 & -0.2 & -17.2 & 17.1 & -56.4 & 118.8 & 40.4 & 6.6 & 91.1 & 30.6 & -32.4 & 63.1 \\
\hline 2 & H120 & I & 3 & 72.1 & 28.1 & 34 & 2.2 & 31.8 & 81 & -21.6 & 3.4 & -22.9 & 26.3 & -52.1 & 88.9 & 44.8 & 0 & 89.9 & 30.5 & -38.6 & 69.2 \\
\hline 2 & $\mathrm{H} 90$ & $\mathrm{E}$ & 1 & 75.4 & 37.6 & 30.6 & -4.5 & 35.1 & 85.1 & -29.4 & 9.7 & -14.2 & 23.9 & -55.6 & 89.4 & 83.1 & 5.3 & 92.4 & 39 & -34.5 & 73.5 \\
\hline 2 & $\mathrm{H} 90$ & $\mathrm{E}$ & 2 & 74.1 & 38.2 & 36.8 & -0.4 & 37.2 & 82.5 & -29.4 & 6.5 & -16.5 & 23.1 & -55 & 76.4 & 78 & 7.6 & 92.8 & 40.4 & -21.9 & 62.3 \\
\hline 2 & H9O & $\mathrm{E}$ & 3 & 83.3 & 37.3 & 30.1 & 0 & 30.1 & 86.7 & -26.9 & 6.5 & -20.7 & 27.2 & -58.7 & 134.9 & 76 & 3.6 & 96.8 & 46 & -36.5 & 82.5 \\
\hline 2 & $\mathrm{H} 90$ & 1 & 1 & 62.5 & 34.5 & 22.1 & 0.6 & 21.5 & 85.6 & -23.3 & 1.4 & -13 & 14.4 & -61.9 & 88.1 & 49.5 & 4.9 & 99.2 & 41.8 & -31.7 & 73.5 \\
\hline 2 & $\mathrm{H} 90$ & 1 & 2 & 69.1 & 30.8 & 25.1 & -3.9 & 29 & 88.8 & -22.9 & 3.5 & -17.5 & 21.1 & -55.7 & 75.3 & 45.2 & 4.6 & 100 & 27.9 & -28.2 & 56.1 \\
\hline 2 & $\mathrm{H} 90$ & I & 3 & 71.3 & 20.8 & 28.8 & -2.8 & 31.5 & 76.6 & -24.3 & 2.4 & -15.3 & 17.7 & -57.7 & 86.4 & 44.2 & 5.1 & 94.5 & 29.7 & -35.4 & 65.1 \\
\hline 2 & v & $\mathrm{E}$ & 1 & 75.7 & 31.9 & 38.9 & 3.2 & 35.7 & 67.3 & -17.8 & 2.1 & -28.2 & 30.3 & -26.6 & 20.9 & 46.1 & 20.2 & 83.2 & 13 & -10 & 23 \\
\hline 2 & V & $\mathrm{E}$ & 2 & 72.9 & 38.4 & 35.1 & 8.4 & 26.7 & 67.2 & -18.2 & -3.5 & -22.8 & 19.4 & -15.8 & 13.8 & 35.2 & 21.6 & 83.3 & 17.5 & -12.7 & 30.2 \\
\hline 2 & v & $\mathrm{E}$ & 3 & 82.4 & 32.1 & 35.4 & 5.5 & 29.9 & 76.9 & -17.7 & -3.1 & -27.3 & 24.2 & -22.4 & 19 & 45.1 & 16.8 & 84.8 & 15.1 & -21.6 & 36.7 \\
\hline 2 & V & 1 & 1 & 62.6 & 28.4 & 32.1 & 11.6 & 20.5 & 58.3 & -18.6 & -2.9 & -20.1 & 17.2 & -28.5 & 20.7 & 41.9 & 21.6 & 75 & 10 & -15.8 & 25.8 \\
\hline 2 & V & 1 & 2 & 62.2 & 26.2 & 28.3 & 11.3 & 17 & 56.9 & -20.8 & -3 & -23 & 20 & -26.1 & 23.4 & 48.6 & 20.2 & 76.4 & 13.9 & -15.8 & 29.7 \\
\hline 2 & v & 1 & 3 & 57.7 & 25.7 & 30 & 6.8 & 23.2 & 53.4 & -20.6 & -4.3 & -22.5 & 18.2 & -19.4 & 15.4 & 33.3 & 17.2 & 76.3 & 16.4 & -16.2 & 32.6 \\
\hline
\end{tabular}




\begin{tabular}{|c|c|c|c|c|c|c|c|c|c|c|c|c|c|c|c|c|c|c|c|c|c|}
\hline Subject & Seat & Task & Rep & LHX+ & LHY+ & $\mathrm{LHZ+}$ & LHZ- & LHZR & RHX+ & RHY- & $\mathrm{RHZ}+$ & RHZ- & RHZR & LKX+ & LKZ+ & LKZ- & LKZR & RKX+ & RKZ+ & RKZ- & RKZR \\
\hline 3 & $\mathrm{H} 120$ & E & 1 & 49.6 & 37.7 & -10.4 & -36.3 & 26 & 65.3 & -19 & 12 & -6.8 & 18.8 & -65.8 & 52.2 & 62.7 & 8.8 & 75.3 & 15.3 & -25.5 & 40.8 \\
\hline 3 & $\mathrm{H} 120$ & $E$ & 2 & 52.2 & 39.2 & -10.2 & -34.5 & 24.3 & 58.2 & -23.5 & 9.9 & -10.7 & 20.6 & -74.3 & 62.1 & 72.2 & 11.8 & 81.1 & 24.2 & -27.3 & 51.4 \\
\hline 3 & $\mathrm{H} 120$ & I & 1 & 63.2 & 36.7 & -11.4 & -33.5 & 22.1 & 54.4 & -13.4 & 20.9 & -4.7 & 25.7 & -68.7 & 54.1 & 68.3 & 6.1 & 96.1 & 19.4 & -25.5 & 44.8 \\
\hline 3 & $\mathrm{H} 120$ & I & 2 & 51.6 & 41.7 & -9 & -24.7 & 15.7 & 43.1 & -10.7 & 11.6 & -10 & 21.6 & -67.8 & 81 & 56.7 & 7.7 & 75.2 & 31.8 & -27.6 & 59.4 \\
\hline 3 & $\mathrm{H} 120$ & 1 & 3 & 51.5 & 38.1 & -7.4 & -25.7 & 18.3 & 48.3 & -11.1 & 8.4 & -3.5 & 11.9 & -67.6 & 52.3 & 69.3 & 4.4 & 70.7 & 8 & -32.2 & 40.1 \\
\hline 3 & H9O & $\mathrm{E}$ & 1 & 77.8 & 45.1 & -7 & -36.8 & 29.8 & 58.6 & -30.9 & 10.2 & -11 & 21.1 & -66.4 & 54.1 & 75.9 & 9.4 & 104.9 & 38.2 & -22 & 60.1 \\
\hline 3 & H9O & $\mathrm{E}$ & 2 & 80.8 & 42.3 & -8.4 & -35.5 & 27.1 & 56.9 & -16.4 & 9.8 & -12.2 & 22 & -70.6 & 67.8 & 78.5 & 7.4 & 99.2 & 32.6 & -28.7 & 61.4 \\
\hline 3 & H9O & E & 3 & 76.2 & 38.4 & -8.4 & -33.8 & 25.4 & 58.7 & -7.2 & 14.7 & -17.6 & 32.3 & -61.6 & 50.2 & 70.6 & 6.8 & 93.7 & 17.4 & -24.7 & 42.2 \\
\hline 3 & H9O & 1 & 1 & 81.2 & 42.2 & -8.3 & -34.3 & 26 & 62.3 & -8.9 & 7.5 & -8.5 & 16 & -69.5 & 51.2 & 67.6 & -1 & 86 & 25.4 & -25.3 & 50.7 \\
\hline 3 & H9O & I & 2 & 75.7 & 40.9 & -7.4 & -32.5 & 25.1 & 65.1 & -8.4 & 8.1 & -10.7 & 18.8 & -53.5 & 59.5 & 72.7 & 8.8 & 86.9 & 34.8 & -28 & 62.9 \\
\hline 3 & H9O & 1 & 3 & 69.6 & 45.6 & -6.5 & -31.7 & 25.1 & 68.6 & -9.7 & 5.3 & -12 & 17.3 & -52.2 & 56.5 & 41.2 & 7 & 87.3 & 19.1 & -31.9 & 50.9 \\
\hline 4 & $\mathrm{H} 120$ & E & 1 & 55.7 & 51.8 & 29.1 & -4 & 33.1 & 70.4 & -5.9 & 0.4 & -32.5 & 32.9 & -76.8 & 107.1 & 79.4 & -17.3 & 134.1 & 16.1 & -26.8 & 43 \\
\hline 4 & $\mathrm{H} 120$ & $\mathrm{E}$ & 2 & 65.3 & 49.5 & 24.1 & -12.6 & 36.7 & 77.8 & -27.1 & -7.8 & -36.8 & 29.1 & $*$ & $*$ & 86.4 & -12.1 & 94.3 & 13.7 & -27.9 & 41.6 \\
\hline 4 & $\mathrm{H} 120$ & $\mathrm{E}$ & 3 & 61.7 & 45.4 & 27.1 & -15.4 & 42.5 & 76.7 & -27.9 & -7.3 & -29.9 & 22.5 & $*$ & $*$ & 88.9 & -13 & 98.2 & 14.6 & -24.2 & 38.8 \\
\hline 4 & $\mathrm{H} 120$ & 1 & 1 & 55 & 51.8 & 31.7 & -12.7 & 44.4 & 85.7 & -15.4 & -4.8 & -49.7 & 44.9 & -46.6 & 51.5 & 47.4 & 0.1 & 95 & 10.9 & -18.3 & 29.2 \\
\hline 4 & $\mathrm{H} 120$ & I & 2 & 75.5 & 52.7 & 21 & -15.7 & 36.7 & 72.5 & -5.9 & -12.4 & -29.2 & 16.8 & -62.2 & 63.8 & 44.8 & 0.4 & 82.8 & 7.7 & -25.3 & 33 \\
\hline 4 & $\mathrm{H} 120$ & 1 & 3 & 70.1 & 52.7 & 23.7 & -17.8 & 41.5 & 77.9 & -5.4 & -5.9 & -28.2 & 22.3 & -70 & 72.4 & 52.6 & 3.2 & 89.9 & 6.9 & -25.3 & 32.2 \\
\hline 4 & H9O & E & 1 & 69.2 & 47.2 & 21.1 & -21.2 & 42.3 & 63.6 & -1.8 & -4.4 & -53.3 & 48.9 & -69.2 & 86.2 & 79.9 & -13.6 & 127.1 & 15.5 & -26.9 & 42.4 \\
\hline 4 & H9O & $\mathrm{E}$ & 2 & 69.7 & 46.4 & 42.6 & -14.5 & 57.1 & 76.3 & -8.4 & -9.3 & -35.7 & 26.5 & -72.5 & 91.8 & 81.8 & -9.2 & 119.4 & 14.5 & -25.1 & 39.7 \\
\hline 4 & H90 & $\mathrm{E}$ & 3 & 70.2 & 49.3 & 36.3 & -7.7 & 44 & 73.6 & -6.4 & -6.4 & -37.3 & 30.9 & -77.5 & 104.2 & 82.4 & -13.2 & 127.2 & 15.9 & -24.9 & 40.8 \\
\hline 4 & H9O & I & 1 & 80.6 & 39.7 & 30.2 & -8.5 & 38.7 & 90.7 & -8.7 & -4.4 & -34.8 & 30.4 & -65.7 & 94.2 & 58.4 & 4.4 & 95.1 & 9.4 & -23.4 & 32.8 \\
\hline 4 & H9O & 1 & 2 & 82.8 & 40.9 & 25.5 & -17.6 & 43.1 & 80.5 & -9.9 & -2.1 & -27.1 & 25 & -62.3 & 113.4 & 64 & 5.4 & 75 & 6.8 & -25.3 & 32.2 \\
\hline 4 & H9O & 1 & 3 & 80.1 & 40.4 & 23.6 & -17.1 & 40.7 & 87.4 & -12.5 & 0.2 & -27.1 & 27.3 & -65.6 & 105.6 & 38.4 & -0.8 & 89.7 & 14.1 & -25.5 & 39.6 \\
\hline 4 & V & E & 1 & 64.7 & 26.3 & 29.4 & -4.5 & 33.9 & 57.1 & -25.4 & -2.8 & -29.4 & 26.6 & -24.2 & 34.1 & 42.2 & 10.6 & 91.8 & 9.8 & -14.5 & 24.2 \\
\hline 4 & V & $\mathrm{E}$ & 2 & 65.5 & 28.8 & 33.8 & -9.8 & 43.6 & 56.8 & -22.3 & -9.8 & -32.8 & 23 & -24.4 & 63.1 & 40.8 & 8.7 & 92.8 & 9.5 & -15.4 & 24.9 \\
\hline 4 & V & $\mathrm{E}$ & 3 & 63.9 & 23.2 & 30.4 & -4.6 & 35 & 57.8 & -24.6 & -1.2 & -26.4 & 25.3 & -25 & 47 & 35.2 & 6.6 & 92.5 & 11.4 & -19.7 & 31.1 \\
\hline 4 & V & 1 & 1 & 72.1 & 30.2 & 30.6 & 8.8 & 21.8 & 68.5 & -17.7 & -6.8 & -29.4 & 22.6 & -30.6 & 27.6 & 42.3 & 19.7 & 89.2 & 8.5 & -11.7 & 20.1 \\
\hline 4 & V & 1 & 2 & 66.5 & 30.9 & 27.8 & 6 & 21.8 & 61.4 & -16.1 & -1 & -29.3 & 28.3 & -30 & 64.5 & 36.6 & 11.7 & 91.2 & 9.4 & -18.3 & 27.7 \\
\hline 4 & V & 1 & 3 & 67.5 & 32.2 & 30.4 & 5.3 & 25.1 & 64.7 & -18.1 & -2.5 & -27 & 24.5 & -30.5 & 76.4 & 36.5 & 14.2 & 89.1 & 9.1 & -16.4 & 25.5 \\
\hline
\end{tabular}




\begin{tabular}{|c|c|c|c|c|c|c|c|c|c|c|c|c|c|c|c|c|c|c|c|c|c|}
\hline Subject & Seat & Task & Rep & LHX+ & LHY+ & LHZ+ & LHZ- & LHZR & RHX+ & RHY- & $\mathrm{RHZ}+$ & RHZ- & RHZR & LKX+ & LKZ+ & LKZ- & LKZR & RKX+ & RKZ+ & RKZ- & RKZR \\
\hline 5 & $\mathrm{H} 120$ & $E$ & 1 & 74.4 & 44.9 & 39.1 & -16.2 & 55.2 & 69.7 & -24.1 & -3 & -34.7 & 31.7 & -75 & 76.4 & 71.6 & -6.3 & 92.4 & 33.7 & -25.6 & 59.3 \\
\hline 5 & $\mathrm{H} 120$ & $\mathrm{E}$ & 2 & 76.3 & 45.5 & 33.3 & -2.4 & 35.6 & 74.3 & -21 & -2.8 & -30.7 & 27.9 & -66.7 & 75.8 & 81 & -0.8 & 96.8 & 23.6 & -18.4 & 42 \\
\hline 5 & $\mathrm{H} 120$ & $\mathrm{E}$ & 3 & 61.6 & 51.3 & 31.7 & 4.3 & 27.4 & 75.6 & -16.5 & -2.5 & -34.2 & 31.7 & $*$ & 101.9 & 86 & -5.8 & 93.8 & 18.9 & -14.3 & 33.2 \\
\hline 5 & $\mathrm{H} 120$ & I & 1 & 64 & 42.1 & 38.3 & -11 & 49.3 & 90.6 & -25.6 & -2.3 & -30.9 & 28.5 & -45.6 & 39.1 & 60.4 & 14.7 & 104.8 & 16 & -21.6 & 37.6 \\
\hline 5 & $\mathrm{H} 120$ & I & 2 & 64 & 46.8 & 42.4 & -11.2 & 53.6 & 86.6 & -26.1 & -4.1 & -36.1 & 32 & -60.5 & 54.1 & 65.9 & 22 & 111 & 16.5 & -24.2 & 40.7 \\
\hline 5 & $\mathrm{H} 120$ & I & 3 & 67.2 & 39.1 & 36.6 & -10.3 & 46.9 & 75.4 & -20.2 & -4.8 & -31.5 & 26.7 & -47.9 & 49.6 & 64.6 & 13.6 & 104.6 & 29.2 & $*$ & $*$ \\
\hline 5 & $\mathrm{H} 90$ & $\mathrm{E}$ & 1 & 79.1 & 41.2 & 33 & -1.8 & 34.8 & 84.6 & -20.1 & -5 & -39.2 & 34.2 & -68.1 & 71 & 67.7 & -15.6 & 95.3 & 20.8 & -8.5 & 29.3 \\
\hline 5 & $\mathrm{H} 90$ & $\mathrm{E}$ & 2 & 75.7 & 49.1 & 36.5 & 7 & 29.5 & 84.3 & -16.5 & -4.7 & -44.8 & 40.1 & -78.5 & 97.1 & 67.7 & -9.3 & 97.1 & 34.2 & -8.8 & 43 \\
\hline 5 & $\mathrm{H} 90$ & $\mathrm{E}$ & 3 & 71.8 & 44 & 39.6 & 4.3 & 35.4 & 85.6 & -15.1 & -4.1 & -32.9 & 28.8 & -66.2 & 69 & 64.4 & -10.2 & 93.6 & 26.6 & -19 & 45.7 \\
\hline 5 & $\mathrm{H} 90$ & I & 1 & 77.1 & 41.9 & 32.1 & -11.5 & 43.6 & 97.3 & -22.9 & -5.3 & -32.2 & 27 & -53.3 & 48.9 & 60.1 & 7.3 & 104.5 & 13.3 & -17.6 & 30.9 \\
\hline 5 & $\mathrm{H} 90$ & I & 2 & 64.6 & 45.4 & 43.1 & 0.1 & 43 & 112.6 & -23.5 & 29.6 & -29.6 & 59.2 & -47.9 & 51.2 & 59.2 & -1.7 & 108.9 & 19.3 & -29.6 & 48.9 \\
\hline 5 & $\mathrm{H} 90$ & I & 3 & 67.5 & 40.2 & 41.5 & -6.2 & 47.7 & 87 & -21.4 & -3.4 & -27.8 & 24.4 & -50.6 & 56.4 & 53.5 & 2.4 & 108.9 & 32.7 & -19.6 & 52.3 \\
\hline 5 & v & $\mathrm{E}$ & 1 & 79.3 & 19.5 & 49.3 & 19.3 & 30 & 78.1 & -12.7 & -5.4 & -27.4 & 22 & -21.8 & 21.6 & 41.5 & 29.7 & 89.8 & 22.4 & 1.3 & 21.2 \\
\hline 5 & v & $\mathrm{E}$ & 2 & 76.4 & 22.3 & 51.8 & 20.3 & 31.5 & 78.9 & -28.3 & -8.4 & -27 & 18.6 & -21.7 & 3.5 & 37.5 & 29.6 & 89.9 & 22.9 & -11.3 & 34.2 \\
\hline 5 & v & $E$ & 3 & 81.5 & 26.6 & 51.7 & 21 & 30.7 & 81.8 & -29.7 & -5.8 & -23.2 & 17.4 & -24.7 & 8.4 & 38.5 & 27.3 & 87.5 & 20.1 & -14 & 34.1 \\
\hline 5 & v & I & 1 & 94.9 & 24.9 & 43.4 & 12.2 & 31.2 & 91.9 & -14.5 & -3.4 & -30.8 & 27.4 & -22.4 & 16.2 & 36.3 & 25.8 & 90.2 & 21.8 & -6.2 & 28 \\
\hline 5 & v & I & 2 & 69.9 & 23.2 & 51.6 & 24.8 & 26.7 & 72.2 & -21.6 & -1.6 & -25.7 & 24.2 & -25.9 & 11.8 & 37.3 & 27.2 & 91 & 22.7 & -2.1 & 24.8 \\
\hline 5 & v & I & 3 & 71.4 & 20 & 43.7 & 13.1 & 30.6 & 68.6 & -20.5 & 1.6 & -24.7 & 26.2 & -28.3 & 11.5 & 33.5 & 27.2 & 90.5 & 23.8 & -6.5 & 30.3 \\
\hline 6 & $\mathrm{H} 120$ & $E$ & 1 & 69.7 & 45.9 & 26.2 & -1.4 & 27.6 & 57.5 & -25.8 & -10.3 & -34.1 & 23.8 & -59.6 & 81.7 & 84.9 & 0.4 & 56 & 30.9 & -2.2 & 33.1 \\
\hline 6 & $\mathrm{H} 120$ & $E$ & 2 & 53 & 44.5 & 26 & 5.8 & 20.2 & 57.4 & -28.8 & -13.5 & -28.4 & 14.9 & -57 & 80.2 & 84.4 & -2 & 65.2 & 33.4 & -5.5 & 38.9 \\
\hline 6 & $\mathrm{H} 120$ & $E$ & 3 & 68.1 & 45.4 & 28 & 0.6 & 27.4 & 58.5 & -23.7 & -9.3 & -37 & 27.6 & $*$ & $*$ & 88.3 & 3.4 & 56.9 & 40.3 & -9.5 & 49.8 \\
\hline 6 & $\mathrm{H} 120$ & I & 1 & 63.3 & 38.5 & 25.6 & -4 & 29.7 & 68 & -6.8 & -12.1 & -27 & 15 & -46 & 42.5 & 49.7 & 12.1 & 52.1 & 31.7 & -8.8 & 40.5 \\
\hline 6 & $\mathrm{H} 120$ & I & 2 & 64.4 & 38.7 & 23.5 & -3.9 & 27.4 & 60.9 & -11.5 & -8.5 & -24.7 & 16.1 & -50.6 & 85.9 & 64.3 & 16.7 & 45.2 & 29.4 & -16.2 & 45.6 \\
\hline 6 & $\mathrm{H} 120$ & I & 3 & 60.4 & 38.6 & 30.3 & -2.2 & 32.5 & 63.6 & -8.2 & -12.2 & -28.9 & 16.6 & -48.5 & 78.9 & 71.9 & 11.5 & 40.1 & 32.7 & -14.4 & 47.1 \\
\hline 6 & $\mathrm{H} 90$ & $\mathrm{E}$ & 1 & 90.8 & 48.6 & 30.8 & -2.6 & 33.4 & 82.2 & -26.9 & -5.9 & -30.5 & 24.7 & $*$ & $*$ & 88.4 & 0.1 & 78.3 & 25.9 & -20.4 & 46.2 \\
\hline 6 & $\mathrm{H} 90$ & $\mathrm{E}$ & 2 & 91.3 & 48.1 & 30.9 & -0.9 & 31.8 & 75.4 & -32.7 & -8.3 & -37.2 & 28.9 & -73.8 & 107.5 & 85.9 & 6.1 & 68.5 & 28.3 & -16.4 & 44.7 \\
\hline 6 & $\mathrm{H} 90$ & $\mathrm{E}$ & 3 & 95.1 & 52 & 32.2 & -7.5 & 39.7 & 80.7 & -13.8 & -7.9 & -29.1 & 21.3 & -59.5 & 110.9 & 86.4 & -4.1 & 77.3 & 24.5 & -9.4 & 33.9 \\
\hline 6 & $\mathrm{H} 90$ & I & 1 & 76.4 & 41.8 & 28.9 & -5 & 33.8 & 82.7 & -9.2 & -6.1 & -34.4 & 28.4 & -54.6 & 59.7 & 62.3 & 12.1 & 73.6 & 26.2 & -6.3 & 32.5 \\
\hline 6 & $\mathrm{H} 90$ & I & 2 & 72 & 31.9 & 30 & -3.6 & 33.6 & 75.8 & -10.4 & -7.6 & -36.3 & 28.7 & -56.6 & 60.2 & 75.1 & 6.7 & 63.8 & 28.5 & -16.9 & 45.4 \\
\hline 6 & $\mathrm{H} 90$ & I & 3 & 80.9 & 34.7 & 30.5 & -4.2 & 34.7 & 79.2 & -12 & -11.6 & -35.4 & 23.8 & -66.7 & 66.5 & 70.8 & 10.8 & 72.4 & 25.7 & -6.9 & 32.6 \\
\hline 6 & v & $\mathrm{E}$ & 1 & 71.3 & 23.2 & 23.1 & 9.1 & 14 & 68.9 & -23.8 & -16.1 & -36.9 & 20.8 & -29.4 & 6.8 & 33.2 & 24.8 & 75.1 & 32 & 0.5 & 31.5 \\
\hline 6 & v & $\mathrm{E}$ & 2 & 75.6 & 26.3 & 19.6 & 7.4 & 12.3 & 73 & -17.9 & -5.9 & -37.4 & 31.4 & -31.6 & 15.8 & 39.5 & 21.9 & 73.3 & 29.3 & -0.7 & 30 \\
\hline 6 & v & $\mathrm{E}$ & 3 & 78 & 28 & 23.1 & 7.6 & 15.5 & 72.8 & -20.5 & -15.5 & -35.2 & 19.7 & -29.6 & 18.5 & 41.8 & 21.3 & 73.2 & 28.6 & -4.9 & 33.6 \\
\hline 6 & v & I & 1 & 70.4 & 27.8 & 17.5 & 0.3 & 17.2 & 63.5 & -19.3 & -14.9 & -38.7 & 23.8 & -29.2 & 18.6 & 36.8 & 22.6 & 78.6 & 30.7 & 4.7 & 26 \\
\hline 6 & v & 1 & 2 & 73.4 & 34.9 & 23.2 & 2.8 & 20.4 & 65.5 & -14.2 & -14.9 & -35.1 & 20.2 & -30.1 & 13 & 35.4 & 24.1 & 73.8 & 27.3 & 1.5 & 25.8 \\
\hline 6 & $\mathrm{v}$ & 1 & 3 & 76.2 & 27.6 & 21.6 & 7.5 & 14.1 & 68.8 & -17.7 & -14.1 & -33.2 & 19.1 & -32.3 & 17 & 36.3 & 19.5 & 72.7 & 28.7 & 0.4 & 28.4 \\
\hline
\end{tabular}




\begin{tabular}{|c|c|c|c|c|c|c|c|c|c|c|c|c|c|c|c|c|c|c|c|c|c|}
\hline Subject & Seat & Task & Rep & LHX+ & LHY+ & LHZ+ & LHZ- & LHZR & RHX+ & RHY- & RHZ+ & RHZ- & RHZR & LKX+ & LKZ+ & LKZ- & LKZR & RKX+ & RKZ+ & RKZ- & RKZR \\
\hline 7 & $\mathrm{H} 120$ & $E$ & 1 & 45.4 & 45.7 & 33 & 1.1 & 31.9 & 64.5 & -35.1 & 1.1 & -20 & 21.1 & -88.3 & 87.4 & 70.2 & -5.6 & 61.3 & 6 & -17.1 & 23.1 \\
\hline 7 & $\mathrm{H} 120$ & $\mathrm{E}$ & 2 & 53.1 & 38.4 & 32.2 & -0.7 & 32.9 & 69.8 & -32.5 & 0.2 & -21.5 & 21.8 & -98.5 & $*$ & 81.4 & -8.8 & 73.7 & 9.7 & -24.8 & 34.6 \\
\hline 7 & $\mathrm{H} 120$ & I & 1 & 52.5 & 30 & 24.1 & -10.7 & 34.8 & 62.5 & -32.8 & 2.8 & -20.6 & 23.4 & -49.4 & 43.8 & 52.3 & 2 & 89.7 & 17 & -16.1 & 33.1 \\
\hline 7 & $\mathrm{H} 120$ & I & 2 & 50.2 & 33.9 & 28.9 & -7.9 & 36.8 & 57.9 & -20 & 3.4 & -29.7 & 33.1 & -63.1 & 76.9 & 63.4 & -2.4 & 84 & 17.8 & -30.4 & 48.2 \\
\hline 7 & $\mathrm{H} 90$ & $\mathrm{E}$ & 1 & 53.1 & 43.6 & 30.6 & 5.7 & 24.9 & 69.1 & -40.1 & 1.8 & -19.2 & 21.1 & -71 & 88.5 & 68.8 & -0.3 & 84.9 & -6 & -36.6 & 30.6 \\
\hline 7 & $\mathrm{H} 90$ & $\mathrm{E}$ & 2 & 56.8 & 47.5 & 29.8 & 3.9 & 25.9 & 66.5 & -40.4 & -3.2 & -24 & 20.8 & -86.8 & 100.6 & 80.1 & -4.5 & 74.7 & -0.4 & -31 & 30.6 \\
\hline 7 & $\mathrm{H} 90$ & $\mathrm{E}$ & 3 & 58.3 & 40.7 & 27.8 & 2.3 & 25.5 & 64.1 & -42.8 & -3.5 & -23.2 & 19.7 & -82 & 107.7 & 71.9 & -6.1 & 74.8 & 3.1 & -28.9 & 32 \\
\hline 7 & $\mathrm{H} 90$ & I & 1 & 43 & 30.2 & 29 & -6.5 & 35.6 & 66 & -24.5 & 4 & -21.5 & 25.5 & -51.4 & 69.4 & 39.7 & 1.6 & 88.7 & 18.7 & -20.6 & 39.3 \\
\hline 7 & $\mathrm{H} 90$ & I & 2 & 60.1 & 30.2 & 30.5 & -5.1 & 35.6 & 72 & -31.3 & 5.5 & -20.4 & 25.9 & -54.1 & 51.9 & 52.9 & -5.1 & 81.4 & 11.9 & -20 & 31.8 \\
\hline 7 & $\mathrm{H} 90$ & I & 3 & 54.9 & 35.7 & 28.8 & 2.8 & 26 & 63 & -23.1 & -1.5 & -22 & 20.5 & -63.2 & 70.3 & 61.2 & -1.1 & 74 & 20.9 & -19.1 & 40 \\
\hline 7 & v & $\mathrm{E}$ & 1 & 50.9 & 13.9 & 20.7 & 7.2 & 13.5 & 54.9 & -27.1 & -2.4 & -23.2 & 20.8 & -10.4 & 5.9 & 30.2 & 20 & 71.5 & 11.4 & -17.1 & 28.5 \\
\hline 7 & v & $\mathrm{E}$ & 2 & 46.5 & 18 & 20.9 & 8.3 & 12.5 & 48.8 & -25 & -3.8 & -23.3 & 19.5 & -12.7 & 4.1 & 27.5 & 18.7 & 70.3 & 9.5 & -16.4 & 25.9 \\
\hline 7 & v & I & 1 & 46.8 & 21.4 & 24.6 & 6.7 & 17.9 & 49.6 & -24.5 & -3.4 & -19.9 & 16.5 & -10.4 & 6.6 & 28.2 & 18.7 & 80.2 & 10.6 & -15.3 & 25.9 \\
\hline 7 & v & I & 2 & 47.5 & 15.5 & 20.1 & 8.9 & 11.3 & 51.5 & -23.1 & -0.7 & -22.1 & 21.5 & -13 & 6.1 & 30.3 & 20.1 & 77 & 12.8 & -16.1 & 29 \\
\hline 8 & $\mathrm{H} 120$ & $\mathrm{E}$ & 1 & 48 & 37.7 & 35.1 & 2.9 & 32.2 & 62.2 & -1.6 & 6.2 & -26.6 & 32.9 & -73.1 & 91.5 & 67.7 & 9.7 & 78.6 & 16.6 & -15.8 & 32.4 \\
\hline 8 & $\mathrm{H} 120$ & $\mathrm{E}$ & 2 & 59.5 & 39.1 & 41.5 & 5.1 & 36.4 & 76.8 & -2.5 & 10.8 & -27.4 & 38.2 & -77 & 98.1 & 64.1 & 9.2 & 78.7 & 27.8 & -16.8 & 44.7 \\
\hline 8 & $\mathrm{H} 120$ & $\mathrm{E}$ & 3 & 50.1 & 39.6 & 33.5 & 0.5 & 33.1 & 70.5 & -3.7 & 3.6 & -32.6 & 36.2 & -68.9 & 98.5 & 71.6 & 10.5 & 80.9 & 24.7 & -3.1 & 27.8 \\
\hline 8 & $\mathrm{H} 120$ & I & 1 & 53.4 & 36.9 & 44.3 & 7.9 & 36.4 & 64.8 & -6.4 & 2.8 & -41.7 & 44.4 & -59.5 & 75.2 & 54 & 10.7 & 61.1 & 36.8 & -10.6 & 47.5 \\
\hline 8 & $\mathrm{H} 120$ & I & 2 & 73.8 & 44.1 & 37 & 4.5 & 32.5 & 77.5 & -3.5 & 5.3 & -18.2 & 23.6 & -63.8 & 86.6 & 69 & 10.3 & 64 & 19.9 & -15.9 & 35.8 \\
\hline 8 & $\mathrm{H} 120$ & I & 3 & 65.9 & 41.2 & 45.9 & 2.5 & 43.4 & 79.2 & -7.4 & 15.4 & -22.2 & 37.6 & -61.1 & 71.8 & 62 & 14.3 & 78.5 & 24.6 & -20.4 & 45 \\
\hline 8 & H90 & $\mathrm{E}$ & 1 & 44.3 & 37.2 & 37.2 & 5.9 & 31.3 & 55.5 & -10.6 & -1.4 & -31.4 & 30 & -92.9 & 111.3 & 73.7 & 7.6 & 79.2 & 31.1 & -10 & 41 \\
\hline 8 & $\mathrm{H} 90$ & $\mathrm{E}$ & 2 & 54.9 & 35.1 & 35.2 & -6.2 & 41.4 & 61.6 & -9.8 & -4 & -30.5 & 26.5 & -76.7 & 89.3 & 67.9 & 8.7 & 78.3 & 34.2 & -14 & 48.2 \\
\hline 8 & $\mathrm{H} 90$ & $\mathrm{E}$ & 3 & 49.7 & 38.1 & 38.7 & -2.2 & 40.9 & 59.5 & -8.3 & -0.6 & -31.6 & 31 & -82.8 & 89.6 & 76.3 & 10.7 & 76.9 & 41.4 & -11.1 & 52.5 \\
\hline 8 & $\mathrm{H} 90$ & I & 1 & 54.5 & 41.6 & 53.8 & 4 & 49.9 & 65.1 & -6.7 & -1.4 & -32.5 & 31.1 & -59.3 & 66.8 & 61.5 & 12.9 & 79 & 32.9 & -0.3 & 33.2 \\
\hline 8 & $\mathrm{H} 90$ & I & 2 & 50.4 & 40.8 & 35.8 & 3 & 32.8 & 62.5 & -9 & 20 & -43.5 & 63.5 & -60.2 & 62.5 & 55.2 & 13.3 & 77.9 & 39.3 & -9.5 & 48.8 \\
\hline 8 & $\mathrm{H} 90$ & I & 3 & 51.6 & 43.3 & 40.1 & 6.1 & 33.9 & 61.4 & -3 & 4.3 & -28.3 & 32.6 & -63.1 & 83.3 & 61 & 17.2 & 78.6 & 44.4 & -8.3 & 52.7 \\
\hline
\end{tabular}




\begin{tabular}{|c|c|c|c|c|c|c|c|c|c|c|c|c|c|c|c|c|c|c|c|c|c|}
\hline Subject & Seat & Task & Rep & LHX+ & LHY+ & $\mathrm{LHZ}+$ & LHZ- & LHZR & RHX+ & RHY- & $\mathrm{RHZ}+$ & RHZ- & RHZR & LKX+ & LKZ+ & LKZ- & LKZR & RKX+ & RKZ+ & RKZ- & RKZR \\
\hline 9 & $\mathrm{H} 120$ & $E$ & 1 & 73 & 43.3 & 0.8 & -39.2 & 40 & 72.3 & -42.2 & 12.4 & -8.3 & 20.7 & -74.5 & 81.4 & 80.8 & -3.2 & 98.9 & 53.3 & -22.5 & 75.8 \\
\hline 9 & $\mathrm{H} 120$ & $\mathrm{E}$ & 2 & 65.4 & 43.2 & 4.3 & -36.2 & 40.5 & 67.4 & -38.6 & 12.4 & -10.8 & 23.2 & -65.4 & 71.3 & 76.6 & -0.8 & 96.7 & 46.9 & -17.6 & 64.5 \\
\hline 9 & $\mathrm{H} 120$ & $\mathrm{E}$ & 3 & 72.6 & 43.7 & -1.5 & -34.6 & 33.2 & 63.8 & -38.8 & 14.2 & -8.1 & 22.4 & -79.1 & 85.4 & 81.4 & -3.1 & 98.7 & 45.8 & -24 & 69.8 \\
\hline 9 & $\mathrm{H} 120$ & I & 1 & 77.9 & 48.1 & 6.8 & -43.5 & 50.3 & 71.5 & -18.8 & 14.6 & -6.3 & 20.9 & -74.8 & 78.5 & 64.7 & 1.1 & 109.7 & 20.2 & -13.9 & 34.1 \\
\hline 9 & $\mathrm{H} 120$ & I & 2 & 65.8 & 47.5 & 7.8 & -30.7 & 38.5 & 55.3 & -17.3 & 33.4 & -7.2 & 40.6 & -60.2 & 80.9 & 41.9 & -2.8 & 95.9 & 38 & -8.6 & 46.6 \\
\hline 9 & $\mathrm{H} 120$ & I & 3 & 73.1 & 44.6 & 2.5 & -42.7 & 45.2 & 58.4 & -20.6 & 13.4 & -6.6 & 20 & -69.3 & 77.3 & 50.8 & 3.8 & 94.7 & 31.5 & -11.3 & 42.8 \\
\hline 9 & H90 & $\mathrm{E}$ & 1 & 82.5 & 45.1 & 1.3 & -40.6 & 41.9 & 84.6 & -45.3 & 18.8 & -1.6 & 20.4 & -75.9 & 75.9 & 75 & -8.9 & 108.4 & 42.3 & -22.4 & 64.6 \\
\hline 9 & $\mathrm{H} 90$ & $\mathrm{E}$ & 2 & 81.7 & 44.3 & 4.8 & -39.8 & 44.5 & 92 & -45.4 & 26.7 & -4.2 & 30.9 & -72 & 67.6 & 62.9 & -6.5 & 111.2 & 44.2 & -27.8 & 72 \\
\hline 9 & $\mathrm{H} 90$ & $\mathrm{E}$ & 3 & 77.4 & 48 & 6.1 & -41.2 & 47.3 & 88 & -45.6 & 22 & -4.7 & 26.7 & -90.4 & 97.4 & 79.6 & -5.9 & 111.3 & 40.2 & -27.4 & 67.6 \\
\hline 9 & $\mathrm{H} 90$ & I & 1 & 76.8 & 42.3 & 1.5 & -48.1 & 49.7 & 80.8 & -35.6 & 18 & -7.5 & 25.4 & -67.9 & 76.9 & 61.8 & -4.5 & 117.6 & 28.6 & -14.7 & 43.3 \\
\hline 9 & $\mathrm{H} 90$ & I & 2 & 86.1 & 42 & 6.7 & -45.4 & 52.1 & 87.3 & -22.9 & 15.4 & -1.6 & 17 & -64.6 & 64.1 & 51.2 & -5.9 & 110.7 & 44.1 & -12.8 & 57 \\
\hline 9 & $\mathrm{H} 90$ & I & 3 & 85.1 & 48.3 & 3 & -40 & 43 & 81.4 & -24.6 & 27.2 & -2.2 & 29.4 & -68.8 & 71.7 & 53.5 & -5.2 & 113.6 & 51.1 & -20.9 & 72 \\
\hline 9 & V & $\mathrm{E}$ & 1 & 66.5 & 20.4 & -10.5 & -30.5 & 20 & 66.7 & -26.3 & 10.5 & -5.8 & 16.3 & -36 & 38.8 & 27.5 & 9.3 & 92.5 & 35.8 & -10.7 & 46.5 \\
\hline 9 & v & $\mathrm{E}$ & 2 & 67.5 & 13.3 & -9.8 & -34.4 & 24.6 & 65.6 & -26.1 & 6.2 & -6.6 & 12.7 & -34.3 & 18.3 & 28.7 & 10.9 & 96.3 & 28.4 & -10.9 & 39.3 \\
\hline 9 & v & $\mathrm{E}$ & 3 & 72.5 & 15.9 & -0.4 & -31.1 & 30.7 & 70.8 & -27.3 & 7.3 & -11.9 & 19.2 & -25.9 & 6.6 & 31.4 & 21 & 93.9 & 22.3 & -18.6 & 40.9 \\
\hline 9 & v & 1 & 1 & 57.4 & 21.7 & -9 & -27.8 & 18.7 & 52.4 & -22.5 & 7.7 & -8 & 15.8 & -17.6 & 38.7 & 21 & 7.4 & 94.1 & 21.2 & -2.5 & 23.7 \\
\hline 9 & v & I & 2 & 64.2 & 29.2 & -9.5 & -33.2 & 23.7 & 63.5 & -22.7 & 13.6 & -5.8 & 19.4 & -18.6 & 11.5 & 34.3 & 22 & 95.9 & 25.4 & -10.9 & 36.3 \\
\hline 9 & v & I & 3 & 66.7 & 26.2 & -9 & -28.7 & 19.7 & 64.1 & -24.5 & 14.6 & -5.9 & 20.5 & -26.7 & 12.6 & 35.2 & 16 & 95 & 27 & -11 & 38 \\
\hline 10 & $\mathrm{H} 120$ & $\mathrm{E}$ & 1 & 34.9 & 41.4 & 9 & -10.5 & 19.5 & 42 & -7.9 & 8.8 & -23 & 31.8 & -55.2 & 86.8 & 52.2 & -1.6 & 71 & 19 & -28.8 & 47.8 \\
\hline 10 & $\mathrm{H} 120$ & $\mathrm{E}$ & 2 & 29.8 & 39.4 & 7.2 & -11.9 & 19.1 & 38.8 & -5.4 & 5.1 & -22.2 & 27.3 & -48.3 & 84 & 56.2 & -4.3 & 65.3 & 22.3 & -30 & 52.3 \\
\hline 10 & $\mathrm{H} 120$ & $\mathrm{E}$ & 3 & 34.8 & 39.6 & 13.4 & -11.3 & 24.8 & 47.5 & -4.4 & 5.2 & -28.4 & 33.6 & -49.7 & 83.5 & 58.8 & -0.8 & 76.8 & 30.9 & -24.8 & 55.7 \\
\hline 10 & $\mathrm{H} 120$ & I & 1 & 38.8 & 25.6 & 16.2 & -7.2 & 23.4 & 40.8 & -7.1 & 5.9 & -19.8 & 25.7 & -51.6 & 74.9 & 47.7 & 5.3 & 76.3 & 22.8 & -30.6 & 53.5 \\
\hline 10 & $\mathrm{H} 120$ & I & 2 & 35.5 & 27.8 & 15.7 & -13.4 & 29.1 & 32 & -8 & 9.4 & -20.4 & 29.9 & -47.8 & 72.9 & 54.2 & 3.3 & 88.2 & 25.2 & -33 & 58.2 \\
\hline 10 & H9O & $\mathrm{E}$ & 1 & 35 & 36.2 & 1.2 & -17.4 & 18.6 & 47.2 & -10.5 & 3.2 & -20.5 & 23.7 & -49.1 & 73.1 & 48.8 & -2.4 & 77.5 & 31.7 & -25.2 & 56.9 \\
\hline 10 & $\mathrm{H} 90$ & $\mathrm{E}$ & 2 & 33.1 & 38 & 8.1 & -8.6 & 16.7 & 44.4 & -11.6 & 3.7 & -21.2 & 24.9 & -55.3 & 73.8 & 55.2 & -2.4 & 79.1 & 18.2 & -34.5 & 52.7 \\
\hline 10 & $\mathrm{H} 90$ & I & 1 & 29.3 & 27.9 & 14.5 & -10.3 & 24.8 & 36.6 & -6.6 & 1.9 & -25.3 & 27.2 & -49.5 & 70 & 48.4 & 0.9 & 87 & 28.8 & -15.8 & 44.6 \\
\hline 10 & $\mathrm{H} 90$ & I & 2 & 46 & 27.9 & 10.7 & -12.4 & 23.1 & 46.8 & -8.5 & 5.1 & -30.4 & 35.6 & -51.7 & 80.1 & 49.9 & 0.5 & 82.5 & 27.2 & -21.7 & 48.9 \\
\hline 10 & $\mathrm{H} 90$ & I & 3 & 37.4 & 25.7 & 14.6 & -14.3 & 28.9 & 29.9 & -5.9 & 7.5 & -20.2 & 27.8 & -60.5 & 95.1 & 58.5 & -1.8 & 88.1 & 21.8 & -30.6 & 52.4 \\
\hline 10 & V & $\mathrm{E}$ & 1 & 35 & 19.8 & 3.1 & -10.4 & 13.5 & 33.7 & -21.5 & 3.7 & -19.6 & 23.2 & -8 & 18.4 & 25.4 & 9.3 & 77.8 & 20.5 & -1.2 & 21.6 \\
\hline 10 & v & $\mathrm{E}$ & 2 & 34.3 & 19.6 & 5 & -10.3 & 15.3 & 33.2 & -19.1 & 2.9 & -17.5 & 20.4 & -8.8 & 23.2 & 22.2 & 6.1 & 79.1 & 21.8 & -1.4 & 23.2 \\
\hline 10 & v & I & 1 & 35.5 & 20.7 & 5 & -7.7 & 12.6 & 30 & -13.1 & -2.9 & -13.9 & 11 & -10.5 & 14.1 & 22 & 4.2 & 82.6 & 17.4 & 3.8 & 13.6 \\
\hline 10 & v & 1 & 2 & 31.5 & 26.4 & 5 & -15.8 & 20.8 & 29.6 & -11.1 & 1.2 & -21.5 & 22.7 & -11.4 & 26.5 & 29.2 & 7.7 & 78.1 & 23.6 & -0.7 & 24.4 \\
\hline 10 & v & I & 3 & 29.6 & 26.2 & 6.9 & -11.2 & 18.2 & 25.9 & -12.7 & 6.3 & -11.4 & 17.7 & -9.6 & 22.4 & 23.7 & 10.6 & 79 & 20.7 & -1.1 & 21.9 \\
\hline
\end{tabular}




\section{APPENDIX G - SUMMARIZED JOINT ANGLE DATA - SHOULDERS}

\begin{tabular}{|c|c|c|c|c|c|c|c|c|c|c|c|c|c|c|c|c|c|c|c|c|c|}
\hline Subject & Seat & Task & Rep & LSX+ & LSX- & LSXR & LSY+ & LSY- & LSYR & LSZ+ & LSZ- & LSZR & RSX+ & RSX- & RSXR & RSY+ & RSY- & RSYR & RSZ+ & RSZ- & RSZR \\
\hline 1 & $\mathrm{H} 120$ & E & 1 & 4 & -66 & 70 & 74.6 & -4.2 & 78.8 & 93.9 & 9.5 & 84.3 & 2.8 & -62.8 & 65.6 & 15.8 & -63.6 & 79.4 & 29.4 & -32.7 & 62.1 \\
\hline 1 & $\mathrm{H} 120$ & $E$ & 2 & 0.1 & -59.9 & 60 & 73.2 & -7.1 & 80.3 & 88 & 4.8 & 83.2 & 11.3 & -43.7 & 54.9 & 12.7 & -63.3 & 76 & 38.4 & -52.8 & 91.2 \\
\hline 1 & $\mathrm{H} 120$ & E & 3 & 2.4 & -52.7 & 55.1 & 60.6 & 5.2 & 55.4 & 85.1 & 9.8 & 75.3 & 1.2 & -44.2 & 45.4 & 13 & -61.1 & 74.1 & 29.9 & -61.1 & 91 \\
\hline 1 & $\mathrm{H} 120$ & I & 1 & -2.4 & -49.3 & 46.9 & 43.2 & 4.3 & 38.9 & 53.2 & -9.8 & 62.9 & 32.5 & -76.3 & 108.8 & 16.7 & -70.4 & 87.1 & 22.1 & -85.2 & 107.3 \\
\hline 1 & $\mathrm{H} 120$ & 1 & 2 & -7.5 & -54.3 & 46.8 & 58.1 & 4.5 & 53.6 & 82.3 & -8.2 & 90.4 & 13.2 & -86 & 99.2 & 13.6 & -63.9 & 77.4 & 55.9 & -76.2 & 132.1 \\
\hline 1 & $\mathrm{H} 120$ & 1 & 3 & 18.1 & -57.3 & 75.4 & 72.9 & 5.1 & 67.8 & 73.5 & -10 & 83.4 & 26 & -75.7 & 101.7 & 6.8 & -68.5 & 75.4 & 21.5 & -59.8 & 81.3 \\
\hline 1 & H9O & E & 1 & 1.8 & -60.9 & 62.7 & 59.2 & 2.7 & 56.5 & 88.6 & -0.3 & 88.9 & 13.7 & -44.9 & 58.6 & 8.6 & -67.3 & 75.9 & 35.1 & -45.3 & 80.4 \\
\hline 1 & $\mathrm{H} 90$ & E & 2 & 8 & -67.3 & 75.2 & 63 & -7.9 & 70.9 & 85.1 & 1.3 & 83.8 & 15 & -55.7 & 70.7 & 7.2 & -66.2 & 73.4 & 47.8 & -44.4 & 92.2 \\
\hline 1 & $\mathrm{H} 90$ & E & 3 & 6.8 & -75.3 & 82.1 & 60.3 & -8.4 & 68.7 & 86.5 & -0.1 & 86.6 & 14.8 & -40.1 & 54.9 & 4.1 & -59.7 & 63.8 & 35.7 & -57.2 & 92.9 \\
\hline 1 & $\mathrm{H} 90$ & I & 1 & -0.6 & -72 & 71.3 & 49.8 & 1.2 & 48.6 & 65.2 & -8.9 & 74.2 & 32.5 & -69.8 & 102.3 & 5.6 & -64.6 & 70.2 & 80.7 & -83.7 & 164.4 \\
\hline 1 & $\mathrm{H} 90$ & I & 2 & 10.6 & -65.9 & 76.5 & 67.6 & 5.7 & 61.8 & 71.4 & -10.5 & 82 & 70.3 & -73.6 & 143.9 & 8.2 & -68.5 & 76.7 & 96.6 & -44 & 140.6 \\
\hline 1 & $\mathrm{H} 90$ & I & 3 & 32.1 & -70.9 & 103.1 & 70.6 & 3.9 & 66.7 & 68.1 & -5.6 & 73.7 & 55.7 & -81.3 & 136.9 & -0.1 & -80 & 79.9 & 66.1 & -61.3 & 127.5 \\
\hline 1 & V & E & 1 & -7.6 & -26.3 & 18.7 & 40.3 & 21.5 & 18.8 & 39.9 & 0.9 & 39 & -17.8 & -31.3 & 13.5 & -23.7 & -36.2 & 12.5 & 4.4 & -17.5 & 21.9 \\
\hline 1 & V & E & 2 & -10.7 & -29 & 18.3 & 41.4 & 28.8 & 12.7 & 31.2 & 7.1 & 24.1 & -27.1 & -35.4 & 8.3 & -28.4 & -36.4 & 8 & -2.6 & -19.6 & 17 \\
\hline 1 & V & $E$ & 3 & -10.9 & -24.4 & 13.5 & 40.2 & 30.8 & 9.4 & 25.4 & 6.7 & 18.8 & -21.6 & -30.9 & 9.3 & -26.9 & -34.1 & 7.2 & 0.1 & -20.1 & 20.2 \\
\hline 1 & V & I & 1 & -12.6 & -27.2 & 14.6 & 37.7 & 26.9 & 10.8 & 26.6 & 12 & 14.5 & -23.8 & -32.4 & 8.6 & -19.6 & -33.4 & 13.8 & -2.4 & -29.5 & 27.1 \\
\hline 1 & v & I & 2 & -7.1 & -30.1 & 23 & 39.8 & 2.5 & 37.3 & 31.9 & 12.3 & 19.6 & -5.1 & -33.4 & 28.4 & -3.5 & -40.1 & 36.6 & 10.4 & -22.1 & 32.5 \\
\hline 1 & V & I & 3 & -16.1 & -28.2 & 12.2 & 38 & 27.2 & 10.7 & 29.3 & 14.5 & 14.8 & -21.7 & -32.9 & 11.1 & -23 & -34.7 & 11.7 & -3.8 & -24.7 & 20.9 \\
\hline 2 & $\mathrm{H} 120$ & E & 1 & 34.2 & -53 & 87.2 & 69.2 & 5.4 & 63.9 & 45.5 & -15.4 & 60.9 & 14.1 & -50.6 & 64.7 & -9.6 & -52 & 42.5 & 29.8 & -37.3 & 67.1 \\
\hline 2 & $\mathrm{H} 120$ & E & 2 & 33.3 & -57.5 & 90.7 & 51.7 & 2 & 49.7 & 46.7 & -3.4 & 50.1 & 18.6 & -45.7 & 64.3 & -11.9 & -50.3 & 38.4 & 29.3 & -13.2 & 42.5 \\
\hline 2 & $\mathrm{H} 120$ & $E$ & 3 & 25 & -57.6 & 82.6 & 44.8 & 0.8 & 44 & 46.9 & 8.6 & 38.2 & 42.9 & -51.7 & 94.5 & -10.3 & -54 & 43.8 & 32.1 & -44.2 & 76.3 \\
\hline 2 & $\mathrm{H} 120$ & I & 1 & 20.7 & -56.9 & 77.7 & 51.9 & -2.3 & 54.2 & 50 & 1.6 & 48.5 & 40.4 & -55.2 & 95.5 & -7 & -59.4 & 52.4 & 38.3 & -95.6 & 134 \\
\hline 2 & $\mathrm{H} 120$ & I & 2 & $*$ & -56.4 & 118.8 & 40.4 & 6.6 & 33.8 & 42.9 & -22.7 & 65.6 & 29.9 & -54 & 83.8 & -5.8 & -62 & 56.2 & 41.8 & -25.6 & 67.5 \\
\hline 2 & $\mathrm{H} 120$ & I & 3 & 36.8 & -52.1 & 88.9 & 44.8 & 0 & 44.8 & 48.3 & -12.9 & 61.1 & 18.8 & -54.3 & 73.1 & -9.9 & -56.9 & 47 & 36.4 & -27.8 & 64.2 \\
\hline 2 & H90 & E & 1 & 33.8 & -55.6 & 89.4 & 83.1 & 5.3 & 77.8 & 65.9 & -6.5 & 72.4 & 10.4 & -52.3 & 62.7 & -11 & -51.2 & 40.1 & 28.6 & -25.5 & 54 \\
\hline 2 & $\mathrm{H} 90$ & E & 2 & 21.4 & -55 & 76.4 & 78 & 7.6 & 70.4 & 71.2 & -3.6 & 74.8 & 15.7 & -57 & 72.7 & -12 & -54.5 & 42.4 & 23.5 & -31.7 & 55.2 \\
\hline 2 & $\mathrm{H} 90$ & E & 3 & $*$ & -58.7 & 134.9 & 76 & 3.6 & 72.4 & 57.5 & -54.6 & 112.2 & 17.4 & -59 & 76.4 & -10.2 & -50.2 & 40 & 30.2 & -19.3 & 49.5 \\
\hline 2 & $\mathrm{H} 90$ & I & 1 & 26.2 & -61.9 & 88.1 & 49.5 & 4.9 & 44.6 & 59.1 & -3.9 & 63 & 32.9 & -60.4 & 93.3 & -9.3 & -67.5 & 58.2 & 32.5 & -30.5 & 63.1 \\
\hline 2 & $\mathrm{H} 90$ & I & 2 & 19.7 & -55.7 & 75.3 & 45.2 & 4.6 & 40.5 & 48.3 & -7 & 55.3 & 28.3 & -54.2 & 82.6 & -2.2 & -67.7 & 65.6 & 34.6 & -27.4 & 61.9 \\
\hline 2 & $\mathrm{H} 90$ & I & 3 & 28.7 & -57.7 & 86.4 & 44.2 & 5.1 & 39.1 & 45 & -6.8 & 51.8 & 36 & -59.8 & 95.7 & -4.7 & -64.5 & 59.9 & 40.1 & -36.3 & 76.4 \\
\hline 2 & V & E & 1 & -5.6 & -26.6 & 20.9 & 46.1 & 20.2 & 25.9 & 27.3 & -10.1 & 37.4 & -11.6 & -30.2 & 18.6 & -8.8 & -27.5 & 18.8 & 23.2 & 7.9 & 15.3 \\
\hline 2 & V & $\mathrm{E}$ & 2 & -2 & -15.8 & 13.8 & 35.2 & 21.6 & 13.6 & 15.7 & -5.5 & 21.3 & -9.9 & -24.1 & 14.1 & -8.7 & -23.2 & 14.6 & 24.4 & 9.6 & 14.8 \\
\hline 2 & V & $E$ & 3 & -3.4 & -22.4 & 19 & 45.1 & 16.8 & 28.3 & 19.8 & -9.9 & 29.8 & -7.2 & -23.3 & 16.1 & -5 & -23.6 & 18.6 & 28 & 13.7 & 14.3 \\
\hline 2 & v & I & 1 & -7.8 & -28.5 & 20.7 & 41.9 & 21.6 & 20.3 & 30.5 & 6.3 & 24.2 & -16.6 & -29.8 & 13.2 & -8.9 & -31.8 & 22.9 & 13.3 & 4.1 & 9.3 \\
\hline 2 & V & I & 2 & -2.8 & -26.1 & 23.4 & 48.6 & 20.2 & 28.4 & 43.2 & -4.7 & 47.9 & -10.4 & -29.5 & 19.1 & -6.7 & -31.2 & 24.5 & 30.1 & -3.1 & 33.2 \\
\hline 2 & v & 1 & 3 & -4 & -19.4 & 15.4 & 33.3 & 17.2 & 16.1 & 20.4 & 0 & 20.4 & -13.7 & -22.5 & 8.9 & -5.8 & -22.9 & 17.1 & 25.6 & 14.3 & 11.3 \\
\hline
\end{tabular}




\begin{tabular}{|c|c|c|c|c|c|c|c|c|c|c|c|c|c|c|c|c|c|c|c|c|c|}
\hline Subject & Seat & Task & Rep & LSX+ & LSX- & LSXR & LSY+ & LSY- & LSYR & LSZ+ & LSZ- & LSZR & RSX+ & RSX- & RSXR & RSY+ & RSY- & RSYR & RSZ+ & RSZ- & RSZR \\
\hline 3 & $\mathrm{H} 120$ & $\mathrm{E}$ & 1 & -13.6 & -65.8 & 52.2 & 62.7 & 8.8 & 54 & 97.3 & -0.8 & 98 & 34.7 & -98.2 & 132.9 & -5.7 & -78.9 & 73.1 & 45.4 & -93 & 138.5 \\
\hline 3 & $\mathrm{H} 120$ & $E$ & 2 & -12.2 & -74.3 & 62.1 & 72.2 & 11.8 & 60.5 & 104.6 & 4.3 & 100.3 & 38.7 & -99.4 & 138.2 & -5.9 & -68.8 & 62.9 & 44.9 & -97.3 & 142.2 \\
\hline 3 & $\mathrm{H} 120$ & 1 & 1 & -14.6 & -68.7 & 54.1 & 68.3 & 6.1 & 62.2 & 81.3 & 10.5 & 70.7 & 59.4 & -63.3 & 122.7 & -9 & -56.6 & 47.6 & 65.9 & -37.4 & 103.3 \\
\hline 3 & $\mathrm{H} 120$ & 1 & 2 & 13.1 & -67.8 & 81 & 56.7 & 7.7 & 49 & 74.4 & -4.8 & 79.2 & 41.1 & -49.7 & 90.8 & -4.6 & -60.9 & 56.3 & 50.8 & -47.8 & 98.6 \\
\hline 3 & $\mathrm{H} 120$ & 1 & 3 & -15.3 & -67.6 & 52.3 & 69.3 & 4.4 & 64.9 & 67.6 & 10.6 & 57 & 35.1 & -47.4 & 82.6 & -4.6 & -57.4 & 52.8 & 45.2 & -39.6 & 84.8 \\
\hline 3 & $\mathrm{H} 90$ & E & 1 & -12.4 & -66.4 & 54.1 & 75.9 & 9.4 & 66.4 & 90 & 7.8 & 82.2 & 34.2 & -45.7 & 79.9 & -9.8 & -80.9 & 71.1 & 49.1 & -36.8 & 85.9 \\
\hline 3 & $\mathrm{H} 90$ & $\mathrm{E}$ & 2 & -2.8 & -70.6 & 67.8 & 78.5 & 7.4 & 71.1 & 97.8 & 6.3 & 91.5 & 18.2 & -86.3 & 104.5 & 0.6 & -87.4 & 87.9 & 19.8 & -85.6 & 105.4 \\
\hline 3 & $\mathrm{H} 90$ & $\mathrm{E}$ & 3 & -11.4 & -61.6 & 50.2 & 70.6 & 6.8 & 63.8 & 84.8 & 10.8 & 74 & 21.7 & -66.2 & 87.9 & -4.8 & -65.3 & 60.5 & 41.4 & -91.9 & 133.4 \\
\hline 3 & $\mathrm{H} 90$ & I & 1 & -18.2 & -69.5 & 51.2 & 67.6 & -1 & 68.6 & 66.9 & 9.9 & 57 & 38.4 & -38.8 & 77.3 & -7 & -66.6 & 59.6 & 52.9 & -37 & 89.9 \\
\hline 3 & $\mathrm{H} 90$ & I & 2 & 6 & -53.5 & 59.5 & 72.7 & 8.8 & 64 & 63.5 & -2.7 & 66.2 & 41.6 & -20.5 & 62.1 & -3.8 & -62.3 & 58.5 & 33.9 & -25.2 & 59.1 \\
\hline 3 & $\mathrm{H} 90$ & I & 3 & 4.3 & -52.2 & 56.5 & 41.2 & 7 & 34.2 & 54.7 & -4 & 58.7 & 57.7 & -31.5 & 89.2 & -1.8 & -62.9 & 61.1 & 52 & -55.5 & 107.5 \\
\hline 4 & $\mathrm{H} 120$ & $E$ & 1 & 30.4 & -76.8 & 107.1 & 79.4 & -17.3 & 96.7 & 62.9 & -44.4 & 107.3 & 22.8 & -42 & 64.8 & -0.8 & -63.1 & 62.4 & 41.2 & -9.3 & 50.5 \\
\hline 4 & $\mathrm{H} 120$ & E & 2 & * & * & * & 86.4 & -12.1 & 98.5 & * & -33 & $*$ & -5.3 & -58.8 & 53.6 & 19.8 & -56 & 75.8 & 36.9 & -24.7 & 61.6 \\
\hline 4 & $\mathrm{H} 120$ & $\mathrm{E}$ & 3 & $*$ & $*$ & $*$ & 88.9 & -13 & 101.9 & 123.3 & $*$ & $*$ & 25.6 & -58 & 83.6 & 25.3 & -54.1 & 79.3 & 52.1 & -17.1 & 69.3 \\
\hline 4 & $\mathrm{H} 120$ & I & 1 & 4.8 & -46.6 & 51.5 & 47.4 & 0.1 & 47.3 & 4.9 & -48.9 & 53.8 & 51.4 & -66.9 & 118.4 & 11.7 & -61.1 & 72.7 & 75.2 & -36.9 & 112.1 \\
\hline 4 & $\mathrm{H} 120$ & I & 2 & 1.6 & -62.2 & 63.8 & 44.8 & 0.4 & 44.4 & 29.1 & -52.1 & 81.2 & 47.9 & -72.7 & 120.5 & 21.4 & -58.8 & 80.2 & 75 & -33.2 & 108.2 \\
\hline 4 & $\mathrm{H} 120$ & I & 3 & 2.3 & -70 & 72.4 & 52.6 & 3.2 & 49.3 & 35.4 & -50.8 & 86.2 & 49.5 & -76.7 & 126.2 & 18.5 & -62.7 & 81.2 & 73.1 & -32 & 105.1 \\
\hline 4 & H9O & $\mathrm{E}$ & 1 & 17 & -69.2 & 86.2 & 79.9 & -13.6 & 93.5 & 55.2 & -37.2 & 92.4 & 11.5 & -56.8 & 68.3 & 14.8 & -47 & 61.8 & 40.5 & -23.8 & 64.3 \\
\hline 4 & $\mathrm{H} 90$ & E & 2 & 19.3 & -72.5 & 91.8 & 81.8 & -9.2 & 91 & 54.3 & -40.5 & 94.7 & 14.2 & -63.1 & 77.3 & 4.5 & -46 & 50.5 & 46.2 & -22.8 & 69.1 \\
\hline 4 & $\mathrm{H} 90$ & $\mathrm{E}$ & 3 & 26.7 & -77.5 & 104.2 & 82.4 & -13.2 & 95.6 & 54.9 & -41.9 & 96.8 & 17.4 & -58.7 & 76.1 & 1 & -49 & 50 & 55 & -23.6 & 78.6 \\
\hline 4 & $\mathrm{H} 90$ & I & 1 & 28.6 & -65.7 & 94.2 & 58.4 & 4.4 & 54 & 22.6 & -49.7 & 72.3 & 39.9 & -77.5 & 117.4 & 20.6 & -54.2 & 74.8 & 65.7 & -28.7 & 94.4 \\
\hline 4 & $\mathrm{H} 90$ & 1 & 2 & 51.1 & -62.3 & 113.4 & 64 & 5.4 & 58.5 & 24.8 & -53 & 77.8 & 42.3 & -75.8 & 118.1 & 26.4 & -60.3 & 86.7 & 69.9 & -14.9 & 84.8 \\
\hline 4 & $\mathrm{H} 90$ & 1 & 3 & 40 & -65.6 & 105.6 & 38.4 & -0.8 & 39.3 & 30.9 & -53 & 83.9 & 38.5 & -71.2 & 109.7 & 27.5 & -48.3 & 75.8 & 59 & -12.1 & 71.1 \\
\hline 4 & V & $\mathrm{E}$ & 1 & 9.9 & -24.2 & 34.1 & 42.2 & 10.6 & 31.6 & -13.3 & -56.7 & 43.3 & 1.5 & -25.3 & 26.8 & -13.4 & -37.6 & 24.2 & 52.4 & 10.9 & 41.5 \\
\hline 4 & V & $E$ & 2 & 38.7 & -24.4 & 63.1 & 40.8 & 8.7 & 32.2 & -3.2 & -57.3 & 54.1 & 24.2 & -39.8 & 64 & -7 & -37.4 & 30.4 & 44.5 & -8.6 & 53.1 \\
\hline 4 & V & $\mathrm{E}$ & 3 & 22.1 & -25 & 47 & 35.2 & 6.6 & 28.6 & -3.9 & -51.8 & 47.9 & 29.8 & -41.5 & 71.3 & -4.8 & -32.2 & 27.4 & 48.3 & -16.3 & 64.6 \\
\hline 4 & V & I & 1 & -3 & -30.6 & 27.6 & 42.3 & 19.7 & 22.5 & -8.6 & -39.6 & 31 & -0.7 & -29.1 & 28.5 & -12.7 & -35.4 & 22.7 & 37.2 & 5.7 & 31.4 \\
\hline 4 & V & 1 & 2 & 34.5 & -30 & 64.5 & 36.6 & 11.7 & 24.9 & -0.9 & -56.4 & 55.6 & 33.3 & -30 & 63.3 & -1.4 & -39 & 37.6 & 45.8 & -2.6 & 48.4 \\
\hline 4 & V & 1 & 3 & 45.9 & -30.5 & 76.4 & 36.5 & 14.2 & 22.3 & 0.6 & -67.7 & 68.3 & 43.4 & -31.2 & 74.6 & -4.4 & -33.9 & 29.5 & 49.8 & -6.4 & 56.1 \\
\hline
\end{tabular}




\begin{tabular}{|c|c|c|c|c|c|c|c|c|c|c|c|c|c|c|c|c|c|c|c|c|c|}
\hline Subject & Seat & Task & Rep & LSX+ & LSX- & LSXR & LSY+ & LSY- & LSYR & LSZ+ & LSZ- & LSZR & RSX+ & RSX- & RSXR & RSY+ & RSY- & RSYR & RSZ+ & RSZ- & RSZR \\
\hline 5 & $\mathrm{H} 120$ & $\mathrm{E}$ & 1 & 1.4 & -75 & 76.4 & 71.6 & -6.3 & 77.9 & 58.8 & -30.6 & 89.4 & 15.6 & -54.5 & 70.1 & 6.7 & -60 & 66.7 & 34 & -17.6 & 51.6 \\
\hline 5 & H120 & $\mathrm{E}$ & 2 & 9.1 & -66.7 & 75.8 & 81 & -0.8 & 81.8 & 66.6 & -46.4 & 113 & 16.1 & -59.3 & 75.5 & 4.4 & -55.5 & 59.9 & 37.7 & -20.5 & 58.2 \\
\hline 5 & $\mathrm{H} 120$ & $\mathrm{E}$ & 3 & 1.6 & * & 101.9 & 86 & -5.8 & 91.8 & 94.6 & -36.9 & 131.5 & 33.3 & -59.4 & 92.6 & 8.5 & -56.4 & 64.9 & 43.1 & -29.4 & 72.6 \\
\hline 5 & $\mathrm{H} 120$ & 1 & 1 & -6.5 & -45.6 & 39.1 & 60.4 & 14.7 & 45.7 & 18.6 & -26.2 & 44.8 & 39.9 & -65.6 & 105.5 & 5.6 & -63 & 68.6 & 54.7 & -54.4 & 109.2 \\
\hline 5 & $\mathrm{H} 120$ & 1 & 2 & -6.4 & -60.5 & 54.1 & 65.9 & 22 & 43.9 & 36.8 & -23.2 & 60 & 37.9 & -61.8 & 99.7 & 3.5 & -72.6 & 76.1 & 54.9 & -28.5 & 83.4 \\
\hline 5 & $\mathrm{H} 120$ & I & 3 & 1.6 & -47.9 & 49.6 & 64.6 & 13.6 & 51 & 36.7 & -26.7 & 63.4 & 41 & -65.1 & 106.1 & 9.4 & -62.6 & 71.9 & 53.2 & -39.3 & 92.5 \\
\hline 5 & $\mathrm{H} 90$ & E & 1 & 3 & -68.1 & 71 & 67.7 & -15.6 & 83.3 & 55 & -13.4 & 68.4 & 34.7 & -52.7 & 87.4 & 8.7 & -63.8 & 72.5 & 52.8 & -18.3 & 71.1 \\
\hline 5 & $\mathrm{H} 90$ & $\mathrm{E}$ & 2 & 18.6 & -78.5 & 97.1 & 67.7 & -9.3 & 76.9 & 60.3 & -20.8 & 81.1 & 28.5 & -56 & 84.5 & 7.5 & -63.9 & 71.4 & 40.9 & -21.3 & 62.3 \\
\hline 5 & $\mathrm{H} 90$ & E & 3 & 2.8 & -66.2 & 69 & 64.4 & -10.2 & 74.6 & 43.4 & -16.9 & 60.3 & 19.7 & -53.8 & 73.5 & 5.2 & -56.5 & 61.7 & 37.4 & -26.2 & 63.6 \\
\hline 5 & $\mathrm{H} 90$ & I & 1 & -4.5 & -53.3 & 48.9 & 60.1 & 7.3 & 52.9 & 30.3 & -23 & 53.3 & 44.5 & -64.3 & 108.8 & 10 & -64.7 & 74.7 & 66.8 & -41.9 & 108.7 \\
\hline 5 & $\mathrm{H} 90$ & I & 2 & 3.2 & -47.9 & 51.2 & 59.2 & -1.7 & 60.9 & 35.8 & -25.2 & 61.1 & 53.9 & -60.2 & 114.2 & 13.7 & -78.2 & 91.9 & 71 & -31.6 & 102.7 \\
\hline 5 & $\mathrm{H} 90$ & I & 3 & 5.8 & -50.6 & 56.4 & 53.5 & 2.4 & 51 & 37.7 & -24 & 61.7 & 33.3 & -65.4 & 98.7 & 6.5 & -67.4 & 73.9 & 45.8 & -54.5 & 100.3 \\
\hline 5 & V & $\mathrm{E}$ & 1 & -0.2 & -21.8 & 21.6 & 41.5 & 29.7 & 11.8 & -8.2 & -37.2 & 29 & -2.5 & -20.2 & 17.7 & -23 & -35.8 & 12.8 & 41.2 & 12.5 & 28.7 \\
\hline 5 & V & $\mathrm{E}$ & 2 & -18.2 & -21.7 & 3.5 & 37.5 & 29.6 & 7.8 & -6.8 & -15 & 8.1 & -8.2 & -18.5 & 10.3 & -23.5 & -34.2 & 10.7 & 31.3 & 15 & 16.3 \\
\hline 5 & V & E & 3 & -16.3 & -24.7 & 8.4 & 38.5 & 27.3 & 11.2 & -3.6 & -16.9 & 13.4 & -7.9 & -20.1 & 12.2 & -18.3 & -31.2 & 12.9 & 33.8 & 14.7 & 19.1 \\
\hline 5 & V & I & 1 & -6.2 & -22.4 & 16.2 & 36.3 & 25.8 & 10.5 & -7.1 & -27.4 & 20.2 & -4.7 & -18.8 & 14.1 & -16 & -31.5 & 15.6 & 34.7 & 12.2 & 22.5 \\
\hline 5 & V & 1 & 2 & -14.2 & -25.9 & 11.8 & 37.3 & 27.2 & 10 & -3.1 & -19.5 & 16.4 & -8.3 & -19.1 & 10.8 & -22.1 & -32.9 & 10.8 & 30.3 & 11.9 & 18.4 \\
\hline 5 & v & I & 3 & -16.8 & -28.3 & 11.5 & 33.5 & 27.2 & 6.3 & -1.1 & -12 & 10.9 & -4.8 & -15.6 & 10.8 & -19.7 & -33.3 & 13.6 & 39.7 & 12.7 & 27 \\
\hline 6 & $\mathrm{H} 120$ & $\mathrm{E}$ & 1 & 22.1 & -59.6 & 81.7 & 84.9 & 0.4 & 84.5 & 12.6 & -77.8 & 90.5 & 20.8 & -53.2 & 74 & 2.7 & -53.3 & 56 & 54.1 & 6 & 48.1 \\
\hline 6 & $\mathrm{H} 120$ & E & 2 & 23.2 & -57 & 80.2 & 84.4 & -2 & 86.4 & 11.8 & -71.3 & 83.1 & 17.1 & -56.5 & 73.6 & 1.4 & -54.7 & 56.2 & 40.5 & -0.8 & 41.4 \\
\hline 6 & $\mathrm{H} 120$ & E & 3 & 21.9 & $*$ & $*$ & 88.3 & 3.4 & 84.9 & 108.4 & -56.9 & $*$ & 14.8 & -67.4 & 82.2 & 5.5 & -66.5 & 72 & 51.9 & -11.1 & 63.1 \\
\hline 6 & $\mathrm{H} 120$ & I & 1 & -3.5 & -46 & 42.5 & 49.7 & 12.1 & 37.6 & -20.4 & -62.5 & 42.1 & 22.1 & -72.6 & 94.7 & 4.3 & -72.5 & 76.8 & 67.1 & -34.6 & 101.8 \\
\hline 6 & $\mathrm{H} 120$ & I & 2 & 35.3 & -50.6 & 85.9 & 64.3 & 16.7 & 47.5 & -22 & -67.4 & 45.4 & 9.3 & -71.2 & 80.5 & 4.7 & -73.1 & 77.7 & 66 & -34.9 & 100.9 \\
\hline 6 & $\mathrm{H} 120$ & I & 3 & 30.4 & -48.5 & 78.9 & 71.9 & 11.5 & 60.4 & -12.7 & -59.8 & 47.1 & 9.8 & -56.5 & 66.4 & 3.1 & -68.6 & 71.7 & 61.6 & -5.6 & 67.2 \\
\hline 6 & H90 & $\mathrm{E}$ & 1 & $*$ & * & $*$ & 88.4 & 0.1 & 88.3 & 109 & * & $*$ & 22.8 & -65.3 & 88 & 1.1 & -68.4 & 69.5 & 55.7 & -3.5 & 59.2 \\
\hline 6 & $\mathrm{H} 90$ & E & 2 & 33.7 & -73.8 & 107.5 & 85.9 & 6.1 & 79.9 & 49.9 & -66.7 & 116.6 & 29.5 & -64.3 & 93.8 & -0.4 & -58.7 & 58.3 & 56.1 & -2.1 & 58.2 \\
\hline 6 & $\mathrm{H} 90$ & $\mathrm{E}$ & 3 & 51.4 & -59.5 & 110.9 & 86.4 & -4.1 & 90.5 & 5 & -83.2 & 88.2 & 36.6 & -62.3 & 98.9 & 1.1 & -60.8 & 61.9 & 64.2 & -1.9 & 66.1 \\
\hline 6 & $\mathrm{H} 90$ & 1 & 1 & 5.1 & -54.6 & 59.7 & 62.3 & 12.1 & 50.3 & 20 & -53.6 & 73.6 & 19.1 & -71 & 90.1 & 9.6 & -76.4 & 86.1 & 64.1 & -25.5 & 89.5 \\
\hline 6 & $\mathrm{H} 90$ & 1 & 2 & 3.6 & -56.6 & 60.2 & 75.1 & 6.7 & 68.4 & 12.7 & -53.3 & 66 & 19.3 & -66.8 & 86 & 10.7 & -69.9 & 80.6 & 58.9 & -20 & 78.9 \\
\hline 6 & $\mathrm{H} 90$ & I & 3 & -0.3 & -66.7 & 66.5 & 70.8 & 10.8 & 60 & 25.7 & -47.7 & 73.3 & 33.2 & -65.1 & 98.3 & 9.7 & -62.8 & 72.5 & 70.7 & -16.7 & 87.4 \\
\hline 6 & V & $\mathrm{E}$ & 1 & -22.6 & -29.4 & 6.8 & 33.2 & 24.8 & 8.3 & -34.3 & -48.5 & 14.3 & -20.7 & -28.3 & 7.6 & -25.5 & -35.8 & 10.3 & 46.9 & 30.9 & 16 \\
\hline 6 & V & E & 2 & -15.8 & -31.6 & 15.8 & 39.5 & 21.9 & 17.7 & -31 & -55.5 & 24.5 & -25.1 & -33.4 & 8.4 & -21.5 & -34.5 & 12.9 & 45.9 & 29.4 & 16.4 \\
\hline 6 & V & $\mathrm{E}$ & 3 & -11.1 & -29.6 & 18.5 & 41.8 & 21.3 & 20.5 & -31.3 & -57.8 & 26.5 & -25.7 & -41 & 15.2 & -10.4 & -35.7 & 25.3 & 45.1 & 17.6 & 27.4 \\
\hline 6 & V & I & 1 & -10.6 & -29.2 & 18.6 & 36.8 & 22.6 & 14.2 & -32.6 & -48.2 & 15.5 & -9.3 & -32 & 22.7 & -18.1 & -36.6 & 18.5 & 49.9 & 28.1 & 21.9 \\
\hline 6 & V & 1 & 2 & -17.1 & -30.1 & 13 & 35.4 & 24.1 & 11.3 & -34.3 & -51.1 & 16.8 & -25.8 & -31.3 & 5.5 & -24.8 & -32.8 & 7.9 & 42.2 & 27.9 & 14.3 \\
\hline 6 & V & 1 & 3 & -15.2 & -32.3 & 17 & 36.3 & 19.5 & 16.9 & -29.8 & -50.4 & 20.6 & -29.3 & -32.9 & 3.6 & -19.2 & -31.4 & 12.3 & 39.6 & 25.4 & 14.2 \\
\hline
\end{tabular}




\begin{tabular}{|c|c|c|c|c|c|c|c|c|c|c|c|c|c|c|c|c|c|c|c|c|c|}
\hline Subject & Seat & Task & Rep & LSX+ & LSX- & LSXR & LSY+ & LSY- & LSYR & LSZ+ & LSZ- & LSZR & RSX+ & RSX- & RSXR & RSY+ & RSY- & RSYR & RSZ+ & RSZ- & RSZR \\
\hline 7 & $\mathrm{H} 120$ & $E$ & 1 & -0.9 & -88.3 & 87.4 & 70.2 & -5.6 & 75.8 & 90.3 & -28 & 118.3 & 46.7 & -46.2 & 93 & 7.1 & -63.9 & 71 & 36.3 & -35.1 & 71.3 \\
\hline 7 & $\mathrm{H} 120$ & $E$ & 2 & 46.7 & -98.5 & $*$ & 81.4 & -8.8 & 90.2 & 94.6 & -52.5 & $*$ & 58.7 & -51.3 & 110 & 12.1 & -58 & 70 & 35.5 & -37.5 & 73 \\
\hline 7 & H120 & I & 1 & -5.6 & -49.4 & 43.8 & 52.3 & 2 & 50.3 & 38.8 & -17.9 & 56.7 & 59.9 & -57 & 116.9 & 15.7 & -64.6 & 80.3 & 48.7 & -67.2 & 116 \\
\hline 7 & $\mathrm{H} 120$ & I & 2 & 13.8 & -63.1 & 76.9 & 63.4 & -2.4 & 65.7 & 48.2 & -27.1 & 75.3 & 62.8 & -56.1 & 118.9 & 12.5 & -80.1 & 92.7 & 53.2 & -59.2 & 112.4 \\
\hline 7 & H90 & $E$ & 1 & 17.5 & -71 & 88.5 & 68.8 & -0.3 & 69.1 & 64.9 & -30 & 94.9 & 51.4 & -47.2 & 98.6 & 1.6 & -60 & 61.7 & 31.1 & -30.5 & 61.6 \\
\hline 7 & $\mathrm{H} 90$ & $E$ & 2 & 13.8 & -86.8 & 100.6 & 80.1 & -4.5 & 84.6 & 91.5 & -26.2 & 117.7 & 57.8 & -45.4 & 103.2 & 0.9 & -55.9 & 56.8 & 33.9 & -29.2 & 63 \\
\hline 7 & $\mathrm{H} 90$ & E & 3 & 25.8 & -82 & 107.7 & 71.9 & -6.1 & 78.1 & 78.2 & -30.8 & 109 & 50.4 & -45.8 & 96.2 & -0.1 & -59.9 & 59.8 & 24.4 & -34.6 & 59 \\
\hline 7 & $\mathrm{H} 90$ & I & 1 & 18 & -51.4 & 69.4 & 39.7 & 1.6 & 38.1 & 35.9 & -31.3 & 67.2 & 57.9 & -47.3 & 105.2 & 17.3 & -71.1 & 88.4 & 46.3 & -49.3 & 95.6 \\
\hline 7 & $\mathrm{H} 90$ & I & 2 & -2.3 & -54.1 & 51.9 & 52.9 & -5.1 & 58 & 39.6 & -36 & 75.6 & 64 & -45.2 & 109.2 & 10.2 & -63 & 73.2 & 48.8 & -56.7 & 105.5 \\
\hline 7 & $\mathrm{H} 90$ & I & 3 & 7.1 & -63.2 & 70.3 & 61.2 & -1.1 & 62.2 & 44.8 & -49.3 & 94.2 & 48.7 & -39.7 & 88.4 & 9.9 & -43.8 & 53.7 & 42.2 & -38.1 & 80.3 \\
\hline 7 & V & $E$ & 1 & -4.4 & -10.4 & 5.9 & 30.2 & 20 & 10.1 & -9.7 & -25.9 & 16.3 & 6.9 & -4.3 & 11.2 & -10.1 & -22.1 & 12 & 13.7 & -2.9 & 16.6 \\
\hline 7 & V & E & 2 & -8.5 & -12.7 & 4.1 & 27.5 & 18.7 & 8.8 & -6.6 & -18.6 & 12 & 1.4 & -4.3 & 5.6 & -11.8 & -23.5 & 11.7 & 11.7 & -2.5 & 14.2 \\
\hline 7 & V & I & 1 & -3.9 & -10.4 & 6.6 & 28.2 & 18.7 & 9.5 & -12.2 & -22.7 & 10.5 & 5.7 & -1.1 & 6.8 & -13.4 & -22.1 & 8.8 & 13.5 & 0.6 & 12.9 \\
\hline 7 & V & 1 & 2 & -6.9 & -13 & 6.1 & 30.3 & 20.1 & 10.2 & -10.8 & -21.3 & 10.6 & 1.5 & -3 & 4.5 & -13.2 & -20.9 & 7.7 & 11.8 & -0.3 & 12.1 \\
\hline 8 & $\mathrm{H} 120$ & $E$ & 1 & 18.4 & -73.1 & 91.5 & 67.7 & 9.7 & 58 & 54.4 & -46.9 & 101.3 & 58.4 & -59 & 117.4 & -9.6 & -75.9 & 66.3 & 71.3 & -35.1 & 106.4 \\
\hline 8 & $\mathrm{H} 120$ & E & 2 & 21.1 & -77 & 98.1 & 64.1 & 9.2 & 54.8 & 49.2 & -42.8 & 92 & 69.2 & -61.8 & 131 & -10.3 & -81.3 & 71 & 72.8 & -38 & 110.8 \\
\hline 8 & $\mathrm{H} 120$ & $\mathrm{E}$ & 3 & 29.7 & -68.9 & 98.5 & 71.6 & 10.5 & 61.1 & 44.7 & -47.3 & 92.1 & 64.3 & -46.1 & 110.4 & -11.8 & -76.9 & 65.1 & 74 & -4.1 & 78 \\
\hline 8 & $\mathrm{H} 120$ & I & 1 & 15.6 & -59.5 & 75.2 & 54 & 10.7 & 43.3 & 22.5 & -49.6 & 72.2 & 53.7 & -109.2 & 162.9 & -9.8 & -81 & 71.2 & 60 & -92 & 152 \\
\hline 8 & $\mathrm{H} 120$ & I & 2 & 22.8 & -63.8 & 86.6 & 69 & 10.3 & 58.7 & 27.1 & -58.9 & 85.9 & 62.1 & -82.5 & 144.6 & -15.6 & -82.1 & 66.4 & 63.6 & -70.1 & 133.7 \\
\hline 8 & $\mathrm{H} 120$ & 1 & 3 & 10.7 & -61.1 & 71.8 & 62 & 14.3 & 47.7 & 12.6 & -46 & 58.6 & 46.8 & -103.7 & 150.5 & -10.4 & -78.7 & 68.4 & 55.3 & -86.9 & 142.2 \\
\hline 8 & H9O & $E$ & 1 & 18.4 & -92.9 & 111.3 & 73.7 & 7.6 & 66.1 & 69.1 & -43 & 112 & 68.1 & -83.7 & 151.7 & -10.8 & -84.2 & 73.4 & 82.1 & -65.3 & 147.3 \\
\hline 8 & $\mathrm{H} 90$ & $E$ & 2 & 12.6 & -76.7 & 89.3 & 67.9 & 8.7 & 59.2 & 66.3 & -50.9 & 117.2 & 71.8 & -86.1 & 157.9 & -10.7 & -84.5 & 73.8 & 86.1 & -57.6 & 143.7 \\
\hline 8 & $\mathrm{H} 90$ & $\mathrm{E}$ & 3 & 6.8 & -82.8 & 89.6 & 76.3 & 10.7 & 65.6 & 72.8 & -38.9 & 111.7 & 68.9 & -64.7 & 133.5 & -12.5 & -85.8 & 73.3 & 76.1 & -46.7 & 122.8 \\
\hline 8 & $\mathrm{H} 90$ & I & 1 & 7.5 & -59.3 & 66.8 & 61.5 & 12.9 & 48.6 & 13.2 & -48.2 & 61.5 & $*$ & -116.2 & $*$ & -4 & -82.8 & 78.9 & $*$ & -108.8 & * \\
\hline 8 & $\mathrm{H} 90$ & I & 2 & 2.4 & -60.2 & 62.5 & 55.2 & 13.3 & 41.9 & 4.8 & -47.3 & 52.2 & 77.4 & -103.8 & $*$ & -18.1 & -85.5 & 67.4 & 79.5 & -100.3 & $*$ \\
\hline 8 & $\mathrm{H} 9 \mathrm{O}$ & 1 & 3 & 20.2 & -63.1 & 83.3 & 61 & 17.2 & 43.8 & 21.1 & -43.5 & 64.6 & 63.7 & -98.6 & 162.3 & -17.7 & -84.5 & 66.8 & 66.6 & -84.7 & 151.3 \\
\hline
\end{tabular}




\begin{tabular}{|c|c|c|c|c|c|c|c|c|c|c|c|c|c|c|c|c|c|c|c|c|c|}
\hline Subject & Seat & Task & Rep & LSX+ & LSX- & LSXR & LSY+ & LSY- & LSYR & LSZ+ & LSZ- & LSZR & RSX+ & RSX- & RSXR & RSY+ & RSY- & RSYR & RSZ+ & RSZ- & RSZR \\
\hline 9 & $\mathrm{H} 120$ & $E$ & 1 & 6.9 & -74.5 & 81.4 & 80.8 & -3.2 & 84 & 75.2 & -18.8 & 94 & -4 & -72.2 & 68.2 & -6.2 & -56.8 & 50.6 & 9.9 & -58.6 & 68.5 \\
\hline 9 & $\mathrm{H} 120$ & E & 2 & 5.9 & -65.4 & 71.3 & 76.6 & -0.8 & 77.4 & 64.2 & -14.4 & 78.6 & -0.2 & -72.7 & 72.6 & -2.8 & -51.5 & 48.6 & 8.5 & -61.8 & 70.2 \\
\hline 9 & $\mathrm{H} 120$ & $\mathrm{E}$ & 3 & 6.3 & -79.1 & 85.4 & 81.4 & -3.1 & 84.5 & 78.3 & -16.7 & 95 & -5.1 & -69.9 & 64.8 & -7.2 & -48.6 & 41.4 & 11.6 & -65.9 & 77.6 \\
\hline 9 & $\mathrm{H} 120$ & I & 1 & 3.7 & -74.8 & 78.5 & 64.7 & 1.1 & 63.6 & 63.4 & -16.7 & 80.1 & 58.1 & -71.4 & 129.5 & -0.3 & -77.8 & 77.5 & 50.4 & -76.9 & 127.3 \\
\hline 9 & $\mathrm{H} 120$ & I & 2 & 20.7 & -60.2 & 80.9 & 41.9 & -2.8 & 44.7 & 52.4 & -26.7 & 79.1 & 66.7 & -77.3 & 144 & 0.4 & -76.2 & 76.7 & 57.8 & -75.7 & 133.5 \\
\hline 9 & $\mathrm{H} 120$ & 1 & 3 & 8 & -69.3 & 77.3 & 50.8 & 3.8 & 47 & 64.9 & -15.6 & 80.5 & 55.3 & -72.4 & 127.7 & -1.7 & -69.7 & 68 & 47 & -66.3 & 113.4 \\
\hline 9 & H9O & E & 1 & 0 & -75.9 & 75.9 & 75 & -8.9 & 83.9 & 76 & -16 & 92 & -0.3 & -68 & 67.7 & -5.1 & -51.2 & 46.1 & 19.9 & -70.6 & 90.5 \\
\hline 9 & $\mathrm{H} 90$ & $\mathrm{E}$ & 2 & -4.4 & -72 & 67.6 & 62.9 & -6.5 & 69.4 & 68.6 & -19.4 & 87.9 & 30.9 & -73.8 & 104.7 & -3.1 & -64.5 & 61.4 & 29.7 & -67.3 & 97 \\
\hline 9 & $\mathrm{H} 90$ & $E$ & 3 & 7 & -90.4 & 97.4 & 79.6 & -5.9 & 85.5 & 90.4 & -22.9 & 113.3 & 9.1 & -72.1 & 81.2 & -5.9 & -51.8 & 45.9 & 17.8 & -71.5 & 89.3 \\
\hline 9 & $\mathrm{H} 90$ & 1 & 1 & 8.9 & -67.9 & 76.9 & 61.8 & -4.5 & 66.3 & 53.1 & -16.7 & 69.8 & 33.2 & -68.3 & 101.5 & 4 & -61.8 & 65.8 & 38.1 & -66.8 & 104.9 \\
\hline 9 & $\mathrm{H} 90$ & I & 2 & -0.4 & -64.6 & 64.1 & 51.2 & -5.9 & 57.2 & 53.9 & -20.4 & 74.3 & 23.9 & -76.4 & 100.3 & 7.9 & -51.8 & 59.7 & 19.4 & -64.6 & 83.9 \\
\hline 9 & $\mathrm{H} 90$ & I & 3 & 2.9 & -68.8 & 71.7 & 53.5 & -5.2 & 58.7 & 56.9 & -22 & 79 & 40.6 & -69.9 & 110.5 & 11.2 & -55.8 & 67.1 & 35.1 & -73.2 & 108.3 \\
\hline 9 & V & $E$ & 1 & 2.8 & -36 & 38.8 & 27.5 & 9.3 & 18.3 & 19.4 & -25.5 & 44.9 & 1.7 & -34.3 & 36 & -8.4 & -32.3 & 23.9 & 18 & -32.8 & 50.8 \\
\hline 9 & V & $E$ & 2 & -16 & -34.3 & 18.3 & 28.7 & 10.9 & 17.9 & 21 & -9.6 & 30.5 & -11.3 & -38.1 & 26.8 & -6.4 & -31.9 & 25.5 & 10.2 & -33.5 & 43.7 \\
\hline 9 & V & $E$ & 3 & -19.3 & -25.9 & 6.6 & 31.4 & 21 & 10.4 & 10 & -3.7 & 13.6 & -17 & -35 & 17.9 & -8.3 & -33.9 & 25.6 & 3.6 & -19.8 & 23.4 \\
\hline 9 & V & 1 & 1 & 21.1 & -17.6 & 38.7 & 21 & 7.4 & 13.6 & 14.8 & -8.8 & 23.6 & 13.9 & -18.5 & 32.4 & -7.1 & -16.9 & 9.7 & 6.6 & -27.2 & 33.9 \\
\hline 9 & V & 1 & 2 & -7.1 & -18.6 & 11.5 & 34.3 & 22 & 12.4 & 3.1 & -13 & 16.1 & -7.6 & -20.9 & 13.3 & -18.9 & -33.6 & 14.7 & 8.8 & -14.5 & 23.4 \\
\hline 9 & V & I & 3 & -14.1 & -26.7 & 12.6 & 35.2 & 16 & 19.2 & 9.8 & -8 & 17.7 & -15.6 & -27.1 & 11.5 & -15.3 & -34.5 & 19.2 & 3.5 & -19 & 22.5 \\
\hline 10 & $\mathrm{H} 120$ & $E$ & 1 & 31.7 & -55.2 & 86.8 & 52.2 & -1.6 & 53.8 & 43.9 & -15.9 & 59.8 & 47.7 & -39.5 & 87.2 & 4 & -58.1 & 62.2 & 26.7 & -32.9 & 59.7 \\
\hline 10 & $\mathrm{H} 120$ & $E$ & 2 & 35.7 & -48.3 & 84 & 56.2 & -4.3 & 60.5 & 36 & -19.2 & 55.2 & 52.4 & -44.6 & 97 & -0.2 & -56.7 & 56.5 & 27.7 & -30.7 & 58.4 \\
\hline 10 & $\mathrm{H} 120$ & $\mathrm{E}$ & 3 & 33.8 & -49.7 & 83.5 & 58.8 & -0.8 & 59.7 & 41.3 & -17.2 & 58.5 & 30.9 & -44.6 & 75.5 & -0.5 & -50.8 & 50.3 & 25.1 & -29.8 & 54.9 \\
\hline 10 & $\mathrm{H} 120$ & I & 1 & 23.3 & -51.6 & 74.9 & 47.7 & 5.3 & 42.4 & 57.5 & -15 & 72.6 & 39.5 & -48.9 & 88.4 & -3 & -60.3 & 57.3 & 23.1 & -45.6 & 68.6 \\
\hline 10 & $\mathrm{H} 120$ & I & 2 & 25.1 & -47.8 & 72.9 & 54.2 & 3.3 & 50.9 & 40.6 & -25.6 & 66.2 & 47.7 & -52.5 & 100.1 & -2.1 & -61.9 & 59.8 & 26.2 & -44.4 & 70.6 \\
\hline 10 & H9O & $\mathrm{E}$ & 1 & 24 & -49.1 & 73.1 & 48.8 & -2.4 & 51.1 & 33.2 & -13 & 46.2 & 30.3 & -37 & 67.3 & -3.8 & -54.8 & 51.1 & 27.3 & -19.8 & 47.1 \\
\hline 10 & $\mathrm{H} 90$ & $E$ & 2 & 18.5 & -55.3 & 73.8 & 55.2 & -2.4 & 57.6 & 51.9 & -17.3 & 69.2 & 33.5 & -36.4 & 69.9 & -2.3 & -51.3 & 49.1 & 18 & -27.9 & 45.9 \\
\hline 10 & $\mathrm{H} 90$ & 1 & 1 & 20.5 & -49.5 & 70 & 48.4 & 0.9 & 47.5 & 42 & -17.4 & 59.4 & 32.4 & -46.6 & 79 & -4.1 & -61 & 56.9 & 29 & -38.2 & 67.2 \\
\hline 10 & H9O & 1 & 2 & 28.4 & -51.7 & 80.1 & 49.9 & 0.5 & 49.4 & 45.4 & -20.5 & 66 & 50.6 & -44.6 & 95.2 & -3.3 & -64.4 & 61.1 & 30.1 & -38.7 & 68.8 \\
\hline 10 & $\mathrm{H} 90$ & 1 & 3 & 34.6 & -60.5 & 95.1 & 58.5 & -1.8 & 60.4 & 49.6 & -28.2 & 77.8 & 47.9 & -52 & 99.9 & -6.9 & -64.3 & 57.4 & 22.6 & -43.9 & 66.5 \\
\hline 10 & V & E & 1 & 10.3 & -8 & 18.4 & 25.4 & 9.3 & 16.1 & 5.4 & -9.7 & 15.1 & 9.2 & -6.5 & 15.7 & -8 & -19.3 & 11.3 & 14.8 & -8.2 & 23.1 \\
\hline 10 & V & E & 2 & 14.4 & -8.8 & 23.2 & 22.2 & 6.1 & 16.1 & 5.2 & -14 & 19.2 & 11.8 & -6.1 & 17.9 & -5.7 & -16.2 & 10.5 & 16.9 & -6.1 & 23 \\
\hline 10 & V & 1 & 1 & 3.6 & -10.5 & 14.1 & 22 & 4.2 & 17.8 & 2.7 & -11.6 & 14.3 & 5.6 & -7.6 & 13.2 & -6.6 & -25.2 & 18.6 & 13.9 & -6.2 & 20.1 \\
\hline 10 & V & 1 & 2 & 15.2 & -11.4 & 26.5 & 29.2 & 7.7 & 21.5 & 6.3 & -13.2 & 19.6 & 13.7 & -13.1 & 26.7 & -9.6 & -24.1 & 14.4 & 14.8 & -4.1 & 18.9 \\
\hline 10 & V & 1 & 3 & 12.8 & -9.6 & 22.4 & 23.7 & 10.6 & 13.1 & 9.7 & -25.9 & 35.7 & 7.4 & -9 & 16.4 & -10.2 & -20 & 9.8 & 19.3 & -3.4 & 22.7 \\
\hline
\end{tabular}


APPENDIX H - SUMMARIZED JOINT ANGLE DATA - TRUNK

\begin{tabular}{|c|c|c|c|c|c|c|c|c|c|c|}
\hline Subject & Seat & Task & Rep & $\mathrm{TX}+$ & TY+ & TY- & TYR & TZ+ & TZ- & TZR \\
\hline 1 & $\mathrm{H} 120$ & $E$ & 1 & 61.6 & 11.1 & -20.7 & 31.8 & 24.8 & -8.1 & 32.9 \\
\hline 1 & $\mathrm{H} 120$ & $E$ & 2 & 60.4 & 10.8 & -31.1 & 41.9 & 30 & -7.4 & 37.4 \\
\hline 1 & $\mathrm{H} 120$ & $E$ & 3 & 58.1 & 12.6 & -23 & 35.6 & 32.7 & -4.6 & 37.2 \\
\hline 1 & $\mathrm{H} 120$ & I & 1 & 60.2 & 7.1 & -19.2 & 26.3 & 23.8 & -11.1 & 34.9 \\
\hline 1 & $\mathrm{H} 120$ & I & 2 & 57.5 & 9 & -19.6 & 28.7 & 25.3 & -18.8 & 44.1 \\
\hline 1 & $\mathrm{H} 120$ & I & 3 & 59.2 & 8 & -21.9 & 29.9 & 30.1 & -9.5 & 39.6 \\
\hline 1 & $\mathrm{H} 90$ & $E$ & 1 & 59.5 & 14.3 & -20.3 & 34.6 & 26.3 & -8.9 & 35.2 \\
\hline 1 & $\mathrm{H} 90$ & $E$ & 2 & 59.5 & 14.5 & -24.1 & 38.6 & 26.3 & -6.5 & 32.8 \\
\hline 1 & $\mathrm{H} 90$ & E & 3 & 65.9 & 9.9 & -21.9 & 31.7 & 34.2 & -5.9 & 40.1 \\
\hline 1 & $\mathrm{H} 90$ & I & 1 & 65.2 & 7.5 & -9.7 & 17.2 & 13.8 & -22.8 & 36.5 \\
\hline 1 & $\mathrm{H} 90$ & I & 2 & 64.6 & 2.7 & -14.8 & 17.5 & 22.8 & -20.9 & 43.7 \\
\hline 1 & $\mathrm{H} 90$ & I & 3 & 61.3 & 6.9 & -21 & 27.9 & 23.6 & -9.7 & 33.3 \\
\hline 1 & V & $E$ & 1 & 26.5 & 8.5 & -2.1 & 10.6 & 10 & -4.3 & 14.3 \\
\hline 1 & V & $E$ & 2 & 19.3 & 8 & -5.5 & 13.6 & 13 & -6.1 & 19.1 \\
\hline 1 & V & $E$ & 3 & 15.4 & 8.8 & -5.1 & 13.9 & 7.3 & -10.4 & 17.7 \\
\hline 1 & V & I & 1 & 35 & 6.1 & -0.8 & 6.9 & 4.2 & -14.4 & 18.6 \\
\hline 1 & V & I & 2 & 27.3 & 5.7 & -5.8 & 11.5 & 8.7 & -8.6 & 17.2 \\
\hline 1 & V & I & 3 & 18.2 & 4.3 & -4.6 & 8.9 & 1.5 & -9.5 & 11 \\
\hline 2 & $\mathrm{H} 120$ & $E$ & 1 & 64.7 & 11.3 & -11.5 & 22.8 & 11.5 & -2.4 & 13.9 \\
\hline 2 & $\mathrm{H} 120$ & $E$ & 2 & 64.5 & 8.3 & -18.6 & 26.9 & 21.2 & -3.4 & 24.6 \\
\hline 2 & $\mathrm{H} 120$ & $E$ & 3 & 63.1 & 6.5 & -12.4 & 18.8 & 14.5 & -4.7 & 19.2 \\
\hline 2 & $\mathrm{H} 120$ & I & 1 & 63 & 14.7 & -17.1 & 31.8 & 14.4 & -0.7 & 15 \\
\hline 2 & $\mathrm{H} 120$ & I & 2 & 62.6 & 13.2 & -23.9 & 37.1 & 23.1 & -7 & 30.1 \\
\hline 2 & $\mathrm{H} 120$ & 1 & 3 & 62.4 & 12.4 & -20.6 & 33.1 & 18.3 & -9.9 & 28.2 \\
\hline 2 & $\mathrm{H} 90$ & $\mathrm{E}$ & 1 & 66.7 & 19.3 & -11.9 & 31.2 & 25.4 & -4.2 & 29.6 \\
\hline 2 & $\mathrm{H} 90$ & $\mathrm{E}$ & 2 & 64.6 & 15 & -13.5 & 28.5 & 18.8 & -5.9 & 24.7 \\
\hline 2 & $\mathrm{H} 90$ & $E$ & 3 & 68.3 & 15.1 & -17.6 & 32.6 & 24.2 & -0.8 & 25 \\
\hline 2 & $\mathrm{H} 90$ & 1 & 1 & 62.2 & 16.7 & -13.2 & 29.9 & 16.2 & 1.8 & 14.4 \\
\hline 2 & $\mathrm{H} 90$ & I & 2 & 64.5 & 15.2 & -14.4 & 29.6 & 16.3 & -4.1 & 20.4 \\
\hline 2 & $\mathrm{H} 90$ & I & 3 & 64.5 & 13.7 & -13.3 & 27 & 22.6 & -6.4 & 29.1 \\
\hline 2 & V & $\mathrm{E}$ & 1 & 49.3 & 11.9 & -4.4 & 16.3 & 3.4 & -13.2 & 16.6 \\
\hline 2 & V & $\mathrm{E}$ & 2 & 45 & 10.5 & -8.2 & 18.7 & 0.9 & -17.2 & 18.1 \\
\hline 2 & V & $E$ & 3 & 41.9 & 16.6 & -5.3 & 21.9 & 6 & -22.8 & 28.8 \\
\hline 2 & V & I & 1 & 50.4 & 11.2 & -6.6 & 17.8 & 8 & -2.3 & 10.3 \\
\hline 2 & V & I & 2 & 55.8 & 15 & -5.1 & 20.1 & 7.3 & -8.5 & 15.8 \\
\hline 2 & V & I & 3 & 64 & 12.6 & -4.9 & 17.5 & 6 & -5.5 & 11.5 \\
\hline 3 & $\mathrm{H} 120$ & $E$ & 1 & 47.6 & 16.2 & -22.4 & 38.6 & 17.7 & -20.7 & 38.4 \\
\hline 3 & $\mathrm{H} 120$ & $E$ & 2 & 39.3 & 14.3 & -25 & 39.2 & 18 & -20.3 & 38.3 \\
\hline 3 & $\mathrm{H} 120$ & I & 1 & 66.2 & 16.3 & -19 & 35.3 & 18.8 & -12.2 & 31 \\
\hline 3 & $\mathrm{H} 120$ & I & 2 & 45.6 & 10 & -27.2 & 37.3 & 32.2 & -35 & 67.2 \\
\hline 3 & $\mathrm{H} 120$ & I & 3 & 42.5 & 7.1 & -18 & 25.1 & 26.5 & -32 & 58.4 \\
\hline 3 & H90 & $E$ & 1 & 57.1 & 27.8 & -8.3 & 36.2 & 10.2 & -24 & 34.2 \\
\hline 3 & $\mathrm{H} 90$ & $E$ & 2 & 59.5 & 32 & -16 & 48 & 11.9 & -13.1 & 24.9 \\
\hline 3 & $\mathrm{H} 90$ & E & 3 & 92.1 & 31.3 & -8 & 39.3 & 2 & -20.1 & 22.2 \\
\hline 3 & $\mathrm{H} 90$ & I & 1 & 52.6 & 23.3 & -9.3 & 32.6 & 17.5 & -25.6 & 43.1 \\
\hline 3 & $\mathrm{H} 90$ & I & 2 & 68 & 22 & -7.5 & 29.5 & 18.4 & -27.2 & 45.6 \\
\hline 3 & $\mathrm{H} 90$ & 1 & 3 & 66.8 & 24 & -12.1 & 36 & 12 & -24.8 & 36.8 \\
\hline
\end{tabular}




\begin{tabular}{|c|c|c|c|c|c|c|c|c|c|c|}
\hline Subject & Seat & Task & Rep & TX+ & TY+ & TY- & TYR & $\mathrm{TZ}+$ & TZ- & TZR \\
\hline 4 & $\mathrm{H} 120$ & $E$ & 1 & 60.6 & 21.6 & -22.4 & 44 & 19.6 & -22.5 & 42 \\
\hline 4 & $\mathrm{H} 120$ & $\mathrm{E}$ & 2 & 47.2 & 3.1 & -24.9 & 28 & 34.1 & -4 & 38.1 \\
\hline 4 & H12O & $\mathrm{E}$ & 3 & 48.6 & 0.9 & -30 & 31 & 37.3 & -5.5 & 42.8 \\
\hline 4 & H12O & 1 & 1 & 66.8 & 6.6 & -28.2 & 34.7 & 32.2 & -4.7 & 36.9 \\
\hline 4 & $\mathrm{H} 120$ & 1 & 2 & 57.5 & 4.2 & -23.6 & 27.8 & 25.3 & -12.6 & 37.8 \\
\hline 4 & H120 & 1 & 3 & 59.5 & 3.6 & -22 & 25.5 & 26.1 & -6.3 & 32.4 \\
\hline 4 & H9O & $\mathrm{E}$ & 1 & 60.3 & 33.2 & -12.1 & 45.3 & 19.1 & -17.1 & 36.1 \\
\hline 4 & H9O & $\mathrm{E}$ & 2 & 57.9 & 34.9 & -16.8 & 51.7 & 29.7 & -17.5 & 47.2 \\
\hline 4 & H9O & $\mathrm{E}$ & 3 & 55.3 & 34.7 & -14 & 48.7 & 31.3 & -12.3 & 43.5 \\
\hline 4 & $\mathrm{H} 90$ & 1 & 1 & 60.9 & 2.8 & -24.1 & 26.9 & 33.6 & -7.5 & 41.1 \\
\hline 4 & H9O & 1 & 2 & 62.7 & 1.2 & -28.1 & 29.3 & 32.1 & -7 & 39.2 \\
\hline 4 & H9O & 1 & 3 & 61.8 & 8.9 & -21.8 & 30.7 & 22.3 & -7.1 & 29.4 \\
\hline 4 & V & $\mathrm{E}$ & 1 & 45 & 10.4 & 1.4 & 9.1 & 9 & -12.4 & 21.4 \\
\hline 4 & V & $E$ & 2 & 39.7 & 10 & -1.6 & 11.6 & 8.8 & -15.6 & 24.4 \\
\hline 4 & V & $E$ & 3 & 51.5 & 13.6 & 0.7 & 12.8 & 8.7 & -12.4 & 21.1 \\
\hline 4 & V & 1 & 1 & 39.7 & 8.2 & 0.3 & 7.9 & 5 & -8.3 & 13.2 \\
\hline 4 & V & 1 & 2 & 37.4 & 9.1 & 0.6 & 8.5 & 5.4 & -8.2 & 13.6 \\
\hline 4 & V & 1 & 3 & 36.2 & 8.2 & 0.7 & 7.5 & 5.5 & -11.1 & 16.7 \\
\hline 5 & $\mathrm{H} 120$ & $E$ & 1 & 63 & 6.2 & -25.2 & 31.4 & 26.7 & -8.7 & 35.4 \\
\hline 5 & $\mathrm{H} 120$ & $E$ & 2 & 54.8 & 5.5 & -31.6 & 37.1 & 32 & -3.6 & 35.6 \\
\hline 5 & $\mathrm{H} 120$ & $\mathrm{E}$ & 3 & 57.4 & 6.6 & -19.6 & 26.1 & 21.1 & -7.4 & 28.5 \\
\hline 5 & $\mathrm{H} 120$ & 1 & 1 & 59.3 & 9.1 & -28.7 & 37.9 & 23.4 & -11.1 & 34.5 \\
\hline 5 & $\mathrm{H} 120$ & 1 & 2 & 57.1 & 6.6 & -29.7 & 36.3 & 25.1 & -12.3 & 37.4 \\
\hline 5 & $\mathrm{H} 120$ & 1 & 3 & 58.9 & 2.4 & -28.1 & 30.5 & 22.3 & -6.5 & 28.8 \\
\hline 5 & $\mathrm{H} 90$ & $\mathrm{E}$ & 1 & 59.7 & 6.2 & -19.6 & 25.8 & 16.1 & -5.8 & 21.9 \\
\hline 5 & H9O & $\mathrm{E}$ & 2 & 64.1 & 6.3 & -17.7 & 24.1 & 18.2 & -6.6 & 24.8 \\
\hline 5 & H9O & $\mathrm{E}$ & 3 & 57.8 & 14.8 & -8.7 & 23.5 & 20.2 & -8 & 28.2 \\
\hline 5 & H9O & 1 & 1 & 59.8 & 2.8 & -22.1 & 24.8 & 14.1 & -8.2 & 22.3 \\
\hline 5 & H9O & 1 & 2 & 61.8 & 13.1 & -33.3 & 46.4 & 22.3 & -10.6 & 32.8 \\
\hline 5 & H9O & 1 & 3 & 60.2 & 13.9 & -19.1 & 33.1 & 19.4 & -8 & 27.5 \\
\hline 5 & V & $\mathrm{E}$ & 1 & 34 & 8.8 & -8.1 & 16.9 & 8 & -3.7 & 11.7 \\
\hline 5 & V & $\mathrm{E}$ & 2 & 28.9 & 9 & -5.6 & 14.6 & 9.3 & -4.8 & 14.1 \\
\hline 5 & V & $E$ & 3 & 28.2 & 5.6 & -6.1 & 11.7 & 4 & -7.4 & 11.4 \\
\hline 5 & V & 1 & 1 & 29.4 & 8.6 & -1.7 & 10.4 & 4.3 & -15 & 19.2 \\
\hline 5 & V & 1 & 2 & 41.5 & 6.1 & -8.5 & 14.6 & 6.6 & -2 & 8.6 \\
\hline 5 & V & 1 & 3 & 49.2 & 8.3 & -4.8 & 13 & 7.3 & -5.6 & 12.8 \\
\hline 6 & H120 & $E$ & 1 & 48.4 & 14.7 & -19.7 & 34.4 & 23 & -6.2 & 29.2 \\
\hline 6 & H12O & $\mathrm{E}$ & 2 & 49.4 & 10.5 & -10.9 & 21.4 & 17.5 & -4.7 & 22.2 \\
\hline 6 & H12O & $\mathrm{E}$ & 3 & 46.9 & 7.2 & -20.1 & 27.4 & 27 & 0.7 & 26.3 \\
\hline 6 & $\mathrm{H} 120$ & 1 & 1 & 51.8 & 4.3 & -17.1 & 21.4 & 19.2 & -9.6 & 28.8 \\
\hline 6 & H120 & 1 & 2 & 49.4 & 9.6 & -17.9 & 27.5 & 21 & -6.2 & 27.1 \\
\hline 6 & H12O & 1 & 3 & 51.4 & 6.7 & -15.1 & 21.8 & 27 & -4.2 & 31.1 \\
\hline 6 & H9O & $\mathrm{E}$ & 1 & 48.9 & 12.6 & -16.2 & 28.8 & 33.1 & 3.3 & 29.8 \\
\hline 6 & $\mathrm{H} 90$ & $\mathrm{E}$ & 2 & 50.4 & 11.2 & -8.4 & 19.6 & 28 & -1.4 & 29.4 \\
\hline 6 & H9O & $\mathrm{E}$ & 3 & 50 & 23.3 & -4.5 & 27.8 & 22.6 & 1.1 & 21.5 \\
\hline 6 & H90 & 1 & 1 & 52.8 & 9.3 & -19.4 & 28.6 & 25.9 & -8.4 & 34.3 \\
\hline 6 & H9O & 1 & 2 & 55.1 & 8.5 & -13.1 & 21.6 & 16 & -4.6 & 20.6 \\
\hline 6 & H9O & 1 & 3 & 53.1 & 8.8 & -11.6 & 20.4 & 16.6 & -3.8 & 20.4 \\
\hline 6 & V & $\mathrm{E}$ & 1 & 29.3 & 8.8 & -1.3 & 10 & 4.8 & -3.4 & 8.2 \\
\hline 6 & V & $\mathrm{E}$ & 2 & 26.4 & 6.9 & -0.7 & 7.6 & 7 & -2.3 & 9.3 \\
\hline 6 & V & $\mathrm{E}$ & 3 & 30.1 & 6.9 & -3.8 & 10.7 & 10.4 & 1.9 & 8.5 \\
\hline 6 & V & 1 & 1 & 28.6 & 6.3 & -2.8 & 9.1 & 8.5 & -2.8 & 11.3 \\
\hline 6 & V & 1 & 2 & 27.8 & 5.1 & -3.9 & 9 & 9.2 & -2.3 & 11.5 \\
\hline 6 & V & 1 & 3 & 22.1 & 5.4 & -4.8 & 10.2 & 8.6 & 0.3 & 8.3 \\
\hline
\end{tabular}




\begin{tabular}{|c|c|c|c|c|c|c|c|c|c|c|}
\hline Subject & Seat & Task & Rep & TX+ & TY+ & TY- & TYR & $\mathrm{TZ}+$ & TZ- & TZR \\
\hline 7 & $\mathrm{H} 120$ & $E$ & 1 & 55.2 & 15.8 & -23.8 & 39.6 & 16.3 & -13.3 & 29.6 \\
\hline 7 & $\mathrm{H} 120$ & $E$ & 2 & 55.9 & 19.2 & -25 & 44.2 & 21.9 & -12.4 & 34.3 \\
\hline 7 & $\mathrm{H} 120$ & I & 1 & 67.1 & 16.6 & -25.9 & 42.5 & 25.8 & -15.2 & 41.1 \\
\hline 7 & $\mathrm{H} 120$ & 1 & 2 & 64 & 14.5 & -33.8 & 48.3 & 19 & -22.2 & 41.2 \\
\hline 7 & $\mathrm{H} 90$ & E & 1 & 57 & 24.5 & -7.3 & 31.8 & 15.8 & -16.2 & 32.1 \\
\hline 7 & H9O & $\mathrm{E}$ & 2 & 57.7 & 24.9 & -9.4 & 34.3 & 16.7 & -18.3 & 35.1 \\
\hline 7 & $\mathrm{H} 90$ & $E$ & 3 & 62.3 & 25.4 & -5.6 & 31 & 18.1 & -15.4 & 33.5 \\
\hline 7 & $\mathrm{H} 90$ & I & 1 & 62.9 & 12.7 & -19.3 & 32 & 15.6 & -21.3 & 36.9 \\
\hline 7 & $\mathrm{H} 90$ & 1 & 2 & 64.4 & 18 & -20.2 & 38.1 & 20.2 & -17.9 & 38.1 \\
\hline 7 & H9O & 1 & 3 & 69 & 17.9 & -20 & 37.9 & 20 & -16.1 & 36.1 \\
\hline 7 & V & $\mathrm{E}$ & 1 & 44 & 1 & -10.8 & 11.8 & 7.1 & -5.1 & 12.2 \\
\hline 7 & V & $\mathrm{E}$ & 2 & 50.9 & 2.2 & -10.4 & 12.6 & 4.9 & -6.2 & 11 \\
\hline 7 & v & I & 1 & 46.2 & 3.3 & -7.6 & 10.9 & 1.5 & -10.1 & 11.7 \\
\hline 7 & V & I & 2 & 46.1 & 2.3 & -8 & 10.3 & 4.1 & -7.2 & 11.3 \\
\hline 8 & $\mathrm{H} 120$ & $E$ & 1 & 63 & 4.3 & -32.6 & 36.9 & 21.8 & -2.8 & 24.7 \\
\hline 8 & $\mathrm{H} 120$ & $E$ & 2 & 52.7 & 1.6 & -39.4 & 41.1 & 25 & -1.6 & 26.5 \\
\hline 8 & $\mathrm{H} 120$ & $E$ & 3 & 61.7 & 1.9 & -36.5 & 38.4 & 23.3 & -4.5 & 27.8 \\
\hline 8 & $\mathrm{H} 120$ & I & 1 & 69.2 & 3.7 & -31.2 & 34.9 & 25 & -15.9 & 40.8 \\
\hline 8 & $\mathrm{H} 120$ & 1 & 2 & 62.6 & 8.4 & -27.2 & 35.6 & 23.1 & -7.9 & 31.1 \\
\hline 8 & $\mathrm{H} 120$ & I & 3 & 56.8 & 1.1 & -29.1 & 30.2 & 20.9 & -9.6 & 30.5 \\
\hline 8 & $\mathrm{H} 90$ & $\mathrm{E}$ & 1 & 65.4 & 8.4 & -23.6 & 31.9 & 21.5 & -0.4 & 21.9 \\
\hline 8 & $\mathrm{H} 90$ & $E$ & 2 & 64.1 & 10.2 & -25.2 & 35.4 & 20.4 & -7 & 27.4 \\
\hline 8 & $\mathrm{H} 90$ & $E$ & 3 & 68.9 & 8 & -24.6 & 32.7 & 23.2 & -2.3 & 25.5 \\
\hline 8 & $\mathrm{H} 90$ & I & 1 & 71.8 & 5.4 & -21.9 & 27.3 & 16.2 & -11.5 & 27.7 \\
\hline 8 & $\mathrm{H} 90$ & 1 & 2 & 78 & 6.4 & -25.6 & 32 & 14.8 & -8.3 & 23.1 \\
\hline 8 & $\mathrm{H} 90$ & 1 & 3 & 73.2 & 9.4 & -25.6 & 35 & 14.6 & -10.6 & 25.2 \\
\hline 9 & $\mathrm{H} 120$ & $E$ & 1 & 74.2 & 7.2 & -10.6 & 17.8 & 16.8 & -2.7 & 19.5 \\
\hline 9 & $\mathrm{H} 120$ & $E$ & 2 & 77.4 & 12.3 & -12.8 & 25.1 & 22.9 & -3.6 & 26.5 \\
\hline 9 & $\mathrm{H} 120$ & $E$ & 3 & 79.7 & 3.7 & -14.2 & 17.9 & 19 & -4.6 & 23.6 \\
\hline 9 & $\mathrm{H} 120$ & I & 1 & 69.7 & 10 & -14.2 & 24.2 & 16.1 & -8.7 & 24.8 \\
\hline 9 & $\mathrm{H} 120$ & 1 & 2 & 77.4 & 7.4 & -20.7 & 28.2 & 15.2 & -10 & 25.2 \\
\hline 9 & $\mathrm{H} 120$ & 1 & 3 & 72.9 & 8.1 & -22.3 & 30.4 & 13.8 & -4.9 & 18.8 \\
\hline 9 & H9O & $E$ & 1 & 75.8 & 4.4 & -10.6 & 15 & 18.9 & -4.1 & 22.9 \\
\hline 9 & $\mathrm{H} 90$ & $E$ & 2 & 77.8 & 7.1 & -14.1 & 21.2 & 18.7 & -5.4 & 24.2 \\
\hline 9 & H9O & $E$ & 3 & 75.5 & 5.4 & -12.6 & 18 & 22.5 & -4.9 & 27.4 \\
\hline 9 & $\mathrm{H} 90$ & 1 & 1 & 76.5 & 10.4 & -19.9 & 30.3 & 20.1 & -8.2 & 28.3 \\
\hline 9 & $\mathrm{H} 90$ & 1 & 2 & 74.8 & 14.6 & -17.2 & 31.8 & 15.7 & -14.5 & 30.2 \\
\hline 9 & $\mathrm{H} 90$ & I & 3 & 75.9 & 10.5 & -20.6 & 31 & 18.6 & -8.5 & 27.1 \\
\hline 9 & V & $E$ & 1 & 52.3 & 7.3 & -3.1 & 10.4 & 4.5 & -4.6 & 9.2 \\
\hline 9 & V & $E$ & 2 & 49.2 & 5.7 & -2.8 & 8.5 & 4.7 & -8.8 & 13.5 \\
\hline 9 & v & $\mathrm{E}$ & 3 & 44.8 & 5.2 & -10.9 & 16.1 & 13.2 & -3.4 & 16.6 \\
\hline 9 & V & I & 1 & 53.4 & 11.7 & 0.5 & 11.2 & 2.3 & -8.9 & 11.2 \\
\hline 9 & v & 1 & 2 & 55.3 & 7.6 & -0.3 & 7.9 & 8.2 & -4.7 & 12.9 \\
\hline 9 & V & 1 & 3 & 44 & 7.9 & -2.3 & 10.2 & 3.3 & -9.1 & 12.5 \\
\hline
\end{tabular}




\begin{tabular}{rrrrrrrrrrr} 
Subject & Seat & Task & Rep & \multicolumn{1}{c}{ TX+ } & \multicolumn{1}{l}{ TY+ } & \multicolumn{1}{l}{ TY- } & \multicolumn{1}{l}{ TYR } & \multicolumn{1}{l}{ TZ+ } & \multicolumn{1}{l}{ TZ- } & \multicolumn{1}{c}{ TZR } \\
10 & H120 & E & 1 & 105.9 & 11.6 & -23.7 & 35.3 & 18.6 & -9.8 & 28.4 \\
10 & H120 & E & 2 & 99.9 & 8.4 & -22.4 & 30.9 & 12.3 & -7.6 & 20 \\
10 & H120 & E & 3 & 103.3 & 4.2 & -25.1 & 29.3 & 18.5 & -12.9 & 31.4 \\
10 & H120 & I & 1 & 92.3 & 3.5 & -28.9 & 32.4 & 17.8 & -7.4 & 25.2 \\
10 & H120 & I & 2 & 98.3 & 4.2 & -27.5 & 31.7 & 19.1 & -6.6 & 25.8 \\
10 & H90 & E & 1 & 102.4 & 12.9 & -8.4 & 21.3 & 12.9 & -10.2 & 23 \\
10 & H90 & E & 2 & 102.9 & 20.5 & -7.6 & 28.1 & 16.4 & -5 & 21.4 \\
10 & H90 & I & 1 & 113.9 & 14.1 & -17.5 & 31.6 & 11.8 & -7.5 & 19.3 \\
10 & H90 & I & 2 & 96.5 & 13.9 & -19.2 & 33.1 & 9.2 & -9.8 & 19 \\
10 & H90 & I & 3 & 109.3 & 7.2 & -20.3 & 27.5 & 19 & -7.8 & 26.7 \\
10 & V & E & 1 & 79.8 & 4.8 & -3.1 & 7.9 & 4 & -6.7 & 10.7 \\
10 & V & E & 2 & 80.4 & 3.7 & -6.5 & 10.2 & 6.3 & -5.4 & 11.7 \\
10 & V & I & 1 & 71.6 & 6.7 & -5.5 & 12.2 & 4 & -5.7 & 9.8 \\
10 & V & I & 2 & 81 & 3.3 & -8.9 & 12.2 & 6.8 & -7.9 & 14.8 \\
10 & V & I & 3 & 78.9 & 3.8 & -6.6 & 10.4 & 3.2 & -6 & 9.2
\end{tabular}




\section{APPENDIX I - SUMMARIZED REACH DATA}

\begin{tabular}{|c|c|c|c|c|c|c|c|c|c|}
\hline Subject & Seat & Plane & Rep & Left Min X & Left Max X & Left Max Y & Right Min X & Right Max X & Right Max Y \\
\hline 1 & H & $\mathrm{F}$ & 1 & -649.17 & 687.5 & 824.1626 & -666.4 & 731.26 & 865.438 \\
\hline 1 & $\mathrm{H}$ & $\mathrm{F}$ & 2 & -655.489 & 676.53 & 826.4484 & -663.577 & 672.81 & 857.059 \\
\hline 1 & $\mathrm{H}$ & $\mathrm{s}$ & 1 & -656.501 & 669.86 & 571.399 & -670.435 & 663 & 609.192 \\
\hline 1 & $\mathrm{H}$ & $\mathrm{s}$ & 2 & -657.957 & 678.68 & 577.734 & -664.642 & 686.64 & 595.723 \\
\hline 1 & $\mathrm{H}$ & T & 1 & -824.8299 & 438.142 & 569.992 & $*$ & $*$ & 598.641 \\
\hline 1 & $\mathrm{H}$ & T & 2 & -836.4743 & 418.573 & 591.167 & -881.773 & 455.953 & 621.025 \\
\hline 1 & V & $\mathrm{F}$ & 1 & -652.899 & 704.9 & 811.075 & -590.191 & 700.68 & 847.665 \\
\hline 1 & v & $\mathrm{F}$ & 2 & -625.364 & 701.52 & 838.331 & -672.767 & 715.56 & 848.749 \\
\hline 1 & V & $\mathrm{S}$ & 1 & -637.231 & 687.33 & 606.97807 & -671.524 & 717.75 & 570.1238 \\
\hline 1 & v & $\mathrm{s}$ & 2 & -605.118 & 693.11 & 604.80573 & -654.209 & 695.54 & 569.8258 \\
\hline 1 & v & T & 1 & -817.102 & 430.75 & 591.1549 & -842.232 & 405.173 & 591.1983 \\
\hline 1 & v & T & 2 & -845.812 & 414.797 & 582.4601 & -846.776 & 419.807 & 598.4251 \\
\hline 2 & $\mathrm{H}$ & $\mathrm{F}$ & 1 & -594.097 & 602.41 & 783.4966 & -610.08 & 599.82 & 760.624 \\
\hline 2 & $\mathrm{H}$ & $\mathrm{F}$ & 2 & -589.01 & 578.72 & 777.68 & -617.939 & 585.16 & 760.654 \\
\hline 2 & $\mathrm{H}$ & $\mathrm{s}$ & 1 & -598.313 & 634.82 & 568.682 & -644.679 & 526.93 & 603.737 \\
\hline 2 & $\mathrm{H}$ & $\mathrm{s}$ & 2 & -603.847 & 592.23 & 569.51 & -644.93 & 586.87 & 586.708 \\
\hline 2 & $\mathrm{H}$ & T & 1 & -777.4224 & 240.399 & 553.384 & -761.961 & 301.013 & 536.808 \\
\hline 2 & $\mathrm{H}$ & T & 2 & -736.4929 & * & 515.324 & -758.156 & 254.111 & 578.184 \\
\hline 2 & v & $\mathrm{F}$ & 1 & -566.261 & 656.86 & 788.289 & -581.256 & 572.06 & 746.988 \\
\hline 2 & v & $\mathrm{F}$ & 2 & -595.662 & 639.54 & 786.705 & -570.37 & 591.89 & 746.57 \\
\hline 2 & V & $S$ & 1 & -612.839 & 654.47 & 581.25135 & -615.716 & 586.92 & 575.9824 \\
\hline 2 & v & $\mathrm{s}$ & 2 & -607.393 & 652.41 & 598.9586 & -609.346 & 584.21 & 566.1407 \\
\hline 2 & V & T & 1 & -788.361 & 306.914 & 592.7834 & -747.93 & 289.2796 & 533.9771 \\
\hline 2 & V & T & 2 & -785.853 & 253.199 & 589.26625 & -749.926 & 262.0562 & 548.2385 \\
\hline 3 & $\mathrm{H}$ & $\mathrm{F}$ & 1 & -461.827 & 668.26 & 771.4817 & -498.581 & 595.91 & 789.478 \\
\hline 3 & $\mathrm{H}$ & $\mathrm{F}$ & 2 & -448.39 & 655.14 & 703.4968 & -450.392 & 601.71 & 763.592 \\
\hline 3 & $\mathrm{H}$ & $\mathrm{s}$ & 1 & -471.234 & 666.05 & 435.025 & -475.091 & 635.99 & 391.298 \\
\hline 3 & $\mathrm{H}$ & $\mathrm{s}$ & 2 & -481.851 & 639.21 & 513.519 & -458.836 & 676.18 & * \\
\hline 3 & $\mathrm{H}$ & T & 1 & -791.3125 & 330.233 & 524.119 & -810.402 & 352.595 & 559.937 \\
\hline 3 & $\mathrm{H}$ & T & 2 & -790.5794 & 345.007 & 518.198 & -810.319 & 330.765 & 522.908 \\
\hline 3 & v & $\mathrm{F}$ & 1 & -555.587 & 669.37 & 791.505 & -595.775 & 658.21 & 767.353 \\
\hline 3 & v & $\mathrm{F}$ & 2 & -537.489 & 669.99 & 792.853 & -587.96 & 650.11 & 769.401 \\
\hline 3 & V & $\mathrm{S}$ & 1 & -551.096 & 678.51 & 499.6898 & -596.539 & 659.84 & 454.3513 \\
\hline 3 & $\mathrm{~V}$ & s & 2 & -559.128 & 675.67 & 506.3989 & -592.71 & 653.41 & 448.3355 \\
\hline 3 & V & T & 1 & -769.536 & 349.758 & 518.8663 & -748.441 & 354.7393 & 514.6095 \\
\hline 3 & v & T & 2 & $*$ & $*$ & * & -756.734 & 353.3359 & 507.6773 \\
\hline
\end{tabular}




\begin{tabular}{|c|c|c|c|c|c|c|c|c|c|}
\hline Subject & Seat & Plane & Rep & Left Min X & Left Max X & Left Max Y & Right Min X & Right Max X & Right Max Y \\
\hline 4 & $\mathrm{H}$ & $\mathrm{F}$ & 1 & -573.336 & 680 & 772.9898 & -612.052 & 685.16 & 788.31 \\
\hline 4 & $\mathrm{H}$ & $\mathrm{F}$ & 2 & -566.241 & 695.08 & 772.5038 & -608.716 & 693.2 & 799.084 \\
\hline 4 & $\mathrm{H}$ & $S$ & 1 & -560.46 & 473.39 & 509.063 & -577.686 & 426.69 & 521.073 \\
\hline 4 & $\mathrm{H}$ & $S$ & 2 & -563.973 & 500.9 & 510.239 & -581.185 & 434.42 & 528.671 \\
\hline 4 & $\mathrm{H}$ & $\mathrm{T}$ & 1 & -789.7019 & 386.654 & 510.517 & -791.707 & 386.58 & 529.535 \\
\hline 4 & $\mathrm{H}$ & $\mathrm{T}$ & 2 & -780.6787 & 337.757 & 454.021 & -793.725 & 389.064 & 532.298 \\
\hline 4 & V & $\mathrm{F}$ & 1 & -571.27 & 632.32 & 781.241 & -602.552 & 624.59 & 787.212 \\
\hline 4 & V & $\mathrm{F}$ & 2 & -584.63 & 630.79 & 779.264 & -615.352 & 623.45 & 793.164 \\
\hline 4 & V & $S$ & 1 & -545.513 & 634.14 & 531.135 & -574.639 & 602.16 & 524.887 \\
\hline 4 & V & $\mathrm{S}$ & 2 & -538.364 & 637.03 & 531.298 & -574.786 & 603.18 & 536.641 \\
\hline 4 & V & $T$ & 1 & -783.303 & 300.472 & 493.162 & -791.534 & 231.6255 & 530.014 \\
\hline 4 & V & $\mathrm{T}$ & 2 & -779.237 & 319.469 & 521.558 & -792.506 & 284.3546 & 435.2246 \\
\hline 5 & $\mathrm{H}$ & $\mathrm{F}$ & 1 & -606.528 & 729.9 & 808.1234 & -636.224 & 687.8 & 829.274 \\
\hline 5 & $\mathrm{H}$ & $\mathrm{F}$ & 2 & -592.871 & 733.72 & 809.4154 & -632.787 & 688.73 & 825.17 \\
\hline 5 & $\mathrm{H}$ & $\mathrm{S}$ & 1 & -602.444 & 726.41 & 543.612 & -657.456 & 687.87 & 603.711 \\
\hline 5 & $\mathrm{H}$ & $\mathrm{S}$ & 2 & -584.159 & 721.25 & 564.784 & -645.803 & 686.14 & 586.743 \\
\hline 5 & $\mathrm{H}$ & $\mathrm{T}$ & 1 & -811.76362 & 446.261 & 549.691 & -812.53 & 446.862 & 580.803 \\
\hline 5 & $\mathrm{H}$ & $\mathrm{T}$ & 2 & -814.7527 & 455.053 & 575.928 & -817.602 & 392.03 & 560.291 \\
\hline 5 & $\mathrm{~V}$ & $\mathrm{~F}$ & 1 & -629.164 & 716.53 & 828.017 & -642.178 & 688.19 & 812.142 \\
\hline 5 & V & $\mathrm{F}$ & 2 & -615.193 & 715.75 & 825.268 & -595.356 & 677.3 & 800.314 \\
\hline 5 & V & $S$ & 1 & -631.729 & 705.2 & 559.0502 & -649.477 & 651.77 & 523.6077 \\
\hline 5 & V & $S$ & 2 & -639.16 & 701.34 & 561.8225 & -639.725 & 643.04 & 545.6056 \\
\hline 5 & V & $\mathrm{T}$ & 1 & -820.129 & 424.192 & 612.835 & -812.034 & 306.7892 & 576.046 \\
\hline 5 & V & $\mathrm{T}$ & 2 & -824.939 & 424.74 & 630.276 & -819.057 & 386.429 & 582.763 \\
\hline 6 & $\mathrm{H}$ & $\mathrm{F}$ & 1 & -608.011 & 599.87 & 750.4037 & -602.358 & 607.56 & 762.771 \\
\hline 6 & $\mathrm{H}$ & $\mathrm{F}$ & 2 & -605.812 & 578.43 & 745.4895 & -600.691 & 586.59 & 756.763 \\
\hline 6 & $\mathrm{H}$ & $S$ & 1 & -596.169 & 578.38 & 507.841 & -590.826 & 583.17 & 533.31 \\
\hline 6 & $\mathrm{H}$ & $S$ & 2 & -598.37 & 564.79 & 491.273 & -598.076 & 588.43 & 516.369 \\
\hline 6 & $\mathrm{H}$ & $\mathrm{T}$ & 1 & -759.3074 & $*$ & 538.788 & -762.463 & 327.181 & 533.177 \\
\hline 6 & $\mathrm{H}$ & $T$ & 2 & -750.4553 & 220.369 & 515.066 & -765.047 & 298.518 & 536.445 \\
\hline 6 & V & $\mathrm{F}$ & 1 & -573.93 & 543.49 & 692.954 & -593.713 & 597.44 & 743.417 \\
\hline 6 & V & $\mathrm{F}$ & 2 & -564.822 & 552.65 & 703.188 & -585.667 & 590.93 & 753.631 \\
\hline 6 & V & $S$ & 1 & -561.541 & 571.25 & 508.0776 & -588.691 & 591.82 & 497.0835 \\
\hline 6 & $\mathrm{~V}$ & $\mathrm{~S}$ & 2 & -563.904 & 567.84 & 498.7151 & -583.72 & 586.27 & 476.1406 \\
\hline 6 & V & $T$ & 1 & -737.458 & 250.19 & 540.296 & -753.7 & 278.0094 & 528.763 \\
\hline 6 & V & $\mathrm{T}$ & 2 & -750.052 & 588.739 & 545.801 & -755.182 & 262.1381 & 525.952 \\
\hline 7 & $\mathrm{H}$ & $\mathrm{F}$ & 1 & -558.249 & 597.39 & 706.9379 & -552.144 & 585.07 & 728.386 \\
\hline 7 & $\mathrm{H}$ & $\mathrm{F}$ & 2 & -544.597 & 592.1 & 694.4321 & -548.185 & 595.28 & 728.728 \\
\hline 7 & $\mathrm{H}$ & $S$ & 1 & -540.377 & 596.98 & 489.464 & -549.651 & 622.06 & 537.05 \\
\hline 7 & $\mathrm{H}$ & $S$ & 2 & -539.179 & 577.58 & 488.705 & -549.176 & 595.03 & 521.551 \\
\hline 7 & $\mathrm{H}$ & $T$ & 1 & -699.6228 & 362.434 & 508.88 & -728.398 & 354.02 & 526.523 \\
\hline 7 & $\mathrm{H}$ & $\mathrm{T}$ & 2 & $*$ & 353.41 & 518.321 & -731.885 & 372.743 & 540.332 \\
\hline 7 & V & $\mathrm{F}$ & 1 & -514.023 & 598.67 & 704.933 & -569.722 & 590.05 & 710.579 \\
\hline 7 & $\mathrm{~V}$ & $\mathrm{~F}$ & 2 & -509.961 & 605.68 & 698.17 & -573.06 & 527.83 & 720.927 \\
\hline 7 & $\mathrm{~V}$ & $S$ & 1 & -510.811 & 595.44 & 459.6886 & -575.024 & 603.39 & 462.0932 \\
\hline 7 & V & $S$ & 2 & -509.285 & 609.48 & 533.1969 & -558.337 & 586.87 & 425.0713 \\
\hline 7 & V & $\mathrm{T}$ & 1 & -701.312 & 353.723 & 508.85184 & -720.857 & 365.002 & 527.0418 \\
\hline 7 & V & $\mathrm{T}$ & 2 & -703.69 & 366.201 & 507.8862 & -721.908 & 354.6929 & 540.1618 \\
\hline
\end{tabular}




\begin{tabular}{|c|c|c|c|c|c|c|c|c|c|}
\hline Subject & Seat & Plane & Rep & Left Min X & Left Max X & Left Max Y & Right Min X & Right Max X & Right Max Y \\
\hline 8 & $\mathrm{H}$ & $\mathrm{F}$ & 1 & -538.71 & 568.862 & 741.441 & -566.411 & 509.76 & 734.65 \\
\hline 8 & $\mathrm{H}$ & $\mathrm{F}$ & 2 & -559.459 & 563.028 & 737.0831 & -529.976 & 533.358 & 725.457 \\
\hline 8 & $\mathrm{H}$ & $S$ & 1 & -540.685 & 566.107 & 532.18 & -520.566 & 615.653 & 529.111 \\
\hline 8 & $\mathrm{H}$ & $S$ & 2 & -547.637 & 495.214 & 528.829 & -511.489 & 566.68 & 520.985 \\
\hline 8 & $\mathrm{H}$ & $\mathrm{T}$ & 1 & -751.5314 & 387.812 & 534.796 & -739.16 & 402.885 & 540.765 \\
\hline 8 & $\mathrm{H}$ & $T$ & 2 & -749.70829 & 346.058 & 536.373 & -735.5 & 382.923 & 524.382 \\
\hline 8 & V & $\mathrm{F}$ & 1 & -576.872 & 641.12 & 753.739 & -550.245 & 626.26 & 727.956 \\
\hline 8 & V & $\mathrm{F}$ & 2 & -490.055 & 645.59 & 745.85 & -583.226 & 614.31 & 719.919 \\
\hline 8 & V & $S$ & 1 & -417.211 & 620.32 & 542.1991 & $*$ & 618.34 & 521.0361 \\
\hline 8 & V & $S$ & 2 & -394.476 & 574.73 & 536.7379 & $*$ & $*$ & $*$ \\
\hline 8 & V & $\mathrm{T}$ & 1 & -759.077 & 382.81 & 555.3066 & -739.217 & 386.516 & 541.0179 \\
\hline 8 & V & $\mathrm{T}$ & 2 & -750.371 & 370.748 & 542.344 & -732.072 & 353.239 & 512.593 \\
\hline 9 & $\mathrm{H}$ & $F$ & 1 & -574.588 & 588.268 & 761.4244 & -571.891 & 638.066 & 786.399 \\
\hline 9 & $\mathrm{H}$ & $F$ & 2 & -573.538 & 608.978 & 771.32485 & -582.364 & 645.701 & 783.975 \\
\hline 9 & $\mathrm{H}$ & $S$ & 1 & -550.033 & 617.83 & 538.514 & -589.082 & 634.623 & 602.862 \\
\hline 9 & $\mathrm{H}$ & $S$ & 2 & -553.3794 & 601.247 & 543.049 & -578.589 & 600.172 & 570.833 \\
\hline 9 & $\mathrm{H}$ & $\mathrm{T}$ & 1 & -774.7971 & 364.743 & 575.755 & -784.856 & 397.371 & 606.231 \\
\hline 9 & $\mathrm{H}$ & $T$ & 2 & -784.2196 & 365.151 & 563.842 & -787.441 & 371.795 & 602.523 \\
\hline 9 & V & $\mathrm{F}$ & 1 & -547.871 & 579.07 & 736.584 & -553.138 & 633.32 & 767.593 \\
\hline 9 & V & $\mathrm{F}$ & 2 & -547.213 & 605 & 726.514 & -518.719 & 624.75 & 728.302 \\
\hline 9 & V & $S$ & 1 & -536.142 & 590.27 & 544.64 & -541.806 & 626.66 & 516.844 \\
\hline 9 & V & $S$ & 2 & -507.327 & 617.28 & 537.171 & -539.671 & 633.77 & 509.865 \\
\hline 9 & V & $\mathrm{T}$ & 1 & -772.619 & 321.847 & 568.889 & -765.253 & 351.1739 & 575.799 \\
\hline 9 & V & $\mathrm{T}$ & 2 & -765.493 & 280.649 & 549.692 & -754.571 & 307.80109 & 557.588 \\
\hline 10 & $\mathrm{H}$ & $\mathrm{F}$ & 1 & -602.659 & 658.18 & 784.78583 & -449.244 & 786.19 & 787.282 \\
\hline 10 & $\mathrm{H}$ & $F$ & 2 & -587.103 & 663.8 & 785.64392 & -609.588 & 640.39 & 774.873 \\
\hline 10 & $\mathrm{H}$ & $S$ & 1 & -600.949 & 663.56 & 564.375 & -604.829 & 641.33 & 557.985 \\
\hline 10 & $\mathrm{H}$ & $S$ & 2 & -585.119 & 667.72 & 560.526 & -595.055 & 646.43 & 555.277 \\
\hline 10 & $\mathrm{H}$ & $\mathrm{T}$ & 1 & -785.80894 & 396.766 & 438.121 & -803.658 & 387.022 & 509.014 \\
\hline 10 & $\mathrm{H}$ & $\mathrm{T}$ & 2 & -781.5661 & 402.195 & $*$ & -804.351 & 396.004 & 534.319 \\
\hline 10 & V & $\mathrm{F}$ & 1 & -586.094 & 632.47 & 776.842 & -599.006 & 633.33 & 786.324 \\
\hline 10 & V & $F$ & 2 & -564.661 & 639.52 & 756.289 & -579.579 & 630.28 & 784.691 \\
\hline 10 & V & $S$ & 1 & -583.328 & 631.15 & 486.824 & -613.031 & 623.34 & 504.696 \\
\hline 10 & V & $S$ & 2 & -559.977 & 619.89 & 506.577 & -608.093 & 603.06 & 512.285 \\
\hline 10 & V & $\mathrm{T}$ & 1 & -710.776 & 288.38 & 545.3133 & -769.466 & 284.092 & 567.5601 \\
\hline 10 & V & $\mathrm{T}$ & 2 & -757.031 & 291.553 & 545.0147 & -744.864 & 271.3 & 557.1725 \\
\hline
\end{tabular}

